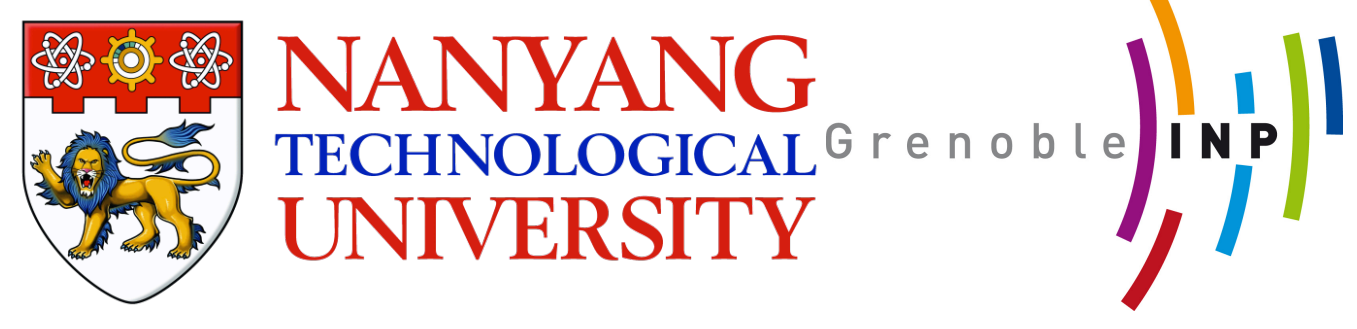

INVESTIGATION ON TIN BASED OXIDES AS POTENTIAL ANODE MATERIAL FOR LI AND NA ION BATTERIES

WANG LUYUAN PAUL

INTERDISCIPLINARY GRADUATE SCHOOL ENERGY RESEARCH INSTITUTE@NTU (ERI@N)

\&

UNIVERSITY OF GRENOBLE ALPES 



\title{
INVESTIGATION ON TIN BASED OXIDES AS POTENTIAL ANODE MATERIAL FOR LI AND NA ION BATTERIES
}

WANG LUYUAN PAUL

\author{
Interdisciplinary Graduate School \\ Energy Research Institute@NTU (ERI@N) \\ $\&$ \\ University of Grenoble Alpes
}

A thesis submitted to Nanyang Technological

University and University of Grenoble Alpes in partial

fulfillment of the requirement for the degree of

Doctor of Philosophy 



\section{Statement of Originality}

I hereby certify that the work embodied in this thesis is the result of original research and has not been submitted for a higher degree to any other University or Institution.

28-Mar-17

Date
Wang Luyuan Paul

Student Name 



\begin{abstract}
The invention of rechargeable energy storage has helped realize the possibility of portable electronic devices and electric vehicles, which have since dramatically improved our quality of life. As technologies continue to advance, there exists a pertinent need for the development of cheaper and more reliable batteries. Both Li-ion batteries (LIBs) and Na-ion batteries (NIBs) have attracted much attention with the latter becoming more prominent in recent years. The heart of battery technology lies primarily in the electrode material, which determines how much charge can be stored and how long the battery can be cycled. Tin (IV) Oxide $\left(\mathrm{SnO}_{2}\right)$ has been widely investigated as an anode material owing to the low operating potential $\left(<0.8 \mathrm{~V}\right.$ vs. $\mathrm{Li}^{+} / \mathrm{Li}$ or $<0.5 \mathrm{~V}$ vs. $\mathrm{Na}^{+} / \mathrm{Na}$ ), high theoretical gravimetric capacity $\left(1493 \mathrm{mAh} \mathrm{g}^{-1}(\mathrm{Li})\right.$ and 1398 $\mathrm{mAh} \mathrm{g}^{-1}(\mathrm{Na})$ assuming full reversibility in conversion \& alloying reactions), reasonable cost and its environmental benignity. Nevertheless, numerous limitations such as low cyclability, large volumetric changes during charging/discharging, poor conductivity and slow kinetics, are still persistent within the system. The objective of this thesis aims to provide several different facile engineering solution to surmount the limitations facing $\mathrm{SnO}_{2}$ as an anode in LIB/NIB.
\end{abstract}

The initial part of this thesis focuses on a one-pot synthesis of reduced graphene oxide (rGO)- $\mathrm{SnO}_{2}$ nanoparticles via laser pyrolysis. We show in this chapter the novelty of this synthesis method and the importance of a graphene conductive substrate. The $\mathrm{rGO}-\mathrm{SnO}_{2}$ sample delivered extremely high specific capacity in both LIB and NIB, which is comparable to other, hitherto reported composites. Four different energy storage behaviors, namely intercalation, conversion, alloying and capacitive were found to be active during lithiation. On the other hand, the intercalation reaction was considered inactive during sodiation due to thermodynamic restrictions. The exceptional electrochemical performance 
could be attributed to the intrinsic design of the composite, where the presence of graphene sheets helps i) accommodate strain incurred during cycling processes and preventing structure degradation; ii) provide a constant conductive pathway for electron transport; iii) offer high contact surface area between electrode and electrolyte.The following segment of this thesis focuses on employing laser pyrolysis for the preparation of pristine and $\mathrm{N}$-doped $\mathrm{SnO}_{2}$ nanoparticles as anode materials in LIB/NIB. While $\mathrm{SnO}_{2}+\mathrm{N} 3 \%$ demonstrated optimum cycability and rate capability in the $\mathrm{Li}$ system, the presence of nitrogen dopants was found to be detrimental in NIB. Ex-situ EXAFS studies suggest that the Sn-N bonds in the structure remains electrochemically inactive throughout the cycling process and serves only to enhance overall electrical conductivity. The small particle sizes achievable due to the laser pyrolysis process also help facilitate rapid ion diffusion while preventing pulverization and agglomeration as observed in ex-situ TEM observation after long period cycling.In the final part of this thesis, we introduce matrix engineering through the fabrication of co-precipitated $\mathrm{ZnSnO}_{3}$ hollow cubes. In these hollow cubes, it was found that $\mathrm{Zn}$ and $\mathrm{Sn}$ elements were evenly distributed. While the lithiation performance of $\mathrm{ZnSnO}_{3}$ is relatively mediocre, the sodiation performance is much better compared to other pristine $\mathrm{SnO}_{2}$ compounds. The relatively poorer lithiation performance compared to sodiation is postulated to be caused by the relatively similar size expansion of $\mathrm{Zn}$ to $\mathrm{Sn}$ during lithiation as compared to sodiation. Moreover, the discharge potential in $\mathrm{ZnSnO}_{3}$ was found to shift to a lower value as compared to pristine $\mathrm{SnO}_{2}$, which will eventually result in higher energy density.

In the final chapter of the thesis, we will conclude by summarizing the electrochemical performances of all the aforementioned tin based oxides and weigh the implications that they may possess. 


\section{Acknowledgements}

First, I would like to express my deepest gratitude to my main supervisor in NTU, Professor Xu Zhichuan, Jason, for his invaluable advice, guidance and full support throughout the entire of my $\mathrm{PhD}$ study. The most tedious times spent on designing experiments and discussing/revising manuscripts were made less exhausting from his optimistic attitude and wisdom, which inspired and kept me going throughout my study in NTU. To my co-supervisors, Dr Yann Leconte, (IRAMIS/CEA) and Dr Philippe Azais (LITEN/CEA) in this joinPh.D. from University of Grenoble Alpes, thank you for looking after me during my stay in France. It was an eye-opener and I have truly learnt plentiful from the times when we worked together in the laboratory. I would also like to express gratitude to Professor Madhavi Srinivasan, for her brilliant research acumen and enthusiasm inspired me to be a better researcher. I am grateful for all the technical advice rendered to me especially during our bi-weekly meetings. I would also like to thank Prof Claude Guet, for reading through my thesis and coordinating to make this joint Ph.D. as smooth as possible.

Apart from my supervisors, I would like to express gratitude to Prof Wang Xin and Prof Yan Qingyu Alex for their professional guidance and support. I appreciate the help from technicians in the organic materials lab, inorganic materials lab and FACTS lab. I would also like to thank the scientists from IRAMIS/CEA, Dr Sarah Bouhadoun, Dr Oliver Sublemontier. Dr Axelle Quinsac and Samantha Bourrioux for their assistance during my stay in France. I would like to extend appreciation to Dr Feng Zhenxing and Dr Ma Qing from Argonne National Laboratory for help with XAS measurements. I would like to thank group members from my research groups for giving constant advice and providing assistance in every area of my research. Special thanks go out to Prof Lydia Helena Wong for introducing me to this $\mathrm{PhD}$ programme, for which everything would not have started in the first place. 
Finally, I would like to thank my parents and siblings for their unwavering support during my study. Appreciation goes out to my wife, for understanding why I have to constantly reply e-mails during our dating sessions.

"You have your way. I have my way. As for the right way, the correct way, and the only way, it does not exist." -Friedrich Nietzsche (Thus Spake Zarathustra) 


\section{Table of Contents}

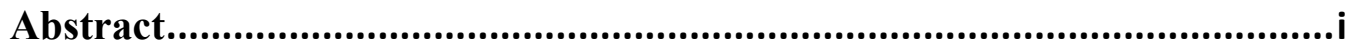

Acknowledgements..................................................................................ii

Table of Contents ...................................................................................... v

Table Captions ..................................................................................................

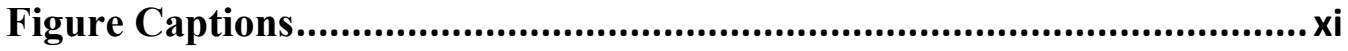

Abbreviations ............................................................................................. xxi

Chapter 1: Introduction .............................................................................2

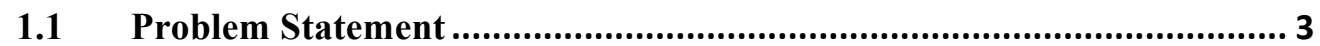

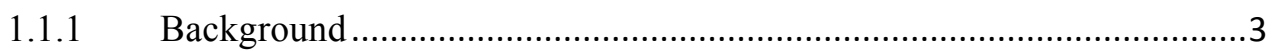

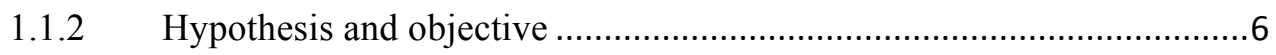

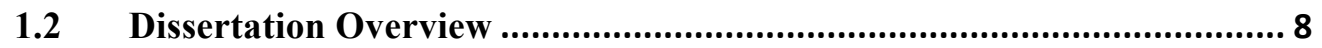

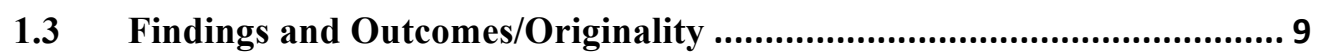

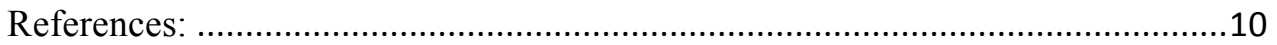

Chapter 2: Literature Review .................................................................13

2.1 Alkali ion batteries (AIBs): Operating mechanism and key parameters 14

2.2 Current progress of anode materials................................................ 17

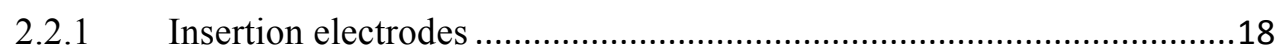

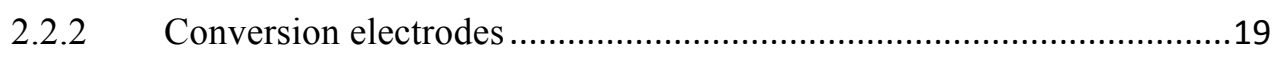

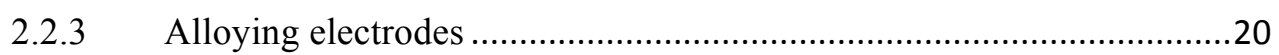

2.3 Metal Oxides as Next Generation Anode........................................... 21

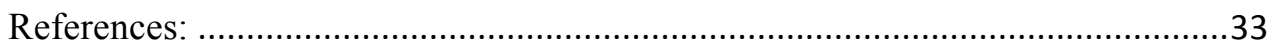

Chapter 3: Experimental Methodology ...................................................39

3.1 Selection of methods and materials ......................................................... 40

3.2 Principle behind synthesis methods.................................................. 42

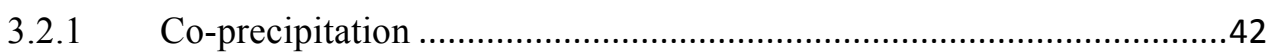

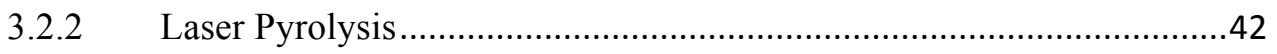

3.3 Principle behind characterization techniques ..................................... 45

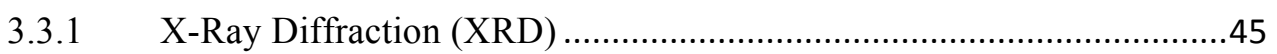

3.3.2 Electron Microscopy (SEM \& TEM) …............................................

3.3.3 Energy Dispersive X-ray Spectroscopy (EDX) ......................................48

3.3.4 X-ray Photoelectron Spectroscopy (XPS) ...........................................48

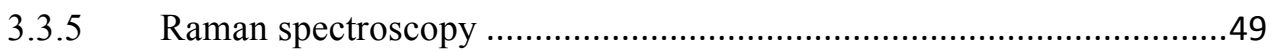

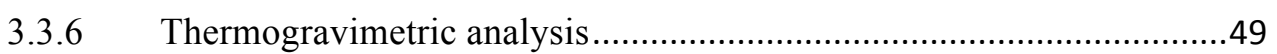

3.3.7 Synchrotron X-ray Absorption Spectroscopy (XAS) ............................50 
3.4 Principle behind electrochemical methods ....................................... 53

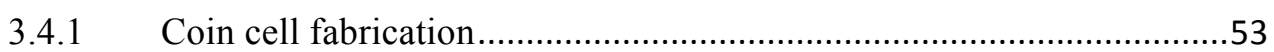

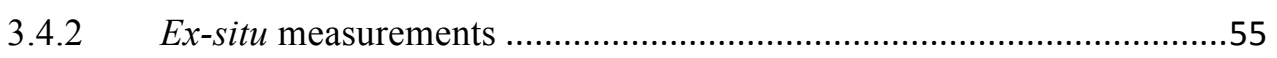

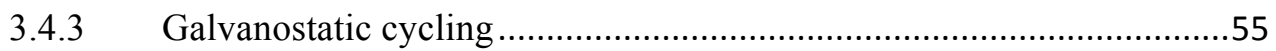

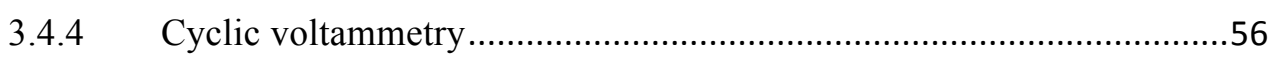

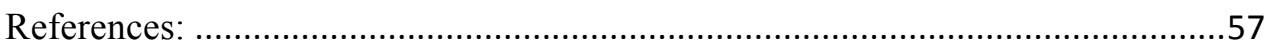

Chapter 4: Investigation and Evaluation on the electrochemical performance of $\mathrm{rGO}_{-\mathrm{SnO}}$ synthesized from a facile one-pot laser pyrolysis

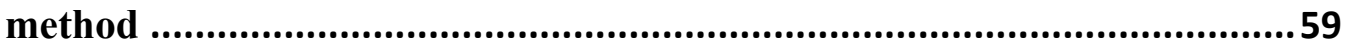

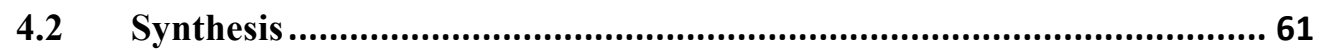

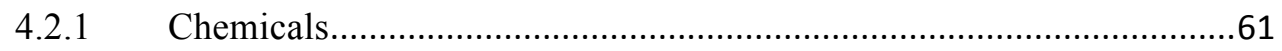

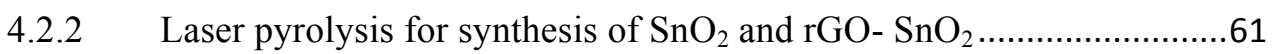

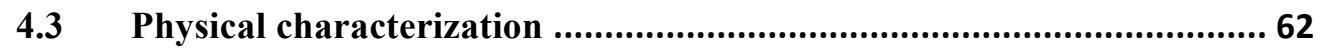

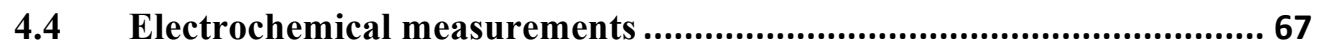

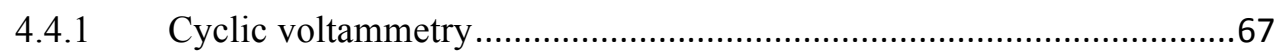

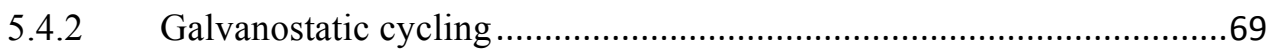

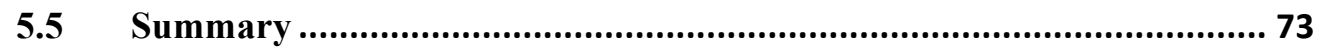

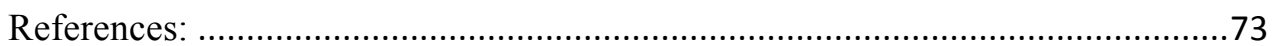

Chapter 5: In-depth evaluation on electrochemical performance of $\mathrm{N}$ doped $\mathrm{SnO}_{2}$ and its fundamental mechanism study .................................75

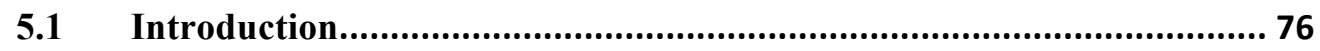

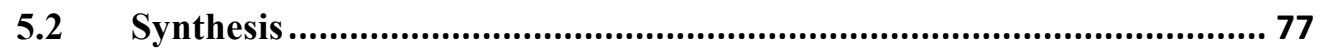

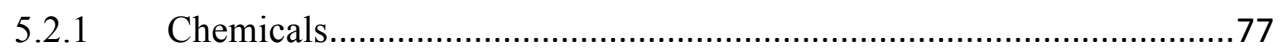

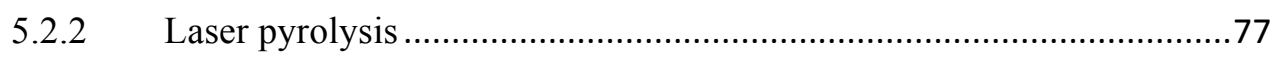

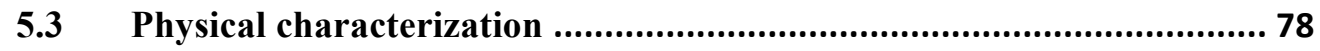

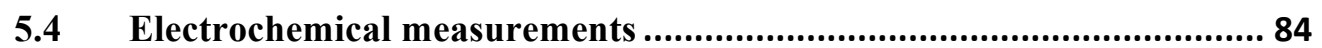

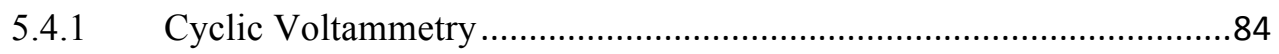

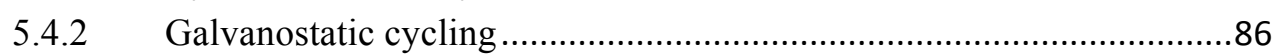

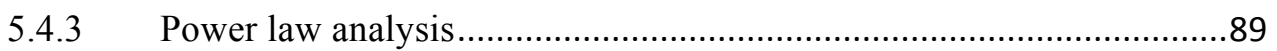

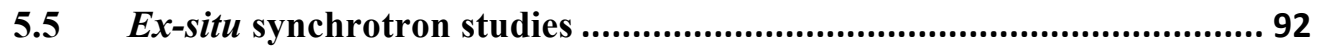

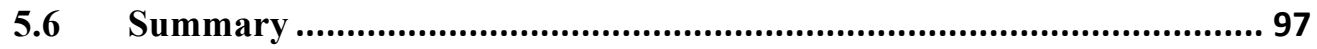

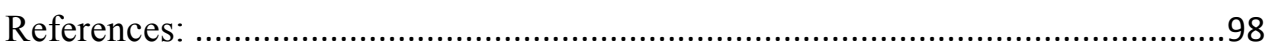

Chapter 6: Understanding and evaluating the effect of matrix engineering with the incorporation of $\mathrm{ZnO}$ to form $\mathrm{ZnSnO}_{3}$................................. 101

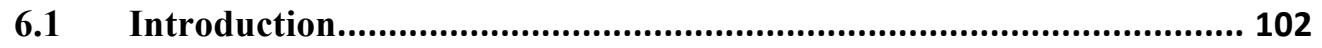

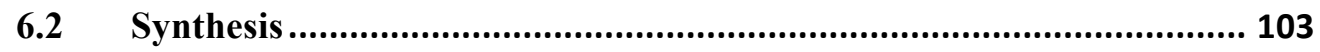

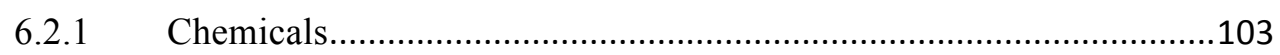

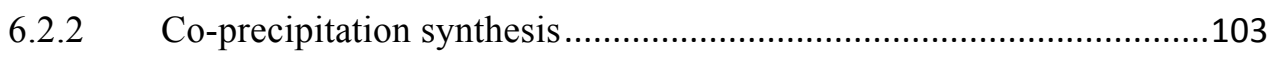

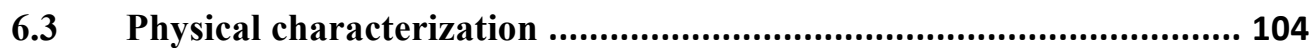


6.4 Electrochemical measurements .................................................... 106

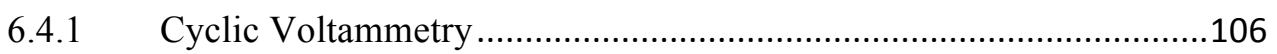

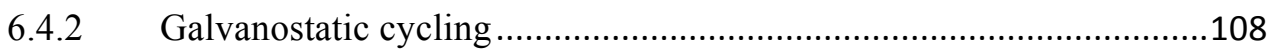

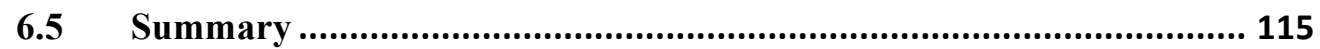

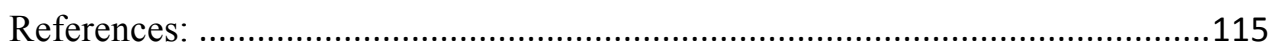

Chapter 7: Discussion and Future work ................................................ 117

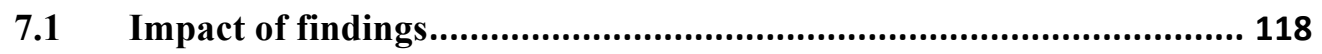

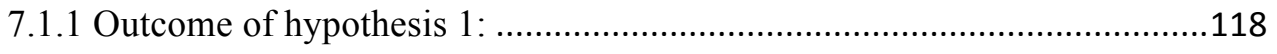

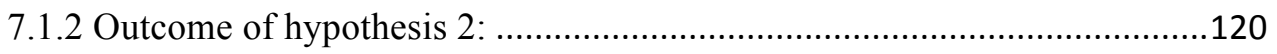

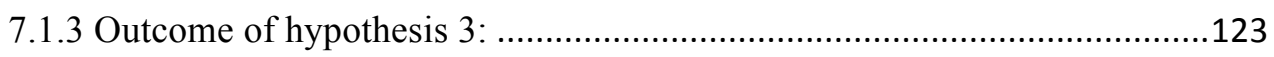

7.2 Outstanding questions and future work ............................................. 126

7.2.1 Investigation onto the gradual capacity decay during initial lithiation cycles 126

7.2.2 Further explore the different types of substitution metal for $\mathrm{ASnO}_{3}$ with

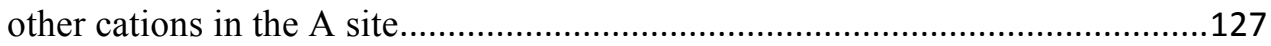

7.2.3 Laser pyrolysis of bimetallic tin oxides for LIB and NIB ..................128

7.2.4 Assembly of full cell ................................................................130

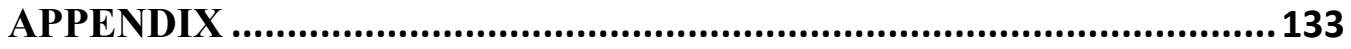




\section{Table Captions}

Table 1 Comparison between Lithium and Sodium

Table 2 Comparison of different $\mathrm{SnO}_{2}$ oxides and its electrochemical performances 
Table Captions 


\section{Figure Captions}

Figure 1.1 Average price of lithium precursor over the years. The sharp increase during 2004 was due to increase in demand for LIB while decline in price during 2008 was attributed to the financial crisis.

Figure 2.1 Schematic illustration of the Li-ion battery

Figure 2.2 Schematic representing the different reaction mechanisms of electrode materials in alkali ion batteries

Figure 2.3 Crystal structure of tetragonal $\mathrm{SnO}_{2}$ (generated using VESTA software)

Figure 2.4 Commonly utilized design structures for alleviating pulverization effect of $\mathrm{SnO}_{2}$ nanomaterials. (a) hollow structure (b) 2D- nanosheets structure (c) amorphous carbon coating

Figure 2.5 (a) Schematic on the template-etching method for preparation of Ndoped carbon coated $\mathrm{SnO}_{2}$ (b) and its corresponding cycling performance. (c) Preparation methodology for obtaining $\mathrm{SnO}_{2}$ anchored on graphene nanoribbons. (d) Comparison between electrochemical properties of pristine $\mathrm{SnO}_{2}$ and graphene nanoribbon- $\mathrm{SnO}_{2}$

Figure 2.6 (a) Schematic of hydrothermal synthesis of F-doped $\mathrm{SnO}_{2}$ and Fdoped $\mathrm{SnO}_{2} @$ graphene. Comparison of (b) cycling performance at $0.1 \mathrm{~A} \mathrm{~g}^{-1}$ and (c)rate capabilities

Figure 2.7 Infrared spectra of $\mathrm{C}_{2} \mathrm{H}_{4}$ 
Figure 3.1 Schematic of the laser pyrolysis working procedure

Figure 3.2 Image of the laser pyrolysis setup.

Figure 3.3 In clockwise direction from top left hand corner, (A) illustrates the bird-eye view of the reactor chamber as labeled in Figure 3.2. Beside it is the impact of the laser with wooden plank without presence of sensitizer gas. Bottom right depicts the reaction zone in the presence of $\mathrm{C}_{2} \mathrm{H}_{4}$ as sensitizer and air as carrier gas. The last picture (B) corresponds to the $\mathrm{CO}_{2}$ laser source utilized during laser pyrolysis.

Figure 3.4 Illustration of the Bragg's diffraction that correlates with the equation $n \lambda=2 d \sin \theta$

Figure 3.5 Photoelectric effect, in which X-ray is absorbed and a core-level electron is ejected out from the atom

Figure 3.6 Interference phenomenon between outgoing photoelectron wave and backscattered wave.

Figure 3.7 A schematic of the coin cell and its components for both $\mathrm{Li}$ and $\mathrm{Na}$ ion battery.

Figure 3.8 (a) Linear increase in potential with respect to time that is commonly used in $\mathrm{CV}$ experiments. (b) The corresponding current response during voltage sweep in $\mathrm{CV}$ with respect to the applied potential.

Figure 4.1 XRD pattern after using $\mathrm{SnCl}_{4}$ as precursor for laser pyrolysis in air $(5.5 \mathrm{slm})$ and $\mathrm{C}_{2} \mathrm{H}_{4}(0.3 \mathrm{slm})$. OSnO2 corresponds to the product and compared to JCPDS standards of tetragonal $\mathrm{SnO}_{2}, \mathrm{SnCl}_{2} \bullet 2 \mathrm{H}_{2} \mathrm{O}$ and $\mathrm{SnO}$. 
Figure 4.2 Flow diagram illustrating the synthesis pathway for $\mathrm{SnO}_{2}$ and $\mathrm{rGO}$ $\mathrm{SnO}_{2}$

Figure 4.3 XRD pattern of pristine $\mathrm{SnO}_{2}$ and $\mathrm{rGO}-\mathrm{SnO}_{2}$ prepared using $\mathrm{Sn}(\mathrm{OH})_{4}$ as precursor.

Figure 4.4 Scanning electron microscope (SEM) and transmission electron microscope (TEM) of (a-b) pristine $\mathrm{SnO}_{2}(\mathrm{c}-\mathrm{d}) \mathrm{rGO}-\mathrm{SnO}_{2}$

Figure 4.5 (a) Thermogravimetric analysis (TGA) and (b) raman spectroscopy of $\mathrm{SnO}_{2}$ and $\mathrm{rGO}-\mathrm{SnO}_{2}$

Figure 4.6 Binding energy values of $\mathrm{Sn} 3 \mathrm{~d}$ measured from X-ray photoelectron spectroscopy (XPS) for (a) pristine $\mathrm{SnO}_{2}$ and (b) $\mathrm{rGO}-\mathrm{SnO}_{2}$.

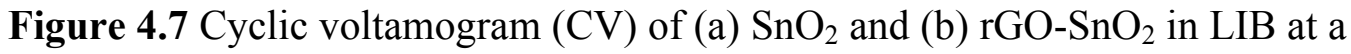
scan rate of $0.1 \mathrm{mV} \mathrm{s}^{-1}$

Figure 4.8 Cyclic voltamogram (CV) of (a) $\mathrm{SnO}_{2}$ and (b) $\mathrm{rGO}^{-\mathrm{SnO}_{2}}$ in NIB at a scan rate of $0.1 \mathrm{mV} \mathrm{s}^{-1}$

Figure 4.9 Galvanostatic charge-discharge profiles of (a) $\mathrm{rGO}^{-\mathrm{SnO}_{2}}$ nanocomposite and (b) pristine $\mathrm{SnO}_{2}$ in LIB at a current of $100 \mathrm{~mA} \mathrm{~g}^{-1}$. Specific capacities were calculated using the total mass in $\mathrm{SnO}_{2} / \mathrm{rGO}-\mathrm{SnO}_{2}$.

Figure 4.10 Galvanostatic charge-discharge profiles of (a) $\mathrm{rGO}^{-\mathrm{SnO}_{2}}$ nanocomposite and (b) pristine $\mathrm{SnO}_{2}$ in NIB at a current of $30 \mathrm{~mA} \mathrm{~g}^{-1}$ Specific capacities were calculated using the total mass in $\mathrm{SnO}_{2} / \mathrm{rGO}-\mathrm{SnO}_{2}$. 
Figure 4.11 (a) Lithiation cycling performance of $\mathrm{rGO}-\mathrm{SnO}_{2}$ and pristine $\mathrm{SnO}_{2}$ at $2 \mathrm{~A} \mathrm{~g}^{-1}$ and $1.4 \mathrm{~A} \mathrm{~g}^{-1}$ respectively. (b) Lithiation rate performance of rGO$\mathrm{SnO}_{2}$ and pristine $\mathrm{SnO}_{2}$ at various current densities.

Figure 4.12 (a) Sodiation cycling performance of $\mathrm{rGO}-\mathrm{SnO}_{2}$ and pristine $\mathrm{SnO}_{2}$ at $30 \mathrm{~mA} \mathrm{~g}^{-1}$. (b) Sodiation rate performance of $\mathrm{rGO}-\mathrm{SnO}_{2}$ and pristine $\mathrm{SnO}_{2}$ at various current densities.

Figure 5.1 Comparison between pristine $\mathrm{SnO}_{2}$ vs $\mathrm{N}$-doped $\mathrm{SnO}_{2}$ in (a) XRD (b) Raman spectroscopy. The spectrum of $\mathrm{SnO}_{2}$ in XRD matches that of rutile tetragonal $\mathrm{SnO}_{2}$ with JCPDS 41-1445. Broad peaks are observed in N-doped samples, which is consistent with HRTEM observations on the existence of small crystallites sizes. Raman spectrum in all 3 samples show distinct peak of Raman active $A_{1 g}$ and $B_{2 g}$ modes and presence of an inactive $A_{2 g}$ mode due small particle size, lattice distortion and modification in bond lengths.

Figure 5.2 HRTEM images of (a) pristine $\mathrm{SnO}_{2}$ (b) $\mathrm{SnO}_{2}-\mathrm{N} 3 \%$, and (c) $\mathrm{SnO}_{2}$ N8\%. The insets display the corresponding FESEM images and the inverse FFT images after applying an array mask. Samples prepared under presence of $\mathrm{NH}_{3}$ displays polycrystalline behavior along with grains of crystalline and amorphous regions. The crystalline grain size regions in both $\mathrm{SnO}_{2}-\mathrm{N} 3 \%$ and $\mathrm{SnO}_{2}-\mathrm{N} 8 \%$ can be estimated to be approximately $<5 \mathrm{~nm}$. (d) SAED pattern for the respective samples in accordance to tetragonal $\mathrm{SnO}_{2}$ standard (JCPDS: 411445). Scale bar of inset FESEM images are $200 \mathrm{~nm}$ and scale bar for SAED is $21 / \mathrm{n} \mathrm{nm}$.

Figure 5.3 General XPS plot comparing pristine $\mathrm{SnO}_{2}$ vs $\mathrm{N}$-doped $\mathrm{SnO}_{2}$. The peaks are calibrated with respect to C 1s standard peak at $284.8 \mathrm{eV}$. 
Figure 5.4 Sn 3d XPS peaks of (a) pristine $\mathrm{SnO}_{2}$, (b) $\mathrm{SnO}_{2}+\mathrm{N} 3 \%$, and (c) $\mathrm{SnO}_{2}+\mathrm{N} 8 \%$. (d) is the N 1s XPS peak which displays relatively higher peak intensity with increasing $\mathrm{NH}_{3}$ content. Additional shoulder peak at 484.7 and $493.4 \mathrm{eV}$ in (c) reveals presence of $\mathrm{Sn}^{0}$. All peaks are calibrated to standard $\mathrm{C}$ 1s peak at $284.4 \mathrm{eV}$ as shown in Figure $\mathrm{S} 2$.

Figure 5.5 $\mathrm{N}_{2}$ adsorption/desorption BET measurements of (a) pristine $\mathrm{SnO}_{2}$ (b) $\mathrm{SnO}_{2}+\mathrm{N} 3 \%$ (c) $\mathrm{SnO}_{2}+\mathrm{N} 8 \%$

Figure 5.6 (a) $1^{\text {st }}$ and (b) $2^{\text {nd }}$ lithiation cycle CV curves for the laser pyrolysed samples at $0.1 \mathrm{mV} \mathrm{s}^{-1}$. Sharp peak at $\sim 0.8 \mathrm{~V}$ corresponds formation of SEI layer on surface of electrode during discharge process.

Figure 5.7 (a) $1^{\text {st }}$ and (b) $2^{\text {nd }}$ sodiation cycle CV curves for the laser pyrolysed samples at $0.1 \mathrm{mV} \mathrm{s}^{-1}$. Sharp peak at $\sim 0.8 \mathrm{~V}$ corresponds formation of SEI layer on surface of electrode during discharge process.

Figure 5.8 Galvanostatic discharge curves of pristine $\mathrm{SnO}_{2}, \mathrm{SnO}_{2}+\mathrm{N} 3 \%$ and $\mathrm{SnO}_{2}+\mathrm{N} 8 \%$ in (a-c) LIB and (d-f) NIB.

Figure 5.9 (a) Cycling performance and the corresponding Columbic efficiency (C.E) at $1.4 \mathrm{~A} \mathrm{~g}^{-1}$.(b) Rate performance (discharge (solid) and charge (hollow)) of pristine $\mathrm{SnO}_{2}$ vs. N-doped $\mathrm{SnO}_{2}$ within a voltage window between $0.01-$ $3.00 \mathrm{~V}$ vs. $\mathrm{Li}^{+} / \mathrm{Li}$.

Figure 5.10 (a) Cycling performance and the corresponding Columbic efficiency (C.E) at $30 \mathrm{~A} \mathrm{~g}^{-1}$. (b) Rate performance (discharge (solid) and charge (hollow)) of pristine $\mathrm{SnO}_{2}$ vs. N-doped $\mathrm{SnO}_{2}$ within a voltage window between $0.01-3.00 \mathrm{~V}$ vs. $\mathrm{Na}^{+} / \mathrm{Li}$. 
Figure 5.11 CV curves illustrating both conversion and alloying redox peaks for (a) pristine $\mathrm{SnO}_{2}$, (b) $\mathrm{SnO}_{2}+\mathrm{N} 3 \%$, and (c) $\mathrm{SnO}_{2}+\mathrm{N} 8 \%$. The insets in top row plots illustrate increasing scan rates from 0.1 to $10 \mathrm{mV} \mathrm{s}^{-1}$. Peak currents are obtained from the point of inflections on respective differential plot in each scan rate as per shown in Figure. S3. Power law $\left(i_{p}=a v^{b}, \log i_{p}=b \log v+\log a\right)$ was applied to study the limiting mechanism during increasing scan rates in $(\mathrm{d}$ e). When $b$ is close to 0.5 , the limiting case would be a semi-infinite linear diffusion controlled process, while a value of 1 would indicate a surface controlled process. A linear dashed line is extrapolated from low scan rate conditions

Figure 5.12 (a) Investigation of different charging/discharging states for ex-situ characterization of $\mathrm{SnO}_{2}+\mathrm{N} 3 \%$ (b-d) SXRD patterns for $\mathrm{SnO}_{2}+\mathrm{N} 3 \%$ at different stages of charge/discharge. X-ray wavelength: $0.72768 \AA$. Symbols: (*) -> $\mathrm{SnO}_{2}$ (JCPDS: 41-1445) (+) -> $\mathrm{Li}_{22} \mathrm{Sn}_{5}$ (JCPDS: 18-0753) (\#) -> Sn (JCPDS: 65-2631). (e) Normalized first derivative of Sn K-edge XANES spectra at different point of interest. (f-h) Sn K-edge normalized absorption spectra of $\mathrm{SnO}_{2}+\mathrm{N} 3 \%$ at different depth of charge/discharge. The inset shows the corresponding Fourier transforms of Sn K-edge EXAFS spectra. (i) TEM image of $\mathrm{SnO}_{2}+\mathrm{N} 3 \%$, after 100 cycles ending with charge at $3.00 \mathrm{~V}$ vs. $\mathrm{Li}^{+} / \mathrm{Li}$. Scale bar is $2 \mathrm{~nm}$. The cell was disassembled within Ar filled glovebox with $\mathrm{O}_{2}$ and $\mathrm{H}_{2} \mathrm{O}$ levels $<1$ ppm.

Figure 5.13 Comparison of EXAFS data for undoped $\mathrm{SnO}_{2}$ against $\mathrm{SnO}_{2}+\mathrm{N} 3 \%$ at full discharge $0.01 \mathrm{~V}$ vs. $\mathrm{Li}^{+} / \mathrm{Li}$

Figure 5.14 (a) $2^{\text {nd }}$ order differential EXAFS results comparing $\mathrm{SnO}_{2}$ and $\mathrm{SnO}_{2}$ $+\mathrm{N} 3 \%$. The peak positions could be reliably compared using the differential plots. The area boxed in green between 1.4 to $1.8 \AA$ is magnified and illustrated in (b). 
Figure 5.15 Sn K-edge (a) XANES normalized absorption and (b) Fourier transformed EXAFS spectrums for $\mathrm{SnO}_{2}+\mathrm{N} 3 \%$ during $\mathrm{OCV}$ and after $1^{\text {st }}$ charge at $3.00 \mathrm{~V}$. (c) \& (d) similarly corresponds to the XANES and FT EXAFS at $0.01 \mathrm{~V}$ during complete discharge in the $1^{\text {st }}$ and $2^{\text {nd }}$ cycle.

Figure 6.1 XRD pattern of the as prepared $\mathrm{ZnSnO}_{3}$

Figure 6.2 (a) low magnification SEM image of the as synthesized ZSO-H (b) TEM image of polycrystalline hollow cubes (c) HRTEM revealing lattice spacing and the agglomerate of nanoparticles (inset shows typical polycrystalline Selected Area Electron Diffraction (SAED) pattern) (d) SEMEDX element mapping of $\mathrm{Zn}, \mathrm{Sn}$ and $\mathrm{O}$ on a single cube.

Figure 6.3 Energy dispersive X-ray mapping of $\mathrm{ZnSnO}_{3}$ hollow cubes.

Figure 6.4 Cyclic voltammogram of $\mathrm{ZnSnO}_{3}$ under a scan rate of $0.1 \mathrm{mV} \mathrm{s}^{-1}$ in (a) LIB and (b) NIB.

Figure 6.5 Initial galvanostatic charge-discharge curves of $\mathrm{ZnSnO}_{3}$ in (a) LIB at $100 \mathrm{~mA} \mathrm{~g}^{-1}$ (b) NIB at $30 \mathrm{~mA} \mathrm{~g}^{-1}$

Figure 6.6 Cycling performance of $\mathrm{ZnSnO}_{3}$ within a voltage window of 0.01 to $3.00 \mathrm{~V}$ vs. $\mathrm{Li}^{+} / \mathrm{Li}$ or $\mathrm{Na}^{+} / \mathrm{Na}$ in (a) LIB at $100 \mathrm{~mA} \mathrm{~g}^{-1}$ and (b) NIB at $240 \mathrm{~mA} \mathrm{~g}^{-1}$

Figure 6.7 Cycling performance of $\mathrm{ZnSnO}_{3}$ in NIB system at $240 \mathrm{~mA} \mathrm{~g}^{-1}$

Figure 6.8 Rate performances of $\mathrm{ZnSnO}_{3}$ hollow cubes in (a) LIB and (b) NIB

Figure 6.9 Initial galvanostatic charge-discharge curves of (a) $\mathrm{ZnO}$ and (b) $\mathrm{ZnO}-\mathrm{SnO}_{2}$ in NIB at $30 \mathrm{~mA} \mathrm{~g}^{-1}$. 
Figure 6.10. Ex-situ SEM-EDX of $\mathrm{ZnSnO}_{3}$ upon full discharge at $30 \mathrm{~mA} \mathrm{~g}^{-1}$.

Figure 6.11 Schematic describing the energy storage process in polycrystalline $\mathrm{ZnSnO}_{3}$ hollow cubes. The $\mathrm{ZnSnO}_{3}$ first undergoes an irreversible conversion process into metallic $\mathrm{Zn}$ and $\mathrm{Sn}$ and subsequently, a reversible alloying process ensues, producing $\mathrm{Na}_{15} \mathrm{Sn}_{4}$ and $\mathrm{NaZn}_{13}$ alloys.

Figure 7.1 Lithiation galvanostatic charge-discharge at a current density of 100 $\mathrm{mA} \mathrm{g}^{-1}$ of (a) laser pyrolyzed pristine $\mathrm{SnO}_{2}$ (b) $\mathrm{ZnSnO}_{3}$ hollow cubes

Figure 7.2 Sodiation galvanostatic charge-discharge at a current density of 30 $\mathrm{mA} \mathrm{g}^{-1}$ of (a) laser pyrolyzed pristine $\mathrm{SnO}_{2}$ (b) $\mathrm{ZnSnO}_{3}$ hollow cubes

Figure 7.3 Specific capacity vs. current density plot of the lithiation performance of different graphene- $\mathrm{SnO}_{2}$ based nanocomposites. * indicates capacity calculated from $\mathrm{SnO}_{2}$ only instead of the nanocomposites

Figure 7.4 Specific capacity vs. current density plot of the sodiation performance of different carbon- $\mathrm{SnO}_{2}$ based nanocomposites. Reference specific capacities are calculated from $\mathrm{SnO}_{2}$ only. Specific capacity of laser pyrolyzed $\mathrm{SnO}_{2}$ is calculated from mass of composite.

Figure 7.5 Charge profile of $\mathrm{SnO}_{2}+\mathrm{N} 3 \%$, in the $2^{\text {nd }}, 5^{\text {th }}, 10^{\text {th }}$ and $15^{\text {th }}$ cycle. Capacity loss can be seen from lower capacity contribution $>1.20 \mathrm{~V}$, indicating poor reversibility of conversion reaction. Alloying process on the other hand showed almost perfect capacity retention within the 15 cycles.

Figure 7.6 XRD spectrum of laser pyrolyzed product utilizing $\mathrm{SnSO}_{4}$ and $\mathrm{ZnCl}_{2}$ as initial precursors. 
Figure Captions

Figure 7.7 Potential requirements for the ideal cathode additives 

Abbreviations

LIB Lithium Ion Battery

NIB Sodium Ion Battery

CV Cyclic Voltammetry

BET Brunauer-Emmett-Teller

EIS Electrochemical Impedance Spectroscopy

FESEM Field Electron Scanning Electron Microscopy

TEM Transmission Electron Microscopy

EDX Energy Dispersive X-ray

TGA Thermogravimetric Analysis

XRD X-ray Diffraction

XAS X-ray Absorption Spectroscopy

XPS X-ray Photoelectron Spectroscopy

HRTEM High Resolution Transmission Electron Microscopy

SAED Selected Area Electron Diffraction

FFT Fast Fourier Transform

SEI Solid Electrolyte Interphase

CMC Carboxymethylcellulose

EC Ethylene carbonate

EMC Ethylmethyl carbonate

DMC Dimethyl carbonate

PC Propylene carbonate

EV Electric Vehicle

HEV Hybrid Electric Vehicle 


\section{Chapter 1}

\section{Introduction}

In the first chapter, we will start off with the problem statement facing the utilization of $\mathrm{SnO}_{2}$ as anode material in LIB/NIB. Following that, we highlight the objective and scope of this dissertation on the engineering of $\mathrm{SnO}_{2}$. Subsequently, an outline of this thesis will be presented before we summarize the novelty/outcome of this research. 


\subsection{Problem Statement}

\subsubsection{Background}

Research on rechargeable alkali batteries began back in the 1980 s where $\mathrm{Li} / \mathrm{Na}$ metal was initially utilized as the anode material. However, due to the problem of dendrite formation that could lead to safety issues, alternative anode materials had to be developed..$^{1-5}$ In the late $1980 \mathrm{~s}$, graphite was discovered to be a promising anode material in Li system owing to the low operating potential and good stability. Since then, the commercialization of Li-ion batteries (LIBs) by Sony in 1991 has opened up a new window for portable/mobile electronic technologies. ${ }^{6}$ LIBs would then go on to face tremendous success, which could be attributed to the high energy density, long cycle life, and lightweight that it offers to the end user. While the success of commercial LIBs has simultaneously slowed down research on $\mathrm{Na}$ based systems, there have been widespread arguments on the availability of Li precursors and whether the geopolitically available precursors could be sustainable for the future, especially with the growing EV/grid storage market. ${ }^{5}$

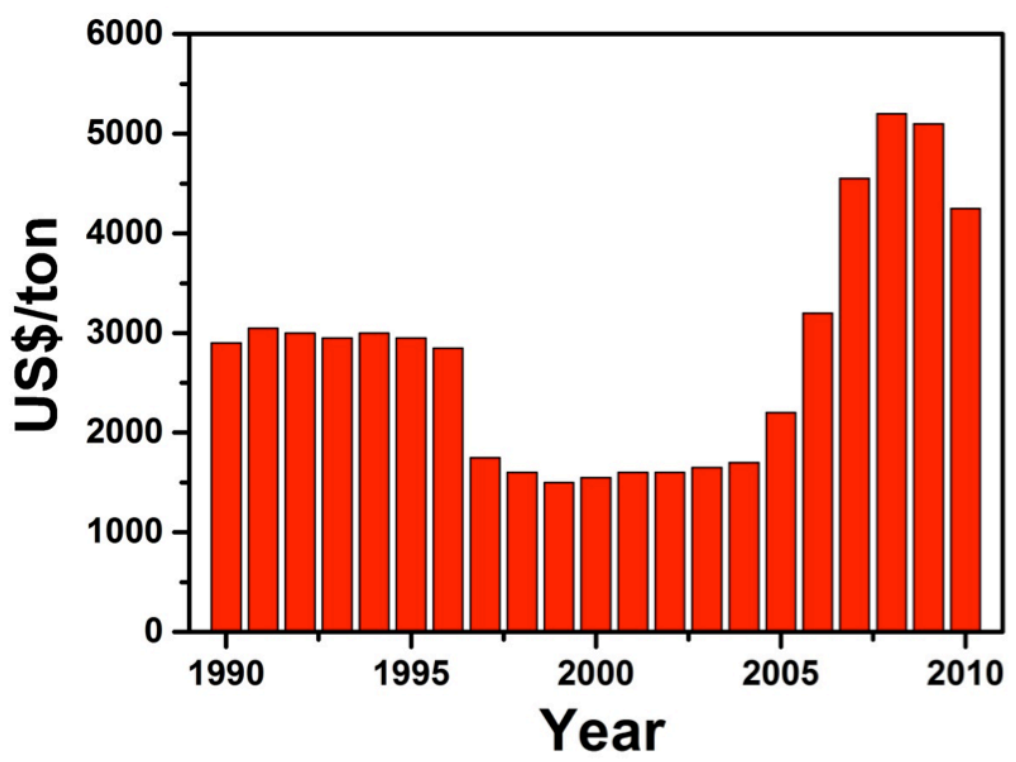

Figure 1.1 Average price of lithium precursor over the years. The sharp increase during 2004 was due to increase in demand for LIB while the decline in price during 2008 was attributed to the financial crisis. ${ }^{5}$ 
Table 1 Comparison between Lithium and Sodium ${ }^{5}$

\begin{tabular}{ccc}
\hline & Sodium & Lithium \\
\hline Potential $($ V vs. S.H.E) & -2.70 & -3.04 \\
Cation radii $(\AA)$ & 0.97 & 0.68 \\
Price $($ US\$ $/$ ton) & $250-300$ & 5800 \\
Atomic Weight $(\mathrm{g})$ & 23 & 6.9 \\
Capacity $\left(\mathrm{mAh} \mathrm{g}^{-1}\right)$ & 1160 & 3860 \\
\hline
\end{tabular}

The controversy has brought research on NIBs back into the limelight. Nonetheless, due to the larger atomic mass of $\mathrm{Na}$ compared to $\mathrm{Li}$, most researchers expect the energy/power density in NIBs to be slightly lower than that of LIBs. Instead of powering EVs, the end-use application of NIBs appears to suit better large-scale stationary energy storage, where they can provide an efficient and reliable way of storing and releasing energy derived from intermittent renewable energy sources. To fulfill the requirements for future technologies, electrode materials with higher energy/power density, longer cyclability, and better rate performance are desired. Electrode materials, which are the heart of these alkali ion batteries, determine how much charge could be stored and the lifetime of the battery. The history of storage of alkali ions goes back into 1959 where Rüdorff studied the insertion behaviors of different alkali ions in graphite. ${ }^{7}$ After that, pioneering work by Whittingham demonstrated the possibility of utilizing such intercalation phenomenon for electrochemical energy storage. ${ }^{8}$ The work led to subsequent discoveries on the compatibility of $\mathrm{LiCoO}_{2}$ and graphite as the cathode and anode, thus resulting in commercialization of Lithium Ion Batteries (LIBs). ${ }^{6,9}$

Graphite is often the main choice of anode material in traditional commercial LIBs. It has a theoretical capacity of $372 \mathrm{mAh} \mathrm{g}^{-1}$ and an operating voltage of $0.3 \mathrm{~V}$ vs. $\mathrm{Li}^{+} / \mathrm{Li}$. It undergoes an intercalation reaction where $1 \mathrm{Li}^{+}$could be stored in gaps perpendicular to the basal graphitic planes. In the sodium system, pristine graphite is rendered electrochemically inactive due to the narrow interlayer spacing that hinders reversible intercalation of $\mathrm{Na}^{+}$. There have been concerns that due to the low operating potential of graphite in LIB, it poses 
safety hazard of Li plating due to polarization when cycled faster rates. Metal oxides on the other hand, generally undergo different electrochemical redox reaction that allows accommodation of more than $1 \mathrm{Li}^{+}$. Tin (IV) Oxide $\left(\mathrm{SnO}_{2}\right)$ is an example of one such metal oxide. It has long been explored as a potential anode material for rechargeable batteries owing to its suitable operating potential $\left(<0.8 \mathrm{~V}\right.$ vs. $\mathrm{Li}^{+} / \mathrm{Li}$ or $<0.5 \mathrm{~V}$ vs. $\left.\mathrm{Na}^{+} / \mathrm{Na}\right)$, high theoretical gravimetric capacity $\left(1493 \mathrm{mAh} \mathrm{g}^{-1}(\mathrm{Li})\right.$ and $1398 \mathrm{mAh} \mathrm{g}^{-1}(\mathrm{Na})$ assuming fully reversible conversion \& alloying reactions), reasonable cost and its environmental benignity. Despite the attractive properties that $\mathrm{SnO}_{2}$ may offer, it still faces a lot of challenges that hampers practical applications. These challenges include poor cyclability, low electronic and ionic conductivity and complicated synthesis process.

It is, therefore, the aim of this thesis to explore different engineering methods for overcoming the challenges pertaining to the poor electrochemical performance of $\mathrm{SnO}_{2}$. Undoubtedly, there has been a plethora of literature covering engineering methods for $\mathrm{SnO}_{2}$ to improve its electrochemical performances. These methods generally nanostructure/nanosize the material to reduce diffusion length and to provide a carbon buffer layer to withstand stress induced during lithiation/sodiation. While most of the results are encouraging, the material preparation methods often require multiple steps and are mostly tedious/time-consuming. Hence, the rationale of the research conducted in this Ph.D thesis plans to cover different facile and time-efficient methods for the preparation of $\mathrm{SnO}_{2}$ with improved electrochemical performances in both LIB and NIB. The synthesized products from facile methods will be self-evaluated and thoroughly compared with reported literature. Next, we will provide 3 hypotheses with different key design criteria and rationale that will be discussed within this thesis. 


\subsubsection{Hypothesis and objective}

Capacity fading in $\mathrm{SnO}_{2}$ is largely attributed to pulverization incurred on the active material during topotactic reactions, which gradually leads to failure of the cell. ${ }^{10,11}$ To date, a few methods have been found to be efficient in mitigating/alleviating this issue. Morphological tailoring, ${ }^{12}{ }^{13}$ reduction of particle size ${ }^{14,15}$ and integration of carbon phases ${ }^{16-18}$ are some of the most commonly explored methods. Nevertheless, most of the methods have tedious and complicated preparation process. Other methods such as elemental doping $^{19,20}$ or the incorporation of a foreign element/matrix ${ }^{21}$ into the structure could be more efficient while at the same time provide the similar enriching effect. Herein, we propose below three different hypothesis and objective that could help improve the overall performance of tin based oxide materials for LIB and NIB application.

Hypothesis 1: The presence of a carbonaceous conductive matrix could be beneficial in enhancing electronic conductivity while improving the overall structural integrity of the material.

Specific Objective 1: Investigation and evaluation on the electrochemical performance of $\mathrm{rGO}-\mathrm{SnO}_{2}$ synthesized from a facile one-pot laser pyrolysis method.

Carbon-based composites are excellent electrode materials that have been extensively explored in LIBs and NIBs. ${ }^{22}$ The carbon-based matrix provides a conductive pathway for electron transport while helping to mitigate pulverization effect sustained from repeated cycling processes. Graphene comprises a single layer of graphitic carbon and offers excellent electronic conductivity and mechanical properties. When brought together with insulating $\mathrm{SnO}_{2}$ material, the resultant composite possesses synergistic properties from 
both individual components. However, such composites often require tedious, time-consuming and complicated preparation processes. In this segment, a time-efficient one-pot laser pyrolysis process for the production of $\mathrm{rGO}-\mathrm{SnO}_{2}$ nanocomposite will be demonstrated.

Hypothesis 2: Heterogeneous doping alters the electronic structure of the material, giving rise to improved conductivity. Prevention of long-range ordering due to the presence of heterogeneous atoms will also be beneficial for cyclability.

Specific Objective 2: In-depth evaluation on electrochemical performance of Ndoped $\mathrm{SnO}_{2}$ and its fundamental mechanism study

Studies on heterogeneous doping in $\mathrm{SnO}_{2}$ have mainly focused on cationic doping with elements such as $\mathrm{Fe},{ }^{19} \mathrm{Co}^{23} \mathrm{Ni}^{24}$ and etc. ${ }^{20}$ While these dopants help improve electronic conductivity and cyclability, the intrinsically heavy weight of these elements pulls down the specific capacity of the overall composite. On the other hand, anionic doping has hardly been studied. Previous studies have shown that with $\mathrm{F}^{-}$doping, better cycling and electronic performance could be achieved in $\mathrm{SnO}_{2}$. While studies on nitrogen doping have mainly yielded encouraging results in other metal oxides, there has not been any studies evaluating the electrochemical performance of $\mathrm{N}$-doped $\mathrm{SnO}_{2}$. Furthermore, due to the ease of reduction of metallic ions into their elemental state during synthesis of nitrogen-doped samples, a more facile and less timeconsuming method has to be developed. In this segment, the impact of nitrogen doping in $\mathrm{SnO}_{2}$ nanoparticles prepared via laser pyrolysis will be evaluated. After that, the underlying mechanism will be elucidated through ex-situ SXRD and XAS to determine the role of nitrogen. 
Hypothesis 3: The incorporation of foreign element/matrix that is either electrochemically active or inactive could help buffer the size expansion incurred and prevent agglomeration during the cycling process.

Specific Objective 3: Understanding and evaluating the effect of matrix engineering with the incorporation of $\mathrm{ZnO}$ to form $\mathrm{ZnSnO}_{3}$.

The theoretical size expansion of $\mathrm{SnO}_{2}$ has been calculated to be $306 \%{ }^{25}$ and $645 \%{ }^{26}$ in $\mathrm{Li}$ and $\mathrm{Na}$ systems respectively. We postulate that it could be possible to introduce a foreign element/matrix that is either electrochemically active or inactive that could help buffer the size expansion incurred during the cycling process. $\mathrm{ZnO}$ was chosen as a potential candidate due to three strategic reasons: i) it has a much smaller size expansion in both $\mathrm{Li}(124 \%)$ and $\mathrm{Na}(\sim 0 \%)$ systems as compared to $\mathrm{SnO}_{2}$; ii) it possesses a different redox potential as compared to $\mathrm{SnO}_{2}$ and therefore, it provides a wider voltage range for buffering volume change during lithiation/sodiation; iii) $\mathrm{Zn}$ does not for alloy with $\mathrm{Sn}$, hence preventing agglomeration of the same element during cycling process. In addition, the morphology of materials is known to have a profound impact in facilitating ion diffusion and buffering cycling induced strain. We design $\mathrm{ZnSnO}_{3}$ hollow cubes via a facile etching process and evaluate its anodic electrochemical performances.

\subsection{Dissertation Overview}

The key motivation of this thesis aims to fabricate novel nanostructured anode materials using facile methods for the development of next-generation batteries. To this end, the thesis will be broken down into several individual chapters of which the contents will be summarized below.

Chapter 1 provides a general background on rechargeable alkali ion batteries. Several research gaps will be identified with specific scope and objectives that 
aim to verify our hypotheses. After that, we will list out the novelty and contribution that this thesis provides to the scientific community.

Chapter 2 reviews and summarizes the literature on related works that have been carried out in both LIBs and NIBs, with a particular focus on studies concerning the modification of $\mathrm{SnO}_{2}$ anode materials.

Chapter 3 elaborates on the various synthesis methods, characterization tools, and techniques that will be utilized in this thesis.

Chapter 4 demonstrates the production of $\mathrm{rGO}-\mathrm{SnO}_{2}$ nanocomposites through a time-efficient laser pyrolysis method and its subsequent electrochemical results.

Chapter 5 elaborates on the production and electrochemical properties of novel $\mathrm{N}$-doped $\mathrm{SnO}_{2}$ through laser pyrolysis. Subsequently, ex-situ synchrotron methods will be utilized to understand fundamental mechanisms and the role of nitrogen.

Chapter 6 presents experimental results for the study of matrix engineering through the incorporation of $\mathrm{ZnO}$ into the matrix of $\mathrm{SnO}_{2}$ for the formation of $\mathrm{ZnSnO}_{3}$.

Chapter 7 then draws together the impact and improvement that each engineering methods have on the overall electrochemical performance in both LIB and NIB. In this chapter, we will also summarize all the key findings and highlight outstanding questions with recommendations for future works.

\subsection{Findings and Outcomes/Originality}

This research has led to several novel outcomes by: 
1. Enabling better cycling performance of $\mathrm{SnO}_{2}$ in NIB through addition of $\mathrm{ZnO}$ into the structure by synthesizing $\mathrm{ZnSnO}_{3}$. This $\mathrm{ZnSnO}_{3}$ was found to possess a lower electrochemical potential compared to pristine $\mathrm{SnO}_{2}$, leading to potentially higher energy density.

2. Demonstrating the synthesis of $\mathrm{SnO}_{2}$ nanoparticles via laser pyrolysis. This has not been done before with cost-effective and non-toxic precursors.

3. Establishing a proof-of-concept method for a one pot synthesis of $\mathrm{rGO} @ \mathrm{SnO}_{2}$ through laser pyrolysis.

4. Understanding the impact of nitrogen doping on the electrochemical performance of $\mathrm{SnO}_{2}$ in both LIB/NIB.

5. Elucidating the fundamental mechanism and role of nitrogen doping in $\mathrm{SnO}_{2}$ by synchrotron methods and established a correlation between $\mathrm{N}$ doping and its electrochemical kinetics.

\section{References:}

1. B. Dunn, H. Kamath and J.-M. Tarascon, Science, 2011, 334, 928-935.

2. M. Armand and J. M. Tarascon, Nature, 2008, 451, 652-657.

3. D. Larcher and J. M. Tarascon, Nat Chem, 2015, 7, 19-29.

4. J. M. Tarascon and M. Armand, Nature, 2001, 414, 359-367.

5. L. P. Wang, L. Yu, X. Wang, M. Srinivasan and Z. J. Xu, Journal of Materials Chemistry A, 2015, 3, 9353-9378.

6. J. B. Goodenough and Y. Kim, Chemistry of Materials, 2009, 22, 587-603.

7. W. Rüdorff, Angewandte Chemie, 1959, 71, 487-491.

8. M. S. WHITTINGHAM, Science, 1976, 192, 1126-1127.

9. J. B. Goodenough and K.-S. Park, Journal of the American Chemical Society, 2013, 135, 1167-1176.

10. J. Ding, Z. Li, H. Wang, K. Cui, A. Kohandehghan, X. Tan, D. Karpuzov and D. Mitlin, Journal of Materials Chemistry A, 2015, 3, 7100-7111.

11. K. Kisu, M. lijima, E. Iwama, M. Saito, Y. Orikasa, W. Naoi and K. Naoi, Journal of Materials Chemistry A, 2014, 2, 13058-13068.

12. P. Gurunathan, P. M. Ette and K. Ramesha, ACS Applied Materials \& Interfaces, 2014, 6, 16556-16564.

13. C. Wang, G. Du, K. Ståhl, H. Huang, Y. Zhong and J. Z. Jiang, The Journal of Physical Chemistry C, 2012, 116, 4000-4011.

14. Y. Chen, B. H. Song, R. M. Chen, L. Lu and J. M. Xue, Journal of Materials Chemistry A, 2014, 2, 5688-5695. 
15. A. Jahel, C. M. Ghimbeu, L. Monconduit and C. Vix-Guterl, Advanced Energy Materials, 2014, 4.

16. Y. Zhao, C. Wei, S. Sun, L. P. Wang and Z. J. Xu, Advanced Science, 2015, 2, n/a-n/a.

17. B. J. Li, H. Q. Cao, J. X. Zhang, M. Z. Qu, F. Lian and X. H. Kong, Journal of Materials Chemistry, 2012, 22, 2851-2854.

18. W. M. Zhang, J. S. Hu, Y. G. Guo, S. F. Zheng, L. S. Zhong, W. G. Song and L. J. Wan, Advanced Materials, 2008, 20, 1160-+.

19. F. Mueller, D. Bresser, V. S. K. Chakravadhanula and S. Passerini, Journal of Power Sources, 2015, 299, 398-402.

20. J. Sun, L. Xiao, S. Jiang, G. Li, Y. Huang and J. Geng, Chemistry of Materials, 2015, 27, 4594-4603.

21. Y. Chen, B. Qu, L. Mei, D. Lei, L. Chen, Q. Li and T. Wang, Journal of Materials Chemistry, 2012, 22, 25373-25379.

22. C. de las Casas and W. Z. Li, Journal of Power Sources, 2012, 208, 74-85.

23. N. Wan, P. Yu, S. Sun, Q. Wu, T. Li and Y. Bai, Materials Letters, 2014, 133, 168-170.

24. X. Ye, W. Zhang, Q. Liu, S. Wang, Y. Yang and H. Wei, New Journal of Chemistry, 2015, 39, 130-135.

25. J. Y. Huang, L. Zhong, C. M. Wang, J. P. Sullivan, W. Xu, L. Q. Zhang, S. X. Mao, N. S. Hudak, X. H. Liu, A. Subramanian, H. Fan, L. Qi, A. Kushima and J. Li, Science, 2010, 330, 1515-1520.

26. M. Gu, A. Kushima, Y. Shao, J.-G. Zhang, J. Liu, N. D. Browning, J. Li and C. Wang, Nano Letters, 2013, 13, 5203-5211. 



\section{Chapter 2}

\section{Literature Review}

Research on Li and Na-based batteries has been carried out since the early 1970s. Since then, numerous discoveries on the fundamentals of electrode materials have been made. In this chapter, we first review the theories and fundamentals of alkali ion battery. We will then go into detail on studies concerning tin based oxide anodes and reported studies on engineering methods that could help improve their performance. 


\subsection{Alkali ion batteries (AIBs): Operating mechanism and key parameters}

Batteries are electrochemical cells that store electrical energy through thermodynamically unfavorable chemical reaction, in which the energy could be spontaneously extracted when connected to an external load. ${ }^{1,2}$ Alkali ion batteries (AIBs) belong to a category called "secondary batteries" and rely on the reversible conversion of electrical and chemical energy. A single cell comprises of 4 key components, namely the cathode, anode, electrolyte and separator.

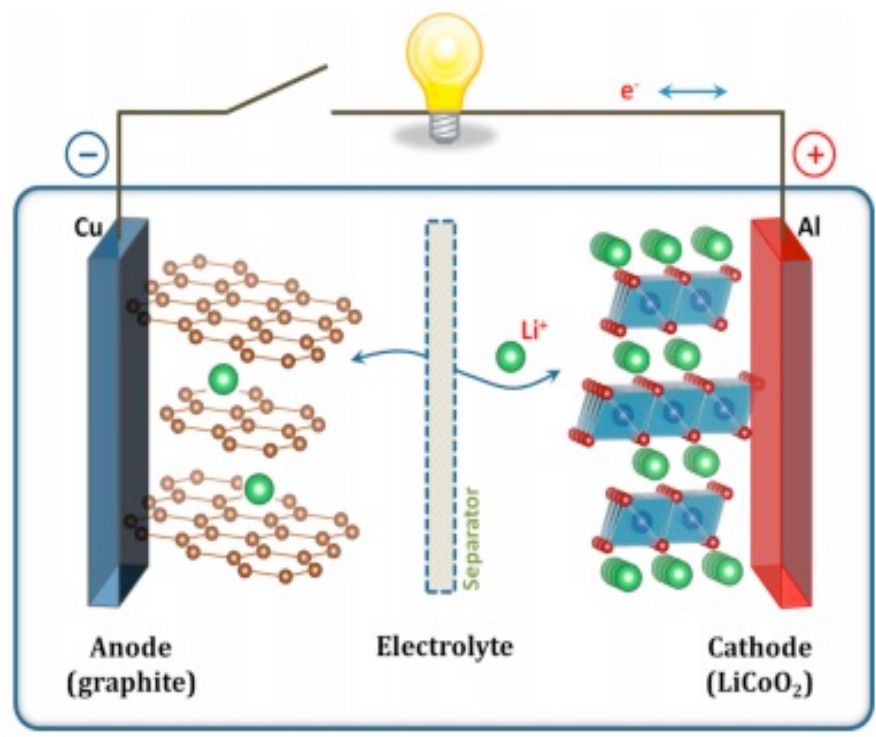

Figure 2.1 Operational illustration of the Li-ion battery ${ }^{2}$

The cathode and anode materials are typically host materials that can accommodate alkali ions through electrochemical redox reactions. They are the most crucial components that determine the overall performance (i.e. energy density, power density, cyclability and etc.) of the battery. The active cathode and anode materials are often intermixed with carbon additives (e.g. carbon black, Super P) and binder solution (e.g. PVDF in NMP) for a prolonged period to obtain coalescence slurry before coating onto battery-grade aluminum and copper foils respectively. The electrolyte is electrically insulating but provides 
an ionic conductive medium for $\mathrm{Li}$ or $\mathrm{Na}$ ions to shuttle between the cathode and anode during charge/discharge processes. Carbonate-based organic compounds (e.g. PC, EC, DEC) are the most commonly utilized electrolyte solvent, while fluorophosphate (e.g. $\mathrm{LiPF}_{6}, \mathrm{NaPF}_{6}$ ) and perchlorates (e.g. $\left.\mathrm{LiClO}_{4}, \mathrm{NaClO}_{4}\right)$ are the most widely used form of alkali salts in both LIBs and NIBs. The separator is a microporous polymeric membrane that is wetted with the electrolyte before use. The key function of the separator helps prevent a direct short between the cathode and anode while allowing alkali ions to permeate and shuttle between electrodes.

During the charging process in a full cell, alkali ions de-intercalate from the cathode and shuttle through the electrolyte before electrochemically reducing the anode. This process is thermodynamically unfavorable and requires an external power source. ${ }^{3}$ Conversely, the reverse occurs in the discharge process. The discharge reaction, on the other hand, is thermodynamically favorable and the driving force is essentially determined by the variation of Gibbs free energy between the reactants and products according to the equation:

$$
\Delta \mathrm{G}_{r x n}^{o}=\Sigma \Delta \mathrm{G}_{f}^{o} \text { (products) }-\Sigma \Delta \mathrm{G}_{f}^{o} \text { (reactants) }
$$

where $\Delta \mathrm{G}_{r x n}^{o}$ is the change in Gibbs free energy from a reaction at standard conditions and $\Delta \mathrm{G}_{f}^{o}$ corresponds to the Gibbs free energy of formation at standard conditions. The equilibrium potential or open-circuit potential could be calculated as:

$$
\mathrm{E}^{\mathrm{o}}=\frac{-\Delta \mathrm{G}_{r x n}^{o}}{z F}
$$

where $\mathrm{E}^{\mathrm{o}}$ is the Open Circuit Potential (O.C.P) of the battery, $\mathrm{z}$ is the number of electrons generated from the redox reactions, and $\mathrm{F}$ corresponds to Faraday constant (96 $485 \mathrm{C} \mathrm{mol}^{-1}$ ). Electrons produced through redox reactions travel through an external circuit where it does work and power devices. The overall voltage is restricted by the effective voltage limit of the electrolyte, where the upper limit is decided by electrolyte decomposition/oxygen evolution ${ }^{4,5}$ and the lower limit defined by alkali metal plating potential ${ }^{6}$. 
The heart of batteries lies in the electrode materials, which determines how much charge could be stored and how long it could be cycled. Specific capacity is the key parameter that determines the quantity of charge that could be accumulated per unit mass of material. Theoretical specific capacity can be calculated using:

$$
\text { Specific capacity }\left(\mathrm{mAh} \mathrm{g}^{-1}\right)=\frac{z F}{M} \times \frac{1000}{3600}
$$

Where $\mathrm{z}$ is the electrons generated from the redox reactions, F corresponds to the Faraday constant (96 $\left.485 \mathrm{C} \mathrm{mol}^{-1}\right)$ and $\mathrm{M}$ is the Molar mass of the active material $\left(\mathrm{g} \mathrm{mol}^{-1}\right)$. As could be deduced, the specific capacity is materials dependent and is also reliant on the materials' reaction mechanism. The coulombic efficiency (C.E) of a particular material is a ratio between the discharging capacity and the charging capacity. It determines the reversibility and charge loss in each charging/discharging cycle.

$$
\text { C.E }=\frac{\text { Discharge capacity }}{\text { Charge capacity }}
$$

A C.E value of $100 \%$ would be ideal as it simply means that all of the stored $\mathrm{Li}$ or $\mathrm{Na}$ ions could be reversibly extracted out. In practical devices, the C.E values are much often less than $100 \%$, which is due to parasitic side reactions that irreversibly consume Li or $\mathrm{Na}$ ions from the electrolyte. Coulombic efficiency is not to be confused with energy efficiency, where voltage hysteresis influences the latter. The time required to charge/discharge a cell is dependent on the current density applied and the specific capacity of the material. Rate capability is one of the key performance indicators that determine how fast a material could be charged. C-rate defines how fast a cell is being cycled. An $\mathrm{nC}$ cycling rate could be defined (with respect to the theoretical capacity of the material) as the amount of current required for the cell completely charge/discharge in $1 / \mathrm{n}$ hours. The specific capacity drops when $\mathrm{C}$ rate increases, which is attributed to diffusion/kinetic limitations and is dependent on morphology, structure and the materials' redox reaction mechanism. ${ }^{7}$ 


\subsection{Current progress of anode materials}

As mentioned in the previous segment, the parameter affecting cell performance depends largely on the choice of material. Anode materials can be divided into three categories as illustrated in Figure 2. ${ }^{7}$ The traditional graphite anode in LIB undergoes an insertion reaction where $1 \mathrm{Li}^{+}$is stored within the basal plane of 6 $\mathrm{C}$ atoms giving rise to a capacity of $372 \mathrm{mAh} \mathrm{g}^{-1}$. While intercalation materials often boast of long cyclability due to minimal size expansion, they are largely limited by their low specific capacities (170-400 $\left.\mathrm{mAh} \mathrm{g}^{-1}\right) .{ }^{8,9}$ Conversely, conversion materials are capable of delivering higher reversible capacity (often in the range $500-1100 \mathrm{mAh} \mathrm{g}^{-1}$ ) but is often accompanied by large polarization and a sloping voltage profile during charge-discharge processes which prevents practical usage in commercial applications. ${ }^{10}$ The last group is the alloying materials, which possesses the highest reversible capacity $\left(800-1800 \mathrm{mAh} \mathrm{g}^{-1}\right.$ ) among the three groups, along with low working potential and relatively good power capabilities. $^{11}$

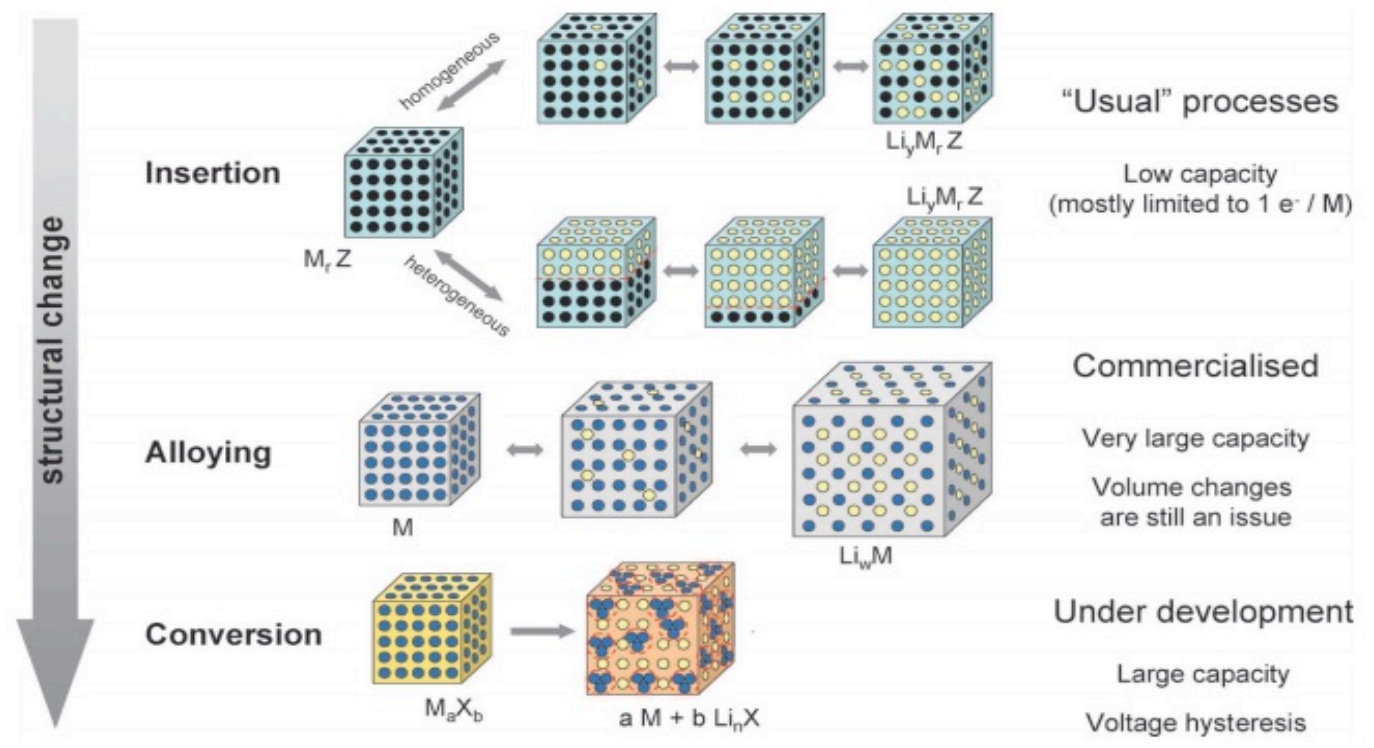

Figure 2.2 Schematic representing the different reaction mechanisms of electrode materials in alkali ion batteries ${ }^{7}$ 
Among the three groups of materials, tremendous efforts have been made on the research of conversion and (or) alloying based transition metal oxides and sulfides. These metal oxides and sulfides possess much higher capacity compared to the traditional graphite anode. ${ }^{12}$ Moreover, they demonstrate relatively better rate capability and cycling performance. Nevertheless, both conversion and (or) alloying materials are often accompanied by substantial volume expansion that contributes to material fracture and is identified as the main factor for its rapid capacity fading. In 2005, Sony announced the use of Nexelion battery comprising of a Sn-Co-C anode, which makes it the first time since the commercialization of LIB that a conversion/alloying anode is utilized in commercial batteries. ${ }^{13}$

While both $\mathrm{Li}$ and $\mathrm{Na}$ are Group I alkali metals, they have reacted differently towards to various materials. For instance, due to the higher reducing potential of $\mathrm{Na}(\mathrm{E}=-2.70 \mathrm{~V}$ vs. S.H.E $)$ as compared to $\mathrm{Li}(\mathrm{E}=-3.04 \mathrm{~V}$ vs. S.H.E), anode materials such as $\mathrm{Si}\left(\sim 0.1 \mathrm{~V}\right.$ vs. $\left.\mathrm{Li}^{+} / \mathrm{Li}\right)$ that operates at potential close to plating in LIB would be rendered inactive in NIB due to thermodynamic limitations. ${ }^{14-}$ 16 Additionally, the ionic size difference between $\mathrm{Li}^{+}$and $\mathrm{Na}^{+}$has a large influence on the reversibility during lithiation/sodiation. ${ }^{17}$ The bigger ionic size of sodium ions $(0.97 \AA)$ compared to lithium ions $(0.68 \AA)$ has resulted in a much larger volume change for all conversion and alloying materials during sodiation as compared to lithiation. ${ }^{14,18}$ This implication could theoretically lead to poorer cyclability and lower volumetric energy in NIB systems.

\subsubsection{Insertion electrodes}

Intercalation materials are characterized by their low working potential with a small, flat working voltage plateau. They require an open structure to host and accommodate the presence of $\mathrm{Li}^{+} / \mathrm{Na}^{+}$. During cation insertion, relatively small/no volume change occurs within the structure, thus translating to longer cyclability. ${ }^{19,20}$ 
Graphite $\left(\sim 372 \mathrm{mAh} \mathrm{g}^{-1}\right)$ stands as the most successful intercalation anode material ever used in commercial LIBs. Up to $1 \mathrm{Li}^{+}$can be inserted at a low operating voltage $\left(\sim 0.5 \mathrm{~V}\right.$ vs. $\left.\mathrm{Li}^{+} / \mathrm{Li}\right)$ within the hexagonal $\mathrm{C}_{6}$ ring, giving rise to a theoretical capacity of $372 \mathrm{~mA} \mathrm{~h} \mathrm{~g}^{-1}$. On the other hand, sodiation of graphite faces thermodynamic restrictions (small interlayer spacing) in forming binary $\mathrm{Na}-\mathrm{C}$ compounds under carbonate-based electrolytes. ${ }^{21,22}$ One of the ways to make insertion of $\mathrm{Na}^{+}$into graphite possible was through the substitution of traditional EC: DEC electrolyte solvents with diglyme-based electrolytes. ${ }^{23}$ Asides from that, using expanded graphite that possesses a wider spacing of $0.43 \mathrm{~nm}$ as compared to pristine graphite $(\sim 0.34 \mathrm{~nm})$ showed relatively good cyclability with capacity retention of $74 \%$ after 2000 cycles. $^{24}$ Several other notable insertion materials include graphene, which is a oneatom-thick sheet of $\mathrm{sp}^{2}$-bonded $\mathrm{C}$ atoms arranged in a hexagonal crystal matrix. It has allured plentiful of interest for application in various fields since its discovery owing to its superior electrical conductivity, excellent mechanical strength, high specific surface area and good thermal/chemical stability. $\mathrm{TiO}_{2}$ is another widely explored intercalation based material that exists in several different polymorphs (e.g. anatase, ${ }^{25} \mathrm{TiO}_{2}-(\mathrm{B}),{ }^{26}$ brookite $^{27}$ and rutile ${ }^{25}$ ) depending on the synthesis condition. $\mathrm{Nb}_{2} \mathrm{O}_{5}$ exists in several polymorphs and the most commonly studied form is orthorhombic structure. ${ }^{28,29}$ It is attractive as anode material owing to the rapid intercalation-pseudocapacitance property.

\subsubsection{Conversion electrodes}

Asides from traditional insertion electrode materials, compounds that undergo different reaction mechanisms are also of large interests. The main advantage of these materials is their capability to store more than $1 \mathrm{Li}^{+}$or $\mathrm{Na}^{+}$per unit compound, which would then translate to higher specific capacity and energy density. However, the ability to accommodate a large amount of alkali cations would be a double-edged sword as it brings along great size expansion and structural damage, thus often resulting in poor cyclability. 
Materials that are capable of undergoing conversion reaction are often transition metal compounds with the formula $\mathrm{M}_{\mathrm{c}} \mathrm{X}_{\mathrm{d}}$ (where $\mathrm{M}=3 \mathrm{~d}$ transition metal, $\mathrm{X}=$ $\mathrm{O}, \mathrm{S}, \mathrm{P}, \mathrm{N}$, etc.). The preliminary work on utilization of such metal oxides was carried out by Tarascon's group, focusing on the effect of particle size and the corresponding cell's performance. ${ }^{30}$ During lithiation/sodiation, the compound converts into elemental metallic nanoparticles that are embedded within a matrix of $\mathrm{Li}_{\mathrm{n}} \mathrm{X} / \mathrm{Na}_{\mathrm{n}} \mathrm{X}$. The electrochemical reaction could be summarized with the equation:

$$
\mathrm{M}_{\mathrm{c}} \mathrm{X}_{\mathrm{d}}+(\mathrm{d} \cdot \mathrm{n}) \mathrm{Li}^{+} / \mathrm{Na}^{+}<->\mathrm{cM}+\mathrm{dLi}_{\mathrm{n}} \mathrm{X} / \mathrm{dNa}_{\mathrm{n}} \mathrm{X}
$$

where $\mathrm{n}$ is the redox number of the anionic compounds $\mathrm{X}^{\mathrm{n}-}$. Conversion materials typically generate capacities in the range between $700-1500 \mathrm{mAh} \mathrm{g}^{-1}$. A table with most of the widely studied metal oxides could be found in Appendix A1.

The iconicity of the M-X bonds within the compound determines the redox potential, which falls within a range between $0.5-1.6 \mathrm{~V}$ vs. $\mathrm{Li}^{+} / \mathrm{Li}$ or $\mathrm{Na}^{+} / \mathrm{Na}$. The main downside of employing conversion based material lies with the large voltage hysteresis between charging and discharging processes, which translates into poor energy efficiency. Furthermore, conversion type materials often operate below $0.5 \mathrm{~V}$ vs. $\mathrm{Li}^{+} / \mathrm{Li}$ or $\mathrm{Na}^{+} / \mathrm{Na}$, which results in the production of a polymeric like SEI layer that hinders ion transport at the interface between the electrode and electrolyte. This formation is known to be the main culprit for the irreversible consumption of alkali ions that leads to low C.E. value in the initial cycle.

\subsubsection{Alloying electrodes}

The last type of alkali storage mechanism is the alloying reaction. It involves the direct formation of a $\mathrm{Li}-\mathrm{A} / \mathrm{Na}-\mathrm{A}$ alloy compound, where $\mathrm{A}$ is a $\mathrm{Li} / \mathrm{Na}$ electrochemically active element/compound (e.g. Group 13, 14, 15 and 16 elements). The alloying compatibility between 2 components can easily be predicted from their corresponding phase diagrams. Alloying based materials 
have much lower operating potential $\left(<0.7 \mathrm{~V}\right.$ vs. $\mathrm{Li}^{+} / \mathrm{Li}$ or $\left.\mathrm{Na}^{+} / \mathrm{Na}\right)$ and higher specific capacity $\left(900-3000 \mathrm{mAh} \mathrm{g}^{-1}\right)$ as compared to conversion materials. The capability to store such large amount of ion/charge causes more extensive size expansions (Appendix A1), thus resulting in poorer cyclability compared to both insertion and conversion materials.

Group 14 elements (e.g. Si, Ge, Sn) are some of the most extensively explored alloying materials in both $\mathrm{Li}$ and $\mathrm{Na}$ systems. Si is known to have the highest gravimetric capacity in the $\mathrm{Li}$ system, because it can store up to $4.4 \mathrm{Li}$ per unit $\mathrm{Si}$. Ge is also widely explored due to its high Li diffusion coefficient value that permits fast charging/discharging of the cell. However, both Si and Ge were found to be electrochemically inactive in $\mathrm{Na}$ system due to thermodynamics restriction. $^{14}$

\subsection{Metal Oxides as Next Generation Anode}

Despite attempts by companies who have tried to utilize different anodes such as $\mathrm{Sn}-\mathrm{Co}-\mathrm{C}$ and $\mathrm{Si}$, the most widely used anode material in commercial LIBs is currently still graphite. As for NIBs, the road to commercialization is still a long shot and requires intensive research to look for better-performing electrodes and electrolytes. Metal oxides itself is a widely explored family of material. $\mathrm{TiO}_{2},{ }^{31-}$ $33 \mathrm{Li}_{4} \mathrm{Ti}_{5} \mathrm{O}_{12}$, ${ }^{19}, 34-36 \mathrm{Na}_{2} \mathrm{Ti}_{3} \mathrm{O}_{7}{ }^{37}$ and $\mathrm{Nb}_{2} \mathrm{O}_{5}{ }^{28,}$, 38-40 are known to possess intercalation mechanism, similar to that of traditional graphite. They have fast reaction kinetics owing to the "open" structure that facilitates ion diffusion into the insertion sites. However, they possess low practical capacity $\left(<\sim 250 \mathrm{mAh} \mathrm{g}^{-}\right.$ $\left.{ }^{1}\right)$ and high reaction potential besides graphite. Conversion based oxides such as $\mathrm{Fe}_{2} \mathrm{O}_{3},{ }^{41-43} \mathrm{Co}_{3} \mathrm{O}_{4},{ }^{44} \mathrm{MoO}_{2}{ }^{45}$ and $\mathrm{CuO}^{46}$ have way much higher capacity $(\sim 600-$ $\left.1000 \mathrm{mAh} \mathrm{g}^{-1}\right)$. The performances of these oxides are dependent on their morphology and size, which critically determines their diffusion kinetics and cyclability. Table A1 illustrates the electrochemical properties of different metal oxides in both LIB and NIB.

Amongst the various metal oxides, $\mathrm{SnO}_{2}$ is one of the more widely explored 
options due to its chemical reactivity in both LIB and NIB. It is a transparent, wide band gap semiconductor (band gap value of $\sim 3.6 \mathrm{eV}$ ) and is widely explored in various applications such as catalysis, ${ }^{47}$ electrochemical sensors ${ }^{48}$ as well as alkali ion battery electrodes. ${ }^{49} \mathrm{SnO}_{2}$ has a tetragonal unit cell with a rutile crystal structure (also known as Casserite). It possesses a space-group symmetry of $\mathrm{P} 42 / \mathrm{mnm}$ and the lattice parameters are $\mathrm{a}=\mathrm{b}=4.737 \AA$ and $\mathrm{c}=$ $3.185 \AA$. The detailed structure information of Casserite could be found in Appendix A2 and A3. The electrochemical performance of pristine $\mathrm{SnO}_{2}$, in general, undergoes a conversion reaction to form $\mathrm{Sn}$ that is embedded within a $\mathrm{Li}_{2} \mathrm{O} / \mathrm{Na}_{2} \mathrm{O}$ matrix. Subsequently, $\mathrm{Sn}$ alloys with $\mathrm{Li}^{+} / \mathrm{Na}^{+}$to form $\mathrm{Li}_{4.4} \mathrm{Sn} / \mathrm{Na}_{3.75} \mathrm{Sn}$. The overall theoretical capacities of $\mathrm{SnO}_{2}$ in LIB and NIB assuming fully reversible conversion and alloying reactions are 1493 and 1378 $\mathrm{mAh} \mathrm{g}^{-1}$ respectively. ${ }^{50-52}$

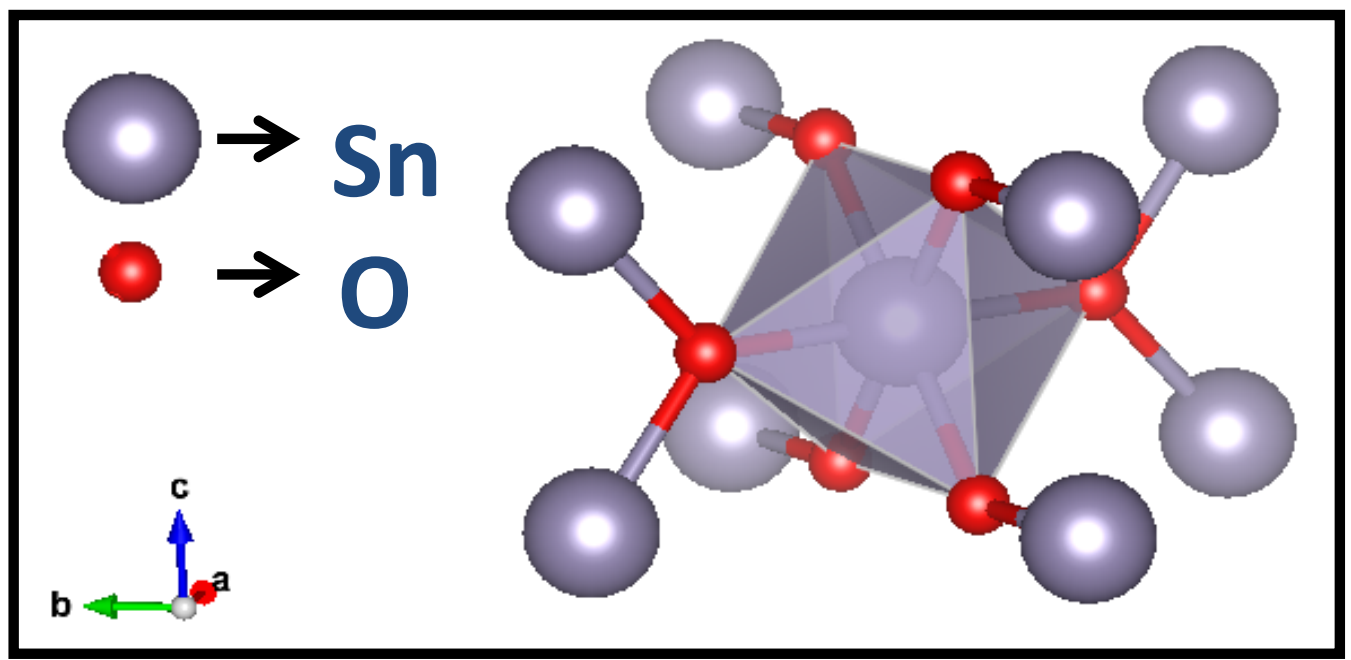

Figure 2.3 Crystal structure of tetragonal $\mathrm{SnO}_{2}$ (generated using VESTA software)

While the alloying reaction is well known to be highly reversible, the reaction corresponding to a reversible conversion of $\mathrm{Sn}$ back into $\mathrm{SnO}_{2}$ in the Li system has been comprehensively debated as of late. In-situ XRD was utilized by Dahn et al. which showed only the presence of crystalline Sn during charging up to $3.00 \mathrm{~V}$ vs. $\mathrm{Li}^{+} / \mathrm{Li}{ }^{53}$ The reversible conversion was deemed inactive due to the 
absence of $\mathrm{SnO}_{2}$. More recently, Kim et al. utilized ex-situ TEM and SAED to investigate on the reversibility. ${ }^{54}$ Similar to Dahn's work, they arrived in conclusion that conversion reaction has no reversibility. The reversible high capacity $\left(\sim 1100 \mathrm{mAh} \mathrm{g}^{-1}\right)$ achieved in the early cycles was claimed to be attributed to reversible electrolyte decomposition, forming $\mathrm{LiOH}$. It is important to note that firstly, both works utilized micron sized $\mathrm{SnO}_{2}$ nanoparticles, which may hinder Li diffusivity for reversible conversion. Secondly, both XRD and TEM are excellent for the detection of crystalline materials but are poor in the analysis of amorphous phases. Ex-situ XAS was also employed to study the fundamental mechanism during lithiation. ${ }^{55} \mathrm{Kim}$ et al. illustrated through XANES that the redox state of Sn rises above 0, but smaller than 4+. Also, EXAFS demonstrated the reversibility the Sn-O bond during de-alloying reaction up to $2.00 \mathrm{~V}$ vs. $\mathrm{Li}^{+} / \mathrm{Li}$. However, while $\mathrm{Sn}-\mathrm{O}$ bond forms, the reversibility lasts only in the first coordination shell, indicating poor long range order. This evidence hints at presence of short-order arrangement (in other words amorphous) $\mathrm{SnO}_{\mathrm{x}}$ that clearly could not be detected by XRD or TEM. The results were also backed by recent in-situ XAS results from Pelliccione et al. ${ }^{56}$ Conversely, the reaction mechanism of $\mathrm{SnO}_{2}$ in NIB is less controversial. The reversible conversion of $\mathrm{SnO}_{2}$ in NIB has been shown to be more feasible as compared to in LIB. Both $\mathrm{Ding}^{57}$ and $\mathrm{Lu}^{58}$ explored the sodiation mechanism of $\mathrm{SnO}_{2}$ through ex-situ XRD which revealed the presence of poorly crystalline $\mathrm{SnO}_{2}$ at the end of charge $\left(3.00 \mathrm{~V}\right.$ vs. $\left.\mathrm{Na}^{+} / \mathrm{Na}\right)$. Nevertheless, the electrochemical performance of $\mathrm{SnO}_{2}$ in NIB has been relatively poor. Gu et al. investigated the failure mechanism of $\mathrm{SnO}_{2}$ nanowires in NIB through in-situ TEM. Due to the size expansion during sodiation, the reverse desodiation process results in the formation of pores within the material itself. These pores have shown to contribute largely towards electrical impedance and thus resulting in poor cyclability. ${ }^{59}$

\subsection{Strategies for Improving Tin (IV) Oxide as Anode}


Therefore, it is of paramount importance to design and fabricate $\mathrm{SnO}_{2}$ with advanced functionalities to overcome the aforementioned intrinsic shortcomings. Several strategies have been widely deployed over the years in an attempt to improve the overall electrochemical performance of $\mathrm{SnO}_{2}$. These examples (Figure 2.6) include designing intrinsic hollow structure, coating an amorphous carbon layer on $\mathrm{SnO}_{2}$ and the template synthesis of $0 \mathrm{D}, 1 \mathrm{D}$ and $2 \mathrm{D}$ nanostructures. Asides from $\mathrm{SnO}_{2}$, these methods could also be extended to other metal oxides.

a

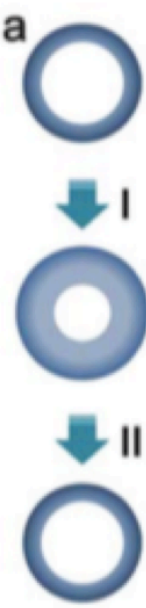

b
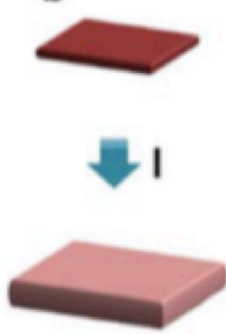

VII

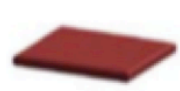

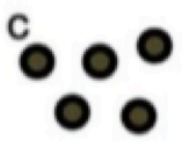
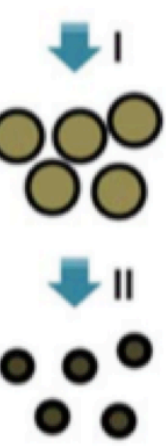

I: lithiation II: Delithiation

Figure 2.4 Commonly utilized design structures for alleviating pulverization effect of $\mathrm{SnO}_{2}$ nanomaterials. (a) hollow structure (b) 2D- nanosheets structure (c) amorphous carbon coating ${ }^{60}$

The most commonly explored design logic would be the introduction of carbon matrices. Carbon materials are often utilized as matrix owing to the excellent conductivity, tensile strength and chemical stability under battery operating conditions. In contrast, $\mathrm{SnO}_{2}$ is a well-known semiconductor with a band gap of $3.6 \mathrm{eV}$ and suffers from poor cyclability during repeated pulverization. ${ }^{61,62}$ When combined, carbon- $\mathrm{SnO}_{2}$ composites can demonstrate synergistic properties and enhanced electrochemical performance as opposed to their single components. For instance, $\mathrm{SnO}_{2} @ \mathrm{~N}$-doped carbon was prepared via a templateetching method (Figure 2a). As could be seen in Figure 2b, the presence of a 
carbon coating enhances the robustness of the nanocomposite that leads to enhanced cyclability and rate performances. ${ }^{63}$ In another example, Zhao et al. designed a cable-like MWCNT@SnO $\mathrm{Sn}_{2} @ \mathrm{C}$ composite which demonstrated superior electrochemical performances in both LIB and NIB. When cycled over 1300 cycles at $1.6 \mathrm{~A} \mathrm{~g}^{-1}$ in LIB, it can retain $412 \mathrm{mAh} \mathrm{g}^{-1}$ with an average capacity loss of $0.025 \mathrm{mAh} \mathrm{g}^{-1}$ per cycle. Similarly, the nanocomposite displayed enhanced cyclability in NIB with $200 \mathrm{mAh} \mathrm{g}^{-1}$ (76\% retention) retained over 300 cycles. $^{64}$ Both examples attribute the remarkable electrochemical performance to the presence of carbon matrices that enhances electrical conductivity, prevents agglomeration and reduce mass loss during cycling. Graphene is also one of the most commonly studied carbon matrix for preparation of nanocomposites. ${ }^{39,65-73}$ As the thinnest material in the world, graphene possesses fascinating properties including superior electrical conductivity, excellent mechanical strength, high specific surface area and good thermal stability. Additionally, several groups have claimed that graphene is capable of storing both $\mathrm{Li}^{+}$and $\mathrm{Na}^{+}$on both sides of the basal plane, as opposed to the $\mathrm{Li}^{+}$accommodating graphite. ${ }^{74-76}$ For example, graphene nanoribbons prepared from 3 days of alkali cation unzipping process was used to anchor fine $\mathrm{SnO}_{2}$ nanoparticles before utilizing as an anode for LIB. Compared to pristine $\mathrm{SnO}_{2}$ the graphene nanoribbon- $\mathrm{SnO}_{2}$ nanocomposite delivered much better cyclability and higher efficiency. ${ }^{77}$ 

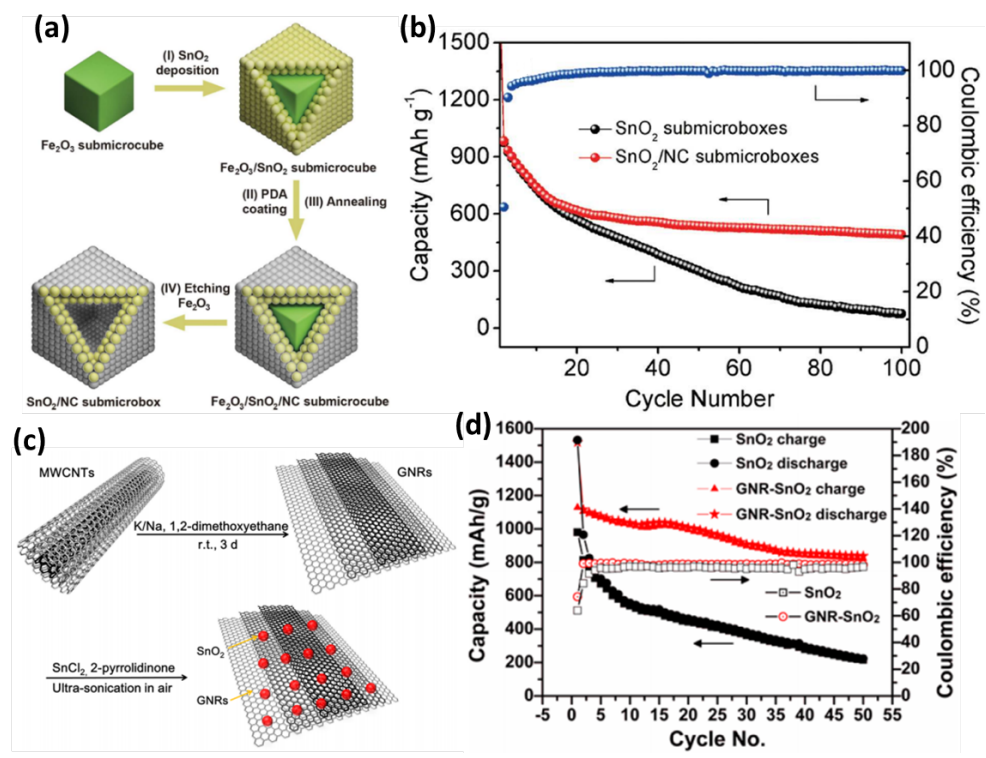

Figure 2.5 (a) Schematic on the template-etching method for preparation of N-doped carbon coated $\mathrm{SnO}_{2}$ (b) and its corresponding cycling performance. ${ }^{63}$ (c) Preparation methodology for obtaining $\mathrm{SnO}_{2}$ anchored on graphene nanoribbons. (d) Comparison between electrochemical properties of pristine $\mathrm{SnO}_{2}$ and graphene nanoribbon- $\mathrm{SnO}_{2}{ }^{77}$

Elemental doping is also another widely explored option for enhancing the electrochemical performance of $\mathrm{SnO}_{2}$. The properties of the doped compounds are highly dependent on the different types of interactions between dopants and the host structure, which results in modification of electronic properties, ${ }^{78}$ modulation of magnetic properties ${ }^{79}$ and influences crystal growth processes. ${ }^{80}$ The electrochemical behaviors of doped $\mathrm{SnO}_{2}$ samples focus largely on the substitution of metallic $\mathrm{Sn}$ with other metals such as $\mathrm{Ni}^{81}, \mathrm{Sb}^{82}$ and etc. ${ }^{83,84}$ Wang et al. investigated the lithiation behavior of $\mathrm{Mo}-\mathrm{SnO}_{2}$ that was first prepared using a silica template and etching method. It was found that at an optimum concentration of $14 \% \mathrm{Mo}$, a specific capacity of $801 \mathrm{mAh} \mathrm{g}^{-1}$ could be delivered after cycling at $100 \mathrm{~mA} \mathrm{~g}^{-1}$ for 60 cycles. Furthermore, the presence of Mo dopants was found to enhance the rate capability of $\mathrm{SnO}_{2}$, where a capacity of $530 \mathrm{mAh} \mathrm{g}^{-1}$ could be achieved at $1600 \mathrm{~mA} \mathrm{~g}^{-1}$ after 60 cycles. The electrochemical performances of anionic doped samples were relatively less studied. ${ }^{85}$ F-doped $\mathrm{SnO}_{2} @$ graphene nanocomposite prepared via hydrothermal 
process was evaluated as an anode in LIB. The presence of $\mathrm{F}^{-}$was found to have led to a more uniform deposition of $\mathrm{SnO}_{2}$ on the graphene sheets that may provide better contact between conductive graphene and insulative $\mathrm{SnO}_{2}$. Compared to the $\mathrm{SnO}_{2} @$ graphene composite, F-doped $\mathrm{SnO}_{2} @$ graphene fared better with higher capacity retention and rate capability as could be observed in Figure $2.2 \mathrm{~b}$ and $\mathrm{c}^{86}$

The introduction of a different phase during synthesis to form ternary compounds is a relatively less popular method as opposed enhancement by adding carbon matrices and elemental doping. While such ternary compounds are sometimes coined mixed transition metal oxides (MTMO) or bimetallic oxides, it is important to clarify that these ternary compounds in consideration here are single-phase materials that comprise of two different metallic cations (i.e. $\mathrm{ZnSnO}_{3}$ instead of $\mathrm{ZnO}-\mathrm{SnO}_{2}$ ). These ternary compounds could be seen as a combination of 2 different metal oxides, with the main aim of synergizing advantages to generate a better, single phase and cost efficient material. ${ }^{87,88}$

(a)

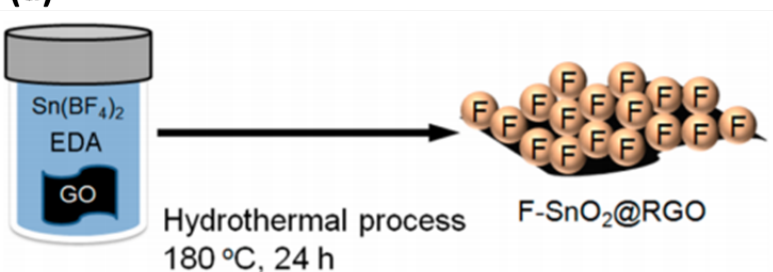
$180^{\circ} \mathrm{C}, 24 \mathrm{~h}$

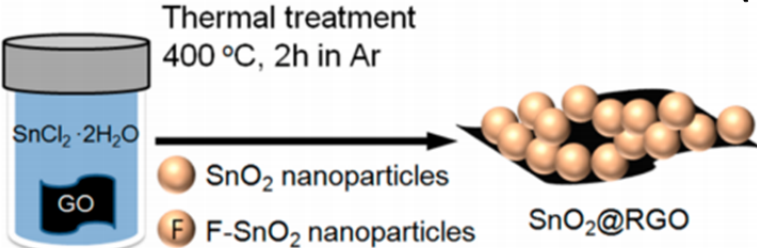

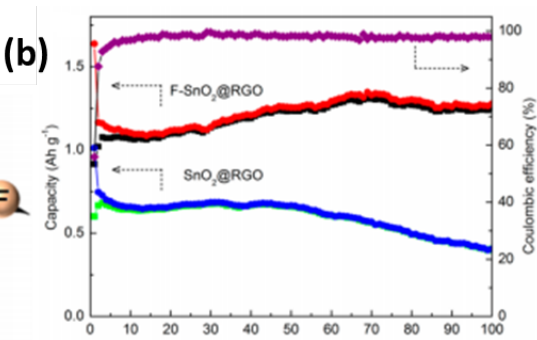

(c)

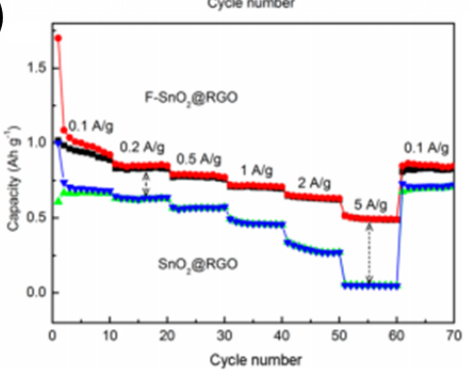

Figure 2.6 (a) Schematic of hydrothermal synthesis of F-doped $\mathrm{SnO}_{2}$ and F-doped $\mathrm{SnO}_{2} @$ graphene. Comparison of (b) cycling performance at $0.1 \mathrm{~A} \mathrm{~g}^{-1}$ and (c)rate capabilities 
In the case of ternary tin based oxides, two different structures have been commonly explored in $\mathrm{LIB}$, i.e. $\mathrm{MSnO}_{3}$ (where $\mathrm{M}=\mathrm{Ca}, \mathrm{Ba}, \mathrm{Zn}, \mathrm{Co}, \mathrm{Zr}$ and $\mathrm{Mg}$ ) and $\mathrm{N}_{2} \mathrm{SnO}_{4}($ Where $\mathrm{N}=\mathrm{Zn}, \mathrm{Co}, \mathrm{Mg}, \mathrm{Sr}, \mathrm{Ca}$ and $\mathrm{Ba}) .{ }^{89-95}$ To the best of our knowledge, such ternary tin based compounds have yet to be reported in NIB. Asides from the primary Sn cation, the secondary metallic cation could either be electrochemically active (i.e. $\mathrm{Zn}$ and $\mathrm{Co}$ ) or inactive (i.e. Sr and $\mathrm{Ba}$ ). During electrochemical process, the initial ternary compound would be decomposed first into individual binary oxides, (i.e. $\mathrm{MO} / 2 \mathrm{NO}$ and $\mathrm{SnO}_{2}$ ). ${ }^{87}, 96$ For electrochemically active secondary oxides such as $\mathrm{CoO}$ or $\mathrm{ZnO}$, they will go on to convert with $\mathrm{SnO}_{2}$ to form metallic nanoparticles $(\mathrm{M} / \mathrm{N}$ and $\mathrm{Sn})$ that are encapsulated with a buffer layer of $\mathrm{Li}_{2} \mathrm{O} / \mathrm{Na}_{2} \mathrm{O}$. Subsequently, alloying reactions occur in the presence of elements such as $\mathrm{Zn}$ or $\mathrm{Sn}$ to form $\mathrm{LiZn} / \mathrm{NaZn}_{13}$ or $\mathrm{Li}_{4.4} \mathrm{Sn} / \mathrm{Na}_{3.75} \mathrm{Sn}^{.97-99}$

For instance, Lou et al have demonstrated the preparation of amorphous $\mathrm{CoSnO}_{3} @ \mathrm{C}$ hollow cubes and evaluated its performance as an anode in LIB. ${ }^{95}$ The even and intimate distribution of different elements within the structure was effective in enhancing the electrochemical performance when compared with $\mathrm{Co}_{2} \mathrm{SnO}_{4} / \mathrm{SnO}_{2}$ and $\mathrm{CoO}-\mathrm{SnO}_{2}$ control experiments. When cycled in a voltage window from 0.01 to $1.50 \mathrm{~V}$ vs. $\mathrm{Li}^{+} / \mathrm{Li}$, a reversible discharge capacity of $480 \mathrm{mAh} \mathrm{g}^{-1}$ could be achieved. Even without carbon coating, a capacity of $\sim 450 \mathrm{mAh} \mathrm{g}^{-1}$ could still be preserved after 120 cycles when cycled at a current density of $200 \mathrm{~mA} \mathrm{~g}^{-1}$. Egg-roll like $\mathrm{CaSnO}_{3}$ prepared from electrospinning was also evaluated as anode material in $\mathrm{LIB} .{ }^{100}$ In the case of $\mathrm{CaSnO}_{3}, \mathrm{CaO}$ that is present after the initial conversion process remains electrochemically inactive as opposed to the previous $\mathrm{CoSnO}_{3} @ \mathrm{C}$ hollow cubes. Intrinsically, $\mathrm{CaSnO}_{3}$ would have a lower theoretical capacity due to higher "inactive mass" in the compound. Nevertheless, this inactive buffer could act as an inactive buffer for the large size expansion of pristine $\mathrm{SnO}_{2}$. As a result of the rational design, a reversible capacity of $565 \mathrm{mAh} \mathrm{g}^{-1}$ could be retained after 50 cycles at a current density of $60 \mathrm{~mA} \mathrm{~g}^{-1}$. 
Table 2. Comparison of different $\mathrm{SnO}_{2}$ oxides and its electrochemical performances

\begin{tabular}{|c|c|c|c|c|c|}
\hline $\begin{array}{l}\text { Compound and } \\
\text { structure }\end{array}$ & Synthesis approach & Cycling stability & Rate capability & Year & Ref. \\
\hline LIBs & & & & & \\
\hline MWNT@ $\mathrm{SnO}_{2}$ & hydrothermal & $344 / 50 / 0.033 \mathrm{~A} \mathrm{~g}^{-1}$ & - & 2006 & 101 \\
\hline MWNT@ $\mathrm{SnO}_{2}$ & wet chemical method & $404 / 20 / 0.1 \mathrm{C}$ & - & 2008 & 102 \\
\hline $\mathrm{SnO}_{2}$ tube-in-CNT & $\begin{array}{l}\text { AAO template two-step } \\
\text { deposition }\end{array}$ & $542 / 200 / 0.5 \mathrm{C}$ & - & 2006 & 103 \\
\hline $\begin{array}{l}\mathrm{SnO}_{2} \mathrm{NPs} \text { within } \\
\text { MWNTs }\end{array}$ & wet chemical filling & $560 / 50 / 0.05 \mathrm{~A} \mathrm{~g}^{-1}$ & $400 / 1 \mathrm{~A} \mathrm{~g}^{-1}$ & 2013 & 104 \\
\hline $\begin{array}{l}\mathrm{MWNT} @ \mathrm{SnO}_{2} \\
\text { nanosheets }\end{array}$ & hydrothermal and annealing & $549 / 40 / 0.16 \mathrm{~A} \mathrm{~g}^{-1}$ & - & 2011 & 105 \\
\hline $\mathrm{SnO}_{2} @ \mathrm{C}$ & $\begin{array}{l}\text { solution mix and } \\
\text { carbonization }\end{array}$ & $398 / 40 / 0.06 \mathrm{~mA} \mathrm{~cm}^{-2}$ & - & 2001 & 49 \\
\hline $\begin{array}{l}\text { hollow } \mathrm{SnO}_{2} @ \mathrm{C} \\
\text { spheres }\end{array}$ & $\begin{array}{l}\text { two-step hydrothermal and } \\
\text { annealing }\end{array}$ & $460 / 100 / 0.5 \mathrm{~A} \mathrm{~g}^{-1}$ & $210 / 3 \mathrm{~A} \mathrm{~g}^{-1}$ & 2009 & 106 \\
\hline $\begin{array}{l}\text { mesoporous } \\
\mathrm{ZnSnO}_{3} @ \mathrm{C} \text { nanocubes }\end{array}$ & sol-gel and annealing & $1060 / 100 / 0.2 \mathrm{~A} \mathrm{~g}^{-1}$ & $650 / 2 \mathrm{~A} \mathrm{~g}^{-1}$ & 2014 & 107 \\
\hline $\begin{array}{l}\mathrm{SnO}_{2} \mathrm{NPs} \text { embedded in } \\
\text { carbon spheres with }\end{array}$ & PS-assisted spray pyrolysis & $509 / 1000 / 1.5 \mathrm{~A} \mathrm{~g}^{-1}$ & $389 / 9 \mathrm{~A} \mathrm{~g}^{-1}$ & 2014 & 108 \\
\hline hollow nanoballs & & & & & \\
\hline $\mathrm{SnO}_{2} @ \mathrm{CMK}-3$ & $\begin{array}{l}\text { SBA-15 templated } \\
\text { nanocasting }\end{array}$ & $220 / 30 / 0.5 \mathrm{~mA} \mathrm{~cm}^{-2}$ & - & 2004 & 109 \\
\hline $\mathrm{SnO}_{2} @ \mathrm{CMK}-5$ & $\begin{array}{l}\text { SBA-15 templated } \\
\text { nanocasting }\end{array}$ & $1039 / 100 / 0.2 \mathrm{~mA} \mathrm{~g}^{-1}$ & $600 / 1.5 \mathrm{~A} \mathrm{~g}^{-1}$ & 2012 & 110 \\
\hline $\begin{array}{l}\mathrm{SnO}_{2} \text { superlattices in } \\
\mathrm{OMC}\end{array}$ & $\begin{array}{l}\text { supercrystals-templated } \\
\text { nanocasting }\end{array}$ & $640 / 200 / 0.6 \mathrm{~A} \mathrm{~g}^{-1}$ & $300 / 3 \mathrm{~A} \mathrm{~g}^{-1}$ & 2015 & 111 \\
\hline $\mathrm{SnO}_{\mathrm{x}} @ \mathrm{CNFs}$ & $\begin{array}{l}\text { electrospinning and } \\
\text { annealing }\end{array}$ & $608 / 200 / 0.2 \mathrm{~A} \mathrm{~g}^{-1}$ & $365 / 2 \mathrm{~A} \mathrm{~g}^{-1}$ & 2014 & 112 \\
\hline $\mathrm{SnO}_{2} @$ void@ $@ \mathrm{TiO}_{2}$ & vapor deposition and ALD & $393 / 1000 / 0.4 \mathrm{~A} \mathrm{~g}^{-1}$ & $241 / 3.2 \mathrm{~A} \mathrm{~g}^{-1}$ & 2014 & 113 \\
\hline
\end{tabular}




\begin{tabular}{|c|c|c|c|c|c|}
\hline \multicolumn{6}{|l|}{ tubes on carbon cloth } \\
\hline $\mathrm{SnO}_{2} /$ graphene & solution mixing & $570 / 30 / 0.05 \mathrm{~A} \mathrm{~g}^{-1}$ & - & 2009 & 114 \\
\hline $\mathrm{SnO}_{2} /$ graphene & $\begin{array}{l}\text { solution-based method and } \\
\text { annealing }\end{array}$ & $840 / 30 / 0.067 \mathrm{~A} \mathrm{~g}^{-1}$ & $\sim 400 / 1 \mathrm{~A} \mathrm{~g}^{-1}$ & 2011 & 115 \\
\hline $\begin{array}{l}\mathrm{SnO}_{2} / \text { graphene } \\
\text { nanoribbon }\end{array}$ & $\begin{array}{l}\text { reflux, oxidization and } \\
\text { annealing }\end{array}$ & $825 / 50 / 0.1 \mathrm{~A} \mathrm{~g}^{-1}$ & $580 / 2 \mathrm{~A} \mathrm{~g}^{-1}$ & 2013 & 77 \\
\hline $\mathrm{SnO}_{2} /$ graphene & microwave-hydrothermal & $1359 / 100 / 0.1 \mathrm{~A} \mathrm{~g}^{-1}$ & $876 / 1 \mathrm{~A} \mathrm{~g}^{-1}$ & 2015 & 116 \\
\hline $\begin{array}{l}\text { porous graphene- } \\
\text { wrapped } \mathrm{SnO}_{2}\end{array}$ & $\begin{array}{l}\text { heating-rate-controlled } \\
\text { thermal reduction }\end{array}$ & $1100 / 100 / 0.144 \mathrm{~A} \mathrm{~g}^{-1}$ & $690 / 3.6 \mathrm{~A} \mathrm{~g}^{-1}$ & 2015 & 117 \\
\hline $\mathrm{SnO}_{2} / \mathrm{N}-\mathrm{G}$ & $\begin{array}{l}\text { freeze-drying and hydrazine } \\
\text { reduction }\end{array}$ & $1346 / 500 / 0.5 \mathrm{~A} \mathrm{~g}^{-1}$ & $417 / 20 \mathrm{~A} \mathrm{~g}^{-1}$ & 2013 & 118 \\
\hline $\begin{array}{l}\mathrm{SnO}_{2} \text { with high-energy } \\
\text { facet/GNS }\end{array}$ & hydrothermal & $844 / 50 / 0.1 \mathrm{~A} \mathrm{~g}^{-1}$ & $555 / 5 \mathrm{~A} \mathrm{~g}^{-1}$ & 2014 & 119 \\
\hline $\begin{array}{l}\text { mesoporous } \\
\mathrm{SnO}_{2} / \text { graphene }\end{array}$ & CTAB-assisted solvothermal & $847 / 50 / 0.078 \mathrm{~mA} \mathrm{~g}^{-1}$ & $621 / 782 \mathrm{~A} \mathrm{~g}^{-1}$ & 2013 & 120 \\
\hline $\mathrm{SnO}_{2}-\mathrm{Fe}_{2} \mathrm{O}_{3} /$ graphene & solvothermal & $958 / 100 / 0.395 \mathrm{~A} \mathrm{~g}^{-1}$ & $530 / 3.95 \mathrm{~A} \mathrm{~g}^{-1}$ & 2011 & 121 \\
\hline MWNT@SnO ${ }_{2} @ \mathrm{C}$ & $\begin{array}{l}\text { layer-by-layer assembly, } \\
\text { hydrothermal, and annealing }\end{array}$ & $462 / 65 / 0.1 \mathrm{~mA} \mathrm{~g}^{-1}$ & - & 2010 & 122 \\
\hline graphene@ $\mathrm{SnO}_{2} @ \mathrm{C}$ & $\begin{array}{l}\text { polymerization and } \\
\text { annealing }\end{array}$ & $800 / 100 / 0.2 \mathrm{~A} \mathrm{~g}^{-1}$ & $260 / 5 \mathrm{~A} \mathrm{~g}^{-1}$ & 2012 & 123 \\
\hline $\begin{array}{l}\mathrm{MWNT} @ \mathrm{SnO}_{2} \\
\text { nanorod@C }\end{array}$ & $\begin{array}{l}\text { solvothermal, hydrothermal, } \\
\text { and annealing }\end{array}$ & $700 / 40 / 0.72 \mathrm{~A} \mathrm{~g}^{-1}$ & $420 / 7.2 \mathrm{~A} \mathrm{~g}^{-1}$ & 2014 & 124 \\
\hline $\begin{array}{l}\mathrm{SnO}_{2} \text { NPs distributed } \\
\text { within graphene/CNTs }\end{array}$ & $\begin{array}{l}\text { solution-based method and } \\
\text { annealing }\end{array}$ & $387 / 50 / 0.1 \mathrm{~A} \mathrm{~g}^{-1}$ & $345 / 1.5 \mathrm{~A} \mathrm{~g}^{-1}$ & 2011 & 125 \\
\hline $\begin{array}{l}\text { graphene-wrapped } \\
\mathrm{SnO}_{\mathrm{x}} @ \mathrm{CNF}\end{array}$ & $\begin{array}{l}\text { electrospinning and solution } \\
\text { mixing }\end{array}$ & $504 / 180 / 0.07 \mathrm{~A} \mathrm{~g}^{-1}$ & $300 / 0.7 \mathrm{~A} \mathrm{~g}^{-1}$ & 2013 & 126 \\
\hline 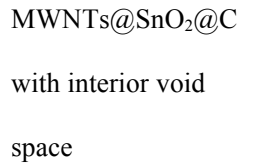 & $\begin{array}{l}\text { hydrothermal, sol-gel, and } \\
\text { carbonization }\end{array}$ & $412 / 1300 / 1.6 \mathrm{~A} \mathrm{~g}^{-1}$ & $375 / 3.2 \mathrm{~A} \mathrm{~g}^{-1}$ & 2015 & 127 \\
\hline NIBs & & & & & \\
\hline MWNT@SnO ${ }_{2}$ & solvothermal & $352 / 50 / 0.05 \mathrm{~A} \mathrm{~g}^{-1}$ & $300 / 0.25 \mathrm{~A} \mathrm{~g}^{-1}$ & 2013 & 128 \\
\hline $\mathrm{SnO}_{2} @ \mathrm{C}$ nanospheres & hydrothermal and annealing & $372 / 200 / 0.08 \mathrm{~A} \mathrm{~g}^{-1}$ & $\sim 200 / 2.56 \mathrm{~A} \mathrm{~g}^{-1}$ & 2015 & 57 \\
\hline $\mathrm{SnO}_{2} @$ mesoporous & soft-templated carbon and & $421 / 4000 / 1.8 \mathrm{~A} \mathrm{~g}^{-1}$ & $285 / 3.6 \mathrm{~A} \mathrm{~g}^{-1}$ & 2015 & 129 \\
\hline
\end{tabular}




\begin{tabular}{|c|c|c|c|c|c|}
\hline carbon & nanocasting & & & & \\
\hline $\begin{array}{l}\text { carbon } \\
\text { cloth@ } \mathrm{SnO}_{2} @ \mathrm{Al}_{2} \mathrm{O}_{3}\end{array}$ & hydrothermal and ALD & $375 / 100 / 0.134 \mathrm{~A} \mathrm{~g}^{-1}$ & $245 / 6.9 \mathrm{~A} \mathrm{~g}^{-1}$ & 2015 & 130 \\
\hline $\begin{array}{l}\text { octahedral } \\
\mathrm{SnO}_{2} / \text { graphene }\end{array}$ & hydrothermal & $638 / 100 / 0.02 \mathrm{~A} \mathrm{~g}^{-1}$ & $143 / 0.64 \mathrm{~A} \mathrm{~g}^{-1}$ & 2013 & 131 \\
\hline $\begin{array}{l}3 \mathrm{D} \mathrm{SnO}_{2} / \text { graphene } \\
\text { aerogel }\end{array}$ & $\begin{array}{l}\text { hydrothermal-induced self- } \\
\text { assembly }\end{array}$ & $322 / 100 / 0.02 \mathrm{~A} \mathrm{~g}^{-1}$ & $220 / 0.64 \mathrm{~A} \mathrm{~g}^{-1}$ & 2015 & 132 \\
\hline $\mathrm{CNF} @ \mathrm{SnO}_{2} @ \mathrm{C}$ & electrodeposition and CVD & $374 / 100 / 0.05 \mathrm{~A} \mathrm{~g}^{-1}$ & $189 / 0.8 \mathrm{~A} \mathrm{~g}^{-1}$ & 2015 & 133 \\
\hline $\begin{array}{l}\text { MWNTs@SnO } 9 \mathrm{C} \\
\text { with interior void } \\
\text { space }\end{array}$ & $\begin{array}{l}\text { hydrothermal, sol-gel, and } \\
\text { carbonization }\end{array}$ & $300 / 60 / 0.05 \mathrm{~A} \mathrm{~g}^{-1}$ & $176 / 1 \mathrm{~A} \mathrm{~g}^{-1}$ & 2015 & 127 \\
\hline
\end{tabular}

\subsection{Laser Pyrolysis}

Laser pyrolysis is a surfactant-free physical vapor nanoparticle synthesis technique where an infrared $\mathrm{CO}_{2}$ laser is used to excite a precursor or a photosensitizer gas (e.g. $\mathrm{C}_{2} \mathrm{H}_{4}, \mathrm{SF}_{6}$ ), which energetically collides and results in decomposition of precursor molecules. ${ }^{134-136}$ This technique was introduced in 1975 by Bachmann et al. for the synthesis of boron trichloride $\left(\mathrm{BCl}_{3}\right){ }^{137}$ The main reason for using $\mathrm{CO}_{2}$ laser is due to the compatible resonance between the emissions of laser at $10.6 \mu \mathrm{m}$ with the absorption of at least one of the precursors. To determine if a precursor is suitable for absorption of $\mathrm{CO}_{2}$ laser, the IR spectrum of should be examined. For example, as could be seen in Figure 2.7, $\mathrm{C}_{2} \mathrm{H}_{4}$ shows absorption at $949.3 \mathrm{~cm}^{-1}(10.53 \mu \mathrm{m})$ in the infrared region, indicating that it is suitable to be used as a photosensitizer. The large thermal gradient between the limited reaction zone and the chamber wall, combined with the short residence time of precursors and growing species, prevents growth during the synthesis process. The temperature inside the chamber is difficult to determine due to its blackbody nature but could be estimated using the Scanning Coherent Anti-stokes Raman Scattering (CARS) method. ${ }^{138}$ Moreover, the rapid synthesis process when operating in a 
continuous flow, can reach up to $1 \mathrm{~kg} \mathrm{~h}^{-1}$ in industrial pilot equipment. ${ }^{139}$ The flexibility of this technique permits synthesis of an extensive range of materials, which includes oxides, ${ }^{136}$ carbides $^{139}$, and elemental nanoparticles. ${ }^{135}$

The earliest report on the preparation of $\mathrm{SnO}_{2}$ by laser pyrolysis was made by Zhang et al. $\mathrm{SnCl}_{4} \cdot 5 \mathrm{H}_{2} \mathrm{O}$ was utilized as a precursor and the produced $\mathrm{SnO}_{2}$ thin film was deposited onto a glass substrate. While the authors claimed that $\mathrm{SnO}_{2}$ was produced, there were no characterization results to back up the claim. ${ }^{140}$ Toxic and expensive precursors such as tetramethyl tin were also employed as a precursor for laser pyrolysis of $\mathrm{SnO}_{2}$ thin film. ${ }^{141}$ More recently, a patent using laser pyrolysis to prepare $\mathrm{SnO}_{2}$ was filed by NanoGram Corp. However, due to poor crystallinity of the prepared $\mathrm{SnO}_{\mathrm{x}}$ compounds, a 2 step laser pyrolysisannealing step was required to obtain $\mathrm{SnO}_{2} \cdot{ }^{142}$ To date, the laser pyrolysis of $\mathrm{SnO}_{2}$ using a cost efficient, non-toxic and reliable precursor has not been demonstrated.

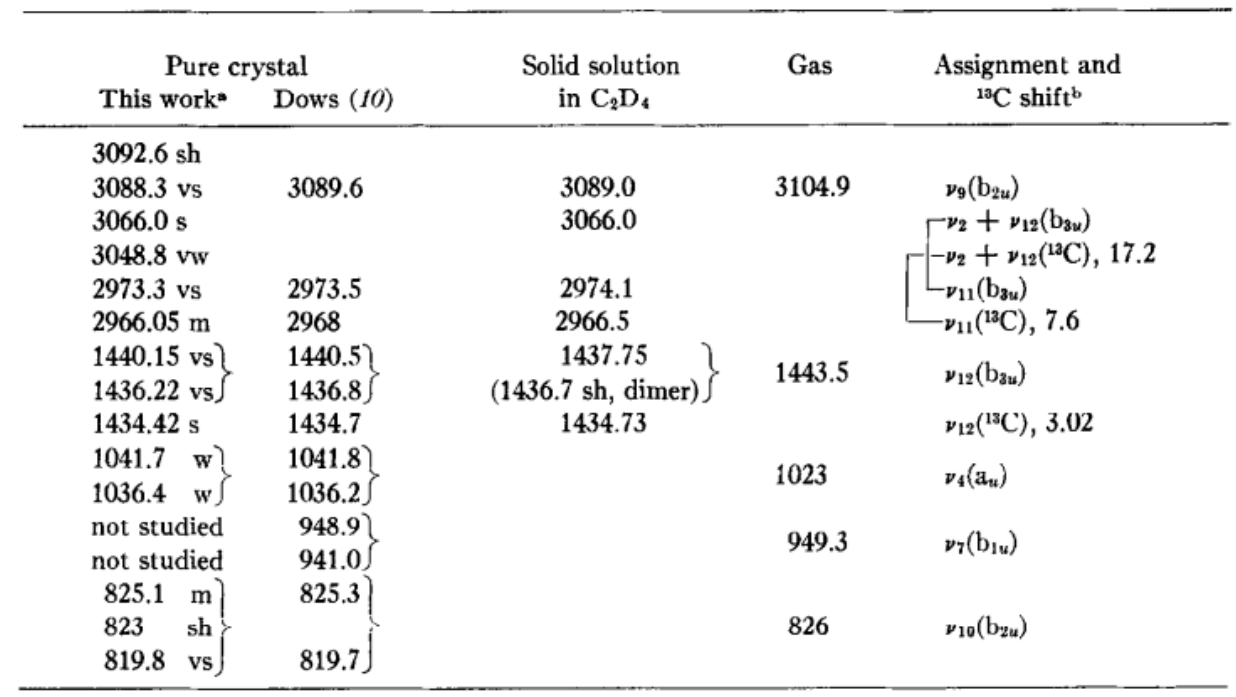

Combination bands observed in the pure crystal spectrum : $4741 \mathrm{vw}, 4703 \mathrm{~m}, 4679 \mathrm{vw}, 4655 \mathrm{vw}, 4573 \mathrm{w}$, $4495 \mathrm{~s}, 4483 \mathrm{vw}, 4435 \mathrm{w}, 4416$ w, 4392 w, $4306 \mathrm{~m}, 4301 \mathrm{~m}, 4271 \mathrm{~m}, 4187 \mathrm{~s}, 2652 \mathrm{vw}, 2428$ w, 2357 w, 2253 vw, $2166 \mathrm{w}, 2041 \mathrm{~s}, 1967 \mathrm{w}, 1897 \mathrm{~s}$.

$\mathrm{s} \mathrm{w}=$ weak, $\mathrm{m}=$ medium, $\mathrm{s}=$ strong, $\mathrm{v}=$ very, $\mathrm{sh}=$ shoulder.

${ }^{\mathrm{b}}$ Fermi resonating vibrational levels are connected by solid lines.

Figure 2.7 Infrared spectra of $\mathrm{C}_{2} \mathrm{H}_{4}{ }^{143}$ 


\section{References:}

1. M. Armand and J. M. Tarascon, Nature, 2008, 451, 652-657.

2. J. B. Goodenough and K.-S. Park, Journal of the American Chemical Society, 2013, 135, 1167-1176.

3. C.-X. Zu and H. Li, Energy \& Environmental Science, 2011, 4, 2614-2624.

4. K. Luo, M. R. Roberts, R. Hao, N. Guerrini, D. M. Pickup, Y.-S. Liu, K. Edström, J. Guo, A. V. Chadwick, L. C. Duda and P. G. Bruce, Nat Chem, 2016, 8, 684-691.

5. E. McCalla, A. M. Abakumov, M. Saubanère, D. Foix, E. J. Berg, G. Rousse, M.-L. Doublet, D. Gonbeau, P. Novák, G. Van Tendeloo, R. Dominko and J.-M. Tarascon, Science, 2015, 350, 1516-1521.

6. Z. W. Seh, J. Sun, Y. Sun and Y. Cui, ACS Central Science, 2015, 1, 449-455.

7. M. R. Palacin, Chemical Society Reviews, 2009, 38, 2565-2575.

8. X. Fan, W. Peng, Y. Li, X. Li, S. Wang, G. Zhang and F. Zhang, Advanced Materials, 2008, 20, 4490-4493.

9. Z. Zhu, F. Cheng, Z. Hu, Z. Niu and J. Chen, Journal of Power Sources, 2015, 293, 626-634.

10. M. V. Reddy, G. V. S. Rao and B. V. R. Chowdari, Chemical Reviews, 2013, 113, 5364-5457.

11. M. Dahbi, N. Yabuuchi, K. Kubota, K. Tokiwa and S. Komaba, Physical Chemistry Chemical Physics, 2014, 16, 15007-15028.

12. V. Aravindan, Y.-S. Lee and S. Madhavi, Advanced Energy Materials, 2015, 5, n/a-n/a.

13. Sony's New Nexelion Hybrid Lithium Ion Batteries http://www.sony.net/Sonylnfo/News/Press/200502/05-006E/, ， (accessed 28/09/2015).

14. L. P. Wang, L. Yu, X. Wang, M. Srinivasan and Z. J. Xu, Journal of Materials Chemistry A, 2015, 3, 9353-9378.

15. M. H. Han, E. Gonzalo, G. Singh and T. Rojo, Energy \& Environmental Science, 2015, 8, 81-102.

16. M. Sawicki and L. L. Shaw, RSC Advances, 2015, 5, 53129-53154.

17. G. Ali, J.-H. Lee, D. Susanto, S.-W. Choi, B. W. Cho, K.-W. Nam and K. Y. Chung, ACS Applied Materials \& Interfaces, 2016, 8, 15422-15429.

18. D. Larcher and J. M. Tarascon, Nat Chem, 2015, 7, 19-29.

19. N. Li, G. M. Zhou, F. Li, L. Wen and H. M. Cheng, Advanced Functional Materials, 2013, 23, 5429-5435.

20. N. Li, G. Liu, C. Zhen, F. Li, L. L. Zhang and H. M. Cheng, Advanced Functional Materials, 2011, 21, 1717-1722.

21. Z. Wang, S. M. Selbach and T. Grande, RSC Advances, 2014, 4, 4069-4079.

22. K. Nobuhara, H. Nakayama, M. Nose, S. Nakanishi and H. Iba, Journal of Power Sources, 2013, 243, 585-587.

23. B. Jache and P. Adelhelm, Angewandte Chemie, 2014, 126, 10333-10337.

24. Y. Wen, K. He, Y. Zhu, F. Han, Y. Xu, I. Matsuda, Y. Ishii, J. Cumings and C. Wang, Nat Commun, 2014, 5. 
25. D. Dambournet, I. Belharouak and K. Amine, Chemistry of Materials, 2010, 22, 1173-1179.

26. V. Etacheri, J. E. Yourey and B. M. Bartlett, ACS Nano, 2014, 8, 1491-1499.

27. R. Buonsanti, V. Grillo, E. Carlino, C. Giannini, T. Kipp, R. Cingolani and P. D. Cozzoli, Journal of the American Chemical Society, 2008, 130, 11223-11233.

28. H. Kim, E. Lim, C. Jo, G. Yoon, J. Hwang, S. Jeong, J. Lee and K. Kang, Nano Energy, 2015, 16, 62-70.

29. A. L. Viet, M. V. Reddy, R. Jose, B. V. R. Chowdari and S. Ramakrishna, The Journal of Physical Chemistry C, 2010, 114, 664-671.

30. D. Larcher, C. Masquelier, D. Bonnin, Y. Chabre, V. Masson, J.-B. Leriche and J.-M. Tarascon, Journal of The Electrochemical Society, 2003, 150, A133-A139.

31. C. Arrouvel, S. C. Parker and M. S. Islam, Chemistry of Materials, 2009, 21, 4778-4783.

32. S. Brutti, V. Gentili, H. Menard, B. Scrosati and P. G. Bruce, Advanced Energy Materials, 2012, 2, 322-327.

33. W. J. H. Borghols, D. Lützenkirchen-Hecht, U. Haake, W. Chan, U. Lafont, E. M. Kelder, E. R. H. van Eck, A. P. M. Kentgens, F. M. Mulder and M. Wagemaker, Journal of The Electrochemical Society, 2010, 157, A582-A588.

34. H. G. Jung, S. T. Myung, C. S. Yoon, S. B. Son, K. H. Oh, K. Amine, B. Scrosati and Y. K. Sun, Energy \& Environmental Science, 2011, 4, 1345-1351.

35. Y. Sun, L. Zhao, H. Pan, X. Lu, L. Gu, Y.-S. Hu, H. Li, M. Armand, Y. Ikuhara, L. Chen and X. Huang, Nat Commun, 2013, 4, 1870.

36. T.-F. Yi, S.-Y. Yang and Y. Xie, Journal of Materials Chemistry A, 2015, 3, 57505777.

37. P. Senguttuvan, G. Rousse, V. Seznec, J.-M. Tarascon and M. R. Palacín, Chemistry of Materials, 2011, 23, 4109-4111.

38. L. P. Wang, L. Yu, R. Satish, J. Zhu, Q. Yan, M. Srinivasan and Z. Xu, RSC Advances, 2014, 4, 37389-37394.

39. P. Arunkumar, A. G. Ashish, S. Sarang, S. Abhin and M. M. Shaijumon, Meeting Abstracts, 2014, MA2014-01, 270.

40. G. Li, X. Wang and X. Ma, Journal of Energy Chemistry, 2013, 22, 357-362.

41. J. Chen, L. Xu, W. Li and X. Gou, Advanced Materials, 2005, 17, 582-586.

42. M. H. Chen, J. L. Liu, D. L. Chao, J. Wang, J. H. Yin, J. Y. Lin, H. J. Fan and Z. X. Shen, Nano Energy, 2014, 9, 364-372.

43. J. S. Cho, Y. J. Hong and Y. C. Kang, Acs Nano, 2015, 9, 4026-4035.

44. L. T. Anh, A. K. Rai, T. V. Thi, J. Gim, S. Kim, V. Mathew and J. Kim, Journal of Materials Chemistry A, 2014, 2, 6966-6975.

45. B. Guo, X. Fang, B. Li, Y. Shi, C. Ouyang, Y.-S. Hu, Z. Wang, G. D. Stucky and L. Chen, Chemistry of Materials, 2012, 24, 457-463.

46. S. Grugeon, S. Laruelle, R. Herrera-Urbina, L. Dupont, P. Poizot and J.-M. Tarascon, Journal of The Electrochemical Society, 2001, 148, A285-A292.

47. Q. Ye, J. Wang, J. Zhao, L. Yan, S. Cheng, T. Kang and H. Dai, Catal Lett, 2010, 138, 56-61.

48. S. Das and V. Jayaraman, Progress in Materials Science, 2014, 66, 112-255.

49. J. Read, D. Foster, J. Wolfenstine and W. Behl, Journal of Power Sources, 2001, 96, 277-281.

50. Y. S. Lin, J. G. Duh and M. H. Hung, J Phys Chem C, 2010, 114, 13136-13141. 
51. Z. Wang, D. Luan, F. Y. C. Boey and X. W. Lou, Journal of the American Chemical Society, 2011, 133, 4738-4741.

52. J. Wang, N. Du, H. Zhang, J. Yu and D. Yang, The Journal of Physical Chemistry C, 2011, 115, 11302-11305.

53. I. A. Courtney and J. R. Dahn, Journal of The Electrochemical Society, 1997, 144, 2045-2052.

54. S.-Y. Lee, K.-Y. Park, W.-S. Kim, S. Yoon, S.-H. Hong, K. Kang and M. Kim, Nano Energy, 2016, 19, 234-245.

55. H. Kim, G. O. Park, Y. Kim, S. Muhammad, J. Yoo, M. Balasubramanian, Y.-H. Cho, M.-G. Kim, B. Lee, K. Kang, H. Kim, J. M. Kim and W.-S. Yoon, Chemistry of Materials, 2014, 26, 6361-6370.

56. C. J. Pelliccione, E. V. Timofeeva and C. U. Segre, The Journal of Physical Chemistry C, 2016, 120, 5331-5339.

57. J. Ding, Z. Li, H. L. Wang, K. Cui, A. Kohandehghan, X. H. Tan, D. Karpuzov and D. Mitlin, Journal of Materials Chemistry A, 2015, 3, 7100-7111.

58. Y. C. Lu, C. Ma, J. Alvarado, T. Kidera, N. Dimov, Y. S. Meng and S. Okada, Journal of Power Sources, 2015, 284, 287-295.

59. M. Gu, A. Kushima, Y. Shao, J.-G. Zhang, J. Liu, N. D. Browning, J. Li and C. Wang, Nano Letters, 2013, 13, 5203-5211.

60. H. B. Wu, J. S. Chen, H. H. Hng and X. Wen Lou, Nanoscale, 2012, 4, 2526-2542.

61. A. Diéguez, A. Romano-Rodríguez, A. Vilà and J. R. Morante, Journal of Applied Physics, 2001, 90, 1550-1557.

62. J. Y. Huang, L. Zhong, C. M. Wang, J. P. Sullivan, W. Xu, L. Q. Zhang, S. X. Mao, N. S. Hudak, X. H. Liu, A. Subramanian, H. Fan, L. Qi, A. Kushima and J. Li, Science, 2010, 330, 1515-1520.

63. X. Zhou, L. Yu and X. W. Lou, Advanced Energy Materials, 2016, 6, n/a-n/a.

64. Y. Zhao, C. Wei, S. Sun, L. P. Wang and Z. J. Xu, Advanced Science, 2015, 2, n/a-n/a.

65. A. Birrozzi, R. Raccichini, F. Nobili, M. Marinaro, R. Tossici and R. Marassi, Electrochimica Acta, 2014, 137, 228-234.

66. S. L. Candelaria, Y. Y. Shao, W. Zhou, X. L. Li, J. Xiao, J. G. Zhang, Y. Wang, J. Liu, J. H. Li and G. Z. Cao, Nano Energy, 2012, 1, 195-220.

67. K. Chang, Z. Wang, G. Huang, H. Li, W. Chen and J. Y. Lee, Journal of Power Sources, 2012, 201, 259-266.

68. Q. N. Chen, W. X. Chen, J. B. Ye, Z. Wang and J. Y. Lee, Journal of Power Sources, 2015, 294, 51-58.

69. S. Q. Chen, P. Bao and G. X. Wan, Nano Energy, 2013, 2, 425-434.

70. Y. Chen, B. H. Song, X. S. Tang, L. Lu and J. M. Xue, Journal of Materials Chemistry, 2012, 22, 17656-17662.

71. L. David, R. Bhandavat and G. Singh, Acs Nano, 2014, 8, 1759-1770.

72. N. Kheirabadi and A. Shafiekhani, Journal of Applied Physics, 2012, 112, 124323.

73. Z. Li, J. Ding, H. L. Wang, K. Cui, T. Stephenson, D. Karpuzov and D. Mitlin, Nano Energy, 2015, 15, 369-378.

74. Y. D. Zhang, J. Xie, S. C. Zhang, P. Y. Zhu, G. S. Cao and X. B. Zhao, Electrochimica Acta, 2015, 151, 8-15. 
75. Y. D. Zhang, P. Y. Zhu, L. L. Huang, J. Xie, S. C. Zhang, G. S. Cao and X. B. Zhao, Advanced Functional Materials, 2015, 25, 481-489.

76. X. J. Zhu, Y. W. Zhu, S. Murali, M. D. Stollers and R. S. Ruoff, Acs Nano, 2011, 5, 3333-3338.

77. J. Lin, Z. W. Peng, C. S. Xiang, G. D. Ruan, Z. Yan, D. Natelson and J. M. Tour, Acs Nano, 2013, 7, 6001-6006.

78. S. G. Kwon, S. Chattopadhyay, B. Koo, P. C. dos Santos Claro, T. Shibata, F. G. Requejo, L. J. Giovanetti, Y. Liu, C. Johnson, V. Prakapenka, B. Lee and E. V. Shevchenko, Nano Letters, 2016, DOI: 10.1021/acs.nanolett.6b01072.

79. S. G. Kwon, S. Chattopadhyay, B. Koo, P. C. dos Santos Claro, T. Shibata, F. G. Requejo, L. J. Giovanetti, Y. Liu, C. Johnson, V. Prakapenka, B. Lee and E. V. Shevchenko, Nano Letters, 2016, 16, 3738-3747.

80. F. Wang, Y. Han, C. S. Lim, Y. Lu, J. Wang, J. Xu, H. Chen, C. Zhang, M. Hong and X. Liu, Nature, 2010, 463, 1061-1065.

81. X. Ye, W. Zhang, Q. Liu, S. Wang, Y. Yang and H. Wei, New Journal of Chemistry, 2015, 39, 130-135.

82. Y. Wang, I. Djerdj, B. Smarsly and M. Antonietti, Chemistry of Materials, 2009, 21, 3202-3209.

83. X. Wang, Z. Li, Z. Zhang, Q. Li, E. Guo, C. Wang and L. Yin, Nanoscale, 2015, 7, 3604-3613.

84. F. Mueller, D. Bresser, V. S. K. Chakravadhanula and S. Passerini, Journal of Power Sources, 2015, 299, 398-402.

85. Y. Xu, M. Zhou, X. Wang, C. Wang, L. Liang, F. Grote, M. Wu, Y. Mi and Y. Lei, Angewandte Chemie, 2015, 127, 8892-8895.

86. J. Sun, L. Xiao, S. Jiang, G. Li, Y. Huang and J. Geng, Chemistry of Materials, 2015, 27, 4594-4603.

87. C. Yuan, H. B. Wu, Y. Xie and X. W. Lou, Angewandte Chemie International Edition, 2014, 53, 1488-1504.

88. P. F. Teh, S. S. Pramana, Y. Sharma, Y. W. Ko and S. Madhavi, ACS Applied Materials \& Interfaces, 2013, 5, 5461-5467.

89. C. T. Cherian, M. Zheng, M. V. Reddy, B. V. R. Chowdari and C. H. Sow, ACS Applied Materials \& Interfaces, 2013, 5, 6054-6060.

90. H. Fan, Z. Liu, J. Yang, C. Wei, J. Zhang, L. Wu and W. Zheng, RSC Advances, 2014, 4, 49806-49810.

91. H. J. Huang, Y. Huang, M. Y. Wang, X. F. Chen, Y. Zhao, K. Wang and H. W. Wu, Electrochimica Acta, 2014, 147, 201-208.

92. W. Song, J. Xie, S. Liu, G. Cao, T. Zhu and X. Zhao, Journal of Materials Research, 2012, 27, 3096-3102.

93. F. Fan, G. Fang, R. Zhang, Y. Xu, J. Zheng and D. Li, Applied Surface Science, 2014, 311, 484-489.

94. G. Fang, S. Kaneko, W. Liu, B. Xia, H. Sun, R. Zhang, J. Zheng and D. Li, Applied Surface Science, 2013, 283, 963-967.

95. Z. Wang, Z. Wang, W. Liu, W. Xiao and X. W. Lou, Energy \& Environmental Science, 2013, 6, 87-91.

96. R. Alcántara, M. Jaraba, P. Lavela and J. L. Tirado, Chemistry of Materials, $2002,14,2847-2848$. 
97. Y. Chen, B. Qu, L. Mei, D. Lei, L. Chen, Q. Li and T. Wang, Journal of Materials Chemistry, 2012, 22, 25373-25379.

98. F. Han, W. C. Li, C. Lei, B. He, K. Oshida and A. H. Lu, Small, 2014, 10, 26372644.

99. L. P. Wang, Y. Zhao, C. Wei, C. Wong, M. Srinivasan and Z. J. Xu, Journal of Materials Chemistry A, 2015, 3, 14033-14038.

100. L. Li, S. Peng, Y. L. Cheah, J. Wang, P. Teh, Y. Ko, C. Wong and M. Srinivasan, Nanoscale, 2013, 5, 134-138.

101. Z. H. Wen, Q. Wang, Q. Zhang and J. H. Li, Advanced Functional Materials, 2007, 17, 2772-2778.

102. Z. Y. Wang, G. Chen and D. G. Xia, Journal of Power Sources, 2008, 184, 432436.

103. Y. Wang, H. C. Zeng and J. Y. Lee, Advanced Materials, 2006, 18, 645-+.

104. X. Liu, M. H. Wu, M. R. Li, X. L. Pan, J. Chen and X. H. Bao, Journal of Materials Chemistry A, 2013, 1, 9527-9535.

105. S. J. Ding, J. S. Chen and X. W. Lou, Advanced Functional Materials, 2011, 21, 4120-4125.

106. X. W. Lou, C. M. Li and L. A. Archer, Advanced Materials, 2009, 21, 2536-+.

107. P. Pal, A. K. Giri, S. Mahanty and A. B. Panda, CrystEngComm, 2014, 16, 10560-10568.

108. Y. N. Ko, S. B. Park and Y. C. Kang, Small, 2014, 10, 3240-3245.

109. J. Fan, T. Wang, C. Z. Yu, B. Tu, Z. Y. Jiang and D. Y. Zhao, Advanced Materials, 2004, 16, 1432-+.

110. F. Han, W. C. Li, M. R. Li and A. H. Lu, Journal of Materials Chemistry, 2012, 22, 9645-9651.

111. Y. C. Jiao, D. D. Han, Y. Ding, X. F. Zhang, G. N. Guo, J. H. Hu, D. Yang and A. G. Dong, Nature Communications, 2015, 6.

112. X. S. Zhou, Z. H. Dai, S. H. Liu, J. C. Bao and Y. G. Guo, Advanced Materials, 2014, 26, 3943-3949.

113. C. Guan, X. H. Wang, Q. Zhang, Z. X. Fan, H. Zhang and H. J. Fan, Nano Letters, 2014, 14, 4852-4858.

114. S. M. Paek, E. Yoo and I. Honma, Nano Letters, 2009, 9, 72-75.

115. X. Y. Wang, X. F. Zhou, K. Yao, J. G. Zhang and Z. P. Liu, Carbon, 2011, 49, 133139.

116. L. L. Liu, M. Z. An, P. X. Yang and J. Q. Zhang, Scientific Reports, 2015, 5.

117. S. Nam, S. J. Yang, S. Lee, J. Kim, J. Kang, J. Y. Oh, C. R. Park, T. Moon, K. T. Lee and B. Park, Carbon, 2015, 85, 289-298.

118. X. S. Zhou, L. J. Wan and Y. G. Guo, Advanced Materials, 2013, 25, 2152-2157.

119. D. P. Cai, T. Yang, B. Liu, D. D. Wang, Y. Liu, L. L. Wang, Q. H. Li and T. H. Wang, Journal of Materials Chemistry A, 2014, 2, 13990-13995.

120. S. Yang, W. B. Yue, J. Zhu, Y. Ren and X. J. Yang, Advanced Functional Materials, 2013, 23, 3570-3576.

121. J. Zhu, Z. Lu, M. O. Oo, H. H. Hng, J. Ma, H. Zhang and Q. Yan, Journal of Materials Chemistry, 2011, 21, 12770-12776.

122. P. Wu, N. Du, H. Zhang, J. X. Yu and D. R. Yang, J Phys Chem C, 2010, 114, 22535-22538. 
123. Y. Z. Su, S. Li, D. Q. Wu, F. Zhang, H. W. Liang, P. F. Gao, C. Cheng and X. L. Feng, Acs Nano, 2012, 6, 8349-8356.

124. S. Chen, Y. L. Xin, Y. Y. Zhou, F. Zhang, Y. R. Ma, H. H. Zhou and L. M. Qi, Journal of Materials Chemistry A, 2014, 2, 15582-15589.

125. B. A. Zhang, Q. B. Zheng, Z. D. Huang, S. W. Oh and J. K. Kim, Carbon, 2011, 49, 4524-4534.

126. J. Zhu, D. N. Lei, G. H. Zhang, Q. H. Li, B. G. Lu and T. H. Wang, Nanoscale, 2013, 5, 5499-5505.

127. Y. Zhao, C. Wei, S. Sun, L. P. Wang and Z. J. Xu, Advanced Science, 2015.

128. Y. Wang, D. W. Su, C. Y. Wang and G. X. Wang, Electrochemistry Communications, 2013, 29, 8-11.

129. A. Jahel, C. M. Ghimbeu, A. Darwiche, L. Vidal, S. Hajjar-Garreau, C. Vix-Guterl and L. Monconduit, Journal of Materials Chemistry A, 2015, 3, 11960-11969.

130. Y. H. Liu, X. Fang, M. Y. Ge, J. P. Rong, C. F. Shen, A. Y. Zhang, H. A. Enaya and C. W. Zhou, Nano Energy, 2015, 16, 399-407.

131. D. W. Su, H. J. Ahn and G. X. Wang, Chemical Communications, 2013, 49, 3131-3133.

132. X. Q. Xie, S. Q. Chen, B. Sun, C. Y. Wang and G. X. Wang, Chemsuschem, 2015, 8, 2948-2955.

133. M. Dirican, Y. Lu, Y. Ge, O. Yildiz and X. Zhang, ACS Applied Materials \& Interfaces, 2015, 7, 18387-18396.

134. K. E. Lewis, D. M. Golden and G. P. Smith, Journal of the American Chemical Society, 1984, 106, 3905-3912.

135. S. Kim, C. Hwang, S. Y. Park, S.-J. Ko, H. Park, W. C. Choi, J. B. Kim, D. S. Kim, S. Park, J. Y. Kim and H.-K. Song, Journal of Materials Chemistry A, 2014, 2, 18070-18075.

136. S. Veintemillas-Verdaguer, M. P. Morales and C. J. Serna, Materials Letters, 1998, 35, 227-231.

137. H. R. Bachmann, H. Nörth, R. Rinck and K. L. Kompa, Chemical Physics Letters, 1974, 29, 627-629.

138. J. Förster, M. von Hoesslin and J. Uhlenbusch, Applied Physics B, 1996, 62, 609-612.

139. Y. Leconte, H. Maskrot, L. Combemale, N. Herlin-Boime and C. Reynaud, Journal of Analytical and Applied Pyrolysis, 2007, 79, 465-470.

140. B. Zhang and W. Wenlou, in Micro System Technologies 90: 1st International Conference on Micro Electro, Opto, Mechanic Systems and Components Berlin, 10-13 September 1990, ed. H. Reichl, Springer Berlin Heidelberg, Berlin, Heidelberg, 1990, DOI: 10.1007/978-3-642-45678-7_47, pp. 330-334.

141. R. Alexandrescu, I. Morjan, F. Dumitrache, R. Birjega, C. Fleaca, C. Luculescu, E. Popovici, I. Soare, I. Sandu and E. Dutu, Journal of optoelectronics and advanced materials, 2010, 12, 599-604.

142. S. Kumar, X. Bi and N. Kambe, Journal, 2001.

143. J. L. Duncan, D. C. McKean and P. D. Mallinson, Journal of Molecular Spectroscopy, 1973, 45, 221-246. 


\section{Chapter 3}

\section{Experimental Methodology}

In this chapter, we will highlight the underlying principles of various synthesis and characterization processes that are used in experiments throughout the thesis. Before that, the rationale for selection of materials and characterization techniques will be presented. Lastly, to evaluate the as-synthesized materials as an anode in alkali ion batteries, the processes for fabrication and testing of our coin cells will be elaborated in detail. 


\subsection{Selection of methods and materials}

The main aim of this thesis is to demonstrate facile time-efficient methods for the production of tin based oxides and its application as superior anode material in both LIB and NIB. We have discussed extensively in the previous chapter about the advantages and limitation of using pristine $\mathrm{SnO}_{2}$ as an anode material in LIBs/NIBs, as well as possible ways that we can overcome these limitations. Three different engineering principles that have been highlighted include:

1) Introduction of foreign phase for the formation of ternary oxide

2) Providing a carbon matrix to enhance conductivity and buffer strain

3) Elemental doping into structure to tailor electronic structure

Before commencing, several key factors have been considered during the selection of precursors and synthesis methods. This include:

i) Reproducibility

ii) Price of precursor

iii) Time required for synthesis

iv) Possibility for scaling up

v) Environmental impact

Keeping in mind these factors, two different methods, namely co-precipitation and laser pyrolysis will be employed for the synthesis of these modified tin based oxides.

The formation of carbon- $\mathrm{SnO}_{2}$ nanocomposites has shown to be an excellent method for enhancing the electrochemical performance. Amongst different carbon-based materials (e.g. $\mathrm{C}_{60}, \mathrm{MWCNT}$, hard carbon), graphene is one of the most widely explored choices owing to its high electrical conductivity and high tensile strength. However, these nanocomposites often require multiple preparation and processing steps that are unfeasible for commercial production. Laser pyrolysis is a versatile but less commonly explored method for the production of well-distributed nanoparticles. While unable to control the morphology of these nanocomposites, it can offer rapid production of nanoparticles in a highly reliable manner. Hence, to reduce time and cost, laser 
pyrolysis will be employed to synthesize $\mathrm{rGO}-\mathrm{SnO}_{2}$ nanocomposite in a rapid one-pot manner.

The substitution of $\mathrm{Sn}^{4+}$ with other multivalent ions such as $\mathrm{Fe}^{3+}, \mathrm{Ni}^{2+}$ and etc. has been widely explored for enhancing the electrochemical performance of $\mathrm{SnO}_{2}$. Comparatively, anionic substitution of $\mathrm{SnO}_{2}$ has been less commonly explored. Asides from $\mathrm{C}_{2} \mathrm{H}_{4}$, other gases such as $\mathrm{H}_{2} \mathrm{~S}, \mathrm{SF}_{6}, \mathrm{SiH}_{4}$ and $\mathrm{NH}_{3}$ are also known to be capable of absorbing $\mathrm{CO}_{2}$ laser. Through tailoring of the different sensitizer gases, it is possible to produce different doping gases. For instance, upon absorbing of $\mathrm{CO}_{2}$ laser $\mathrm{NH}_{3}$ will decompose into $\mathrm{N}_{2}$ and $\mathrm{H}_{2}$ gas. During laser pyrolysis, the high temperature derived from the blackbody radiation during absorption of sensitizer gas along with the presence of dopants could directly dope into the crystal structure of $\mathrm{SnO}_{2}$.

For the last design principle, we shortlisted $\mathrm{ZnO}$ as a potential foreign phase that could be introduced for the formation of the ternary $\mathrm{ZnSnO}_{3}$ compound. As $\mathrm{Zn}$ is much cheaper and more readily abundant compared to $\mathrm{SnO}_{2}$, it could help lower the cost and increase feasibility for future commercialization. However, we take into consideration that $\mathrm{ZnSnO}_{3}$ is a metastable phase and will decompose into $\mathrm{Zn}_{2} \mathrm{SnO}_{4} / \mathrm{SnO}_{2}$ under strong heating $\left(>600{ }^{\circ} \mathrm{C}\right)$. Therefore, methods such as solid-state synthesis that require high sintering temperature to ensure consistent reaction should be avoided. Comparatively, the temperature needed for dehydration to occur is much lesser $\left(300-500{ }^{\circ} \mathrm{C}\right)$ as compared to solid-state synthesis $\left(800-1000{ }^{\circ} \mathrm{C}\right)$. Hence, we utilize co-precipitation method to synthesize a template $\left(\mathrm{ZnSn}(\mathrm{OH})_{6}\right)$ first before dehydrating it to form $\mathrm{ZnSnO}_{3}$.

Different characterization methods will be employed to understand the physical properties of these compounds both under pristine and ex-situ conditions. 


\subsection{Principle behind synthesis methods}

\subsubsection{Co-precipitation}

Co-precipitation is a flexible facile synthesis technique that could be used to produce a wide variety of materials with unique morphologies and sizes. The key to this synthesis technique is widely based on the addition of a precipitation agent (e.g. $\mathrm{NaOH}, \mathrm{NaHCO}_{3}$ and etc) to a single/multi-elemental solution. As a result, insoluble products will be precipitated due to the reactions between the cations and precipitation agent. The key advantage of this synthesis method is that it allows the cations to be well distributed in the solution first before the structure coordinating precipitation agent is added. To this end, co-precipitation is much more favorable for obtaining evenly distributed compounds as compared to conventional solid-state synthesis/ball-milling. Furthermore, modifications to the precipitated products (e.g. etching) can be carried out during synthesis through the addition of highly acidic/caustic solution or by adjusting the temperature.

While the simplicity of this process allows for scaling up to industry level, several drawbacks should be considered. The key disadvantage is that it requires an additional annealing step to obtain oxides. Depending on the heat treatment temperature/time, the structure and morphology may or may not be easily controlled. Additionally, this method requires the use of metallic salts such as chlorides or nitrates, which might turn out to be more costly for certain elements.

\subsubsection{Laser Pyrolysis (@CEA Saclay)}

As mentioned in section 2.5, laser pyrolysis is a surfactant-free physical vapor nanoparticle synthesis technique where an infrared $\mathrm{CO}_{2}$ laser is used to excite a precursor or a photosensitizer gas (e.g. $\mathrm{C}_{2} \mathrm{H}_{4}, \mathrm{SF}_{6}$ ), which energetically collides and results in decomposition of precursor molecules. ${ }^{1-3}$ The large thermal gradient between the limited reaction zone and the chamber wall, combined with the short residence time of precursors and growing species, prevents 
growth during the synthesis process. The entire synthesis process is as illustrated in Figure 3.1.

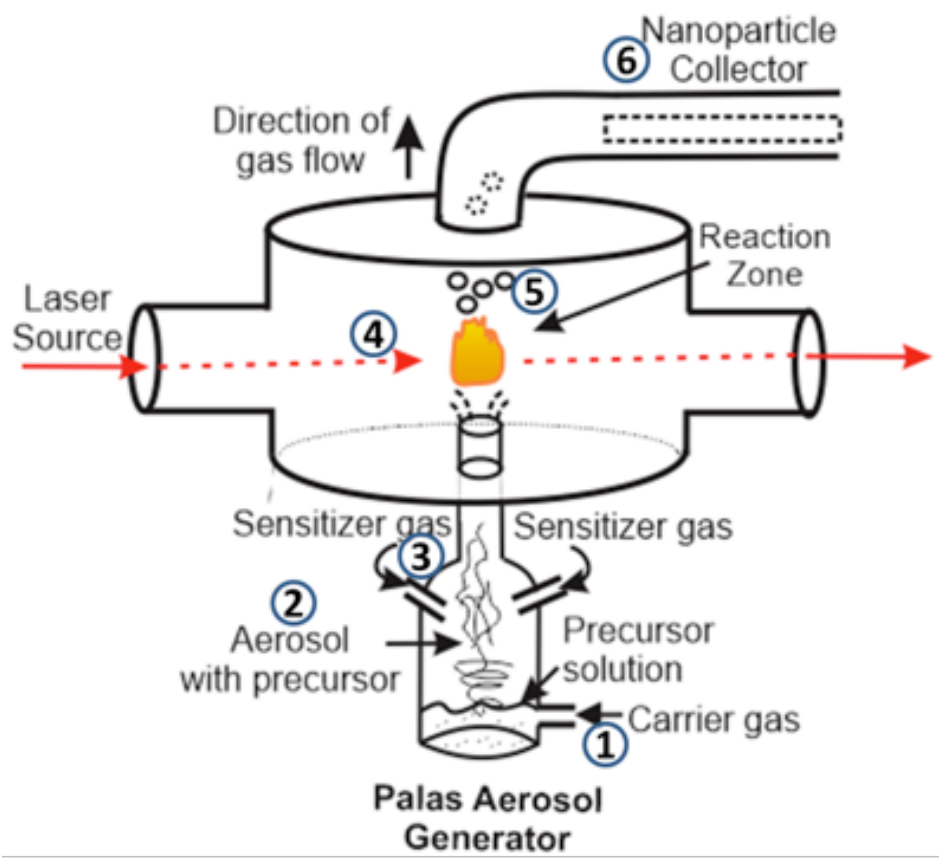

Figure 3.1 Schematic of the laser pyrolysis working procedure

In a typical laser pyrolysis process, the precursor solutions were first loaded into a glass bottle before connecting it to the aerosol generator (PALAS, AGK 2000). The carrier gas used was either compressed air or argon that was directly linked to the aerosol generator. The massive flow of gas across a small nozzle generated a mist of aerosol droplets that flowed tangentially into a cyclone. Large aerosol droplets $(>10 \mu \mathrm{m})$ were separated by its small centrifugal force compared to weight and flowed back into the precursor solution, while the smaller droplets came into the mix with the sensitizer gas before entering the reactor. The sensitizer gas $\left(\mathrm{C}_{2} \mathrm{H}_{4} / \mathrm{NH}_{3}\right)$ enabled the absorption of the $\mathrm{CO}_{2}$ laser (10.6 $\mu \mathrm{m}$ wavelength, PRC Laser, PRC 2200), resulting in visible light emission corresponding to a pyrolysis flame that can be compared to a combustion flame when oxygen and fuel are combined, or on the contrary distinguished from combustion flame when no oxygen is involved. This pyrolysis flame is generated by either the blackbody radiation of hot growing 
particles or radicals emission coming from the decomposition of reaction molecules (or a combination of both), depending on the type of carrier and sensitizer gas used. The powders produced after passing through the reaction zone were transported and collected on nanoparticle filters via Ar flow. To put things into perspective, images of the actual setup are depicted in Figure 3.2 and 3.3.

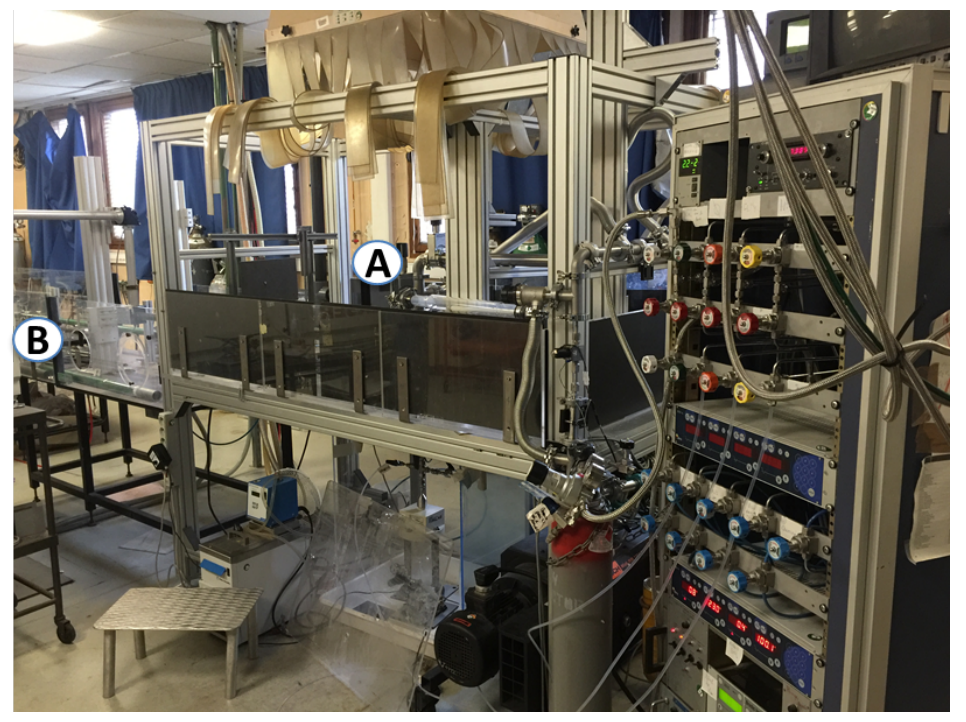

Figure 3.2 Image of the laser pyrolysis setup.

During laser pyrolysis, different sensitizer and carrier gases were utilized depending on the design requirement of the $\mathrm{SnO}_{2}$ nanoparticles. For instance, to prevent combustion of GO, argon was used instead of air. As the entire synthesis process is carried out in a continuous flow manner, there is uniform deposition of nanoparticles onto the nanoparticle collector. The nanoparticle collector is a metallic porous hollow rod that is connected to the vacuum pump to direct the flow of nanoparticles. During the synthesis process, depending on the flow rate and quality of nanoparticle collector, the nanoparticle collector is susceptible to blockage. When the collector is blocked, the entire experiment would have to be shut down to prevent internal pressure from building up. Subsequently, collection of nanoparticles was carried out on clean collectors so as to rule out contamination and to ensure reproducibility. 


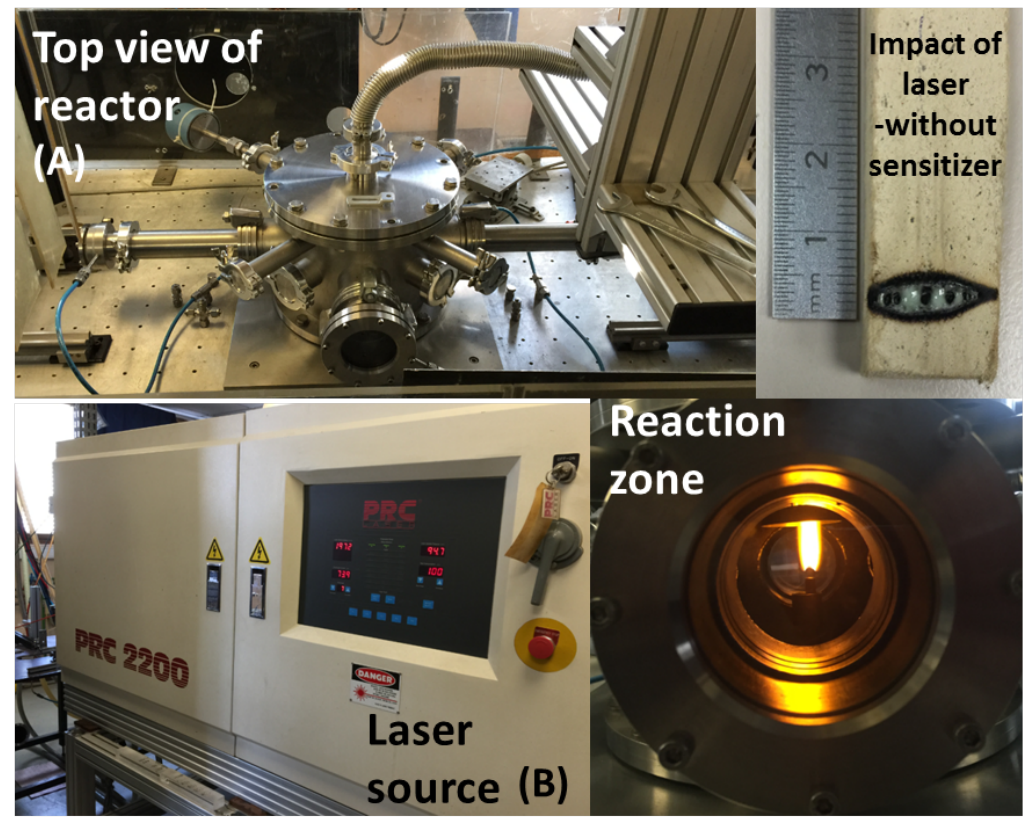

Figure 3.3 In a clockwise direction from top left-hand corner, (A) illustrates the birdeye view of the reactor chamber as labeled in Figure 3.2. Beside it is the impact of the laser with wooden plank without the presence of sensitizer gas. Bottom right depicts the reaction zone in the presence of $\mathrm{C}_{2} \mathrm{H}_{4}$ as sensitizer and air as a carrier gas. The last picture (B) corresponds to the $\mathrm{CO}_{2}$ laser source utilized during laser pyrolysis.

\subsection{Principle behind characterization techniques}

\subsubsection{X-Ray Diffraction (XRD)}

X-ray diffraction (XRD) is one of the most versatile methods utilized for understanding the long-range atomic order of a particular structure. During operation, X-rays passes into the lattice of the structure and are scattered when in contact with the atoms. The constructive interference derived from the superimposition of scattered X-rays comes with a diffraction angle $\theta$ that must satisfy the equation:

$$
\lambda=2 d \sin \theta
$$

This equation is also known as Bragg's Law, where; $\lambda$ is the $\mathrm{X}$-ray wavelength that is source dependent, and $\mathrm{d}$ is the $\mathrm{d}$ spacing of the crystal plane that is structure and crystal plane dependent. In this thesis, the X-ray source used for powder $\mathrm{XRD}$ is $\mathrm{Cu}(1.5418 \AA)$ while the $\mathrm{x}$-ray wavelength for synchrotron 
XRD is $0.72768 \AA$. The correlation between XRD patterns and crystal structures provides us with a powerful tool for identifying the different phase compositions of powders that are present in the sample. As each crystalline sample has a distinctive set of diffraction patterns (due to different atomic bond length and crystal structure), this method is highly reliable for phase identification. The main drawback of this method is that the material has to be crystalline or possess a long-range periodic ordering of atoms. Hence, it does not work well for amorphous materials or crystals with short order arrangement where there is random scattering of diffracted X-rays.

For synchrotron X-ray diffraction (SXRD), it was performed at beamline 17BM at APS of ANL to characterize phase identities. Samples at the different charging/discharging states were attached to Kapton ${ }^{\mathrm{TM}}$ tapes and measured in transmission mode. A PerkinElmer amorphous silicon flat panel detector was used to collect two-dimensional XRD data. Integration of the $2 \mathrm{D}$ data to conventional plots of intensity versus 2-theta. The X-ray wavelength was $0.72768 \AA$.

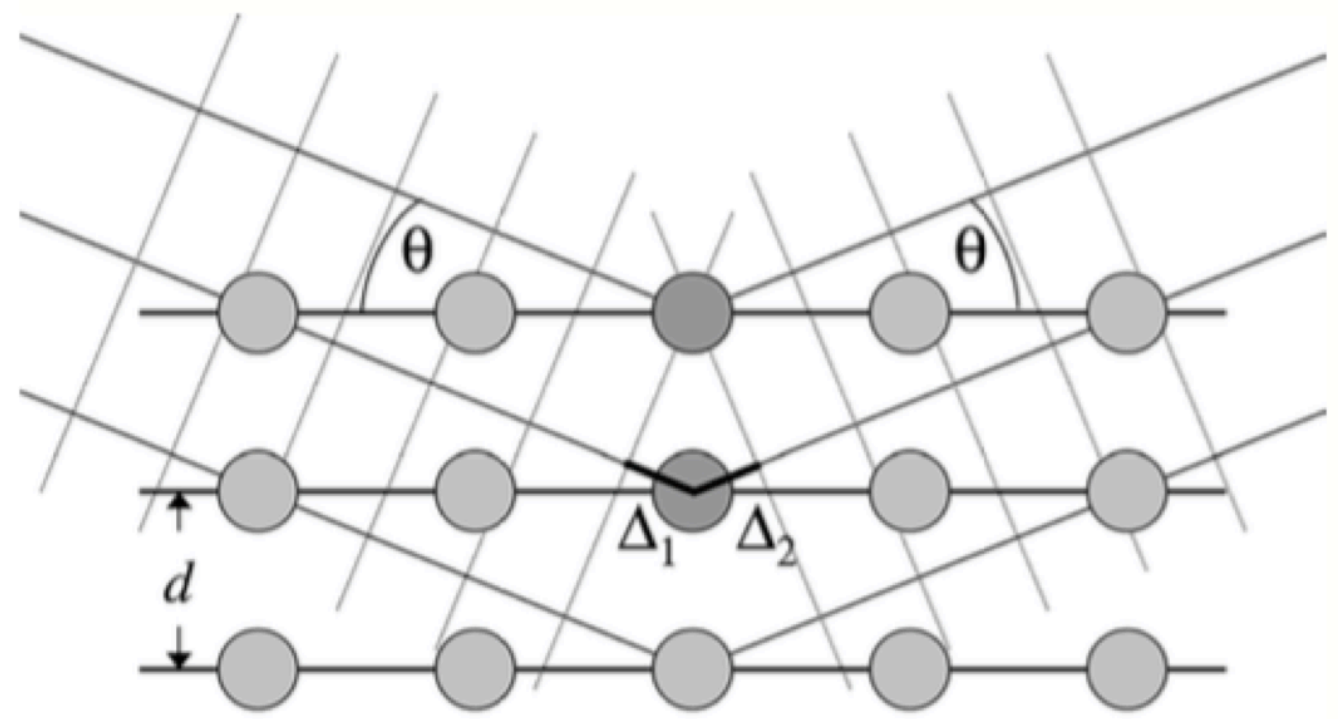

Figure 3.4 Illustration of the Bragg's diffraction that correlates with the equation $\lambda=$ $2 d \sin \theta^{4}$ 


\subsubsection{Electron Microscopy (SEM \& TEM)}

The scanning electron microscopy (SEM) uses a focused beam of electrons to produce a wide variety of signals at the surface of the sample. These signals could be used to obtain various information including the morphology, size distribution and orientation of materials. In this thesis, the secondary electrons obtained in SEM are used to produce an image of our sample, which is then termed secondary electron image (SEI). Before electron imaging, a thin layer of platinum was coated on top of the poorly conducting oxide samples. The accelerating voltage used in the SEM is between $5-30 \mathrm{kV}$ and the general resolution using SEM is approximately $30-50 \mathrm{~nm}$. To study materials that are much smaller, the resolution has to be improved. The most direct way is to reduce the wavelength of the electron source, which is indirectly proportional to the accelerating voltage of the electron source via the de Broglie equation.

Transmission electron microscopy (TEM) has an accelerating voltage of 40 $300 \mathrm{kV}$ which translates to a better resolution. As opposed to SEM, the beam of electrons during TEM operation interacts and passes through the sample. Naturally, the projected images, viewed in transmission would be 2D in nature. The unscattered electrons are then projected as an image onto a fluorescent screen. The brightness of the image depends on several factors, including material's density, size of the particle, the morphology of sample (i.e. hollow or solid samples) and etc. In TEM, electrons are treated more as wave-like than particle like, where it has a wavelength that is few hundreds of a $\AA$ and is about ten times larger than that of the crystal lattice spacing. As a result, diffraction of an electron can also be used to study the orientation, lattice spacing and the crystallinity of a sample. This mode is also known as selected area electron diffraction (SAED). In SAED, the crystal planes are projected as bright spots in the reciprocal space instead of the real space. 


\subsubsection{Energy Dispersive X-ray Spectroscopy (EDX)}

The energy dispersive X-ray spectroscopy is briefly used in Chapter 6 of our work. EDX works at a higher accelerating voltage compared to the SEI mode. It depends on the absorption of electrons by the sample, which knocks up a corelevel electron out from its electron shell where the atom goes into an excited state. Subsequently, due to relaxation, the excited electron drops back into the original shell and filling up the original hole. X-rays are then emitted during relaxation and used to identify elements present. As each element has a unique electronic structure, this method could be used as a fingerprint method for identifying elements. However, elements that have similar electronic structure may face difficulty in identifying due to close energy levels.

\subsubsection{X-ray Photoelectron Spectroscopy (XPS)}

X-ray photoelectron spectroscopy (XPS) is a surface sensitive spectroscopic technique that is used for probing the surface chemistry of samples. It requires high vacuum conditions and reliably probes only $\sim 10 \mathrm{~nm}$ in depth of the sample. When X-ray photons are irradiated onto the surface of the sample, it excites and ejects a core-level electron out. This emitted electron possesses kinetic energy value inherited from the incident X-ray and the corresponding binding energy value could be obtained through the Ernest Rutherford equation:

$$
E_{\text {Binding }}=E_{\text {photon }}-\left(E_{\text {Kinetic }}+\Phi\right)
$$

where $E_{\text {Binding }}$ is the binding energy of the electron, $E_{\text {photon }}$ is the energy of the $\mathrm{X}$-ray photon; $E_{\text {Kinetic }}$ is the measured kinetic energy of the electron and $\Phi$ is the work function that is instrument dependent. 2 key information could be derived from the XPS spectra. First, the peak intensity is directly proportional to the concentration of particular species on the surface. Secondly, the peak positions are characteristic of the materials' electronic structure. Similar to EDX, each and every element on the periodic has a unique spectrum and position of its own. 
In Chapter 4 and 5, XPS will be used to characterize the samples. In particular, it will be used to understand the oxidation state of Sn samples obtained after synthesis. Following that, fitting of the samples will be carried out using CASA XPS software. During the fitting, the samples are calibrated using the $\mathrm{C} 1 \mathrm{~s}$ peak at $284.8 \mathrm{eV}$. Following that, each peak, i.e. Sn $3 \mathrm{~d}_{5 / 2}$ and $\mathrm{Sn} 3 \mathrm{~d}_{3 / 2}$ will be isolated and fitted independently of one another. The baseline that is of use would be the linear mode.

\subsubsection{Raman spectroscopy}

Raman spectroscopy is based on the response of the material to an irradiated monochromatic laser beam. Upon illumination, the laser interacts with the vibrational modes in molecules of the structure and generates an exiting scattered light. As a result of this inelastic collision, the energy that is transferred between photons and molecular vibration constitutes to Raman scattering. ${ }^{5}$ In this thesis, Raman spectroscopy was utilized to obtain two particular information: i) In Chapter 4, the extent of graphene reduction in the rGO-SnO ${ }_{2}$ nanocomposite ii) In Chapter 5, study the differences in the microstructure of $\mathrm{N}$-doped vs. undoped $\mathrm{SnO}_{2}$ nanoparticles. To investigate the first point, the Raman signals at $1400 \mathrm{~cm}^{-1}$ and $1600 \mathrm{~cm}^{-1}$ that correspond to $I_{D}$ and $\mathrm{I}_{\mathrm{G}}$ of $\mathrm{GO} / \mathrm{rGO}$ will be compared. As for comparing the microstructure of $\mathrm{N}$ doped and undoped $\mathrm{SnO}_{2}$, Raman spectrum between 300 to $800 \mathrm{~cm}^{-1}$ will be evaluated for the different vibrational modes in tetragonal $\mathrm{SnO}_{2}$. Raman measurements were made with WITEC alpha300 SR using $488 \mathrm{~nm}$ wavelength Argon-ion laser.

\subsubsection{Thermogravimetric analysis}

Thermogravimetric analysis is briefly utilized in Chapter 4 to measure the graphene content within the rGO-SnO2 nanocomposite quantitatively. It involves the gradual heating of the sample within an enclosed chamber filled with either air or argon gas. In the case of air, combustion will take place with 
graphene, resulting in the formation of $\mathrm{CO}_{2}$. Due to the decomposition of carbon moieties, a mass loss will be induced within the sample and hence, the composition of graphene within the sample could be effectively measured. In our experiments, TGA Q500 instrument was utilized for heating of sample within 30 to $700{ }^{\circ} \mathrm{C}$ at a heating rate of $5^{\circ} \mathrm{C} \min ^{-1}$ under airflow.

\subsubsection{Synchrotron X-ray Absorption Spectroscopy (XAS) (@ Argonne)}

Chapter 5 focuses on the results and discussion of nitrogen doping in $\mathrm{SnO}_{2}$. Asides from understanding its electrochemical performance, it is also important to understand the fundamental mechanism and the role that nitrogen plays. Hence, ex-situ XAS was carried out to understand how the redox state of Sn changes throughout cycling (XANES) and also to study the structural changes (EXAFS). XAS refers to how $\mathrm{x}$-rays are absorbed by an atom at energies near and above its core-level binding energies. The extent of X-ray absorption is unique for individual elements, where parameters such oxidation state, coordination chemistry, bond length and coordination number modulates how a particular species absorption capability. X-ray absorption is a measure of the sample's response to the absorption of X-ray. The equation,

$$
I=I_{o} e^{-\mu t}
$$

which is also known as the Beer-Lambert's Law, is used to measure the linear absorption coefficient, $\mu$. $I_{o}$ corresponds to the intensity of the incident X-ray; I relates to the intensity of X-ray that is transmitted through the sample and $t$ is the thickness of the sample. This $\mu$ value is directly proportional to absorbant's atomic number $(Z)$ and energy of the $\mathrm{X}$-ray $(E)$ through the equation

$$
\mu=\frac{\rho Z^{4}}{A E^{3}}
$$

where $\rho$ is the density of the sample and A is the atomic mass of the sample. Furthermore, the physical and chemical properties of both crystalline and amorphous materials could be studied in this instance. The X-ray absorption spectrum can be divided into two parts, X-ray absorption near-edge spectroscopy (XANES) and extended X-ray absorption fine-structure 
spectroscopy (EXAFS). XANES is strongly sensitive to the oxidation state and coordination chemistry of the probing species, while EXAFS allows us to understand the interatomic bonding distances, coordination number, and species of the neighbor atoms.

When the X-ray energy is higher than the binding energy of the core-level electrons (Figure 3.5), a photoelectron will be produced along with a core electron level that is left empty. This energy value is known as the near edge value, and a sharp jump in the XANES spectrum can be observed. The excited state will then proceed to decay within few femtoseconds according to 2 different mechanisms, i.e. X-ray fluorescence and Auger effect. According to the energies values, the absorption coefficient value, $\mu$ could be measured. In our XANES experiments, the differential curves will be used to measure and compare the near-edge value that is directly proportional to a material's oxidation and reduction state.

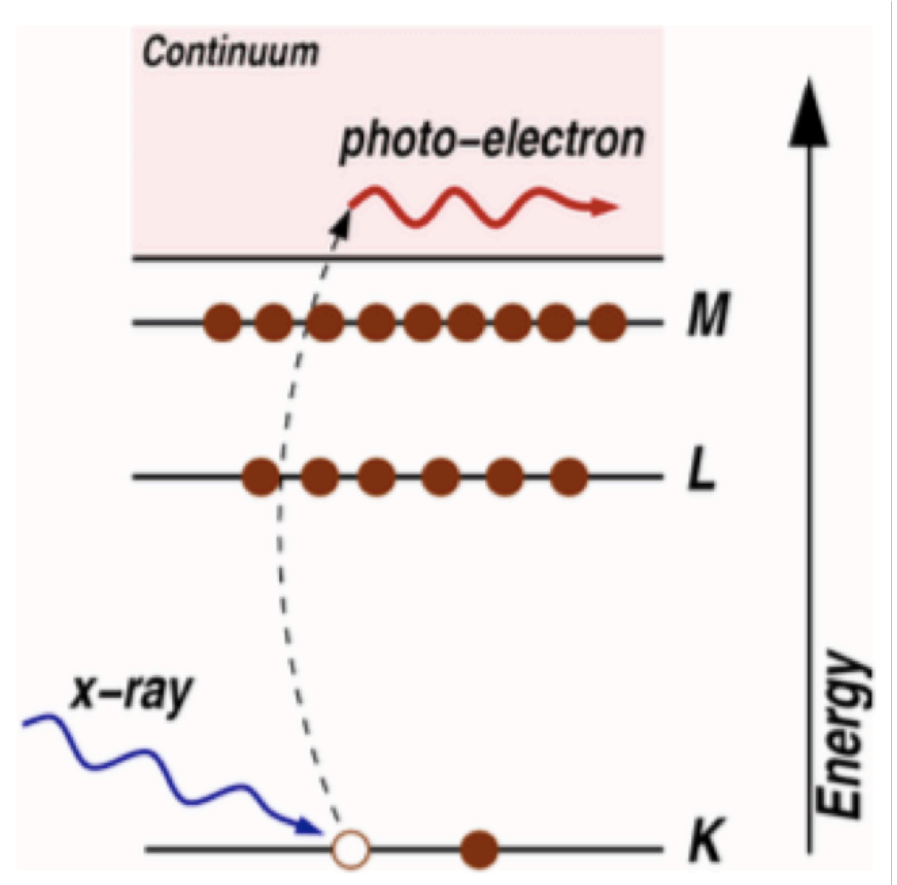

Figure 3.5 Photoelectric effect, in which X-ray is absorbed and a core-level electron is ejected out from the atom 
The other mode of interest in this thesis would be the EXAFS mode. The EXAFS mode measures the oscillations at energy levels far above the absorption edge values. The spectrum is a phenomenon generated by the interference between outgoing photoelectron wave and backscattered wave. Due to various interferences (constructive and destructive), information about the interatomic distances, coordination numbers and type of neighbor could be easily obtained. This technique is independent of the long-range order (crystallinity) and is one of the most effective methods for investigating amorphous/poorly crystalline materials.

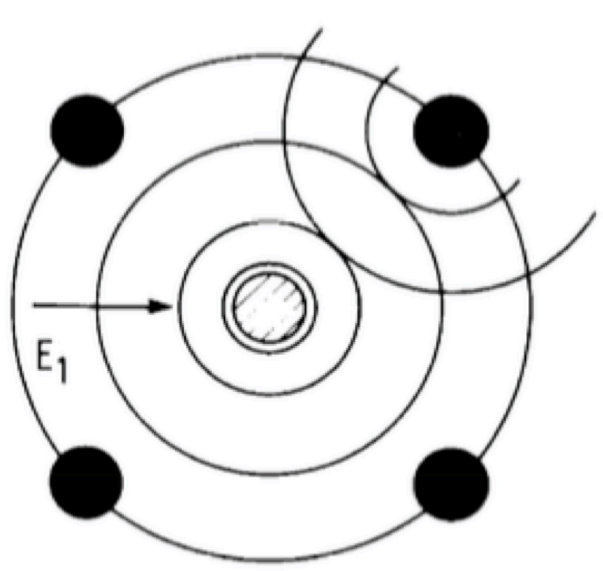

constructive

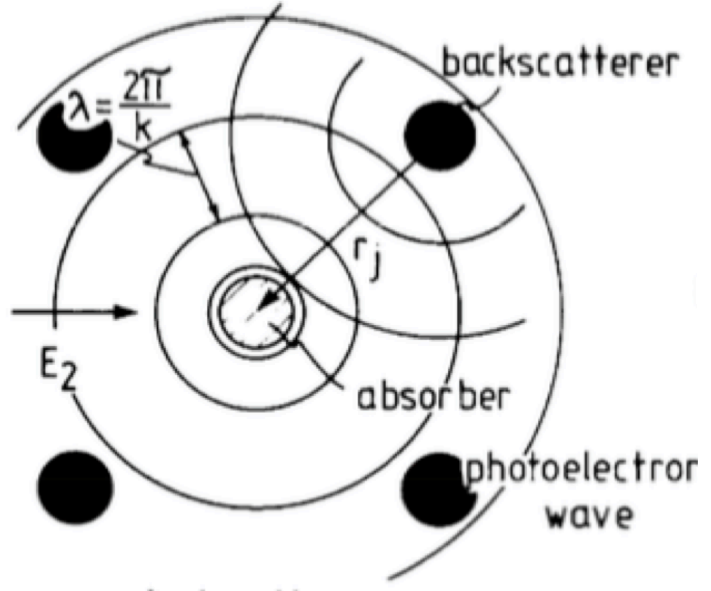

destructive

interference

Figure 3.6 Interference phenomenon between outgoing photoelectron wave and backscattered wave.

All data for XAS analyses were collected in fluorescence mode. Data reduction and analysis were performed with the Athena software. The pre-edge was linearly fitted and subtracted. The post-edge background was determined by using a cubic-spline-fit procedure and then subtracted. The data were normalized by the height of the absorption edge. 


\subsection{Principle behind electrochemical methods}

\subsubsection{Coin cell fabrication}

The electrochemical properties of all samples were evaluated in a coin cell (CR2032) two-electrode set up with lithium/sodium metal as the counter and reference electrode at room temperature. The working electrode comprises of active material, carbon black (Super-P) conductive additive and carboxymethyl cellulose (CMC) binder in a weight ratio of 7:2:1. Water is used as the solvent for dispersing all components to generate the slurry. The carbon black additive serves to provide a percolating pathway for the transport of the otherwise electronically insulative tin based oxide materials. The binder helps to hold the active material and conductive additive together while helping at adhering to the current collector. The electrode preparation formula has been varied between $6: 2: 2,8: 1: 1$ and $7: 1: 2$, where the ratio of $7: 2: 1$ shows the optimum lamination. It is to be noted that while the best performance (highest conductivity, rate performance) might not come from the $7: 2: 1$ formulation, the ratio provides the best stability when placed with electrolyte during cell assembly (i.e. no over-agglomeration during slurry preparation/no delamination). The current collector used for LIB and NIB testing in this thesis is etched copper and etched aluminum foils respectively. These etched foils have a constant density and thickness throughout the entire roll and hence, all new foils (without any coating) that are punched out from the electrodepreparing die should be of the same/similar weight. While the energy storage community employs a wide variety of preparation method, our methods listed here might not be the most efficient, but it serves to enhance reliability and reproducibility.

Following coating of the slurry onto either the copper or aluminum foil, the samples are dried in air at a temperature $<80^{\circ} \mathrm{C}$ to prevent critical thermal fracture due to the rapid contraction of the coating due to water evaporation. After leaving the slurry-coated foil to dry for 2 hours, electrodes are then punched out from an electrode preparation die with a diameter of $12 \mathrm{~mm}$. The 
electrodes are subsequently stored in individual zip-lock bags to prevent contamination. Thereafter, the samples will be transported into a vacuum oven $\left(80^{\circ} \mathrm{C}\right)$ to remove further the remnant water content that might be inaccessible in ambient drying conditions. These zip-lock bags should not be entirely closed, where a small opening should allow the water to escape. Samples should be left to dry overnight $>10 \mathrm{hrs}$ to ensure complete drying. Following complete drying, these electrodes will be pressed under a weight of at approximately 500 psi to improve interparticle contact. Weight measurement will then be carried out for the individual electrodes with sensitivity up to $0.005 \mathrm{mg}$. At least ten blank electrodes will be measured for their average weight and to further calculate the active material mass in each electrode. In this thesis, the masses of electrodes range between $1-2.3 \mathrm{mg}_{\text {active material. }}$.

Generally, for electrochemical measurements, three electrode setups will be used. First of the three electrodes would be the working electrode that contains our active material. The second is a reference electrode, which is a standard for measurement and comparison of the material's redox potential. Examples of reference electrode would be $\mathrm{Ag} / \mathrm{AgCl}, \mathrm{Li}^{+} / \mathrm{Li}$ and etc. No currents should pass through the reference electrode, so as to prevent redox reaction from happening in the reference electrode that may result in deviation of its standard potential. The last of the three electrodes would be the counter electrode, which functions to complete the electrochemical circuit with the working electrode.

For LIB testing, the electrolyte used was $1 \mathrm{M} \mathrm{LiPF}_{6}$ in ethylene carbonate (EC): ethyl methyl carbonate (EMC): dimethyl carbonate (DMC) $(1: 1: 1, \mathrm{v} / \mathrm{v} / \mathrm{v})$. For NIB testing, the electrolyte used was $1 \mathrm{M} \mathrm{NaClO}_{4}$ in Ethylene Carbonate (EC): Propylene Carbonate (PC) $(1: 1 \mathrm{v} / \mathrm{v})$ with $5 \mathrm{wt} \%$ Fluoroethylene Carbonate (FEC) additive, prepared inside the Ar-filled glove box. As mentioned above, both lithium and sodium metal foils are utilized as the reference and counter electrode during coin cell fabrication. The excess presence of $\mathrm{Li}^{+}$and $\mathrm{Na}^{+}$will help maintain a constant and semi-infinite situation in the entire setup. A schematic of the coin cell can be found in Figure 3.7 


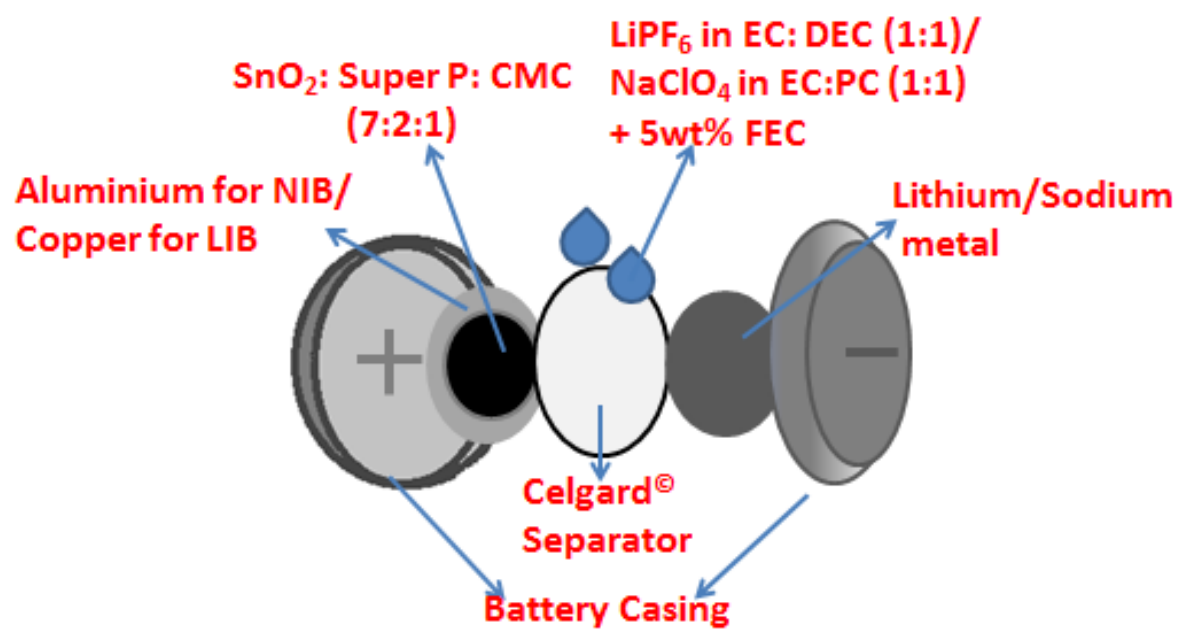

Figure 3.7 A schematic of the coin cell and its components for both $\mathrm{Li}$ and $\mathrm{Na}$ ion battery.

\subsubsection{Ex-situ measurements}

In Chapter 5, ex-situ synchrotron characterizations were carried out, where $\mathrm{SnO}_{2}$ and $\mathrm{N}$-doped $\mathrm{SnO}_{2}$ anode materials at pristine and different charged/discharged state was sealed in Kapton tapes for measurements. The samples at various charged/discharged states were prepared by the following method. The cells were cycled to the point of interest in the respective electrochemical profiles before disassembly in the Ar-filled glove box. The electrodes are washed with dimethyl carbonate (Sigma-Aldrich, anhydrous, $>99 \%$ ) to remove excess $\mathrm{Li}^{+}$and electrolyte from the electrode surface. The electrodes are left to dry overnight in the glovebox before sealing with Kapton ${ }^{\mathrm{TM}}$ tape, followed by thermally sealing within an aluminum pouch to minimize contamination during transportation of samples.

\subsubsection{Galvanostatic cycling}

The galvanostatic charge/discharge tests were performed using battery-testing equipment (Neware Electronic Co., China) at different current densities with a cut-off voltage window of $0.01-3.00 \mathrm{~V}$ vs. $\mathrm{Li}^{+} / \mathrm{Li}$ or $\mathrm{Na}^{+} / \mathrm{Na}$. This method allows us to quantitatively measure the specific capacity of a material. It applies 
a constant current to the working electrode while monitoring the voltage change with respect to the reference electrode (i.e. $\mathrm{Li}$ or $\mathrm{Na}$ metal foil). The results are plotted out in a voltage vs. specific capacity plot, where the energy density of the active material could be estimated. For anode materials, the cycling begins with a discharge process, where lithiation/sodiation takes place and vice versa. This method also allows us to calculate the coulombic efficiency of the cell. In half-cell anode testing, this is a measure of the ratio between the charge capacity vs. the discharge capacity in a particular cycle. This coulombic efficiency is not to be confused with energy efficiency (where the voltage difference between charge and discharge reactions are also being considered). The rate capability of a particular material could also be measured by varying different current density during testing. This technique helps us to evaluate the response of various materials under different charging/discharging timings. As have been described in Chapter 2, the ionic size of $\mathrm{Na}^{+}$is much larger compared to $\mathrm{Li}^{+}$and hence, more sluggish rate capabilities is to be expected. Therefore, the maximum current subjected to LIB and NIB testing would be $10 \mathrm{~A} \mathrm{~g}^{-1}$ and 2 $\mathrm{A} \mathrm{g}^{-1}$ respectively.

\subsubsection{Cyclic voltammetry}

Cyclic voltammetry $(\mathrm{CV})$ is carried out by subjecting the coin cell to small increments in voltage and measuring the corresponding current generated from the electrode (Figure 3.8). Through observation of current jump across certain potential, the redox potential for faradaic electrochemical reactions could be recorded. Additionally, it can also assist us in detecting the presence of unwanted side reactions. For a material to exhibit excellent reversibility, the $\mathrm{CV}$ curves in different cycles should demonstrate excellent overlapping, indicating no current/active material loss during cycling. While this method can help identify the redox species when conducted at low scan rates (often at $0.1 \mathrm{mV} \mathrm{s}^{-}$ $\left.{ }^{1}\right)$, scanning the samples at high scan rates $\left(5-10 \mathrm{mV} \mathrm{s}^{-1}\right)$ or increasing scan rates could help elucidate the kinetics of the particular electrochemical reaction. 
For instance, in Chapter 5, we utilized power law to investigate the impact of nitrogen doping during lithiation of $\mathrm{SnO}_{2}$. Peak currents were plotted against increasing scan rate according to the power $\operatorname{law}, \log i_{p}=b \log v+\log a$, where $i_{p}$ is the peak current, $\mathrm{v}$ is the scan rate, while $\mathrm{a}$ and $\mathrm{b}$ are adjustable parameters obtained from the y-intercept and gradient, respectively. The scan rates were varied at $0.1,0.2,0.5,1,2,5,10 \mathrm{mV} \mathrm{s}^{-1}$ for all samples. In the situation where $\mathrm{b}$ $=0.5$, the current is mainly limited by semi-infinite linear diffusion. A value of $\mathrm{b}=1$ would imply that majority of the capacity is contributed in a surface controlled reaction, which also implies that reaction rate is rapid. ${ }^{6}$ All $\mathrm{CV}$ measurements were performed using Solartron 1260 (UK) instrument.

(a)

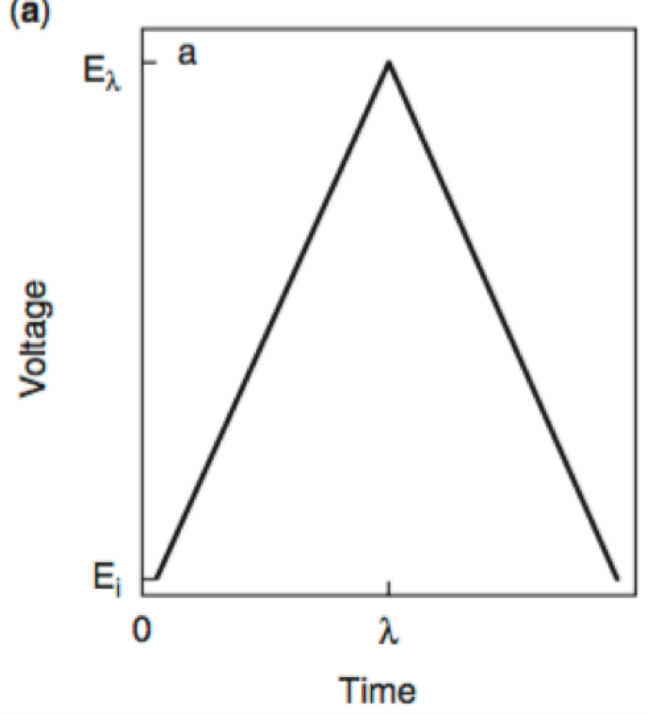

(b)

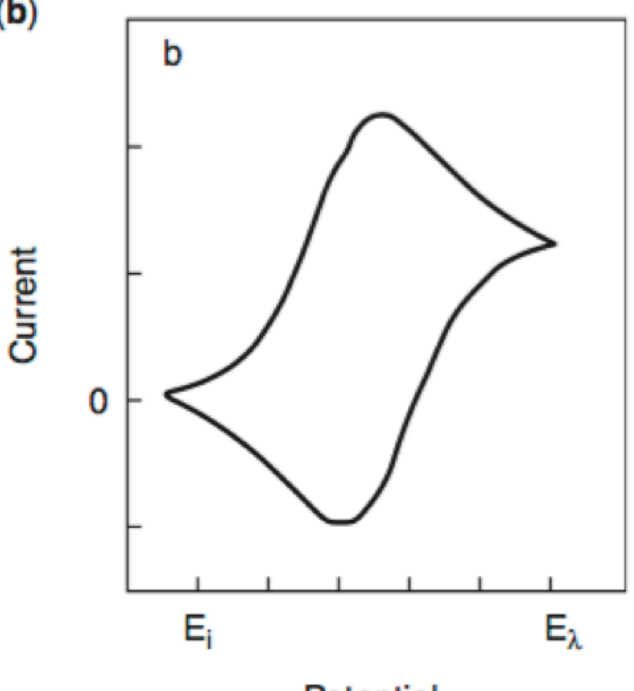

Potential

Figure 3.8 (a) Linear increase in potential with respect to time that is commonly used in CV experiments. (b) The corresponding current response during voltage sweep in $\mathrm{CV}$ with respect to the applied potential. ${ }^{7}$

\section{References:}

1. K. E. Lewis, D. M. Golden and G. P. Smith, Journal of the American Chemical Society, 1984, 106, 3905-3912.

2. S. Kim, C. Hwang, S. Y. Park, S.-J. Ko, H. Park, W. C. Choi, J. B. Kim, D. S. Kim, S. Park, J. Y. Kim and H.-K. Song, Journal of Materials Chemistry A, 2014, 2, 18070-18075. 
3. S. Veintemillas-Verdaguer, M. P. Morales and C. J. Serna, Materials Letters, 1998, 35, 227-231.

4. M. Birkholz, in Thin Film Analysis by X-Ray Scattering, Wiley-VCH Verlag GmbH \& Co. KGaA, 2006, DOI: 10.1002/3527607595.ch1, pp. 1-40.

5. G. S. Bumbrah and R. M. Sharma, Egyptian Journal of Forensic Sciences, DOI: http://dx.doi.org/10.1016/j.ejfs.2015.06.001.

6. V. Augustyn, J. Come, M. A. Lowe, J. W. Kim, P.-L. Taberna, S. H. Tolbert, H. D. Abruña, P. Simon and B. Dunn, Nat Mater, 2013, 12, 518-522.

7. A. B. Bocarsly, in Characterization of Materials, John Wiley \& Sons, Inc., 2002, DOI: 10.1002/0471266965.com050.pub2. 


\section{Chapter 4}

\section{Investigation and evaluation on the electrochemical performance of $\mathrm{rGO}^{-\mathrm{SnO}_{2}}$ synthesized from a facile one-pot laser pyrolysis method}

Loading active materials onto graphene sheets have been well explored for enhancing the overall electrochemical performance. However, methods to prepare such composites are often tedious and time-consuming. In this chapter, we carry out the synthesis of $r G O$ $\mathrm{SnO}_{2}$ (reduced graphene oxide-tin dioxide) nanocomposite through laser pyrolysis. The nanocomposite demonstrated exceptional electrochemical energy storage behavior in both LIB and NIB. The system of $\mathrm{SnO}_{2}$ nanoparticles deposited onto the surface of $r G O$ synergistically leads to enhanced conductivity and a better buffer for mitigating strain induced during conversion \& alloying reactions.

*Experimental data collection was done at CEA Saclay (IRAMIS)

**This section comprises of data that for a patent that is currently in submission. 
One pot laser pyrolysis of $\mathrm{SnO}_{2} @$ rGO composite (@CEA Saclay) Chapter 4

\subsection{Introduction}

As have been reviewed in Chapter $2, \mathrm{SnO}_{2}$ has been extensively studied as an anode material owing to its electrochemical compatibility in both LIB and NIB. Nevertheless, while it is capable of exhibiting high specific capacity at a low operating potential (which translates to high energy density), its poor cycling performance is still subpar when compared to other anode materials. ${ }^{1,2}$ The preparation of graphene-based composites have been demonstrated to be capable of enhancing the overall electrochemical performance of battery materials. ${ }^{3-6}$ These composites synergize the excellent electrical conductivity, remarkable tensile strength and flexibility of carbon-based materials along with the excellent reactivity and high theoretical capacity of metal oxides into one., 7 However, most of the commonly reported synthetic methods for graphenebased composites require time-consuming and tedious preparation processes.

As compared to wet-chemical methods that require washing and drying steps, laser pyrolysis is a surfactant-free physical vapor nanoparticle synthesis technique where an infrared $\mathrm{CO}_{2}$ laser is used to excite a precursor or a photosensitizer gas (e.g. $\mathrm{C}_{2} \mathrm{H}_{4}, \mathrm{SF}_{6}$ ), which energetically collides and results in

decomposition of precursor molecules. ${ }^{8-14}$ The large thermal gradient between the limited reaction zone and the chamber wall, combined with the short residence time of precursors and growing species, prevents growth during the synthesis process. Moreover, the rapid synthesis process, operating in a continuous flow, can reach up to $1 \mathrm{~kg} \mathrm{~h}^{-1}$ in industrial pilot equipment. ${ }^{12}$ The flexibility of this technique permits synthesis of a wide variety of materials, including oxides, ${ }^{10}$ carbides $^{12}$, and elemental nanoparticles. ${ }^{9}$

In retrospect to previous attempts for the synthesis of $\mathrm{SnO}_{2}$ nanoparticles using laser pyrolysis, we found that the reported works require either the use of toxic and expensive precursors ${ }^{15}$ or need a two-step pyrolysis-annealing process ${ }^{16}$. Herein, we demonstrate the synthesis of $\mathrm{rGO}-\mathrm{SnO}_{2}$ (reduced graphene oxidetin dioxide) nanoparticles from a one-pot laser pyrolysis method utilizing costeffect precursors. The as-synthesized nanocomposite delivered exceptional 
One pot laser pyrolysis of $\mathrm{SnO}_{2} @$ rGO composite (@CEA Saclay) Chapter 4

electrochemical performance owing to additional capacity contribution from rGO. Furthermore, the presence of $\mathrm{SnO}_{2}$ nanoparticles deposited onto the surface of rGO synergistically leads to enhanced conductivity and a better buffer for mitigating strain induced during conversion \& alloying reactions.

\subsection{Synthesis}

\subsubsection{Chemicals}

Tin (IV) chloride pentahydrate $\left(\mathrm{SnCl}_{4} \bullet 5 \mathrm{H}_{2} \mathrm{O}\right)$ was purchased and received from Sigma-Aldrich without further purification. Sodium hydroxide $(\mathrm{NaOH})$ was purchased and received from Normapur, France without further purification. Graphene oxide (GO) was bought and received from Graphenea, Spain without further purification. Air, argon (Ar), ethylene gas $\left(\mathrm{C}_{2} \mathrm{H}_{4}\right)$ and ammonia gas $\left(\mathrm{NH}_{3}\right)$ were purchased and received from Messer, France without further purification. Coin cell components and etched copper/aluminum foils were purchased from MTI corp. and used as received.

\subsubsection{Laser pyrolysis for synthesis of $\mathrm{SnO}_{2}$ and $\mathrm{rGO}-\mathrm{SnO}_{2}$}

For the preparation of $\mathrm{SnCl}_{4}$ precursor solution, $0.25 \mathrm{M} \mathrm{SnCl}_{4} \cdot 5 \mathrm{H}_{2} \mathrm{O}$ was dissolved in $300 \mathrm{ml}$ of deionized water $\left(\mathrm{DI} \mathrm{H}_{2} \mathrm{O}\right)$ under vigorous stirring to form the aerosol solution. For the preparation of $\mathrm{Sn}(\mathrm{OH})_{4}$ precursor solution, $0.1 \mathrm{M} \mathrm{SnCl}_{4} \cdot 5 \mathrm{H}_{2} \mathrm{O}$ is first dissolved in $300 \mathrm{ml}$ of deionized water $\left(\mathrm{DI} \mathrm{H}_{2} \mathrm{O}\right)$ under vigorous stirring. Subsequently, $0.1 \mathrm{M}$ of $\mathrm{NaOH}$ is added to the solution pellet by pellet. After reaction for $30 \mathrm{~min}$, a white suspension will be produced. The solution is washed with $\mathrm{DI} \mathrm{H}_{2} \mathrm{O}$ followed by absolute ethanol before dilution in $150 \mathrm{ml}$ of $\mathrm{DI} \mathrm{H}_{2} \mathrm{O}$ again. For the preparation of $\mathrm{GO}-\mathrm{Sn}(\mathrm{OH})_{4}$ precursor solution, the as-prepared $\mathrm{Sn}(\mathrm{OH})_{4}$ solution was dispersed in $150 \mathrm{ml}$ of graphene oxide $(\mathrm{GO})$ and further diluted with another $300 \mathrm{ml}$ of $\mathrm{DI} \mathrm{H}_{2} \mathrm{O}$ to reduce solution viscosity.

The procedure for laser pyrolysis is as depicted in the previous Figure 3.1. The pressure within the reaction chamber was kept constant at $\sim 740$ Torr throughout 
One pot laser pyrolysis of $\mathrm{SnO}_{2} @$, rGO composite (@,CEA Saclay) Chapter 4

the entire experiment and the laser power was set up at 1980-1995 W. For the synthesis of pristine $\mathrm{SnO}_{2}$ nanoparticles, air (5.5 $\mathrm{slm}$ (standard litres per min)) and $\mathrm{C}_{2} \mathrm{H}_{4}(0.3 \mathrm{slm})$ were used as carrier and sensitizer gasses respectively. For the synthesis of $\mathrm{rGO}-\mathrm{SnO}_{2}$ nanocomposites, Argon $(5.5 \mathrm{slm})$ and $\mathrm{C}_{2} \mathrm{H}_{4}(0.3 \mathrm{slm})$ were used as carrier and sensitizer gases respectively. The utilization of Ar gas for the synthesis of $\mathrm{rGO}-\mathrm{SnO}_{2}$ is to prevent the combustion of $\mathrm{GO}$ with air.

\subsection{Physical characterization}

Initially, $\mathrm{SnCl}_{4}$ was directly utilized as a precursor for the synthesis of $\mathrm{SnO}_{2}$ nanoparticles. The parameters for synthesis when using $\mathrm{SnCl}_{4}$ directly as precursor were: air as carrier gas $(5.5 \mathrm{slm})$ and $\mathrm{C}_{2} \mathrm{H}_{4}(0.3 \mathrm{slm})$ as sensitizer gas. The as-synthesized product was first characterized via XRD and is as shown in Figure 4.1. The product (labeled $\mathrm{OSnO} 2$ ) was then compared against the JCPDS standards of tetragonal $\mathrm{SnO}_{2}, \mathrm{SnCl}_{2} \cdot 2 \mathrm{H}_{2} \mathrm{O}$ and $\mathrm{SnO}$. As could be seen, the as-synthesized products exactly match that of $\mathrm{SnCl}_{2} \cdot 2 \mathrm{H}_{2} \mathrm{O}$ instead of $\mathrm{SnO}_{2}$. Intrigued by the results, two different possibilities were hypothesized for not obtaining the desired $\mathrm{SnO}_{2}$ nanoparticles. Firstly, the formation of $\mathrm{SnCl}_{2}$ instead of $\mathrm{SnO}_{2}$ could be attributed to a lower Gibbs free energy of $\mathrm{SnCl}_{2} \cdot 2 \mathrm{H}_{2} \mathrm{O}$ compared to $\mathrm{SnO}_{2}$, i.e. $\Delta \mathrm{G}_{\mathrm{SnCl} 2 \cdot 2 \mathrm{H} 2 \mathrm{O}}(-760.5 \mathrm{~kJ} / \mathrm{mol})$ vs. $\Delta \mathrm{G}_{\mathrm{SnO} 2}(-516.640$ $\mathrm{kJ} / \mathrm{mol}) .{ }^{17}$ The other reason could be due to the short residence time that $\mathrm{SnCl}_{4}$ precursors spend in the pyrolysis chamber, hence an inadequate time for oxidation to occur. Therefore, a combination of the two reasons could have prevented the formation of $\mathrm{SnO}_{2}$ nanoparticles.

To prevent the chlorination of Sn during laser pyrolysis, a pre-dechlorination step was carried out by reaction of $\mathrm{SnCl}_{4}$ with aqueous $\mathrm{NaOH}$ in stoichiometric amounts. The resultant solution would consist of a $\mathrm{Sn}(\mathrm{OH})_{4}$ suspension dispersed within a $\mathrm{NaCl}$ solution. $\mathrm{NaCl}$ was removed via centrifugation and the $\mathrm{Sn}(\mathrm{OH})_{4}$ was immediately dispersed within DI $\mathrm{H}_{2} \mathrm{O}$ before use as a precursor. A flow diagram illustrating the preparation-pyrolysis process is shown in Figure 4.2 . 
One pot laser pyrolysis of $\mathrm{SnO}_{2} @$, rGO composite (@CEA Saclay) Chapter 4

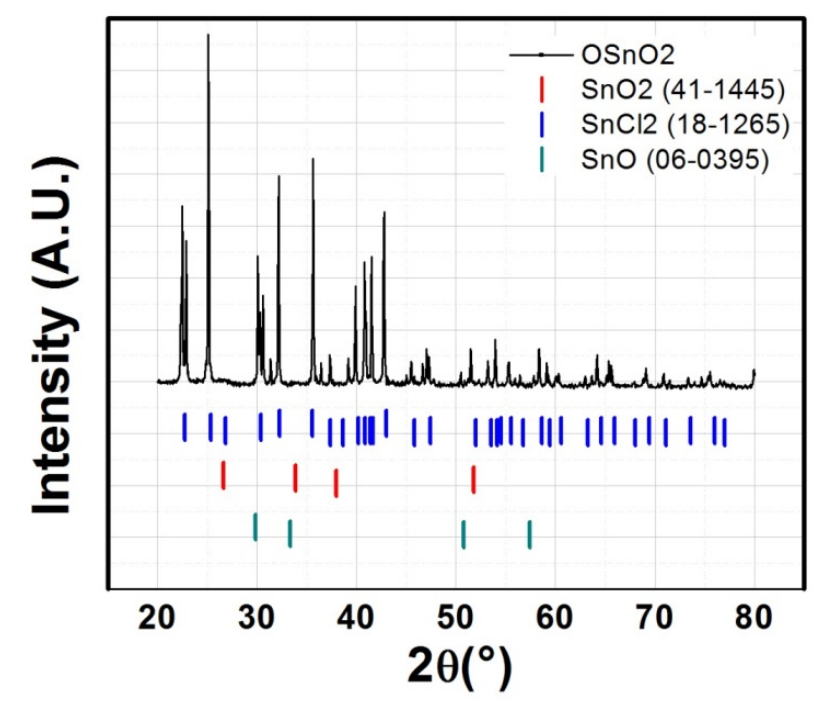

Figure 4.1 XRD pattern after using $\mathrm{SnCl}_{4}$ as a precursor for laser pyrolysis in air (5.5 slm) and $\mathrm{C}_{2} \mathrm{H}_{4}(0.3 \mathrm{slm})$. OSnO2 corresponds to the product and compared to JCPDS standards of tetragonal $\mathrm{SnO}_{2}, \mathrm{SnCl}_{2} \cdot 2 \mathrm{H}_{2} \mathrm{O}$ and $\mathrm{SnO}$.
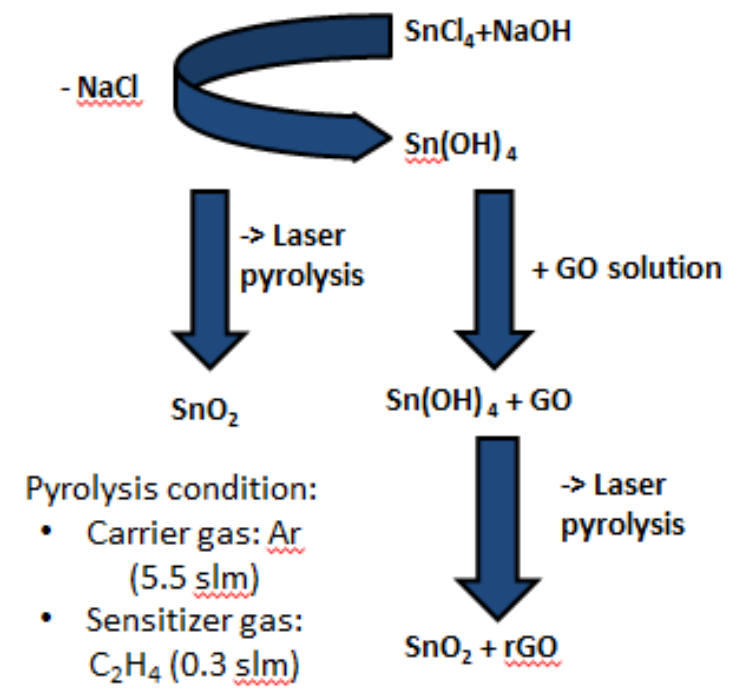

Figure 4.2 Flow diagram illustrating the synthesis pathway for $\mathrm{SnO}_{2}$ and $\mathrm{rGO}-\mathrm{SnO}_{2}$

The as-synthesized powders were first characterized via XRD as shown in Figure 4.3. The pattern for pristine $\mathrm{SnO}_{2}$ could be well matched to that of tetragonal $\mathrm{SnO}_{2}$ (JCPDS 41-1445). The broad background signal between 20 $40^{\circ}$ in the pristine $\mathrm{SnO}_{2}$ sample is attributed to the contribution from the XRD holder. On the other hand, the $\mathrm{rGO}-\mathrm{SnO}_{2}$ nanocomposite displayed broader and 
weaker peaks compared to pristine $\mathrm{SnO}_{2}$, signifying poorer crystallinity or smaller nanoparticles. Nevertheless, the main peaks are still present which can help identify that the $\mathrm{rGO}-\mathrm{SnO}_{2}$ nanocomposite is still largely made up of $\mathrm{SnO}_{2}$. Similarly, the broad peak from $20-40^{\circ}$ could also be attributed to the XRD glass holder contribution. Interestingly, the characteristic peak of rGO at 24-28 could not be observed in the composite. It could be due to the overlapping peaks from $\mathrm{SnO}_{2}$ and/or low rGO content within the nanocomposite.

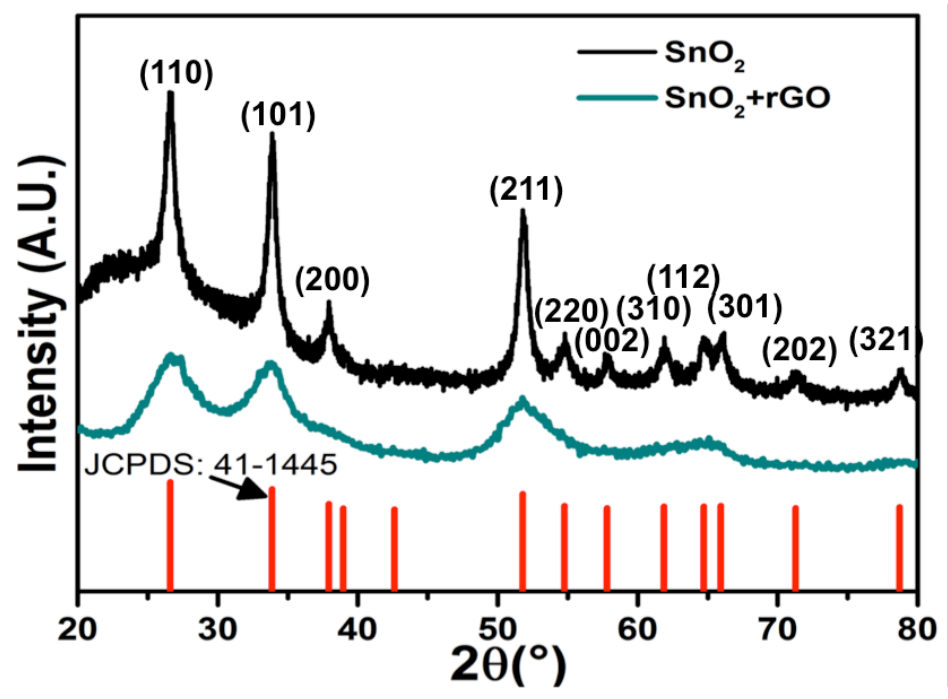

Figure 4.3 XRD pattern of pristine $\mathrm{SnO}_{2}$ and $\mathrm{rGO}-\mathrm{SnO}_{2}$ prepared using $\mathrm{Sn}(\mathrm{OH})_{4}$ as precursor.

Thereafter, electron microscopy (Figure 4.4) was performed to investigate the morphology of both samples. As could be seen from the SEM image of pristine $\mathrm{SnO}_{2}$ in Figure 4.4a, the sample is made up of smaller individual balls of agglomerated nanoparticles of size between 300 to $600 \mu \mathrm{m}$. It is also observable from the inset image that the agglomerated islands possess a fluffy surface with loose ends of nanoparticles. The loose connection of particles is exemplified using TEM as seen in Figure 4.4b. The nanoparticles with sizes approximately 8 to $30 \mathrm{~nm}$, appears to be connected with one another. Gaps are also apparent between nanoparticles, indicating that agglomeration does not occur. Additionally, these gaps could be beneficial for $\mathrm{Li}^{+} / \mathrm{Na}^{+}$transport during 
One pot laser pyrolysis of $\mathrm{SnO}_{2} @$, rGO composite (@CEA Saclay) Chapter 4

charging/discharging process, giving rise to enhanced rate capabilities. Figure $4.4 \mathrm{c}$ displays the SEM image of the $\mathrm{rGO}-\mathrm{SnO}_{2}$ nanocomposite. In the picture, no separate rGO sheets could be observed. However, in the diagonal direction, we can point out a templated structure growing upwards. This could hint that the $\mathrm{SnO}_{2}$ particles fully cover the rGO sheets and are hard to observe. TEM image of the nanocomposites (Figure 4.4d) further supports our claim on the whereabouts of rGO. It is noticeable that there are sheets of $\mathrm{rGO}$ with $\mathrm{SnO}_{2}$ nanoparticles loaded onto it. Furthermore, the sizes of the $\mathrm{SnO}_{2}$ nanoparticles in rGO-SnO $\mathrm{S}_{2}$ nanocomposite are much smaller as compared to the pristine $\mathrm{SnO}_{2}$ nanoparticles. This might be attributed to the fact that a portion of the blackbody radiation could be used to reduce the $\mathrm{GO}$, hence the $\mathrm{Sn}(\mathrm{OH})_{4}$ precursors in the composite might not be able to crystallize to a large extent. This is also evident in the above XRD data.
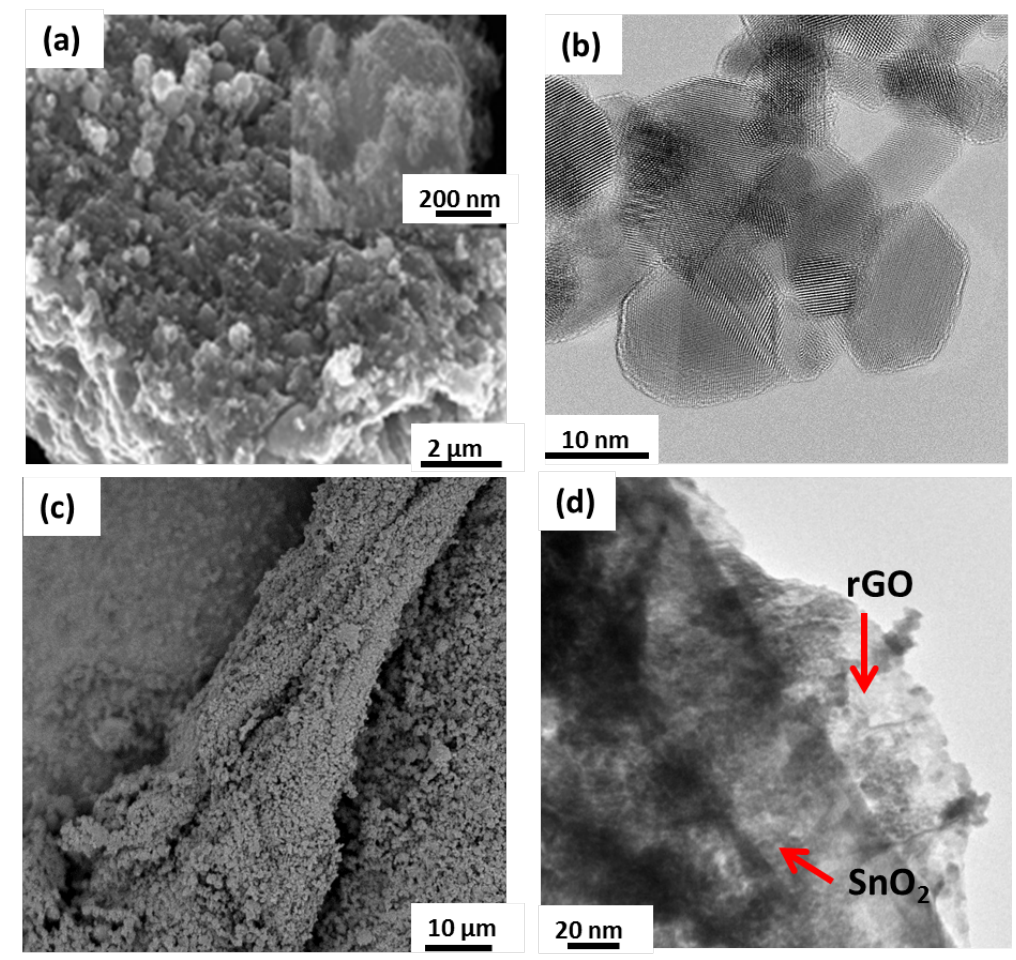

Figure 4.4 Scanning electron microscope (SEM) and transmission electron microscope (TEM) of (a-b) pristine $\mathrm{SnO}_{2}$ (c-d) $\mathrm{rGO}_{-} \mathrm{SnO}_{2}$. Inset in (a) is a magnified view of the $\mathrm{SnO}_{2}$ nano particulates 
TGA (Figure 4.5a) was carried out in an air environment to measure the amount of $\mathrm{rGO}$ that was present within the nanocomposite. For the pristine $\mathrm{SnO}_{2}$ nanoparticles, it could be observed that there was negligible mass loss up to $700{ }^{\circ} \mathrm{C}$. On the other hand, the nanocomposite presented a mass loss of $19 \%$ within the temperature range between $400-600{ }^{\circ} \mathrm{C}$, which corresponds to the combustion of rGO into $\mathrm{CO}_{2}{ }^{18}$ Raman spectroscopy (Figure 4.5b) was also carried out to probe into the reduction of GO into rGO. Raman bands at $\sim 1600$ $\mathrm{cm}^{-1}$ (G-band) have been ascribed to be the vibration of $\mathrm{sp}^{2}$ carbon atoms, i.e. graphene layer in graphite. The other band located at $\sim 1370 \mathrm{~cm}^{-1}$ has been known to describe the defects present within the material. An $I_{D} / I_{G}$ intensity ratio that is $\geq 1$ in our nanocomposite indicates that GO has been successfully reduced into reduced graphene oxide. ${ }^{18-20}$
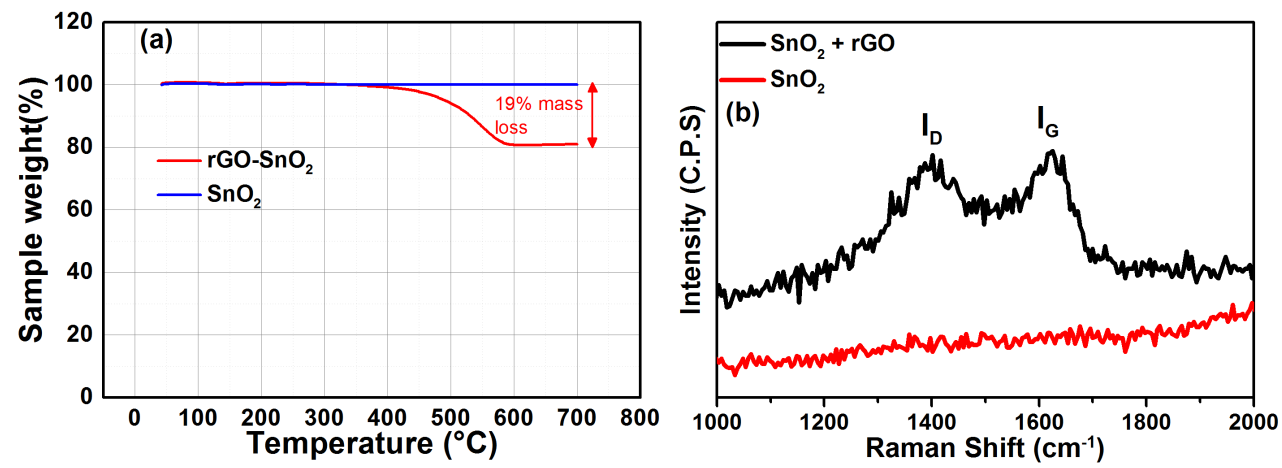

Figure 4.5 (a) Thermogravimetric analysis (TGA) and (b) Raman spectroscopy of $\mathrm{SnO}_{2}$ and $\mathrm{rGO}-\mathrm{SnO}_{2}$

XPS was utilized to probe into the redox state of laser pyrolyzed $\mathrm{SnO}_{2}$ and rGO-SnO ${ }_{2}$, with peaks calibrated to $\mathrm{C} 1 \mathrm{~s}$ peak at $284.8 \mathrm{eV}$ before analysis. The spectrum in Figure 4.6 illustrates the $\mathrm{Sn} 3 \mathrm{~d}$ peak positions of both $\mathrm{SnO}_{2}$ and rGO-SnO ${ }_{2}$. Both plots displayed great overlap between the fitting curve and the obtained data, indicating that only 1 set of $\mathrm{Sn}$ species (i.e. $\mathrm{Sn}^{4}+$ ) is present in both samples. This also shows that the presence of rGO does not result in reduction $\mathrm{Sn}^{4+}$ into $\mathrm{Sn}^{2+}$ or $\mathrm{Sn}^{0}$. 


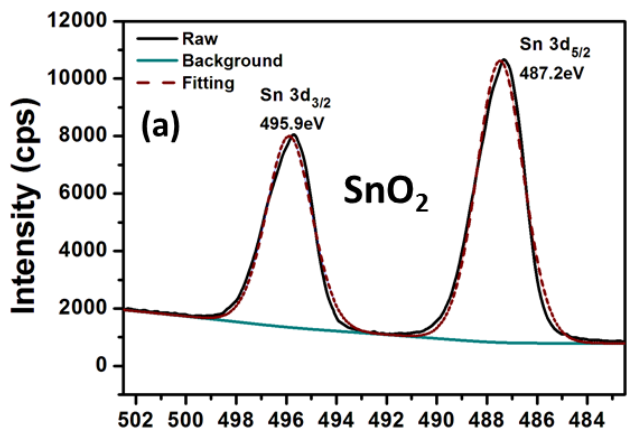

Binding Energy (eV)

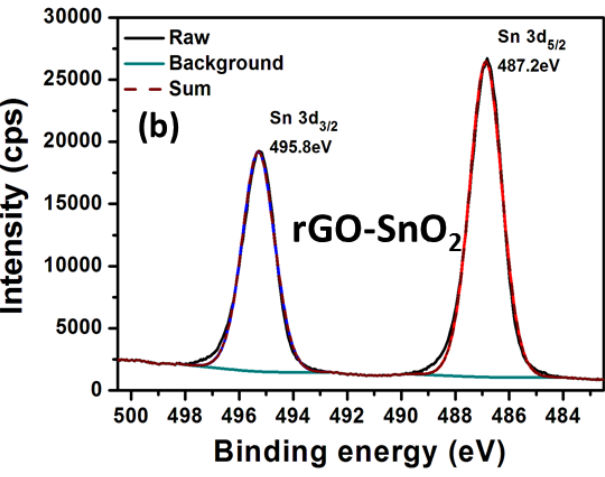

Figure 4.6 Binding energy values of $\mathrm{Sn} 3 \mathrm{~d}$ measured from X-ray photoelectron spectroscopy (XPS) for (a) pristine $\mathrm{SnO}_{2}$ and (b) $\mathrm{rGO}-\mathrm{SnO}_{2}$.

\subsection{Electrochemical measurements}

\subsubsection{Cyclic voltammetry}
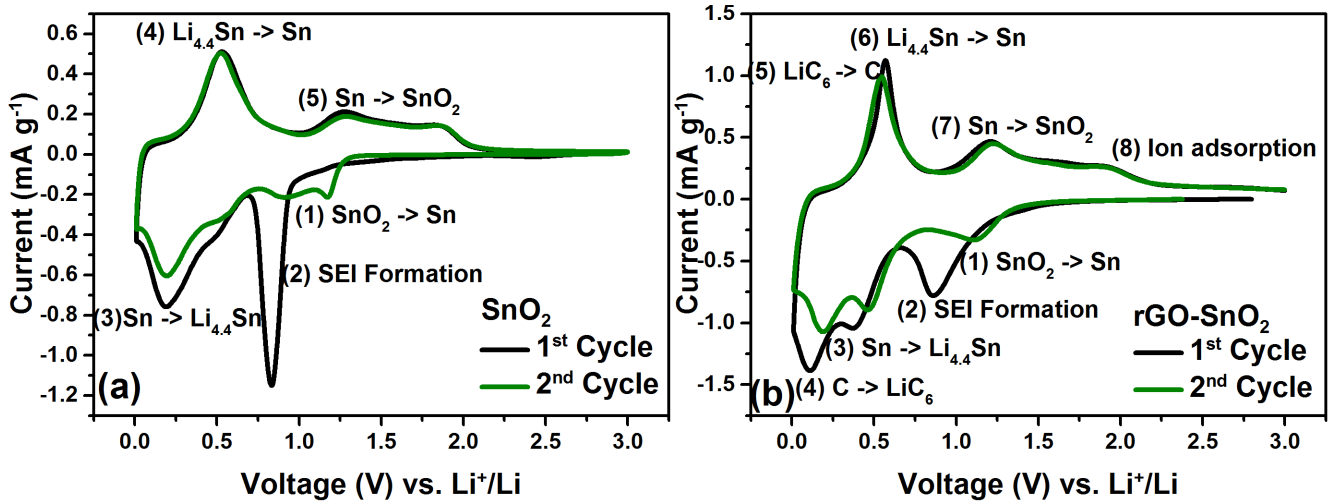

Figure 4.7 Cyclic voltamogram (CV) of (a) $\mathrm{SnO}_{2}$ and (b) $\mathrm{rGO}^{-\mathrm{SnO}_{2}}$ in LIB at a scan rate of $0.1 \mathrm{mV} \mathrm{s}^{-1}$

Figure 4.7 illustrates the $\mathrm{CV}$ diagrams for both pristine $\mathrm{SnO}_{2}$ and $\mathrm{rGO}-\mathrm{SnO}_{2}$ in LIB at a scan rate of $0.1 \mathrm{mV} \mathrm{s}^{-1}$ In the first cathodic process; both profiles demonstrate a peak at $0.70 \mathrm{~V}$ that could be assigned to the reduction of $\mathrm{SnO}_{2}$ to Sn and the formation of solid electrolyte interface (SEI) layer. The other reduction peak at $0.3-0.4 \mathrm{~V}$ could be attributed to the alloying process for the formation of $\mathrm{Li}_{\mathrm{x}} \mathrm{Sn}(0 \leq \mathrm{x} \leq 4.4)$. In the case of $\mathrm{rGO}-\mathrm{SnO}_{2}$ nanocomposite (Figure 4.7b), the alloying process occurs at lower overpotential due to presence of highly conductive rGO sheets. In addition, intercalation behavior attributed 
One pot laser pyrolysis of $\mathrm{SnO}_{2} @$, rGO composite (@CEA Saclay) Chapter 4

to the insertion of $\mathrm{Li}^{+}$into layers of graphene could also be observed near 0.20 $\mathrm{V}$ for the $\mathrm{rGO}-\mathrm{SnO}_{2}$ nanocomposite. In the first anodic process, the strong peak at $0.5 \mathrm{~V}$ corresponds to the dealloying process of $\mathrm{Li}_{\mathrm{x}} \mathrm{Sn}$ and delithiation of $\mathrm{rGO}$, while the broad peak at $1.35 \mathrm{~V}$ can generally be ascribed to the oxidation of $\mathrm{Sn}$ back into $\mathrm{SnO}_{2}{ }^{21,22}$ Additionally, it is observable that there is current response in $\mathrm{rGO}-\mathrm{SnO}_{2}$ when charged above $2.0 \mathrm{~V}$. This additional current contribution comes from ion adsorption, similar to that of electrochemical double layer capacitance and will be elaborated in later part of the chapter.
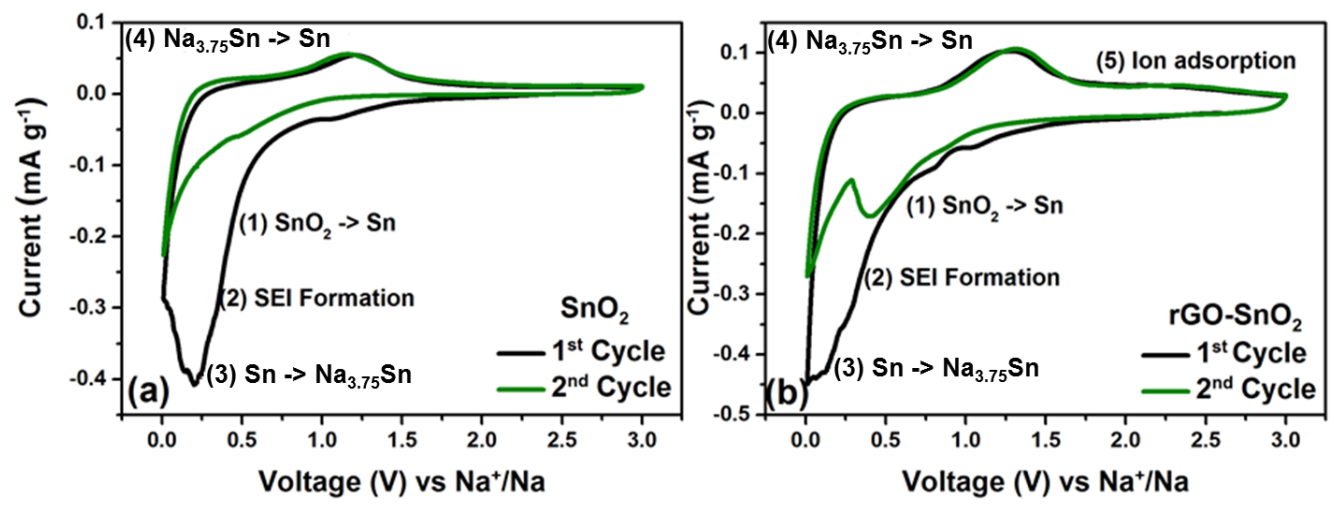

Figure 4.8 Cyclic voltammogram (CV) of (a) $\mathrm{SnO}_{2}$ and (b) $\mathrm{rGO}-\mathrm{SnO}_{2}$ in $\mathrm{NIB}$ at a scan rate of $0.1 \mathrm{mV} \mathrm{s}^{-1}$

Similar to LIB, the CV profiles (Figure 4.8) for both pristine $\mathrm{SnO}_{2}$ and rGO$\mathrm{SnO}_{2}$ in NIB exhibits a broad peak starting from $1.0 \mathrm{~V}$, corresponding to the formation of the SEI and the reduction of $\mathrm{SnO}_{2}$ into $\mathrm{Sn}$. Following that, alloying reaction between $\mathrm{Sn}$ and $\mathrm{Na}$ takes place at $\sim 0.1 \mathrm{~V}$ to form $\mathrm{Na}_{3.75} \mathrm{Sn}$. In the reverse anodic process, dealloying process occurs at $\sim 0.9-1.5 \mathrm{~V}$ in a view to yield metallic Sn. Due to the narrow interlayer spacing between graphene sheets, intercalation of $\mathrm{Na}^{+}$is thermodynamically not possible for unexpanded graphene sheets. ${ }^{23}$ It is observable that there is an additional broad peak in Figure $4.8 \mathrm{~b}$ at voltage $\sim 0.4 \mathrm{~V}$ in the cathodic sweep. The presence of this peak could be due to a shift in Sn-redox position that is resultant from the enhancement in conductivity in the $\mathrm{rGO}-\mathrm{SnO}_{2}$ nanocomposites which results in less polarization. This is also validated in the reverse oxidation process, where 
the dealloying peak is much sharper as compared to in pristine $\mathrm{SnO}_{2}$. We also rule out the possibility of side reactions happening between functional groups (i.e. $-\mathrm{OH},-\mathrm{COOH},-\mathrm{COC}$-) of graphene sheets as the Raman spectrum has shown that GO has been well reduced into rGO.

\subsubsection{Galvanostatic cycling}
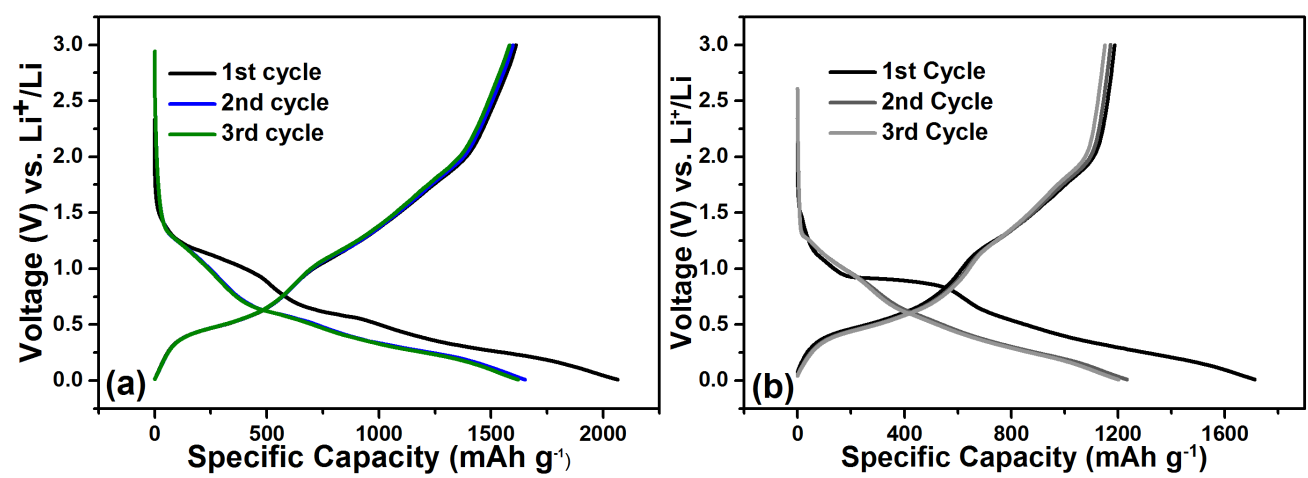

Figure 4.9 Galvanostatic charge-discharge profiles of (a) $\mathrm{rGO}^{-\mathrm{SnO}_{2}}$ nanocomposite and (b) pristine $\mathrm{SnO}_{2}$ in LIB at a current of $100 \mathrm{~mA} \mathrm{~g}^{-1}$. Specific capacities were calculated using the total mass in $\mathrm{SnO}_{2} / \mathrm{rGO}-\mathrm{SnO}_{2}$.

The lithiation properties of $\mathrm{rGO}-\mathrm{SnO}_{2}$ and pristine $\mathrm{SnO}_{2}$ were evaluated through galvanostatic cycling under a constant current of $100 \mathrm{~mA} \mathrm{~g}^{-1}$ as could be seen in Figure 4.9. The initial discharge capacities of $\mathrm{rGO}-\mathrm{SnO}_{2}$ and pristine $\mathrm{SnO}_{2}$ were measured to be 2064 and $1712 \mathrm{mAh} \mathrm{g}^{-1}$ respectively, while the initial C.E for both samples were calculated to be $78.06 \%$ and $69.34 \%$ respectively. The significant capacity loss in the initial cycle is a result of the irreversible consumption of $\mathrm{Li}^{+}$during the formation of SEI layer. The discharge capacities for the second cycle were measured to be 1651 and $1234 \mathrm{mAh} \mathrm{g}^{-1}$ for rGO$\mathrm{SnO}_{2}$ and $\mathrm{SnO}_{2}$ respectively. It can simply be observed from both samples that the discharge profiles in the second and third cycle well overlap one another, indicating excellent lithiation reversibility. The C.E measured in the second cycle for both samples were $97 \%$ and $96 \%$ respectively. Additionally, it is noticeable in the graphene composite that the discharge profile (Figure 4.9a) demonstrates a sloping behavior at above $2.0 \mathrm{~V}$, similar to that of the electrical 
double layer capacitance behavior in supercapacitors that was observed in the above $\mathrm{CV}$ result. Contrastingly, pristine $\mathrm{SnO}_{2}$ showed almost negligible capacity above $2.00 \mathrm{~V}$, which could be due to the absence of high surface area graphene within the composite.
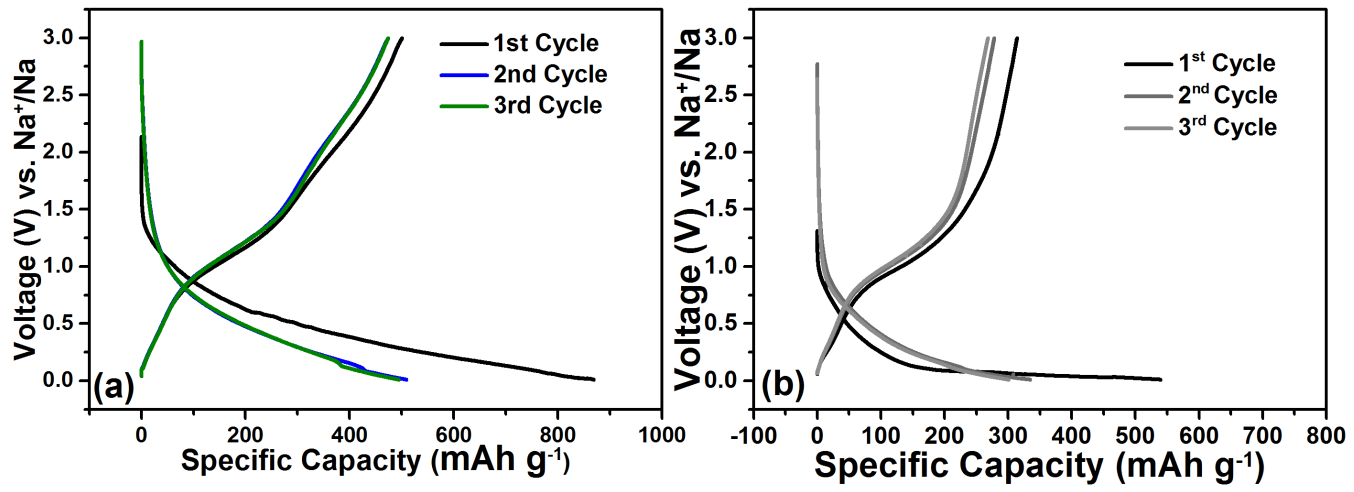

Figure 4.10 Galvanostatic charge-discharge profiles of (a) $\mathrm{rGO}^{-\mathrm{SnO}_{2}}$ nanocomposite and (b) pristine $\mathrm{SnO}_{2}$ in NIB at a current of $30 \mathrm{~mA} \mathrm{~g}^{-1}$ Specific capacities were calculated using the total mass in $\mathrm{SnO}_{2} / \mathrm{rGO}-\mathrm{SnO}_{2}$.

Figure 4.10 illustrates the galvanostatic cycling profiles of $\mathrm{rGO}-\mathrm{SnO}_{2}$ and pristine $\mathrm{SnO}_{2}$ in NIB at a current density of $30 \mathrm{~mA} \mathrm{~g}^{-1}$. The discharge capacity in the first cycle for $\mathrm{rGO}-\mathrm{SnO}_{2}$ and $\mathrm{SnO}_{2}$ are measured to be 869 and $594 \mathrm{mAh}$ $\mathrm{g}^{-1}$ respectively, while the first C.E for both samples are calculated to be $57.65 \%$ and $58.26 \%$ respectively. The following discharge capacities were then measured to be 511 and $334 \mathrm{mAh} \mathrm{g}^{-1}$ respectively. The sodiation discharge capacities measured were far from the calculated theoretical value (i.e. 1378 $\mathrm{mAh} \mathrm{g}^{-1}$ ). This could due to the high thermodynamic barrier that $\mathrm{Na}_{2} \mathrm{O}$ has to undergo for reversible conversion to occur. Hence, only reversible alloying process contributes to the overall capacity in pristine $\mathrm{SnO}_{2}$. 

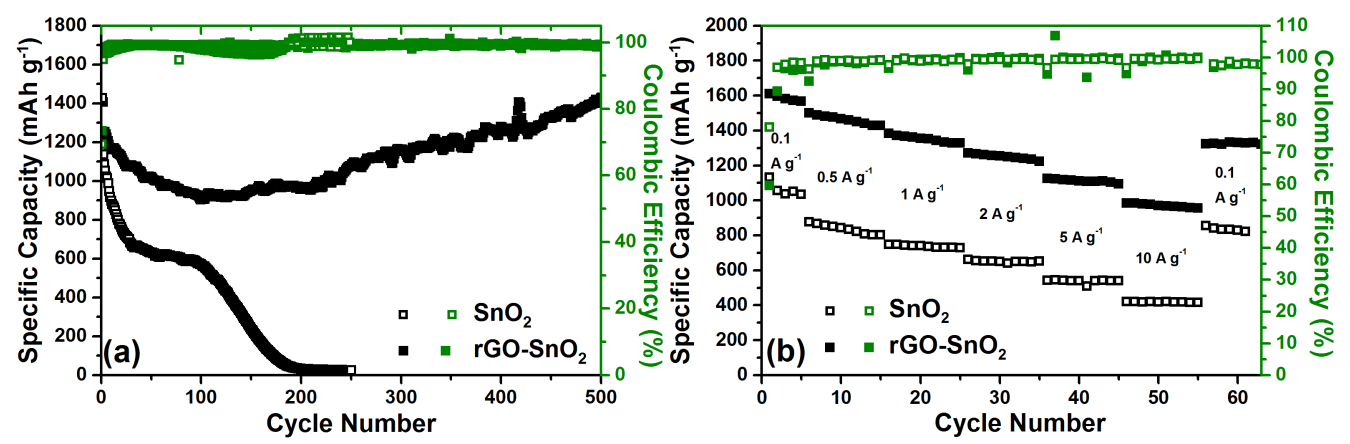

Figure 4.11 (a) Lithiation cycling performance of $\mathrm{rGO}-\mathrm{SnO}_{2}$ and pristine $\mathrm{SnO}_{2}$ at $2 \mathrm{~A}$ $\mathrm{g}^{-1}$ and $1.4 \mathrm{~A} \mathrm{~g} \mathrm{~g}^{-1}$ respectively. (b) Lithiation rate performance of $\mathrm{rGO}_{-} \mathrm{SnO}_{2}$ and pristine $\mathrm{SnO}_{2}$ at various current densities.

The cycling performance of $\mathrm{rGO}-\mathrm{SnO}_{2}$ and pristine $\mathrm{SnO}_{2}$ in LIB is as illustrated in Figure 4.11(a). Excellent cyclability could be observed in the $\mathrm{rGO}-\mathrm{SnO}_{2}$ nanocomposite, with a capacity of $1486 \mathrm{mAh} \mathrm{g}^{-1}$ recorded at the end of 500 cycles, while the capacity for pristine $\mathrm{SnO}_{2}$ nanoparticles dropped down to $\sim 0$ $\mathrm{mAh} \mathrm{g}^{-1}$ by the end of the $200^{\text {th }}$ cycle. Interestingly, an increment in the capacity can be observed that is initiated from approximately the $200^{\text {th }}$ cycle onwards. The increment in capacity can be attributed to the reversible formation of a polymeric gel-like layer from the decomposition of the electrolyte, which opens up new active surface area for lithiation. The superior cyclability and higher specific capacity in the $\mathrm{rGO}-\mathrm{SnO}_{2}$ nanocomposite can be attributed to the presence of graphene, which provides a buffer layer to hold onto the $\mathrm{SnO}_{2}$ nanoparticles to the surface that prevents terminal detachment during pulverization process. Additionally, the presence of intercalation reaction and ion adsorption on the surface of graphene sheets provide additional capacity on top of the redox reaction in $\mathrm{SnO}_{2}$, thus resulting in high specific capacity. The rate capabilities of both samples were also compared in Figure 4.11(b). The general trend shows that the discharge capacities of $\mathrm{rGO}-\mathrm{SnO}_{2}$ at different currents were much higher compared to pristine $\mathrm{SnO}_{2}$. Impressively, the rGO$\mathrm{SnO}_{2}$ nanocomposite delivers an average specific capacity of $973 \mathrm{mAh} \mathrm{g}^{-1}$ at 10 $\mathrm{A}^{-1}$, as compared to only $396 \mathrm{mAh} \mathrm{g}^{-1}$ in pristine $\mathrm{SnO}_{2}$. The enhanced 
conductivity can be correlated with the design of the nanocomposite, where the direct contact between $\mathrm{SnO}_{2}$ and rGO permits direct electron transfer during the redox reaction.
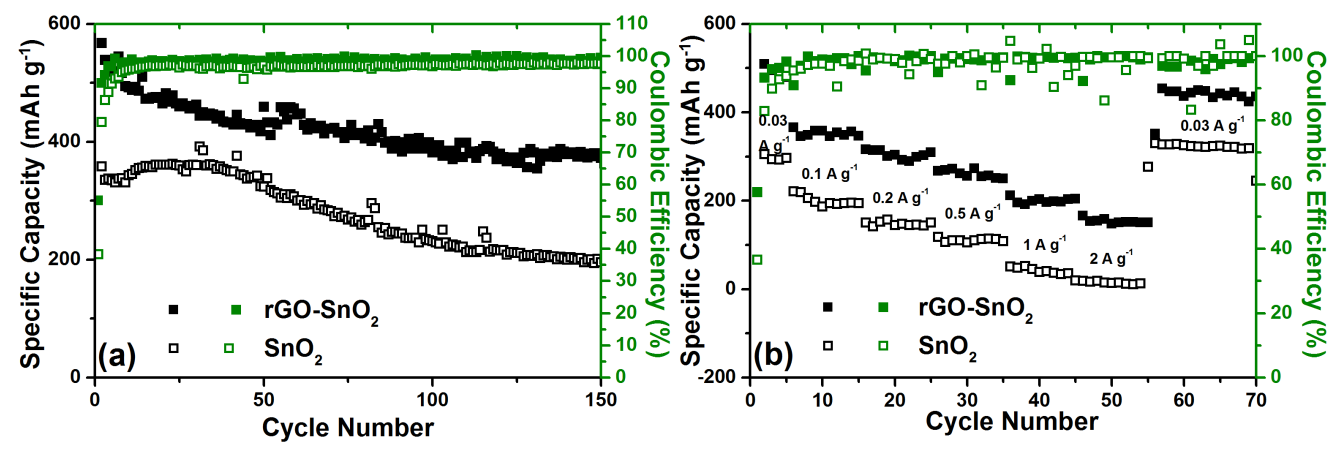

Figure 4.12 (a) Sodiation cycling performance of $\mathrm{rGO}-\mathrm{SnO}_{2}$ and pristine $\mathrm{SnO}_{2}$ at 30 $\mathrm{mA} \mathrm{g}{ }^{-1}$. (b) Sodiation rate performance of $\mathrm{rGO}-\mathrm{SnO}_{2}$ and pristine $\mathrm{SnO}_{2}$ at various current densities.

The long term cycling performances of $\mathrm{rGO}-\mathrm{SnO}_{2}$ and pristine $\mathrm{SnO}_{2}$ in NIB are illustrated in Figure 4.12(a). Capacities of 385 and $199 \mathrm{mAh} \mathrm{g}^{-1}$ were recorded for rGO-SnO $\mathrm{Sn}_{2}$ and pristine $\mathrm{SnO}_{2}$ after 150 cycles respectively. As could be observed, both specimens displayed gradual capacity decay. The capacities retained at the end of the 150th cycle were $66.4 \%$ and $56.9 \%$ of its initial capacity respectively. Despite the presence of graphene, the size expansion for the sodiation of $\mathrm{Sn}$ was perhaps too large, resulting in detachment of active material from conductive surface resulting in an irreversible capacity loss. The rate performances of both samples are illustrated in Figure 4.12(b). When the current density was $2 \mathrm{~A} \mathrm{~g}^{-1}$, the recorded capacity was 172 and $15 \mathrm{mAh} \mathrm{g}^{-1}$ in rGO-SnO 2 and pristine $\mathrm{SnO}_{2}$ respectively. Hence, while graphene fails to mitigate the pulverization effect during sodiation fully, it can still serve a conductive pathway for electron transport during the redox process and enhance the overall electrochemical performance. 
One pot laser pyrolysis of $\mathrm{SnO}_{2} @$ rGO composite (@CEA Saclay) Chapter 4

\subsection{Summary}

In summary, we have demonstrated a one-pot synthesis method for the rapid production of $\mathrm{rGO}-\mathrm{SnO}_{2}$ nanocomposite and $\mathrm{SnO}_{2}$ nanoparticles. Compared to traditional methods such as hydrothermal or electrostatic deposition, the laser pyrolysis method is less time consuming and allows the production of fine nanoparticles. Characterization shows that $\mathrm{rGO}$ in the nanocomposite was successfully reduced. When tested in LIBs and NIBs, excellent electrochemical results could be obtained. The enhanced electrochemical performance in the rGO-SnO ${ }_{2}$ nanocomposite could be attributed to a combination of factors namely: 1) a graphene buffer layer that helps to mitigate stress/strain induced during cycling process while holding on to the $\mathrm{SnO}_{2}$ nanoparticles undergoing pulverization; 2) a direct contact between $\mathrm{SnO}_{2}$ and the graphene layer that provides superior electron pathway during redox processes, thus lowering resistance and overpotential; 3) capacity contribution from additional redox process such as intercalation into layers of graphene and ion adsorption. While the presence of graphene fails to mitigate the pulverization effect during sodiation fully, it can still serve a conductive pathway for electron transport during the redox process and enhance the overall electrochemical performance.

\section{References:}

1. J. Park, J.-W. Park, J.-H. Han, S.-W. Lee, K.-Y. Lee, H.-S. Ryu, K.-W. Kim, G. Wang, J.-H. Ahn and H.-J. Ahn, Materials Research Bulletin, 2014, 58, 186-189.

2. Y. Wang, D. Su, C. Wang and G. Wang, Electrochemistry Communications, 2013, 29, 8-11.

3. H. Cao, X. Zhou, C. Zheng and Z. Liu, ACS Applied Materials \& Interfaces, 2015, 7, 11984-11990.

4. S. L. Candelaria, Y. Shao, W. Zhou, X. Li, J. Xiao, J.-G. Zhang, Y. Wang, J. Liu, J. Li and G. Cao, Nano Energy, 2012, 1, 195-220.

5. K. Chen, S. Song, F. Liu and D. Xue, Chemical Society Reviews, 2015, 44, 62306257.

6. J. Zhu, D. Yang, Z. Yin, Q. Yan and H. Zhang, Small, 2014, 10, 3480-3498.

7. K. Chang and W. Chen, ACS Nano, 2011, 5, 4720-4728.

8. K. E. Lewis, D. M. Golden and G. P. Smith, Journal of the American Chemical Society, 1984, 106, 3905-3912. 
9. S. Kim, C. Hwang, S. Y. Park, S.-J. Ko, H. Park, W. C. Choi, J. B. Kim, D. S. Kim, S. Park, J. Y. Kim and H.-K. Song, Journal of Materials Chemistry A, 2014, 2, 18070-18075.

10. S. Veintemillas-Verdaguer, M. P. Morales and C. J. Serna, Materials Letters, 1998, 35, 227-231.

11. A. Galvez, N. Herlin-Boime, C. Reynaud, C. Clinard and J.-N. Rouzaud, Carbon, 2002, 40, 2775-2789.

12. Y. Leconte, H. Maskrot, L. Combemale, N. Herlin-Boime and C. Reynaud, Journal of Analytical and Applied Pyrolysis, 2007, 79, 465-470.

13. S. Veintemillas-Verdaguer, M. Morales and C. Serna, Materials letters, 1998, 35, 227-231.

14. J. Saint, M. Morcrette, D. Larcher, L. Laffont, S. Beattie, J. P. Pérès, D. Talaga, M. Couzi and J. M. Tarascon, Advanced Functional Materials, 2007, 17, 17651774.

15. R. Alexandrescu, I. Morjan, F. Dumitrache, R. Birjega, C. Fleaca, C. Luculescu, E. Popovici, I. Soare, I. Sandu and E. Dutu, Journal of optoelectronics and advanced materials, 2010, 12, 599-604.

16. S. Kumar, X. Bi and N. Kambe, Journal, 2001.

17. H. Gamsjaeger, T. GAJDA, J. Sangster, S. K. Saxena and W. Voigt, Chemical Thermodynamics Vol 12 - Chemical Thermodynamics of tin, Nuclear Energy Agency of the OECD (NEA), 2012.

18. L. P. Wang, L. Yu, R. Satish, J. Zhu, Q. Yan, M. Srinivasan and Z. Xu, RSC Advances, 2014, 4, 37389-37394.

19. M. J. Allen, V. C. Tung and R. B. Kaner, Chemical Reviews, 2010, 110, 132-145.

20. X. H. Cao, Y. M. Shi, W. H. Shi, X. H. Rui, Q. Y. Yan, J. Kong and H. Zhang, Small, 2013, 9, 3433-3438.

21. Y. Zhao, J. X. Li, Y. H. Ding and L. H. Guan, Rsc Advances, 2011, 1, 852-856.

22. Y. Zhao, J. X. Li, N. Wang, C. X. Wu, G. F. Dong and L. H. Guan, J Phys Chem C, 2012, 116, 18612-18617.

23. Y. Wen, K. He, Y. Zhu, F. Han, Y. Xu, I. Matsuda, Y. Ishii, J. Cumings and C. Wang, Nat Commun, 2014, 5. 


\section{Chapter 5}

\section{In-depth evaluation on electrochemical performance of $\mathrm{N}$-doped $\mathrm{SnO}_{2}$ and its fundamental mechanism study}

We report a laser-assisted pyrolysis method for the synthesis of pristine $\mathrm{SnO}_{2}$ and $\mathrm{N}$-doped $\mathrm{SnO}_{2}$ nanoparticles. In particular, the synthesis process is made possible by utilizing the short residence time in the reaction zone to limit particle growth, while providing an intimate mixture of $\mathrm{N}$ atoms during the growth of $\mathrm{SnO}_{2}$ nanoparticles. To the best of our knowledge, the electrochemical performance of $\mathrm{N}$-doped $\mathrm{SnO}_{2}$ was evaluated for the first time. While the sample with 3\% of $\mathrm{N}$-doping exhibited optimum performance during lithiation, the incorporation of nitrogen doping was found to have a detrimental effect on the sodiation performance. XAS was utilized to monitor the position and the function of $N$ dopant as well as to investigate the local chemical state of Sn during lithiation processes. The exceptional conductivity and cyclability could be attributed to the presence of an unreactive $S n-N$ bonding in the structure during charge/discharge. Moreover, the small particle sizes achievable from to the laser pyrolysis process promoted rapid ion diffusion while preventing pulverization and agglomeration.

*This section is published in L.P. Wang et al. Adv. Mater., 2016, Accepted 
Laser pyrolyzed N-doped $\mathrm{SnO}_{2}$ for LIB and NIB (@CEA Saclay) Chapter 5

\subsection{Introduction}

In the previous chapter, we have evaluated methods for improving the electrochemical performance of $\mathrm{SnO}_{2}$ by extrinsically introducing different compounds. For this chapter, we demonstrate an intrinsic method of enhancing the performance of $\mathrm{SnO}_{2}$ via nitrogen doping.

Nanostructuring and elemental doping are other alternatives that improve the performance of the material by directly altering both the physical and electronic structure of the crystal. The properties of the doped compounds are dependent on the different types of interactions between dopants and the host structure, which may result in modification of electronic properties, ${ }^{1}$ modulations of magnetic properties, ${ }^{2}$ and influence crystal growth processes. ${ }^{3}$ The elements commonly utilized for doping in $\mathrm{SnO}_{2}$ have mainly focused on the substitution of metallic $\mathrm{Sn}$ with other metals such as $\mathrm{Ni}^{4}, \mathrm{Sb}^{5}$ and etc. ${ }^{6,7}$ In contrast, studies on anion doping in $\mathrm{SnO}_{2}$ has been relatively limited due to the lack of effective synthesis method for anionic doping. ${ }^{8}$ Doping of nitrogen in $\mathrm{SnO}_{2}$ (N-doped $\mathrm{SnO}_{2}$ ) has not been extensively studied, while most of the works focus on simulations. ${ }^{9,} 10$ For example, Sun et al. showed that $\mathrm{N}$ is energetically favorable for substituting $\mathrm{O}$ under $\mathrm{O} / \mathrm{Sn}$-rich conditions and would lead to a reduction in the band gap. ${ }^{11}$ Experimental results also showed promising electrical properties, with reported conductivities of up to $1.1 \times 10^{-3} \mathrm{~S} \mathrm{~cm}^{-1}$ for bulk N-doped $\mathrm{SnO}_{2}{ }^{12}$ Nevertheless, the electrochemical performance of nitrogen-doped $\mathrm{SnO}_{2}$ has yet to be demonstrated thus far.

Herein we carefully design and fabricate both pristine and $\mathrm{N}$-doped $\mathrm{SnO}_{2}$ nanoparticles via laser induced pyrolysis process. The as-synthesized powders exhibit exceptional cyclability and rate capability as anode material for both LIB and NIB. Notably, the synthesized powders did not consist of any carbon modification but are still competitive enough compared to other rationally designed $\mathrm{SnO}_{2} / \mathrm{C}$ composites. ${ }^{13}$ Under precise control of nitrogen, the sample containing $3 \% \mathrm{~N}$ was capable of achieving an unprecedented capacity of 522 $\mathrm{mAh} \mathrm{g}{ }^{-1}$ per gram of active material under high current conditions $10 \mathrm{~A} \mathrm{~g}^{-1}$ at 
Laser pyrolyzed N-doped $\mathrm{SnO}_{2}$ for LIB and NIB (@CEA Saclay) Chapter 5

room temperature and a reversible capacity of $1192 \mathrm{mAh} \mathrm{g}^{-1}$ after 500 cycles at 1.4 $\mathrm{A} \mathrm{g}^{-1}$ in $\mathrm{Li}$ system. On the other hand, it appears that $\mathrm{N}$-doping is countereffective in enhancing the electrochemical performance in NIBs. Pristine $\mathrm{SnO}_{2}$ nanoparticles were found to demonstrate the best performance, with $\mathrm{SnO}_{2}+\mathrm{N} 8 \%$ displaying the worst performance. Also, since nitrogen doping in $\mathrm{SnO}_{2}$ demonstrates an enhanced performance in LIB and it is the first time that this compound is being studied electrochemically, we further investigate the underlying nature of nitrogen doping through electron microscopy and synchrotron X-ray diffraction and absorption methods.

\subsection{Synthesis}

\subsubsection{Chemicals}

Tin (IV) chloride pentahydrate $\left(\mathrm{SnCl}_{4} \bullet 5 \mathrm{H}_{2} \mathrm{O}\right)$ was purchased and received from Sigma-Aldrich without further purification. Sodium hydroxide $(\mathrm{NaOH})$ was purchased and received from Normapur, France without further purification. Graphene oxide (GO) was bought and received from Graphenea, Spain without further purification. Air, argon (Ar), ethylene gas $\left(\mathrm{C}_{2} \mathrm{H}_{4}\right)$ and ammonia gas $\left(\mathrm{NH}_{3}\right)$ were purchased and received from Messer, France without further purification. Coin cell components and etched copper/aluminum foils were purchased from MTI corp. and used as received.

\subsubsection{Laser pyrolysis}

The laser pyrolysis operating process can be found in Figure 3.1. The pressure within the reaction chamber was kept constant at $\sim 740$ Torr throughout the entire experiment and the laser power was set up at 1980-1995 W. For the synthesis of pristine $\mathrm{SnO}_{2}$ nanoparticles, air (5.5 slm (standard litres per min)) and $\mathrm{C}_{2} \mathrm{H}_{4}(0.3 \mathrm{slm})$ were used as carrier and sensitizer gasses respectively. For the synthesis of $\mathrm{N}$-doped $\mathrm{SnO}_{2}, \mathrm{Ar}(5.5 \mathrm{slm})$ and $\mathrm{NH}_{3}(0.66 / 1.17 \mathrm{slm})$ were used as carrier and sensitizer gasses respectively. The use of Ar in the synthesis of $\mathrm{N}$-doped samples prevented the oxidation of $\mathrm{NH}_{3}$ into $\mathrm{NO}_{2}$, while the use of 
Laser pyrolyzed N-doped $\mathrm{SnO}_{2}$ for LIB and NIB (@CEA Saclay) Chapter 5

air in $\mathrm{C}_{2} \mathrm{H}_{4}$ conditions prevented the carbon contamination. Carrier gas flow results of the inlet pressure applied for atomizing gas in the aerosol spray generator.

\subsection{Physical characterization}

The sample synthesized in the presence of $\mathrm{C}_{2} \mathrm{H}_{4}$ and air is herein labeled as $\mathrm{SnO}_{2}$. The other two samples where $0.66 \mathrm{slm}$ and $1.17 \mathrm{slm}$ of $\mathrm{NH}_{3}$ were used are denoted as $\mathrm{SnO}_{2}+\mathrm{N} 3 \%$ and $\mathrm{SnO}_{2}+\mathrm{N} 8 \%$ (see detailed explanation in X-ray photoelectron spectroscopy (XPS) results below) respectively. The crystal phases of the samples synthesized from $\mathrm{Sn}(\mathrm{OH})_{4}$ precursor were examined through XRD in Figure 5.1a. All the samples presented peaks at $2 \theta$ values of $26.6^{\circ}, 33.9^{\circ}$ and $51.8^{\circ}$, which can be indexed to the (110), (101) and (211) plane reflection in rutile tetragonal $\mathrm{SnO}_{2}$ (JCPDS 41-1445). While $\mathrm{SnO}_{2}+\mathrm{N} 3 \%$ and $\mathrm{SnO}_{2}+\mathrm{N} 8 \%$ revealed dominant $\mathrm{XRD}$ peaks of tetragonal $\mathrm{SnO}_{2}$, it also showed effects of peak broadening when compared to pristine $\mathrm{SnO}_{2}$, indicating small crystallites sizes and/or poor crystallinity. ${ }^{14}$ The structure differences between pristine and $\mathrm{N}$-doped $\mathrm{SnO}_{2}$ were further investigated by Raman spectroscopy (Figure 5.1b) According to group theory, the normal vibration modes of rutile tetragonal $\mathrm{SnO}_{2}$ at the center of the Brillouin zone could be represented by, $\Gamma=\mathrm{A}_{1 \mathrm{~g}}+\mathrm{A}_{2} \mathrm{~g}+2 \mathrm{~A}_{2 \mathrm{U}}+\mathrm{B}_{1 \mathrm{~g}}+\mathrm{B}_{2 \mathrm{~g}}+2 \mathrm{~B}_{1 \mathrm{U}}+\mathrm{E}_{\mathrm{g}}+4 \mathrm{E}_{\mathrm{U}}$. Among these vibration modes, there exist three non-degenerate modes $\left(\mathrm{B}_{1 \mathrm{~g}}, \mathrm{~B}_{2 \mathrm{~g}}\right.$, and $\left.\mathrm{A}_{1 \mathrm{~g}}\right)$ vibrating within the plane and perpendicular to c-axis and one doubly degenerate mode $\left(\mathrm{E}_{\mathrm{g}}\right)$ vibrating along the c-axis that is Raman active. ${ }^{15,16} \mathrm{We}$ noticed that the $A_{1 g}$ mode for all three samples shifted from the standard value $\left(635 \mathrm{~cm}^{-1}\right)$, which could be related to the presence of small crystal sizes as well as modification of bond length due to the presence of $\mathrm{N}$ dopants. ${ }^{17}$ In addition, the $\mathrm{A}_{1 \mathrm{~g}}$ peak was found to display a decrease in wavenumber with increasing $\mathrm{N}$ content. The shift can be attributed to the release of compressive strain within the rutile lattice and could be beneficial for strain inducing electrochemical alloying process. ${ }^{18,19}$ Despite similar $\mathrm{A}_{1 \mathrm{~g}}$ and $\mathrm{B}_{2 \mathrm{~g}}$ peaks in all samples, several 
spectral features including the D mode (near $550-575 \mathrm{~cm}^{-1}$ ) attributed to the inactive $A_{2 g}$ in rutile structure, appears to be stronger in N-doped samples as compared to pristine $\mathrm{SnO}_{2}{ }^{20}$ The $\mathrm{D}$ mode is prominent only in very small nanoparticles $(<9 \mathrm{~nm})$ due to modification of bond length, space symmetry reduction and presence of surface imperfections. ${ }^{21,22}$ This observation is in agreement with above HRTEM and SAED results which can be related to the presence of significant disorder owing to presence of small crystallite sizes $(<5$ $\mathrm{nm}$ ) surrounded by grain boundaries, thus preventing atoms from vibrating in phase. $^{16}$
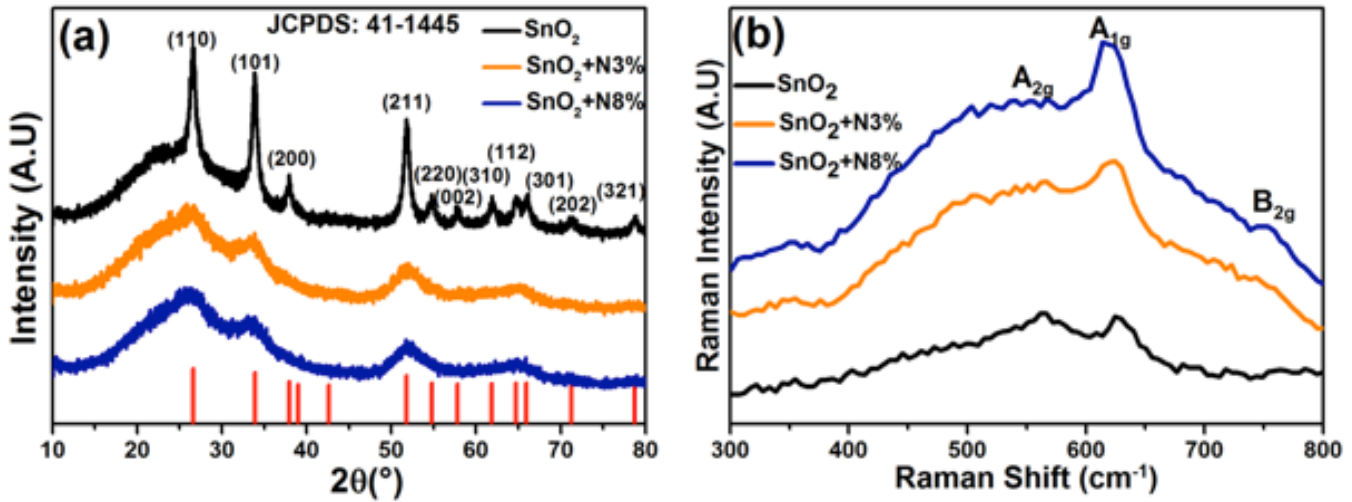

Figure 5.1 Comparison between pristine $\mathrm{SnO}_{2}$ vs. N-doped $\mathrm{SnO}_{2}$ in (a) $\mathrm{XRD}$ (b) Raman spectroscopy. The spectrum of $\mathrm{SnO}_{2}$ in XRD matches that of rutile tetragonal $\mathrm{SnO}_{2}$ with JCPDS 41-1445. Broad peaks are observed in N-doped samples, which is consistent with HRTEM observations on the existence of small crystallites sizes. Raman spectrum in all three samples shows distinct peak of Raman active $A_{1 g}$ and $B_{2 g}$ modes and presence of an inactive $\mathrm{A}_{2 \mathrm{~g}}$ mode due to small particle size, lattice distortion and modification in bond lengths.

The as-synthesized pristine and $\mathrm{N}$-doped $\mathrm{SnO}_{2}$ were subsequently imaged through electron microscopy. High-resolution TEM (HRTEM) image of pristine $\mathrm{SnO}_{2}$ (Figure 5.2a) revealed the presence of spacious crystalline nanoparticles of sizes $5-20 \mathrm{~nm}$, while $\mathrm{SnO}_{2}+\mathrm{N} 3 \%$ and $\mathrm{SnO}_{2}+\mathrm{N} 8 \%$ (Figure $5.2 \mathrm{~b}-\mathrm{c}$ ) were dominated by the existence of non-porous polycrystalline grains within smaller nanoparticles. The introduction of heterogeneous atoms 
(nitrogen atoms) within host lattice may have resulted in a reduction of grain size due to suppression of long-range order formation. ${ }^{3,23}$ In addition, several amorphous grains (circled in green) can be spotted in $\mathrm{SnO}_{2}+\mathrm{N} 3 \%$, along with Morié patterns that are probably due to the overlapping of different faceted particles. The presence of polycrystalline particles with indistinct boundaries makes it difficult to study the particle size distribution in $\mathrm{SnO}_{2}+\mathrm{N} 3 \%$ and $\mathrm{SnO}_{2}+\mathrm{N} 8 \%$. Inset images in Figure $5.2 \mathrm{~b}$ and $\mathrm{c}$ exemplify the reconstructed inverse fast Fourier transform (FFT) images of crystalline regions circled in red. Characteristic lattice fringes of $0.329 \mathrm{~nm}, 0.261 \mathrm{~nm}$, and $0.176 \mathrm{~nm}$ in the TEM images can be assigned to the interplanar distance of (110), (101), and (211) planes in tetragonal $\mathrm{SnO}_{2}$, respectively.
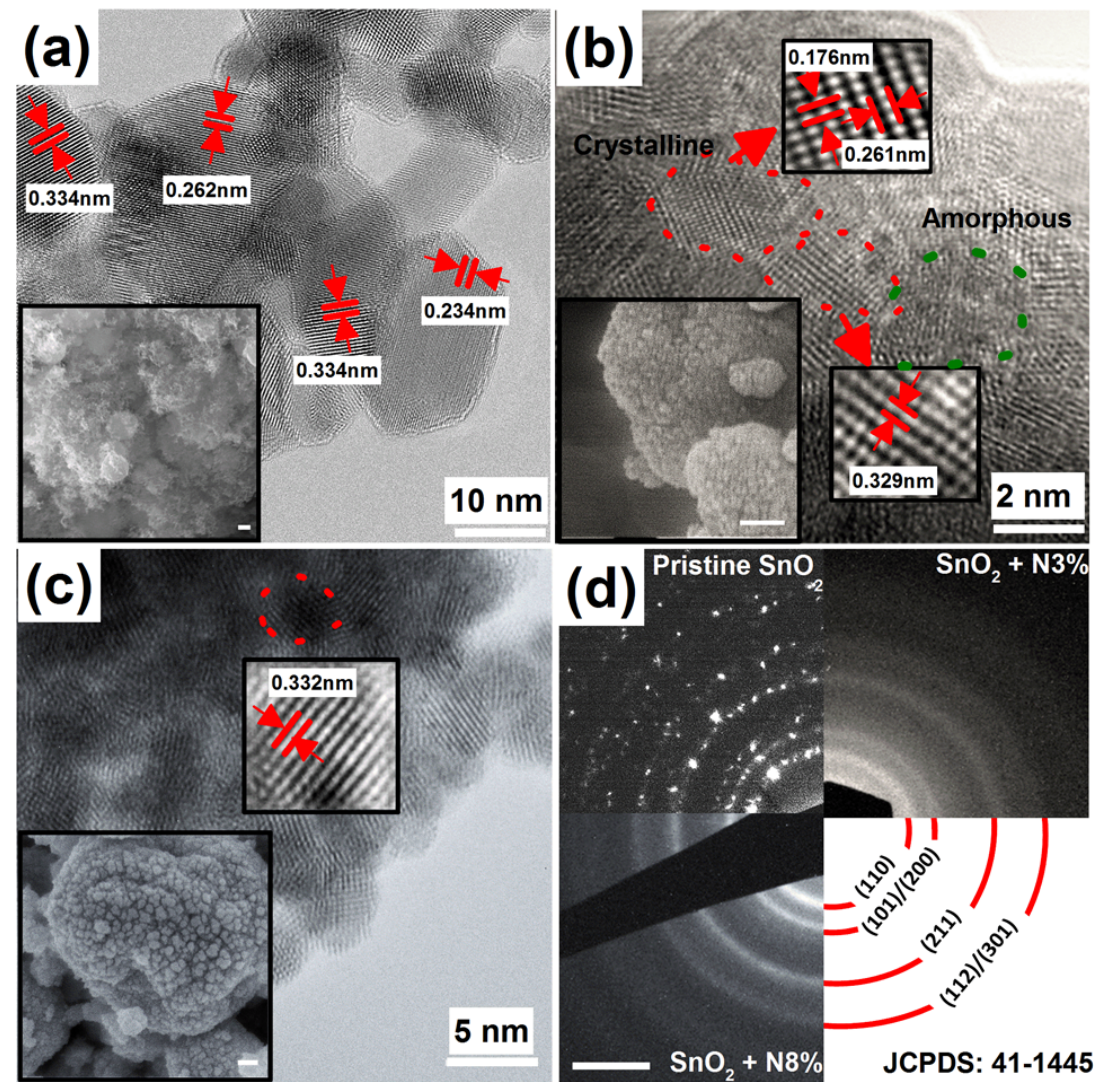

Figure 5.2 HRTEM images of (a) pristine $\mathrm{SnO}_{2}$ (b) $\mathrm{SnO}_{2}-\mathrm{N} 3 \%$, and (c) $\mathrm{SnO}_{2}-\mathrm{N} 8 \%$. The insets display the corresponding FESEM images and the inverse FFT images after applying an array mask. Samples prepared under the presence of $\mathrm{NH}_{3}$ displays polycrystalline behavior along with grains of crystalline and amorphous regions. The 
crystalline grain size regions in both $\mathrm{SnO}_{2}-\mathrm{N} 3 \%$ and $\mathrm{SnO}_{2}-\mathrm{N} 8 \%$ can be estimated to be approximately $<5 \mathrm{~nm}$. (d) SAED pattern for the respective samples in accordance with tetragonal $\mathrm{SnO}_{2}$ standard (JCPDS: 41-1445). Scale bar of inset FESEM images are 200 $\mathrm{nm}$ and scale bar for SAED is $21 / \mathrm{n} \mathrm{nm}$.

The insets in Figure 5.2a to c correspond to the respective FESEM images of the pristine $\mathrm{SnO}_{2}, \mathrm{SnO}_{2}+\mathrm{N} 3 \%$ and $\mathrm{SnO}_{2}+\mathrm{N} 8 \%$ respectively. The highresolution FESEM images displayed a common morphology for all three samples, with large irregular particles of sizes between 100 to $300 \mathrm{~nm}$. Upon a more close-up observation in each corresponding inset image, it could be deduced that the large agglomerates were made up of smaller nanoparticles. The selected area electron diffraction (SAED) patterns (Figure 5.2d) for $\mathrm{SnO}_{2}+\mathrm{N} 3 \%$ and $\mathrm{SnO}_{2}+\mathrm{N} 8 \%$ illustrates the presence of diffuse diffraction rings corresponding to a polycrystalline nature, as compared to distinct bright spots in pristine $\mathrm{SnO}_{2}$.

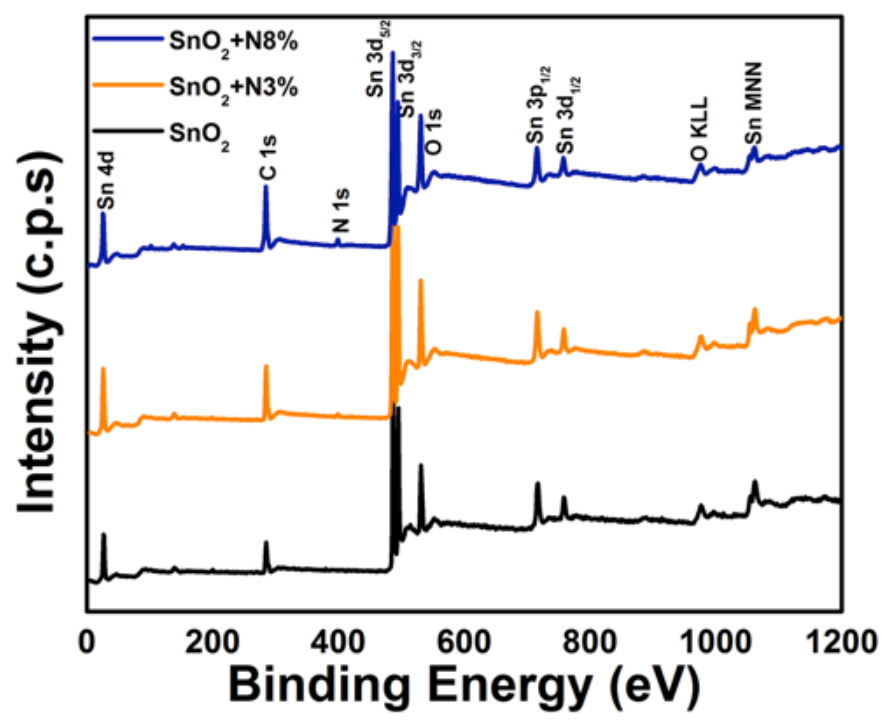

Figure 5.3 General XPS plot comparing pristine $\mathrm{SnO}_{2}$ vs. N-doped $\mathrm{SnO}_{2}$. The peaks are calibrated with respect to $\mathrm{C} 1 \mathrm{~s}$ standard peak at $284.8 \mathrm{eV}$.

XPS measurements were carried out to obtain detailed information on the surface composition and redox states of $\mathrm{Sn}$ and $\mathrm{N}$ in the laser pyrolyzed samples. The general survey scan of the entire spectrum (Figure 5.3) was 
calibrated with $\mathrm{C}$ 1s standard $(284.8 \mathrm{eV})$ before analysis. Figure 5.4 presents the emission spectra of both $\mathrm{Sn} 3 \mathrm{~d}$ and $\mathrm{N}$ 1s peaks in all samples. The $\mathrm{Sn} 3 \mathrm{~d}$ spectra of pristine $\mathrm{SnO}_{2}$ (Figure 5.4a) can be directly fitted with the standard $\mathrm{Sn}$ $3 \mathrm{~d}_{3 / 2}$ and $\mathrm{Sn} 3 \mathrm{~d}_{5 / 2}$ peaks of rutile $\mathrm{SnO}_{2}$ at 495.4 and $487.0 \mathrm{eV}$, respectively, thus implying that $\mathrm{Sn}$ exists only in the $4+$ state. However, for $\mathrm{SnO}_{2}+\mathrm{N} 3 \%$ and $\mathrm{SnO}_{2}+\mathrm{N} 8 \%$, the $\mathrm{Sn} 3 \mathrm{~d}$ spectrums could be deconvoluted into several different sets of peaks. The variation of core binding energy of $\operatorname{Sn} 3 \mathrm{~d}^{5 / 2}$ and $3 \mathrm{~d}^{3 / 2}$ could be attributed to i) the presence of either $\mathrm{Sn}$ in a different oxidation state; ii) a more negative $\mathrm{N}^{3-}$ compared to $\mathrm{O}^{2-}$ that results in shifting of $3 \mathrm{~d}$ orbital energy level due to higher coulombic potential. ${ }^{17}$ The slight shift of Sn $3 \mathrm{~d}$ peaks to lower energies could also imply that doping with nitrogen is accompanied by the formation of oxygen vacancies and a lower $\mathrm{Sn}$ oxidation state. ${ }^{24}$ In particular, the $\mathrm{Sn} 3 \mathrm{~d}$ peaks of $\mathrm{SnO}_{2}+\mathrm{N} 3 \%$ (Figure 5.4b) can be deconvoluted into two different set of doublets with similar relative intensities.
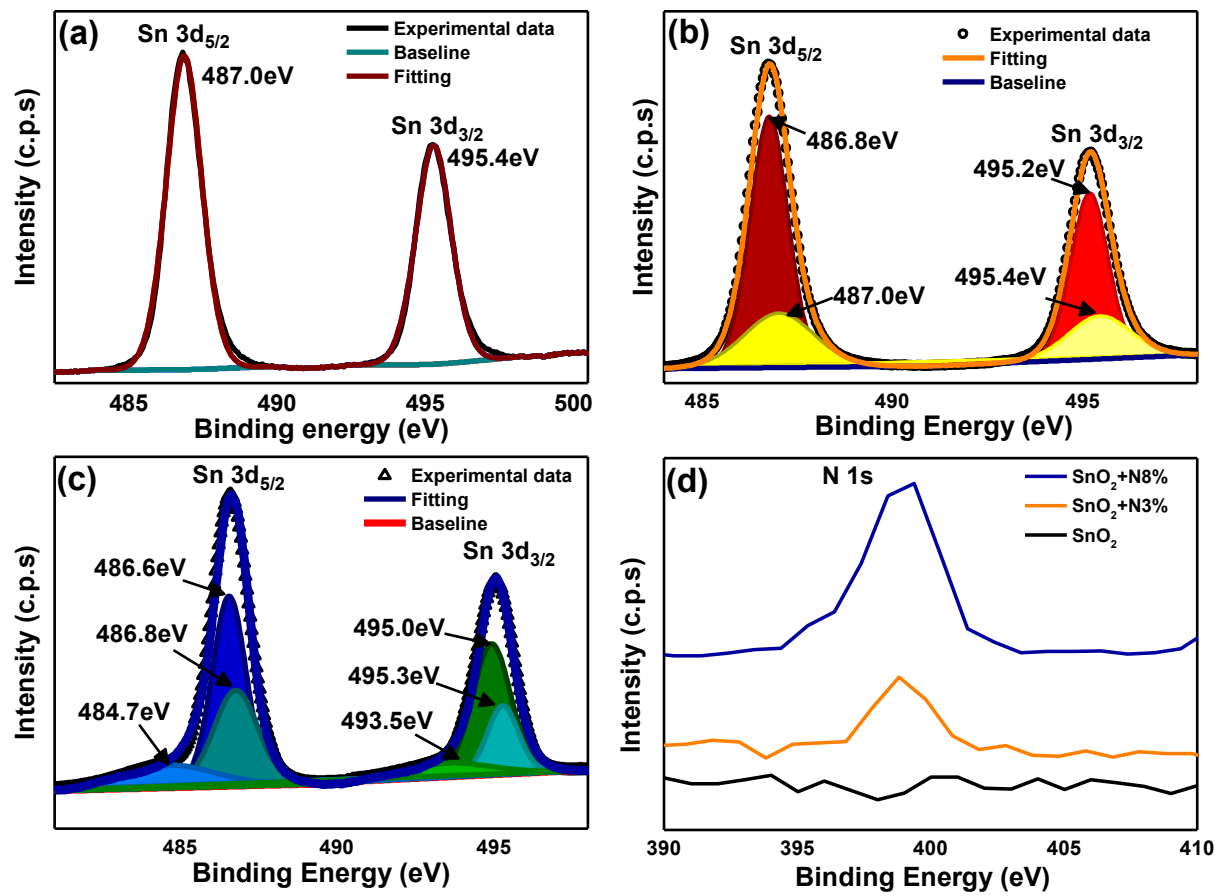

Figure 5.4 Sn 3d XPS peaks of (a) pristine $\mathrm{SnO}_{2}$, (b) $\mathrm{SnO}_{2}+\mathrm{N} 3 \%$, and (c) $\mathrm{SnO}_{2}+\mathrm{N} 8 \%$. (d) is the N 1s XPS peak which displays relatively higher peak intensity with increasing $\mathrm{NH}_{3}$ content. Additional shoulder peak at 484.7 and $493.4 \mathrm{eV}$ in (c) reveals 
Laser pyrolyzed N-doped $\mathrm{SnO}_{2}$ for LIB and NIB (@CEA Saclay) Chapter 5

the presence of $\mathrm{Sn}^{0}$. All peaks are calibrated to standard C 1 s peak at $284.4 \mathrm{eV}$ as shown in Figure S2.

On the other hand, the $\mathrm{Sn} 3 \mathrm{~d}$ peaks in $\mathrm{SnO}_{2}+\mathrm{N} 8 \%$ (Figure 5.4c) could be deconvoluted into three different set of doublets. For $\mathrm{SnO}_{2}+\mathrm{N} 8 \%$, there exist two sets of peaks at energy values of approximately 487 and $495 \mathrm{eV}$ that are associated with $\mathrm{Sn}^{4+}$ at $\mathrm{Sn} 3 \mathrm{~d}_{5 / 2}$ and $3 \mathrm{~d}_{3 / 2}$ respectively. In addition to that, a set of weaker and broader peaks can be fitted in $\mathrm{SnO}_{2}+\mathrm{N} 8 \%$ near 484.7 and 493.4 $\mathrm{eV}$, which can be assigned to metallic $\mathrm{Sn}^{0}{ }^{25}$ In this aspect, we can determine that excess $\mathrm{NH}_{3}$ in the case of $\mathrm{SnO}_{2}+\mathrm{N} 8 \%$ causes reduction of $\mathrm{Sn}^{4+}$ in $\mathrm{Sn}^{0}$ and is in accordance with previous reports. ${ }^{26}$ Quantitative results show that the $\mathrm{N}$ contents were $3.12 \%$ and $8.87 \%$ in $\mathrm{SnO}_{2}+\mathrm{N} 3 \%$ and $\mathrm{SnO}_{2}+\mathrm{N} 8 \%$ respectively, while the concentration of $\mathrm{Sn}^{0}$ in $\mathrm{SnO}_{2}+\mathrm{N} 8 \%$ is determined to be $15.31 \%$.

$\mathrm{N}_{2}$ adsorption/desorption measurements at $77 \mathrm{~K}$ were performed to understand of the microstructure and porosity of the samples (Figure 5.5). Specific surface area was determined by Brunauer-Emmett-Teller (BET) equation. Adsorption/desorption isotherm profile of $\mathrm{SnO}_{2}$ reflects a typical type III adsorption isotherm, where adsorption volume increases with relative pressure. In contrast, $\mathrm{SnO}_{2}+\mathrm{N} 3 \%$ and $\mathrm{SnO}_{2}+\mathrm{N} 8 \%$ revealed type II BET adsorption isotherms, indicating the presence of nonporous surfaces with multilayered adsorption, capillary filling followed by capillary condensation. ${ }^{27}$ Very low hysteresis can be observed between the adsorption and desorption curves, indicating easy access to the $\mathrm{N}_{2}$ gas to the pore sites. The specific surface areas are $43.5,163.6$, and $109.2 \mathrm{~m}^{2} / \mathrm{g}$ for $\mathrm{SnO}_{2}, \mathrm{SnO}_{2}+\mathrm{N} 3 \%$, and $\mathrm{SnO}_{2}+\mathrm{N} 8 \%$, respectively.
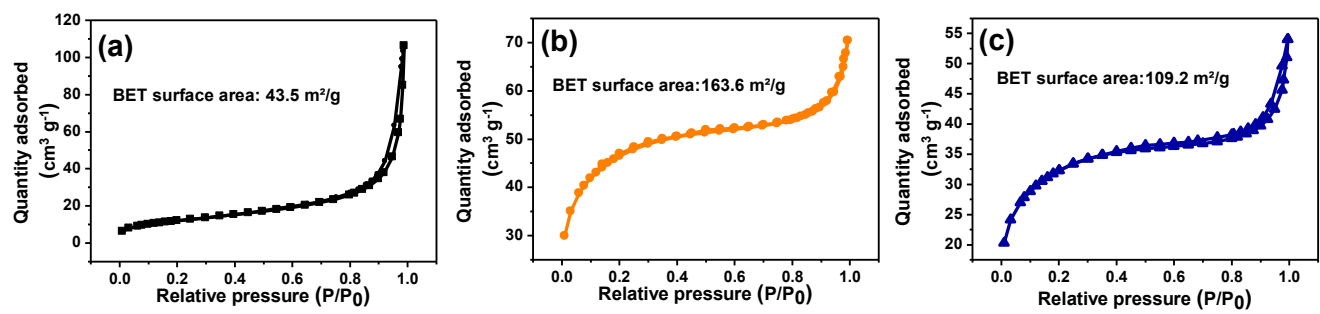

Figure 5.5 $\mathrm{N}_{2}$ adsorption/desorption BET measurements of (a) pristine $\mathrm{SnO}_{2}$ (b) 
Laser pyrolyzed N-doped $\mathrm{SnO}_{2}$ for LIB and NIB (@CEA Saclay) Chapter 5

$\mathrm{SnO}_{2}+\mathrm{N} 3 \%$ (c) $\mathrm{SnO}_{2}+\mathrm{N} 8 \%$

\subsection{Electrochemical measurements}

\subsubsection{Cyclic Voltammetry}

Coin cells are fabricated with the synthesized powders as the cathode and $\mathrm{Li}$ foil as the anode to evaluate the electrochemical properties of pristine and Ndoped $\mathrm{SnO}_{2}$. The first and second cycle cyclic voltammetry (CV) curves collected at a scan rate of $0.1 \mathrm{mV} \mathrm{s}^{-1}$ are as illustrated in Figure 5.6a and 5.6b respectively. In the first cycle, a broad reduction peak associated with the reduction of $\mathrm{SnO}_{2}\left(\mathrm{Sn}^{4+}->\mathrm{Sn}^{0}\right)$ and formation of $\mathrm{Li}_{2} \mathrm{O}$ could be observed starting from $1.50 \mathrm{~V}$. This is followed by a sharp peak at approximately $0.80 \mathrm{~V}$, which is related to the reduction of the electrolyte. ${ }^{28,29}$ Subsequently, a wider peak can be observed at $<0.70 \mathrm{~V}$, which could be attributed to the multi-step alloying reaction between $\mathrm{Li}$ and $\mathrm{Sn} .{ }^{30}$ In the reverse oxidation scan, a broad peak can be seen at $0.50 \mathrm{~V}$ and it can be attributed to the dealloying reaction of $\mathrm{Li}_{\mathrm{x}} \mathrm{Sn}$ back to $\mathrm{Sn}^{0}$, assuming completely reversible reaction. The ensuing oxidation peak stretching from $1.10-2.00 \mathrm{~V}$ can be assigned to the reversible oxidation of $\mathrm{Sn}\left(\mathrm{Sn}^{0}->\mathrm{Sn}^{4+}\right) .{ }^{31}$
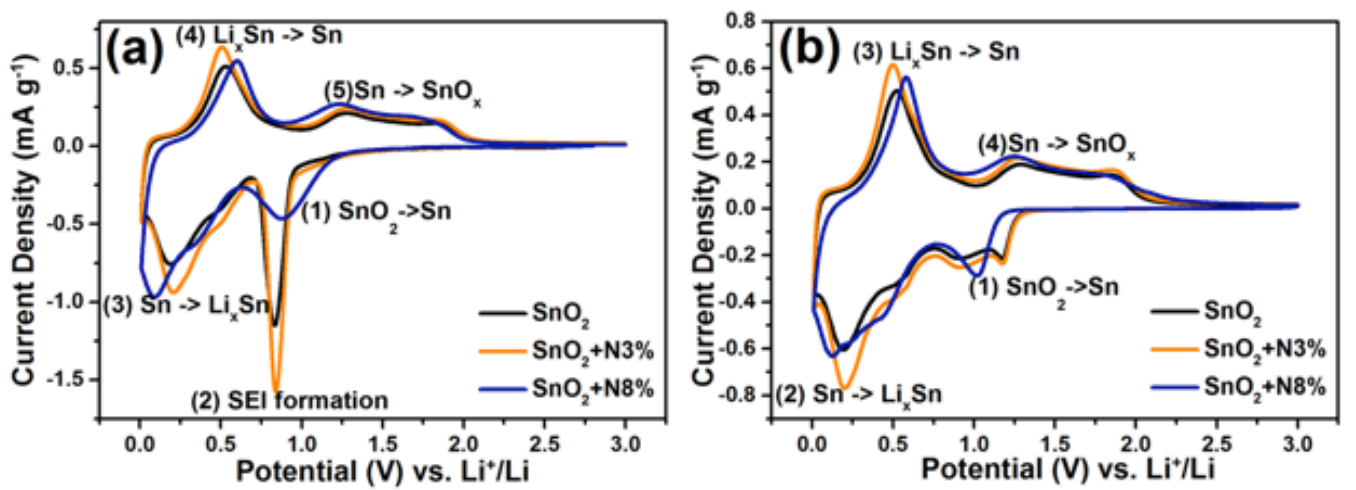

Figure 5.6 (a) $1^{\text {st }}$ and (b) $2^{\text {nd }}$ lithiation cycle CV curves for the laser pyrolysed samples at $0.1 \mathrm{mV} \mathrm{s}^{-1}$. The sharp peak at $\sim 0.8 \mathrm{~V}$ corresponds formation of SEI layer on the surface of the electrode during the initial discharge process.

The main difference in the second cycle lies with the absence of the peak 
associated with a reduction of the electrolyte at $\sim 0.70 \mathrm{~V}$. It was found that the redox peaks for $\mathrm{SnO}_{2}+\mathrm{N} 8 \%$ were all slightly shifted in the direction of higher overpotential compared to pristine $\mathrm{SnO}_{2} \& \mathrm{SnO}_{2}+\mathrm{N} 3 \%$. The shift in redox potential suggests poorer electronic conductivity and reaction kinetics when the nitrogen doping concentration increases to $8 \%$. The weak conversion peak in $\mathrm{SnO}_{2}+\mathrm{N} 8 \%$ could be ascribed to the presence of $\mathrm{Sn}^{0}$ phase initially, where it contributes only towards the alloying reaction. In addition, we observed that the non-faradaic capacity generated when scanned above $2.00 \mathrm{~V}$ is insignificant compared to the capacity generated from faradaic reactions, indicating that capacitive contribution is almost negligible towards the overall capacity despite differences in surface area between pristine $\mathrm{SnO}_{2}$ and N-doped samples. More importantly, we did not observe any additional redox peaks in $\mathrm{SnO}_{2}+\mathrm{N} 3 \%$ and $\mathrm{SnO}_{2}+\mathrm{N} 8 \%$ that could be attributed to side reactions between $\mathrm{Li}$ and $\mathrm{N}$.
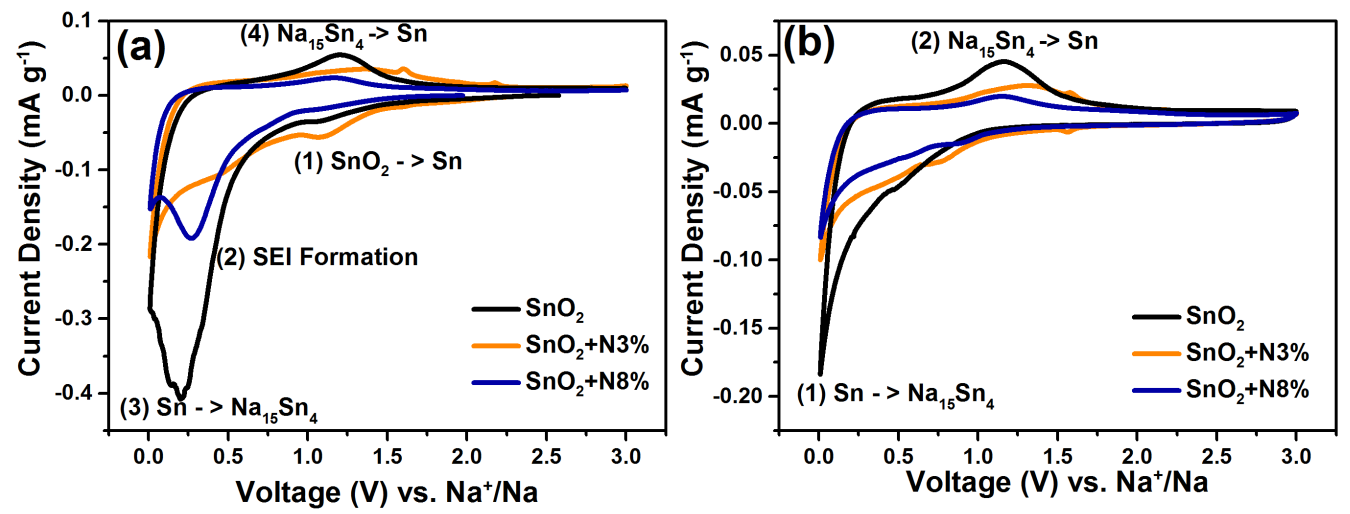

Figure 5.7 (a) $1^{\text {st }}$ and (b) $2^{\text {nd }}$ sodiation cycle CV curves for the laser pyrolysed samples at $0.1 \mathrm{mV} \mathrm{s}^{-1}$. Sharp peak at $\sim 0.6 \mathrm{~V}$ corresponds formation of SEI layer on the surface of the electrode during the initial discharge process.

Similar to LIB, the CV profiles (Figure 5.7a) for the pristine and $\mathrm{N}$-doped $\mathrm{SnO}_{2}$ in NIB for the first cycle exhibit broad peaks starting from $1.0 \mathrm{~V}$, corresponding to the decomposition of electrolyte to form SEI layer and the reduction of $\mathrm{SnO}_{2}$ into Sn. Following that, alloying reaction between $\mathrm{Sn}$ and $\mathrm{Na}$ takes place at $\sim 0.2 \mathrm{~V}$ to form $\mathrm{Na}_{3.75} \mathrm{Sn}$. In the reverse anodic process, dealloying process 
occurs at $\sim 0.9-1.5 \mathrm{~V}$ to yield metallic $\mathrm{Sn}$. In the second cycle, the broad peak starting at $1.0 \mathrm{~V}$ was found to be absent, indicating the complete formation of SEI layer. The area encapsulated within the $\mathrm{CV}$ curve for pristine $\mathrm{SnO}_{2}$ was found to be larger compared to the N-doped samples, indicating superior charge storage capabilities and is in contrast with the lithiation behavior. Additionally, the intensity of the peak in the anodic reaction was observed to be smaller for $\mathrm{N}$-doped samples, with a slight shift to higher potentials. This is indicative of poor reversibility as well as inferior conductivity during sodiation.

\subsubsection{Galvanostatic cycling}
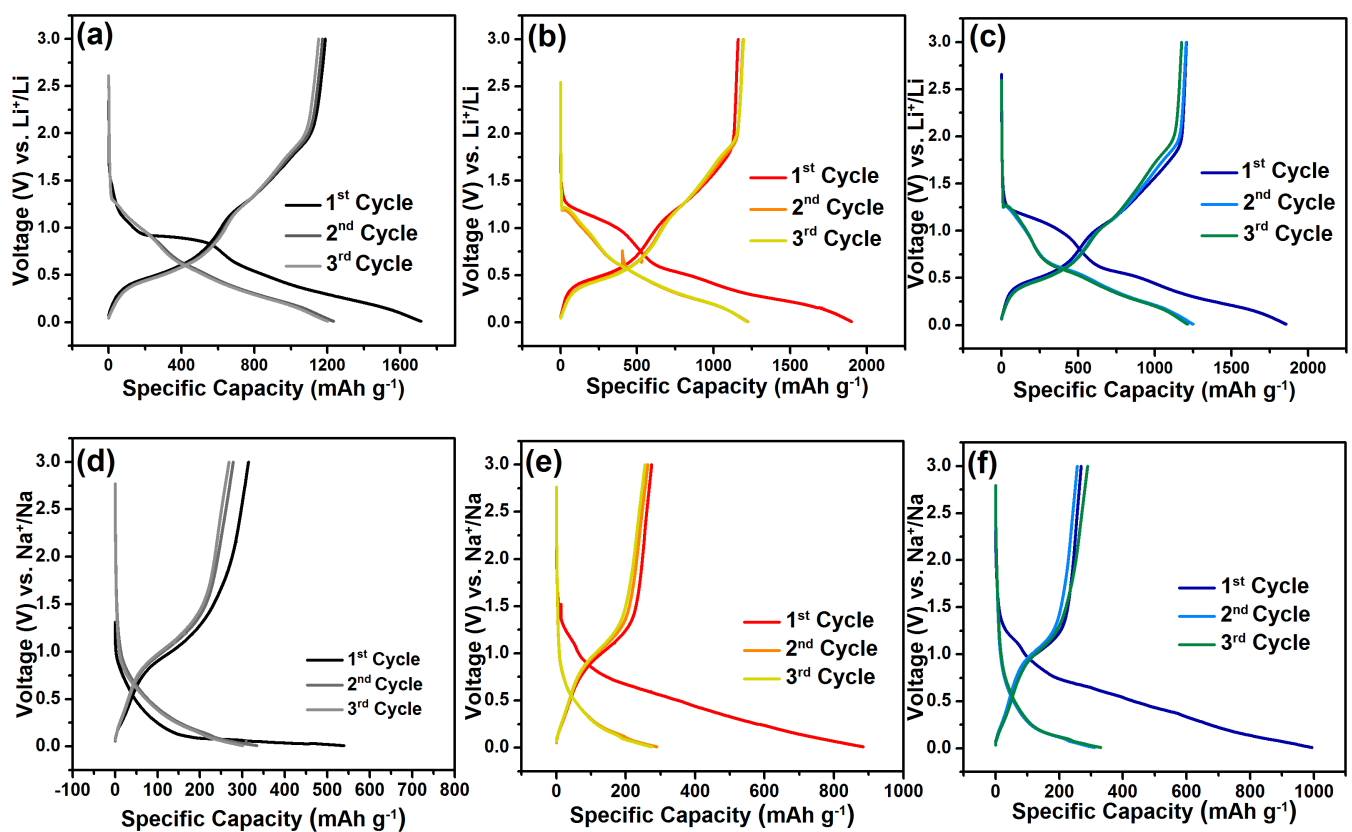

Figure 5.8 Galvanostatic discharge curves of pristine $\mathrm{SnO}_{2}, \mathrm{SnO}_{2}+\mathrm{N} 3 \%$ and $\mathrm{SnO}_{2}+\mathrm{N} 8 \%$ in (a-c) LIB and (d-f) NIB.

The galvanostatic charge-discharge profiles of the as-synthesized samples were first evaluated in LIB at $100 \mathrm{~mA} \mathrm{~g}^{-1}$ per gram of active material for the initial three cycles (Figure 5.8a-c). The initial discharge capacities are 1713, 1899, and $1856 \mathrm{mAh} \mathrm{g}^{-1}$ for $\mathrm{SnO}_{2}, \mathrm{SnO}_{2}+\mathrm{N} 3 \%$, and $\mathrm{SnO}_{2}+\mathrm{N} 8 \%$, respectively. An irreversible capacity loss (about 30\%) could be observed during the first and second discharge cycles, which is associated with the formation of a solid 
electrolyte interphase (SEI). The irreversible loss of $\mathrm{Li}^{+}$was also observed in above CV results and gave an initial coulombic efficiency (C.E) of $69 \%, 61 \%$, and $64 \%$, respectively. The C.E subsequently rises to $97 \sim 99 \%$ in the second cycle, indicating that a stable SEI layer has been formed. The following reversible discharge capacities in the second cycle showed similar capacities of 1209,1241 , and $1211 \mathrm{mAh} \mathrm{g}^{-1}$. It should be noted that $\mathrm{SnO}_{2}+\mathrm{N} 8 \%$ should have the lowest theoretical capacity $\left(1416 \mathrm{mAh} \mathrm{g}^{-1}\right)$ due to the presence of $\mathrm{Sn}^{0}$ that does not contribute to the conversion reaction capacity of the compound and assuming that $\mathrm{N}$ does not contribute to charge storage. Galvanostatic profile of all samples demonstrated a voltage independent behavior at potential $>2.00 \mathrm{~V}$, which reinforces our earlier observation that the contribution from double-layer capacitance was minimal. ${ }^{32,33}$

Galvanostatic evaluation of the pristine and N-doped $\mathrm{SnO}_{2}$ nanoparticles in NIB is presented in Figure 5.8d-f. The initial discharge capacities measured at 30 $\mathrm{mA} \mathrm{g}^{-1}$ were 594, 889 and $1014 \mathrm{mAh} \mathrm{g}^{-1}$ for pristine $\mathrm{SnO}_{2}, \mathrm{SnO}_{2}+\mathrm{N} 3 \%$ and $\mathrm{SnO}_{2}+\mathrm{N} 8 \%$ respectively. The corresponding charge capacities in the initial cycle were 334, 298 and $316 \mathrm{mAh} \mathrm{g}^{-1}$ respectively. Evidently, the presence of nitrogen doping did not help in increasing the specific capacity of N-doped $\mathrm{SnO}_{2}$ in NIB but conversely, resulted in poorer C.E. Similar to the tests conducted in LIB, the N-doped samples in NIB showed low initial coulombic efficiency of $56 \%, 34 \%$ and $32 \%$ respectively.

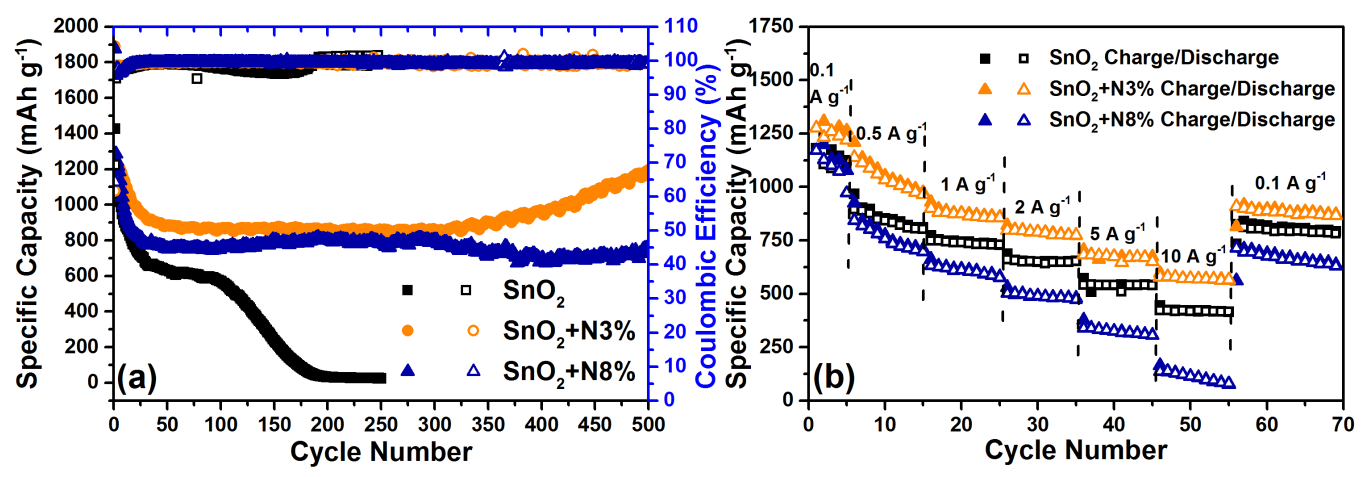

Figure 5.9 (a) Cycling performance and the corresponding Columbic efficiency (C.E) at $1.4 \mathrm{~A} \mathrm{~g} \mathrm{~g}^{-1}$. (b) Rate performance (discharge (solid) and charge (hollow)) of pristine $\mathrm{SnO}_{2}$ vs. N-doped $\mathrm{SnO}_{2}$ within a voltage window between $0.01-3.00 \mathrm{~V}$ vs. $\mathrm{Li}^{+} / \mathrm{Li}$. 
The lithiation cycling performance at $1400 \mathrm{~mA} \mathrm{~g}^{-1}(\sim 1 \mathrm{C})$ is shown in Figure 5.9a. At the $50^{\text {th }}$ cycle, the capacity was 631,837 , and $754 \mathrm{mAh} \mathrm{g}^{-1}$ for $\mathrm{SnO}_{2}$, $\mathrm{SnO}_{2}+\mathrm{N} 3 \%$, and $\mathrm{SnO}_{2}+\mathrm{N} 8 \%$, respectively. The capacity of pristine $\mathrm{SnO}_{2}$ gradually decayed down from the $178^{\text {th }}$ cycle to $0 \mathrm{mAh}^{-1}$. Interestingly, $\mathrm{SnO}_{2}+\mathrm{N} 3 \%$ demonstrated slight increase in capacity at the $322^{\text {th }}$ cycle, which is a characteristic the gradual formation of a stable SEI layer on the surface of the material, resulting in a capacity of $1195 \mathrm{mAh} \mathrm{g}^{-1}$ at the end of the $500^{\text {th }}$ cycle. ${ }^{14}$ Figure $5.9 \mathrm{~b}$ compares the rate performance of pristine $\mathrm{SnO}_{2}$ with $\mathrm{N}$-doped samples at current densities of $0.1,0.5,1,2,5$, and $10 \mathrm{~A} \mathrm{~g}^{-1} . \mathrm{SnO}_{2}+\mathrm{N} 3 \%$ logged an average capacity of $1212 \mathrm{mAh} \mathrm{g}^{-1}$ at $100 \mathrm{~mA} \mathrm{~g}^{-1}$, while a remarkable average capacity of $522 \mathrm{mAh} \mathrm{g}^{-1}$ could be obtained when current density was increased to $10 \mathrm{~A} \mathrm{~g}^{-1}$. The rate performance of $\mathrm{SnO}_{2}+\mathrm{N} 3 \%$ at $10 \mathrm{~A} \mathrm{~g}^{-1}$ is one of the best performing $\mathrm{SnO}_{2}$ materials reported thus far (Appendix A5). In contrast, $\mathrm{SnO}_{2}$ and $\mathrm{SnO}_{2}+\mathrm{N} 8 \%$ presented much lower capacity of 421 and $112 \mathrm{mAh} \mathrm{g}^{-1}$ at $10 \mathrm{~A}$ $\mathrm{g}^{-1}$, respectively. Despite the presence of metallic $\mathrm{Sn}, \mathrm{SnO}_{2}+\mathrm{N} 8 \%$ demonstrated the worst rate capability. Two plausible reasons could explain this observation: i) there exists an optimal concentration of N-doping in enhancing conductivity and stability within the rutile structure, ${ }^{34}$ ii) cycling up to $3.00 \mathrm{~V}$ involves reversibly converting $\mathrm{Sn}$ and $\mathrm{Li}_{2} \mathrm{O}$ back into $\mathrm{SnO}_{2}$, but the presence of initial $\mathrm{Sn}$ requires removal of the intrinsic SEI layer, resulting in a deficiency of $\mathrm{Li}_{2} \mathrm{O}$ during the reversed conversion reaction. ${ }^{35,36}$ Furthermore, when the current was increased to $>5 \mathrm{~A} \mathrm{~g}^{-1}$, the capacity in $\mathrm{SnO}_{2}+\mathrm{N} 8 \%$ showed decaying capacity, indicating loss of contact with active material that might be caused by the more forceful/sluggish SEI formation.

Compared to the performance in LIB, both undoped and $\mathrm{N}$-doped $\mathrm{SnO}_{2}$ showed relatively stable cycling performances over 50 cycles at a current of $30 \mathrm{~mA} \mathrm{~g}^{-1}$. For instance, a capacity of $311 \mathrm{mAh} \mathrm{g}^{-1}$ could be retained after 50 cycles, which corresponding to retention value of $93 \%$ (Figure $5.10 \mathrm{a}$ ). The rate performance on the other hand, shows contrastingly different performance as compared to its lithium counterpart. The samples showed inverse electrochemical performance 
with increasing nitrogen content, where $\mathrm{SnO}_{2}+\mathrm{N} 8 \%$ delivered the worst performance. While the capacities were relatively similar at $30 \mathrm{~mA} \mathrm{~g}^{-1}$, the difference in rate performance could be observed as soon as the current density was increased to $100 \mathrm{~mA} \mathrm{~g}^{-1}$ (Figure 5.10b). At $100 \mathrm{~mA} \mathrm{~g}^{-1}$, the average specific capacities of $\mathrm{SnO}_{2}, \mathrm{SnO}_{2}+\mathrm{N} 3 \%$ and $\mathrm{SnO}_{2}+\mathrm{N} 8 \%$ were 204, 136 and $67 \mathrm{mAh} \mathrm{g}^{-}$ ${ }^{1}$ respectively. It is apparent that the capacities of nitrogen doped samples dropped more rapidly as compared to that of the undoped $\mathrm{SnO}_{2}$. Additionally, it is also noted that an average discharge capacity of $\sim 90 \mathrm{mAh} \mathrm{g}^{-1}$ could be obtained at $800 \mathrm{~mA} \mathrm{~g}^{-1}$.

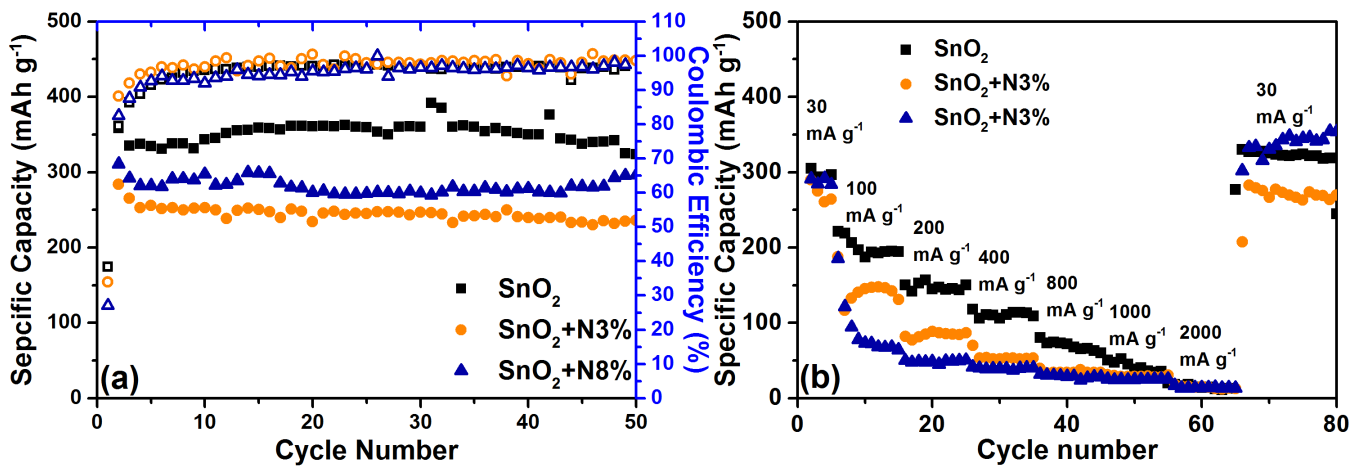

Figure 5.10 (a) Cycling performance and the corresponding Columbic efficiency (C.E) at $30 \mathrm{~A} \mathrm{~g}^{-1}$. (b) Rate performance (discharge (solid) and charge (hollow)) of pristine $\mathrm{SnO}_{2}$ vs. N-doped $\mathrm{SnO}_{2}$ within a voltage window between $0.01-3.00 \mathrm{~V}$ vs. $\mathrm{Na}^{+} / \mathrm{Li}$.

\subsubsection{Power law analysis}

To investigate into how $\mathrm{N}$ doping is beneficial during lithiation, electrochemical kinetic studies were carried out to probe into how reactionlimiting scenarios change with different concentration of $\mathrm{N}$ doping. Figure 5.11a-c illustrates the electrochemical response of the three samples under increasing scan rates. As could be seen, there was significant distortion and peak shifts when scan rates were increased from 0.1 to $10 \mathrm{mV} \mathrm{s}^{-1}$. Peak currents were plotted against increasing scan rate according to the power law, $\log i_{p}=b$ $\log \mathrm{v}+\log \mathrm{a}$, where $\mathrm{i}_{\mathrm{p}}$ is the peak current, $\mathrm{v}$ is the scan rate, while $\mathrm{a}$ and $\mathrm{b}$ are adjustable parameters obtained from the y-intercept and gradient, respectively. 
The peak currents were determined from the individual derivative plot of the $\mathrm{CV}$ curve. In the situation where $\mathrm{b}=0.5$, the current is mainly limited by semiinfinite linear diffusion. A value of $b=1$ would imply that majority of the capacity is contributed in a surface controlled reaction, which also implies that reaction rate is rapid. ${ }^{37}$ Figure $5.11 \mathrm{~d}$-e illustrates the respective power law plots for the different samples. At low scan rates $\left(<1 \mathrm{mV} \mathrm{s}^{-1}\right)$, b values for all samples fall within a range between $\sim 0.7$ to 0.9 , indicating a combination of solid state diffusion and surface limited reactions for both alloying and oxidation reactions. At higher scan rates between $1-10 \mathrm{mV} \mathrm{s}^{-1}$, all $\mathrm{b}$ values fall close to 0.5 for alloying reaction while values for conversion reaction remained around 0.7. This suggests that while alloying reactions shift from surface controlled to solid-state diffusion with increasing rate, conversion reactions remain as surface controlled and are rapid. The deviation of collected data from the extrapolated line at higher scan rates stems from numerous sources including diffusion limitations and ohmic contribution. ${ }^{37,38} \mathrm{SnO}_{2}+\mathrm{N} 3 \%$ demonstrated the least change in $b$ value as well as a small deviation from extrapolated line, which suggests rapid kinetics on the surface during redox processes. On the other hand, it is evident that $\mathrm{SnO}_{2}+\mathrm{N} 8 \%$ did not scale well with increasing scan rate, which is indicated by a significant deviation from extrapolated line and lower $b$ value at high scan rates. The poor surface kinetics in $\mathrm{SnO}_{2}+\mathrm{N} 8 \%$ also helps to explain the poor rate capability shown in Figure 5.9b. 

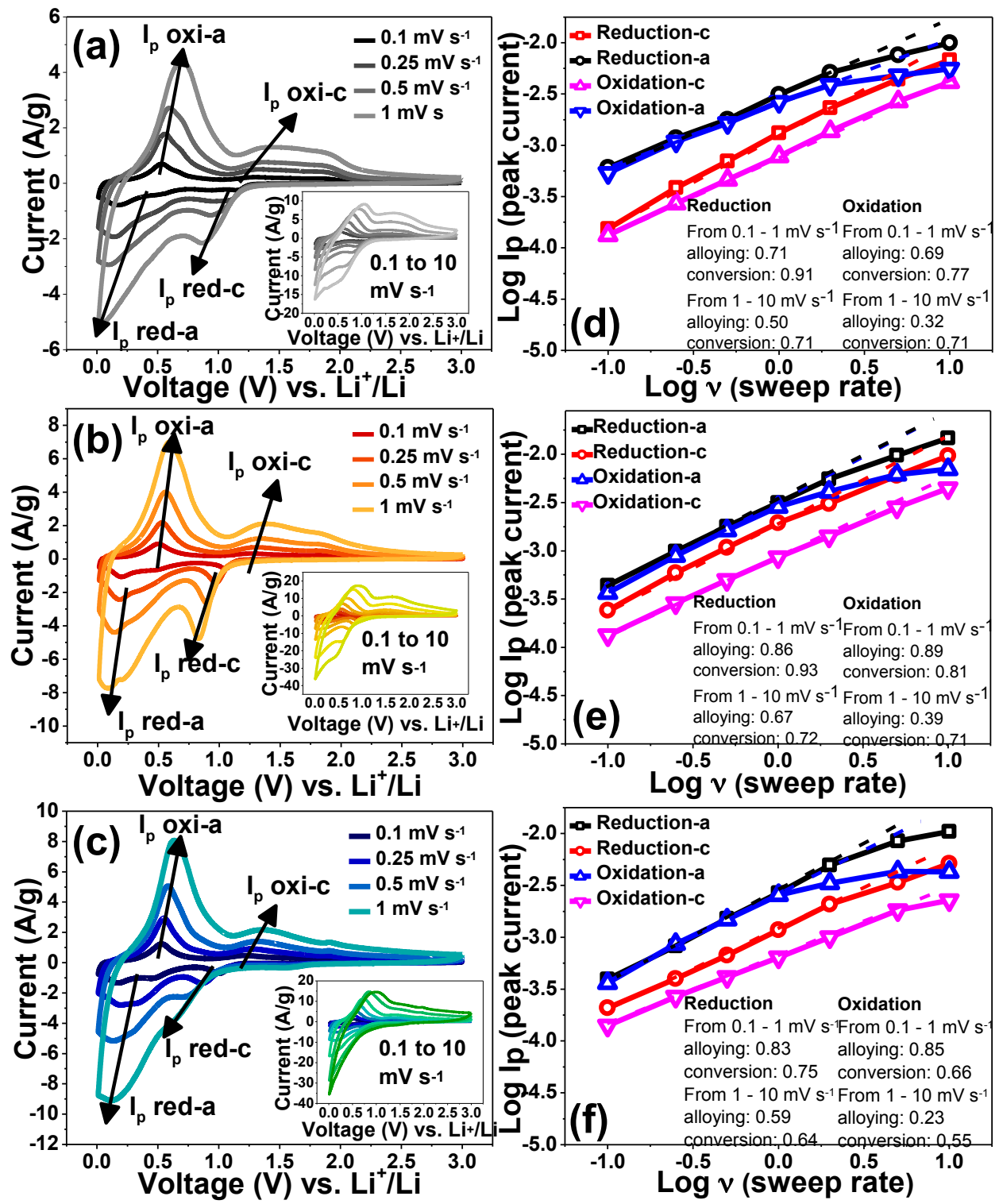

Figure 5.11 CV curves illustrating both conversion and alloying redox peaks for (a) pristine $\mathrm{SnO}_{2}$, (b) $\mathrm{SnO}_{2}+\mathrm{N} 3 \%$, and (c) $\mathrm{SnO}_{2}+\mathrm{N} 8 \%$. The insets in top row plots illustrate increasing scan rates from 0.1 to $10 \mathrm{mV} \mathrm{s}^{-1}$. Peak currents are obtained from the point of inflections on the individual differential plot in each scan rate. Power law $\left(i_{p}=a v^{b}, \log i_{p}=b \log v+\log a\right)$ was applied to study the limiting mechanism during increasing scan rates in (d-e). When $b$ is close to 0.5 , the limiting case would be a semi-infinite linear diffusion controlled process, while a value of 1 would indicate a surface controlled process. A linear dashed line is extrapolated from low scan rate conditions 


\subsection{Ex-situ synchrotron studies}
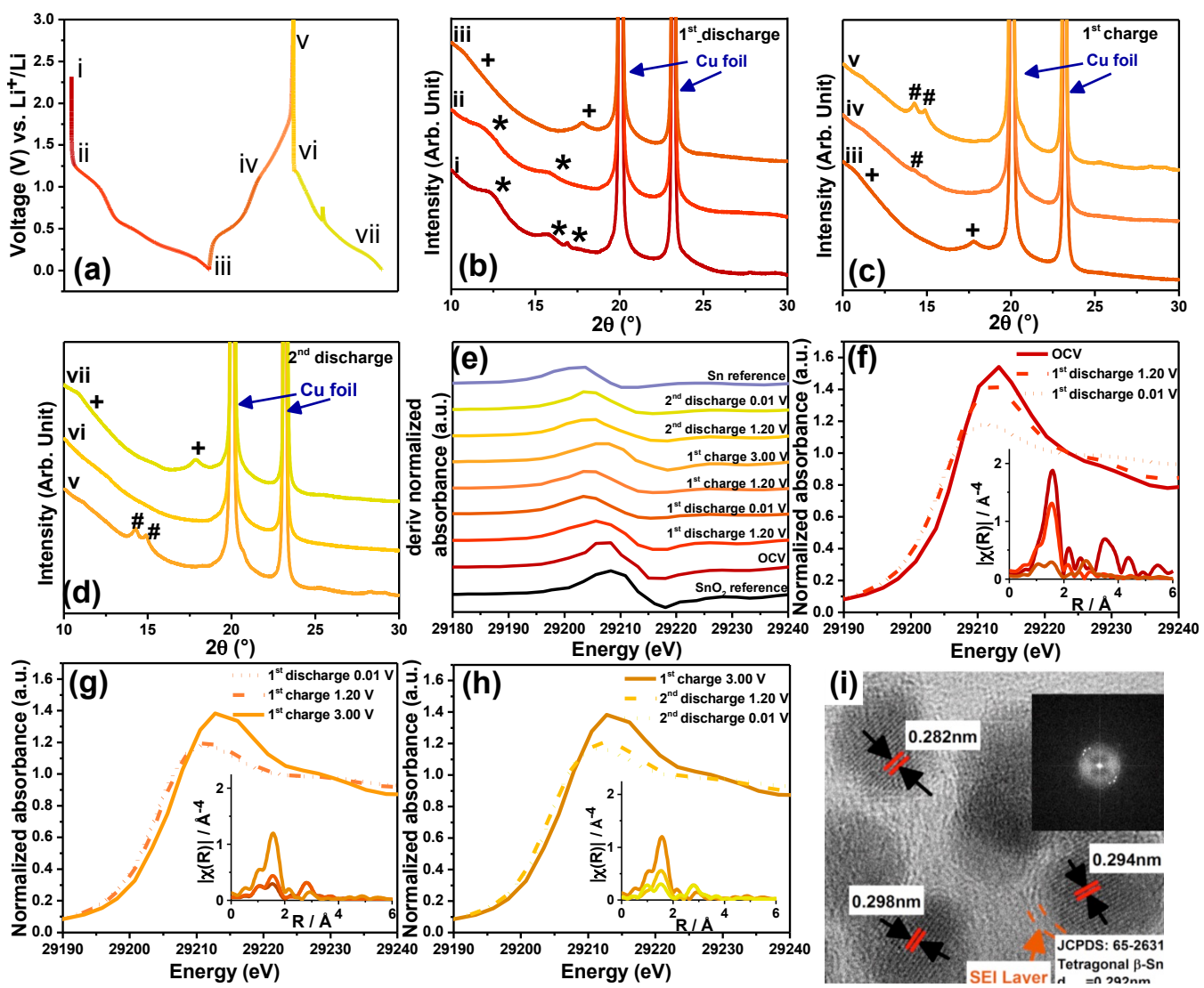

Figure 5.12 (a) Investigation of different charging/discharging states for ex-situ characterization of $\mathrm{SnO}_{2}+\mathrm{N} 3 \%$ (b-d) SXRD patterns for $\mathrm{SnO}_{2}+\mathrm{N} 3 \%$ at different stages of charge/discharge. X-ray wavelength: $0.72768 \AA$. Symbols: (*) -> $\mathrm{SnO}_{2}$ (JCPDS: 411445) (+) -> $\mathrm{Li}_{22} \mathrm{Sn}_{5}$ (JCPDS: 18-0753) (\#) -> Sn (JCPDS: 65-2631). (e) Normalized first derivative of Sn K-edge XANES spectra at different point of interest. (f-h) Sn Kedge normalized absorption spectra of $\mathrm{SnO}_{2}+\mathrm{N} 3 \%$ at different depth of charge/discharge. The inset shows the corresponding Fourier transforms of Sn K-edge EXAFS spectra. (i) TEM image of $\mathrm{SnO}_{2}+\mathrm{N} 3 \%$, after 100 cycles ending with charge at $3.00 \mathrm{~V}$ vs. $\mathrm{Li}^{+} / \mathrm{Li}$. Scale bar is $2 \mathrm{~nm}$. The cell was disassembled within Ar filled glovebox with $\mathrm{O}_{2}$ and $\mathrm{H}_{2} \mathrm{O}$ levels $<1$ ppm.

Doping is well established as a method to modify and improve the properties of material. However, doping at the nanoscale is challenging, and the reasons for exceptional performance are not well understood. ${ }^{1}$ In this segment, ex-situ 
Laser pyrolyzed N-doped $\mathrm{SnO}_{2}$ for LIB and NIB (@CEA Saclay) Chapter 5

measurements will be carried out in an attempt to elucidate the details behind doping of $\mathrm{N}$ in $\mathrm{SnO}_{2}$. Cells terminated at seven different charged/discharged states (Figure 5.12a) were chosen for the investigation to help understand the function and position of $\mathrm{N}$ in $\mathrm{SnO}_{2}+\mathrm{N} 3 \%$ as well as changes in the chemical state of Sn during conversion and alloying reactions. Ex-situ SXRD was first carried out on $\mathrm{SnO}_{2}+\mathrm{N} 3 \%$ as shown in Figure 5.12b-d. The peaks corresponding to $\mathrm{SnO}_{2}$ becomes less intense during lithiation (Figure 5.12b), while a broad peak $\left(17.5^{\circ}\right)$ that could be assigned to that of $\mathrm{Li}_{22} \mathrm{Sn}_{5}$ appears upon complete lithiation. The disappearance of $\mathrm{SnO}_{2}$ peaks and the presence of $\mathrm{Li}_{22} \mathrm{Sn}_{5}$ indicated complete conversion of $\mathrm{SnO}_{2}$ into $\mathrm{Sn}$ followed by alloying of Li with Sn. Using the Scherrer's equation, we can estimate the crystallite size of $\mathrm{Li}_{22} \mathrm{Sn}_{5}$ to be about $2.5 \mathrm{~nm}$ based on the peak at $17.5^{\circ}$. No additional phases or impurities were present after complete discharge. During the charging process (Figure 5.12c), we observed the formation of crystalline $\mathrm{Sn}$ of which the crystallite size can be estimated to be $\sim 9 \mathrm{~nm}$. However, at the end of the charging process (point $\mathrm{v}$ in Figure 5.12c), crystalline $\mathrm{SnO}_{2}$ was not detected, which could be due to poor crystallinity as previously suggested in other works. ${ }^{31}$ Similarly, no impurity peaks were detected during complete charging. Subsequently, in the second discharge, we noted the presence of a more crystalline $\mathrm{Li}_{22} \mathrm{Sn}_{5}$ peak at the end of discharge (Figure 5.12d), which suggests growth in crystallite size during the cycling process.

X-ray absorption near-edge structure (XANES) and extended X-ray absorption fine structure (EXAFS) were then carried out to understand the role of $\mathrm{N}$ in $\mathrm{SnO} 2+\mathrm{N} 3 \%$ better. Figure 5.12e illustrates the first derivative of the normalized absorption at the Sn K-edge position, where the peak position can be directly correlated with the average oxidation state of Sn. It is noticeable for the OCV sample that the oxidation state is smaller than $4+$, which is consistent with our previous XPS results. The reduction of $\mathrm{Sn}$ is initiated from the start of discharge, where the first derivative peak shows a slight shift towards lower energy values, specifying a decrease in the average oxidation state of Sn. The white-line of the 
XANES spectrum in Figure 5.12f was found to broaden upon lithiation, signifying a reduction in density of the unoccupied $5 \mathrm{p}$ electronic states that could be associated with the phase transition from $\mathrm{SnO}_{2}$ to $\mathrm{Sn}$ during the initial conversion reaction. ${ }^{39}$ The inset in Figure $5.12 \mathrm{f}$ is the Fourier Transform (FT) of the corresponding Sn K-edge EXAFS spectrum. We can observe that the intensities of the Sn-O/Sn-N $(\sim 1.6 \AA)$ and $\mathrm{Sn}-\mathrm{Sn}(\sim 3.8 \AA)$ bonds in the first and fourth coordination shells decreases drastically during lithiation due to phase transformation into cubic Sn. ${ }^{40}$ Interestingly, the XANES edge position of $\mathrm{Sn}$ was found to be higher than $\mathrm{Sn}^{0}$ at complete discharge. The shift to higher energy level is caused by a small redistribution of charge between different metals in alloys (i.e. $\mathrm{Li}_{\mathrm{x}} \mathrm{Sn}$ ) so as to minimize the electrostatic energy while maintaining overall charge neutrality. ${ }^{41,42}$ It is noteworthy that there are two broad humps between $0.8-2.0 \AA$ along with a peak at $\sim 2.6 \AA(\mathrm{Sn}-\mathrm{Sn}(\mathrm{Li}))$ in the EXAFS spectrum at full discharge. The first hump at $\sim 1.1 \AA$ is attributed to background contribution, while the latter hump at $\sim 1.5 \AA$ can be profiled to contribution from Sn-O and/or Sn-N bonds. ${ }^{43}$ During the discharge process, Sn$\mathrm{O}$ bonds should have been fully broken for the conversion of $\mathrm{SnO}_{2}$ into $\mathrm{Sn}$ and hence, the first coordination shell Sn-O bonding signal should be low/negligible. This assumption has been shown in similar reported EXAFS studies. ${ }^{31,36} \mathrm{We}$ believe that this is also true for $\mathrm{SnO}_{2}+\mathrm{N} 3 \%$ considering the high capacity that is only achievable with reversible conversion and alloying process. To prove that the $\mathrm{Sn}-\mathrm{N}$ bond remains electrochemically inactive during lithiation, we compare the ex-situ EXAFS data between fully lithiated undoped $\mathrm{SnO}_{2}$ and $\mathrm{SnO}_{2}+\mathrm{N} 3 \%$, which is shown in Figure 5.13. Prior to the discharge reaction, $\mathrm{SnO} 2+\mathrm{N} 3 \%$ should largely comprise of Sn-O bonds and much lesser Sn-N bonds (only 3\% $\mathrm{N}$ content from XPS analysis), therefore resulting in a peak closer to $1.63 \AA$ when in $\mathrm{OCV}$ condition. This is consistent with the $\mathrm{SnO}_{2}$ standard reference powder (in pink) purchased from Sigma-Aldrich (Figure 5.14). Upon full discharge, this peak shifted to $\sim 1.55$ A for the $\mathrm{SnO} 2+\mathrm{N} 3 \%$ sample, which could be due to breaking of Sn-O bonds while the Sn-N bonds remain. 
Laser pyrolyzed N-doped $\mathrm{SnO}_{2}$ for LIB and NIB (@, CEA Saclay) Chapter 5

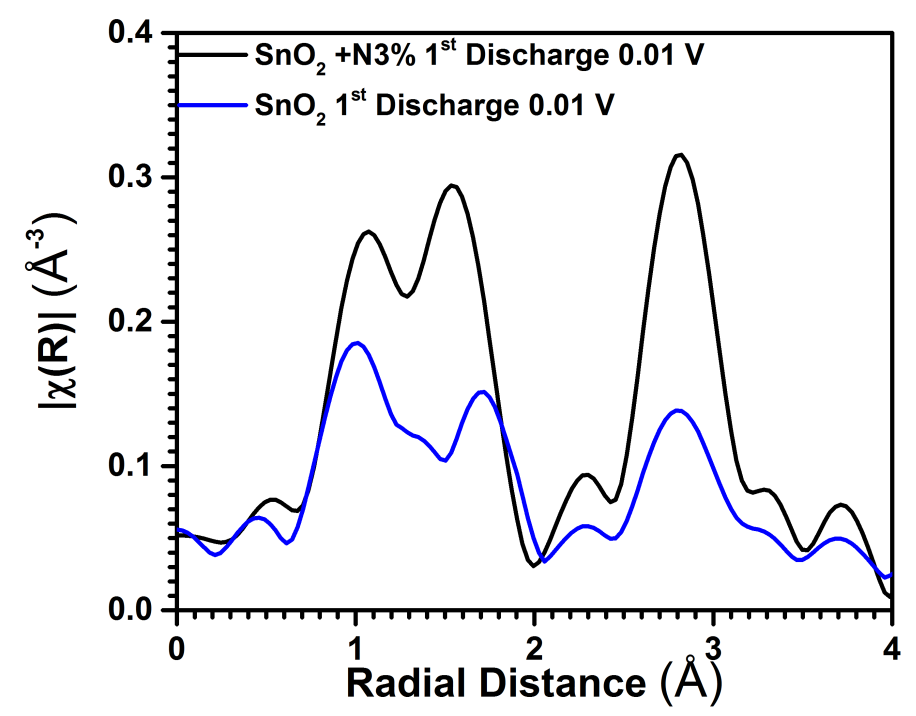

Figure 5.13 Comparison of EXAFS data for undoped $\mathrm{SnO}_{2}$ against $\mathrm{SnO}_{2}+\mathrm{N} 3 \%$ at full discharge $0.01 \mathrm{~V}$ vs. $\mathrm{Li}^{+} / \mathrm{Li}$
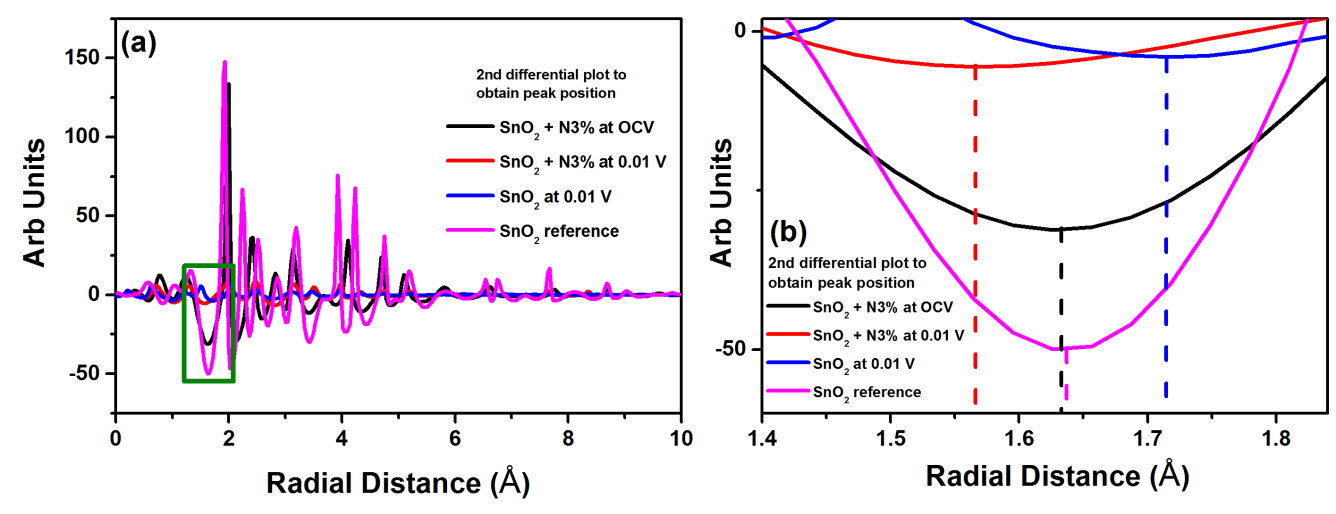

Figure 5.14 (a) $2^{\text {nd }}$ order differential EXAFS results comparing $\mathrm{SnO}_{2}$ and $\mathrm{SnO}_{2}+\mathrm{N} 3 \%$.

The peak positions could be reliably compared using the differential plots. The area boxed in green between 1.4 to $1.8 \AA$ is magnified and illustrated in (b).

Contrastingly, the peak position in the undoped $\mathrm{SnO} 2$ sample is slightly higher at close to 1.7. Should the Sn-N bond be electrochemically reactive and the leftover peak at 1.5-1.6 $\AA$ be assigned to Sn-O, we should should see similar peak position between undoped $\mathrm{SnO} 2$ and $\mathrm{SnO} 2+\mathrm{N} 3 \%$. However, this is not the case. In the fully discharged condition, due to superimposition between the high amount of Sn-N bonds as compared to $\mathrm{Sn}-\mathrm{O}$, a peak at $1.55 \mathrm{~A}$ is therefore 
observed instead of a peak at $1.7 \AA$. Therefore, we provide strong evidence that $\mathrm{Sn}-\mathrm{N}$ does not react during the lithiation process. We can also draw conclusion that $\mathrm{N}$ exists more preferentially by forming bonds with Sn instead of existing as interstitials. In the reverse charging process (Figure $5.12 \mathrm{~g}$ ), there is minimal XANES edge energy shift when charging to $1.20 \mathrm{~V}$, indicating that the dominant charge storage mechanism is the alloying process. A more significant shift can be observed when the anode is fully charged up to $3.00 \mathrm{~V}$. As could be seen in Figure 5.15a, the XANES Sn K-edge position at OCV and after $1^{\text {st }}$ cycle at $3.00 \mathrm{~V}$ are similar with one another, signifying efficient redox processes during cycling processes. Nevertheless, the white-line region in XANES (Figure 5.15a) appears to be less intense compared to the OCV state while the EXAFS spectra (Figure 5.15b) shows incomplete recovery of the Sn-O bonds in the $1^{\text {st }}$ and $3^{\text {rd }}$ coordination shells during full charge. ${ }^{31,39}$ The incomplete recovery of $\mathrm{Sn}-\mathrm{O}$ bond indicates that $\mathrm{SnO}_{2}$ converts into $\mathrm{SnO}_{\mathrm{x}}$ after the first charging cycle while the absence of $\mathrm{SnO}_{\mathrm{x}}$ (where $\mathrm{x}=1$ or 2) peaks in ex-situ SXRD suggests that the $\mathrm{SnO}_{\mathrm{x}}$ is amorphous. The Sn K-edge XANES plot in Figure $5.15 \mathrm{c}$ shows excellent fitting between the $1^{\text {st }}$ and $2^{\text {nd }}$ cycle when discharged to $0.01 \mathrm{~V}$. The corresponding FT EXAFS spectra (Figure 5.15d) depicts slight differences in local structure ordering between $1^{\text {st }}$ and $2^{\text {nd }}$ cycles at $0.01 \mathrm{~V}$. The broad peaks in between $0.8-2.0 \AA$ appears to be better resolved, which implies that structure reordering happens during lithiation/delithiation. The main difference in our results compared to other XAS studies clearly lies with the presence of the Sn-N bond observed during lithiation, suggesting that the high specific capacity during cycling is attributed to the excellent reversibility while $\mathrm{N}$ doping serves only as a positive influence in enhancing electrical conductivity. ${ }^{31,36}$

HRTEM analyses were performed to get insights on the material's structure integrity after cycling at $1.4 \mathrm{~A} \mathrm{~g}^{-1}$ over 100 cycles. The cells were terminated in the charged state followed by disassembly in the glovebox. Figure 5.12i presents the ex-situ HRTEM image of $\mathrm{SnO}_{2}+\mathrm{N} 3 \%$, which revealed the presence 
of very fine crystalline $\beta$-Sn (JCPDS: $65-2631$ ). We believe that there is minimal crystal-electron beam interaction because of the co-existence of noncrystalline particles. As could be seen, an amorphous layer that could possibly be $\mathrm{Li}_{2} \mathrm{O}$ covers the $\mathrm{Sn}$ particles homogeneously. The particles appear to be single crystalline and measures about $8-10 \mathrm{~nm}$ in diameter, which is consistent with our XRD results.
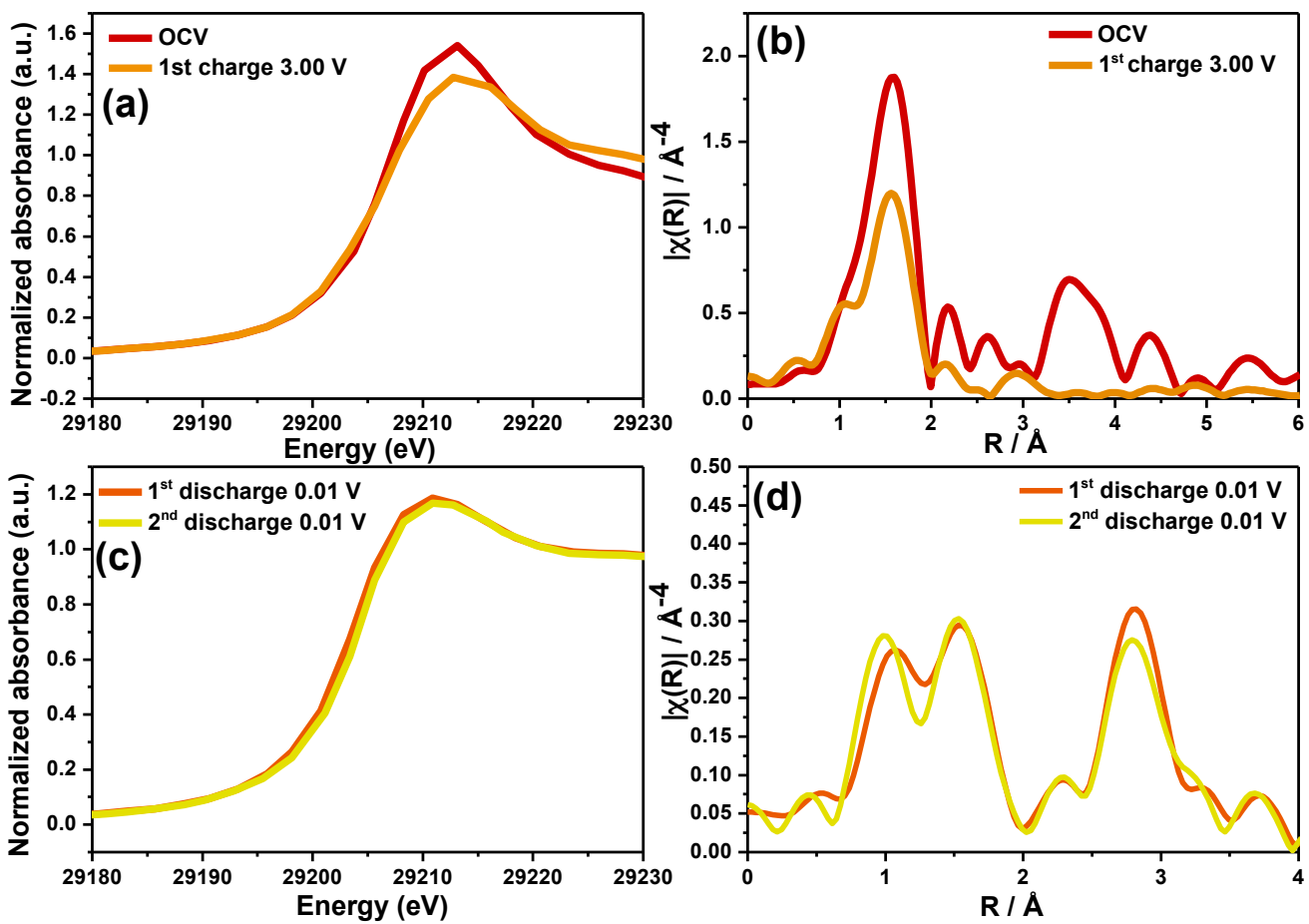

Figure 5.15 Sn K-edge (a) XANES normalized absorption and (b) Fourier transformed EXAFS spectrums for $\mathrm{SnO}_{2}+\mathrm{N} 3 \%$ during OCV and after $1^{\text {st }}$ charge at $3.00 \mathrm{~V}$. (c) \& (d) similarly corresponds to the XANES and FT EXAFS at $0.01 \mathrm{~V}$ during full discharge in the $1^{\text {st }}$ and $2^{\text {nd }}$ cycle.

\subsection{Summary}

In this chapter, we systematically compared the electrochemical performance between pristine $\mathrm{SnO}_{2}$ nanoparticles with $\mathrm{N}$-doped samples that were synthesized from a one-step laser-assisted pyrolysis process. To the best of our knowledge, the electrochemical performance of $\mathrm{N}$-doped $\mathrm{SnO}_{2}$ as an anode in 
Laser pyrolyzed N-doped $\mathrm{SnO}_{2}$ for LIB and NIB (@,CEA Saclay) Chapter 5

both LIB and NIB is reported for the first time. In the lithiation system, both pristine and $\mathrm{N}$-doped $\mathrm{SnO}_{2}$ nanoparticles demonstrated superior electrochemical performances as compared to other carbon-based $\mathrm{SnO}_{2}$ or doped $\mathrm{SnO}_{2}$. In particular, reversible capacities of 1241 and $522 \mathrm{mAh} \mathrm{g}^{-1}$ were recorded for $\mathrm{SnO}_{2}+\mathrm{N} 3 \%$ at 0.1 and $10 \mathrm{~A} \mathrm{~g}^{-1}$ respectively, along with a capacity of $1192 \mathrm{mAh}$ $\mathrm{g}^{-1}$ that could be maintained at $1.4 \mathrm{~A} \mathrm{~g} \mathrm{~g}^{-1}$ after 500 cycles. $\mathrm{SnO}_{2}+\mathrm{N} 3 \%$ outperformed other samples especially at high current rates due to their more efficient charge transfer processes that could be associated with an optimum dopant concentration. Attempts to increase $\mathrm{N}$ concentration resulted in a reduction of $\mathrm{Sn}^{4+}$ into $\mathrm{Sn}^{0}$, which is inversely accompanied by more sluggish kinetic. XAS was utilized to monitor the position and the function of $\mathrm{N}$ dopant as well as to investigate the local chemical state of Sn during cycling. The exceptional conductivity and cyclability could be attributed to the presence of an unreactive Sn-N bonding in the structure during charge/discharge. Moreover, the small particle sizes achievable from to the laser pyrolysis process permit rapid ion diffusion while preventing pulverization and agglomeration. In contrast, pristine $\mathrm{SnO}_{2}$ demonstrated the best performance (334 $\mathrm{mAh} \mathrm{g}^{-1}$ ) among the three samples when tested in NIB. Despite the low capacity, the electrochemical performance can be considered one of the best among pristine $\mathrm{SnO}_{2}$ nanoparticles. The inclusion of nitrogen dopants was however, found to hurt the electrochemical performance, with $\mathrm{SnO}_{2}+\mathrm{N} 3 \%$ and $\mathrm{SnO}_{2}+\mathrm{N} 8 \%$ delivering specific capacities of 298 and $316 \mathrm{mAh} \mathrm{g}^{-1}$ respectively.

\section{References:}

1. S. G. Kwon, S. Chattopadhyay, B. Koo, P. C. dos Santos Claro, T. Shibata, F. G. Requejo, L. J. Giovanetti, Y. Liu, C. Johnson, V. Prakapenka, B. Lee and E. V. Shevchenko, Nano Letters, 2016, DOI: 10.1021/acs.nanolett.6b01072.

2. J. H. Yu, S.-H. Kwon, Z. Petrášek, O. K. Park, S. W. Jun, K. Shin, M. Choi, Y. I. Park, K. Park, H. B. Na, N. Lee, D. W. Lee, J. H. Kim, P. Schwille and T. Hyeon, Nat Mater, 2013, 12, 359-366.

3. F. Wang, Y. Han, C. S. Lim, Y. Lu, J. Wang, J. Xu, H. Chen, C. Zhang, M. Hong and X. Liu, Nature, 2010, 463, 1061-1065. 
Laser pyrolyzed N-doped $\mathrm{SnO}_{2}$ for LIB and NIB (@,CEA Saclay) Chapter 5

4. X. Ye, W. Zhang, Q. Liu, S. Wang, Y. Yang and H. Wei, New Journal of Chemistry, 2015, 39, 130-135.

5. Y. Wang, I. Djerdj, B. Smarsly and M. Antonietti, Chemistry of Materials, 2009, 21, 3202-3209.

6. X. Wang, Z. Li, Z. Zhang, Q. Li, E. Guo, C. Wang and L. Yin, Nanoscale, 2015, 7, 3604-3613.

7. F. Mueller, D. Bresser, V. S. K. Chakravadhanula and S. Passerini, Journal of Power Sources, 2015, 299, 398-402.

8. J. Sun, L. Xiao, S. Jiang, G. Li, Y. Huang and J. Geng, Chemistry of Materials, 2015, 27, 4594-4603.

9. D. O. Scanlon and G. W. Watson, Journal of Materials Chemistry, 2012, 22, 25236-25245.

10. E. Albanese, C. Di Valentin, G. Pacchioni, F. Sauvage, S. Livraghi and E. Giamello, The Journal of Physical Chemistry C, 2015, 119, 26895-26903.

11. X. Sun, R. Long, X. Cheng, X. Zhao, Y. Dai and B. Huang, The Journal of Physical Chemistry C, 2008, 112, 9861-9864.

12. F. Fang, Y. Zhang, X. Wu, Q. Shao and Z. Xie, Materials Research Bulletin, 2015, 68, 240-244.

13. Y. Zhao, C. Wei, S. Sun, L. P. Wang and Z. J. Xu, Advanced Science, 2015, 2, n/a-n/a.

14. L. P. Wang, Y. Zhao, C. Wei, C. Wong, M. Srinivasan and Z. J. Xu, Journal of Materials Chemistry A, 2015, 3, 14033-14038.

15. V. Bonu, A. Das, A. K. Sivadasan, A. K. Tyagi and S. Dhara, Journal of Raman Spectroscopy, 2015, 46, 1037-1040.

16. A. Diéguez, A. Romano-Rodríguez, A. Vilà and J. R. Morante, Journal of Applied Physics, 2001, 90, 1550-1557.

17. S. S. Pan, G. H. Li, L. B. Wang, Y. D. Shen, Y. Wang, T. Mei and X. Hu, Applied Physics Letters, 2009, 95, 222112.

18. J. Y. Huang, L. Zhong, C. M. Wang, J. P. Sullivan, W. Xu, L. Q. Zhang, S. X. Mao, N. S. Hudak, X. H. Liu, A. Subramanian, H. Fan, L. Qi, A. Kushima and J. Li, Science, 2010, 330, 1515-1520.

19. J. Jiang, Y. Lu, B. Kramm, F. Michel, C. T. Reindl, M. E. Kracht, P. J. Klar, B. K. Meyer and M. Eickhoff, physica status solidi (b), 2016, 253, 1087-1092.

20. F. Matossi, The Journal of Chemical Physics, 1951, 19, 1543-1546.

21. V. Bonu, A. Das, S. Amirthapandian, S. Dhara and A. K. Tyagi, Physical Chemistry Chemical Physics, 2015, 17, 9794-9801.

22. A. Leonardy, W.-Z. Hung, D.-S. Tsai, C.-C. Chou and Y.-S. Huang, Crystal Growth \& Design, 2009, 9, 3958-3963.

23. X. Feng, C. Shen, N. Ding and C. Chen, Journal of Materials Chemistry, 2012, 22, 20861-20865.

24. M. Kitano, K. Funatsu, M. Matsuoka, M. Ueshima and M. Anpo, The Journal of Physical Chemistry B, 2006, 110, 25266-25272.

25. Z. Li, A. Mikula and Z. Qiao, Monatshefte für Chemie / Chemical Monthly, 2005, 136, 1835-1840.

26. A. M. Glushenkov, D. Hulicova-Jurcakova, D. Llewellyn, G. Q. Lu and Y. Chen, Chemistry of Materials, 2010, 22, 914-921.

27. W. Wang, P. Liu, M. Zhang, J. Hu and F. Xing, 2012. 
Laser pyrolyzed N-doped $\mathrm{SnO}_{2}$ for LIB and NIB (@,CEA Saclay) Chapter 5

28. S. J. Clark, D. Wang, A. R. Armstrong and P. G. Bruce, Nat Commun, 2016, 7.

29. Y.-Y. Hu, Z. Liu, K.-W. Nam, O. J. Borkiewicz, J. Cheng, X. Hua, M. T. Dunstan, X. Yu, K. M. Wiaderek, L.-S. Du, K. W. Chapman, P. J. Chupas, X.-Q. Yang and C. P. Grey, Nat Mater, 2013, 12, 1130-1136.

30. Y. Xu, Q. Liu, Y. Zhu, Y. Liu, A. Langrock, M. R. Zachariah and C. Wang, Nano Letters, 2013, 13, 470-474.

31. H. Kim, G. O. Park, Y. Kim, S. Muhammad, J. Yoo, M. Balasubramanian, Y.-H. Cho, M.-G. Kim, B. Lee, K. Kang, H. Kim, J. M. Kim and W.-S. Yoon, Chemistry of Materials, 2014, 26, 6361-6370.

32. V. Augustyn, P. Simon and B. Dunn, Energy \& Environmental Science, 2014, 7, 1597-1614.

33. M. Okubo, E. Hosono, J. Kim, M. Enomoto, N. Kojima, T. Kudo, H. Zhou and I. Honma, Journal of the American Chemical Society, 2007, 129, 7444-7452.

34. C. Mao, Y. Zhao, X. Qiu, J. Zhu and C. Burda, ECS Transactions, 2009, 16, 67-77.

35. C.-M. Park, J.-H. Kim, H. Kim and H.-J. Sohn, Chemical Society Reviews, 2010, 39, 3115-3141.

36. C. J. Pelliccione, E. V. Timofeeva and C. U. Segre, The Journal of Physical Chemistry C, 2016, 120, 5331-5339.

37. V. Augustyn, J. Come, M. A. Lowe, J. W. Kim, P.-L. Taberna, S. H. Tolbert, H. D. Abruña, P. Simon and B. Dunn, Nat Mater, 2013, 12, 518-522.

38. M. Park, X. Zhang, M. Chung, G. B. Less and A. M. Sastry, Journal of Power Sources, 2010, 195, 7904-7929.

39. L. Y. Lim, N. Liu, Y. Cui and M. F. Toney, Chemistry of Materials, 2014, 26, 3739-3746.

40. K. Kisu, M. lijima, E. Iwama, M. Saito, Y. Orikasa, W. Naoi and K. Naoi, Journal of Materials Chemistry A, 2014, 2, 13058-13068.

41. J. S. Tian, G. M. Han, H. Wei, Q. Zheng, T. Jin, X. F. Sun and Z. Q. Hu, Philosophical Magazine, 2013, 93, 2161-2171.

42. H. H. Hsieh, Y. K. Chang, W. F. Pong, J. Y. Pieh, P. K. Tseng, T. K. Sham, I. Coulthard, S. J. Naftel, J. F. Lee, S. C. Chung and K. L. Tsang, Physical Review B, 1998, 57, 15204-15210.

43. D. Luetzenkirchen-Hecht, N. Scotti, H. Jacobs and R. Frahm, Journal of synchrotron radiation, 2001, 8, 698-700. 


\section{Chapter 6}

\section{Understanding and evaluating the effect of matrix engineering with the incorporation of $\mathrm{ZnO}$ to form $\mathrm{ZnSnO}_{3}$}

This chapter evaluates the impact of introducing $\mathrm{ZnO}$ into the matrix of $\mathrm{SnO}_{2}$ for the formation of $\mathrm{ZnSnO}_{3}$ hollow cubes. This concept is demonstrated in NIB for the first time and shows superior electrochemical performances compared to other reported $\mathrm{SnO}_{2}$ materials. Conversely, this method was shown not to be as effective in $L I B$. 


\subsection{Introduction}

In contrast to the preparation of graphene-based composites and elemental doping to enhance the performance of $\mathrm{SnO}_{2}$, the incorporation of a foreign phase into $\mathrm{SnO}_{2}$ has been uncommon in LIB and even more so in NIB. Nevertheless, proper design by incorporating different phases under intimate proximity into the structure has been shown to be effective in enhancing cyclability. The different phases could be electrochemically active $(\mathrm{ZnO})$ or inactive $(\mathrm{CaO})$ and may form different phases (i.e. $\mathrm{ZnSnO}_{3}, \mathrm{CaSnO}_{3}$ ) when synthesized collectively. Such phases may also induce an inductive effect that allows tuning of the electrochemical working potential window.

Furthermore, hollow structured materials in particular, have demonstrated the ability to withstand large volumetric changes during cycling while providing for the large surface area necessary to facilitate electrochemical reactions. ${ }^{1,2}$ Similarly, homogeneous agglomeration of nanoparticles could be avoided by designing a composite that comprises of a well-distributed matrix of heterogeneous elements. Alcántara et al. was first to briefly report the electrochemical performance of spinel $\mathrm{NiCo}_{2} \mathrm{O}_{4}$ as a prospective anode for sodium-ion batteries (NIBs). ${ }^{3}$ However since then, reports on mixed transition metal oxides (MTMOs) in NIB application have been scarce due to a more complicated sodiation nature as compared to lithiation. ${ }^{4}$ Nevertheless, we believe that such MTMOs could hold prospect for not just LIBs but also in NIB application.

Herein, we evaluate the electrochemical performance of hollow $\mathrm{ZnSnO}_{3}$ that was prepared from a facile co-precipitation $\&$ annealing strategy as a promising anode material for both LIB and NIBs. Elemental mapping results revealed the presence of well distributed $\mathrm{Zn}$ and $\mathrm{Sn}$ in the as-synthesized cubes. When tested in NIBs, $\mathrm{ZnSnO}_{3}$ was found to benefit from the difference in size expansion, which led to enhanced performance compared to previously reported $\mathrm{SnO}_{2}$ materials. Conversely, the effectiveness of using $\mathrm{ZnSnO}_{3}$ was found to be less prominent in LIBs. We postulate that the poorer performance in LIB could be 
due to lesser buffering effect of $\mathrm{Zn}$ with $\mathrm{Li}(174 \%)$ as compared to $\mathrm{Na}(\sim 0 \%)$.

\subsection{Synthesis}

\subsubsection{Chemicals}

Tin (IV) chloride pentahydrate $\left(\mathrm{SnCl}_{4} \bullet 5 \mathrm{H}_{2} \mathrm{O}\right)$, Sodium citrate monobasic $\left(\mathrm{HOC}(\mathrm{COONa})\left(\mathrm{CH}_{2} \mathrm{COOH}\right)_{2}\right)$ and Sodium hydroxide $(\mathrm{NaOH})$ were purchased and received from Sigma-Aldrich without further purification. Anhydrous Zinc (II) chloride $\left(\mathrm{ZnCl}_{2}\right)$, Zinc Oxide $(\mathrm{ZnO})$ and Tin (IV) oxide $\left(\mathrm{SnO}_{2}\right)$ were purchased and received from Alfa Aesar without further purification. Coin cell components and etched copper/aluminum foils were purchased from MTI corp.

\subsubsection{Co-precipitation synthesis}

Synthesis processes were carried out in similar fashion with previously reported literature but with modifications to yield polycrystalline hollow cubes. ${ }^{1,5}$ Two separate solutions were individually prepared before the reaction. Solution A contains $0.2 \mathrm{M} \mathrm{SnCl}_{4} \cdot 5 \mathrm{H}_{2} \mathrm{O}$ dissolved into $10 \mathrm{ml}$ of ethanol while Solution B comprises of $0.1 \mathrm{M}$ anhydrous $\mathrm{ZnCl}_{2}$ and $0.1 \mathrm{M}$ of sodium citrate monobasic dissolved in $20 \mathrm{ml}$ of DI water. Subsequently, solution A and B were mixed with one another under vigorous stirring for 10 mins to obtain a homogeneous solution. $50 \mathrm{ml}(0.41 \mathrm{M}) \mathrm{NaOH}$ was subsequently added to the mixture, resulting in the formation of a white precipitate $\left(\mathrm{ZnSn}(\mathrm{OH})_{6}\right)$. After $30 \mathrm{~min}$ of vigorous stirring, an additional amount of $30 \mathrm{ml}(3 \mathrm{M}) \mathrm{NaOH}$ was added in as an etching agent. The resultant precipitate was collected, centrifuged, washed and then dried at $80{ }^{\circ} \mathrm{C}$ for 12 hours under vacuum condition. Thereafter, thermal annealing was carried out at $500{ }^{\circ} \mathrm{C}$ for 2 hours to yield polycrystalline hollow $\mathrm{ZnSnO}_{3}$. Solid $\mathrm{ZnSnO}_{3}$ cubes were synthesized in a similar fashion except that $3 \mathrm{M} \mathrm{NaOH}$ was not added in the final step to etch the core of the structure. Henceforth, the $\mathrm{ZnSnO}_{3}$ cubes with hollow and solid cores will be termed $\mathrm{ZSO}-\mathrm{H}$ and $\mathrm{ZSO}$, respectively. The $\mathrm{ZnO}-\mathrm{SnO}_{2}$ mixture was prepared by grinding it in an agate mortar bowl and pestle. 


\subsection{Physical characterization}

XRD was first utilized to probe into the crystal structure of the as-synthesized $\mathrm{ZnSnO}_{3}$ and is presented in Figure 6.1. The corresponding XRD peaks of the assynthesized $\mathrm{ZnSnO}_{3}$ could not be clearly isolated while only a broad asymmetric peak could be observed ranging from $25-38^{\circ}$, suggesting an overlap of 2 different diffraction peaks. However, the results are not conclusive with $\mathrm{XRD}$; therefore further methods are required to characterize the product.

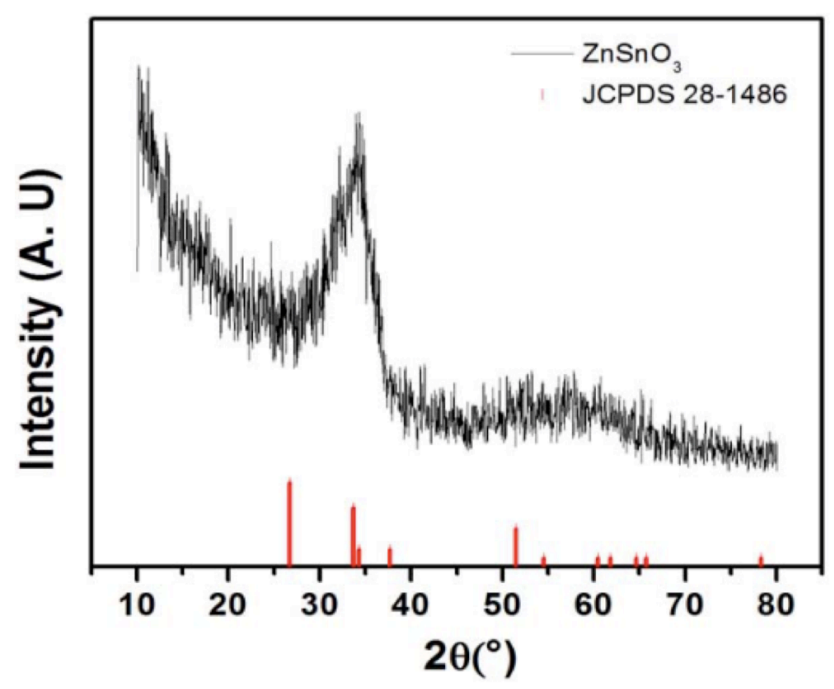

Figure 6.1 XRD pattern of the as-prepared $\mathrm{ZnSnO}_{3}$

The Scanning Electron Microscopy (SEM) image of the $\mathrm{ZnSnO}_{3}$ cubes is illustrated in Figure 6.2a. As could be seen, the morphology is cubic in shape with sizes ranging from 1.0-2.0 $\mu \mathrm{m}$. Several cubes were found to have broken edges thus exposing the hollow interior of the structure. The cube walls appear to be rough, of which the entire cube seems to be made up of self-assembled nanoparticles. TEM investigations (Figure 6.2b) further confirm that these cubes are indeed hollow and possess a wall thickness of about $\sim 150 \mathrm{~nm}$. HRTEM of $\mathrm{ZnSnO}_{3}$ (Figure 6.2c) indicated the presence of 2 different sets of lattice spacing with distances of $\sim 0.337 \mathrm{~nm}$ and $\sim 0.271 \mathrm{~nm}$, which are close to the interplanar distance of (012) and (110) respectively, in orthorhombic 
$\mathrm{ZnSnO}_{3}$ (JCPDS no. 28-1486). This is in agreement with previously reported $\mathrm{ZnSnO}_{3}$ nanorods and nanospheres. ${ }^{6,7}$ Additionally, the HRTEM image indicates that the microcubes are made up of agglomerated polycrystalline $\mathrm{ZnSnO}_{3}$ nanoparticles that are of sizes between $5-15 \mathrm{~nm}$. Further analysis by employing SAED showed typical polycrystalline $\operatorname{rings}^{8,9}$ of which the innermost 2 brightest rings could be indexed to diffraction peaks of $26.5^{\circ}(012)$ and $33.7^{\circ}(110)$ in JCPDS NO. 28-1486, respectively.

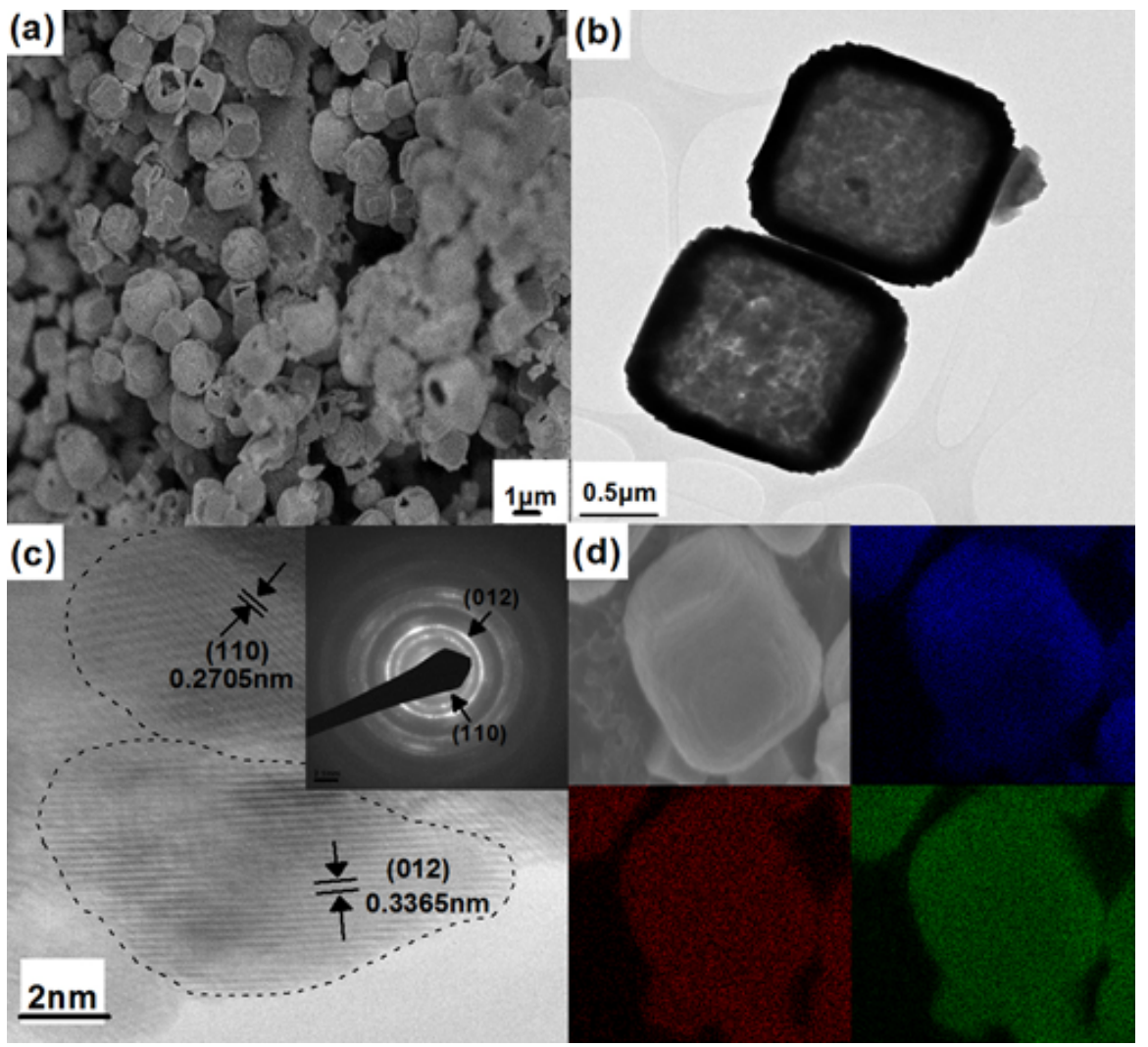

Figure 6.2 (a) low magnification SEM image of the as-synthesized ZSO-H (b) TEM image of polycrystalline hollow cubes (c) HRTEM revealing lattice spacing and the agglomerate of nanoparticles (inset shows typical polycrystalline Selected Area Electron Diffraction (SAED) pattern) (d) SEM-EDX element mapping of Zn, Sn and O on a single cube.

At this juncture, HRTEM results and the corresponding SAED diffraction pattern could be used to explain the above XRD spectrum. The existence of small-sized particulates may have led to peak broadening, which results in the overlapping of adjacent peaks $\left(26.5^{\circ}\right.$ and $\left.33.7^{\circ}\right) .{ }^{10}$ The XRD result is also 
similar with that of previously reported stannates prepared via co-precipitation methods. ${ }^{11}$ Figure 6.3 illustrates the qualitative Energy Dispersive X-ray (EDX) and quantitative results that $\mathrm{Zn}$ and $\mathrm{Sn}$ exist in an atomic \% ratio of $\sim 1$. Element mapping of a single cube could be seen in Figure $6.2 \mathrm{~d}$, which revealed the exceptionally uniform distribution of $\mathrm{Zn}, \mathrm{Sn}$ and $\mathrm{O}$ elements. Hence, we can qualitatively determine that the as-synthesized product is $\mathrm{ZnSnO}_{3}$.

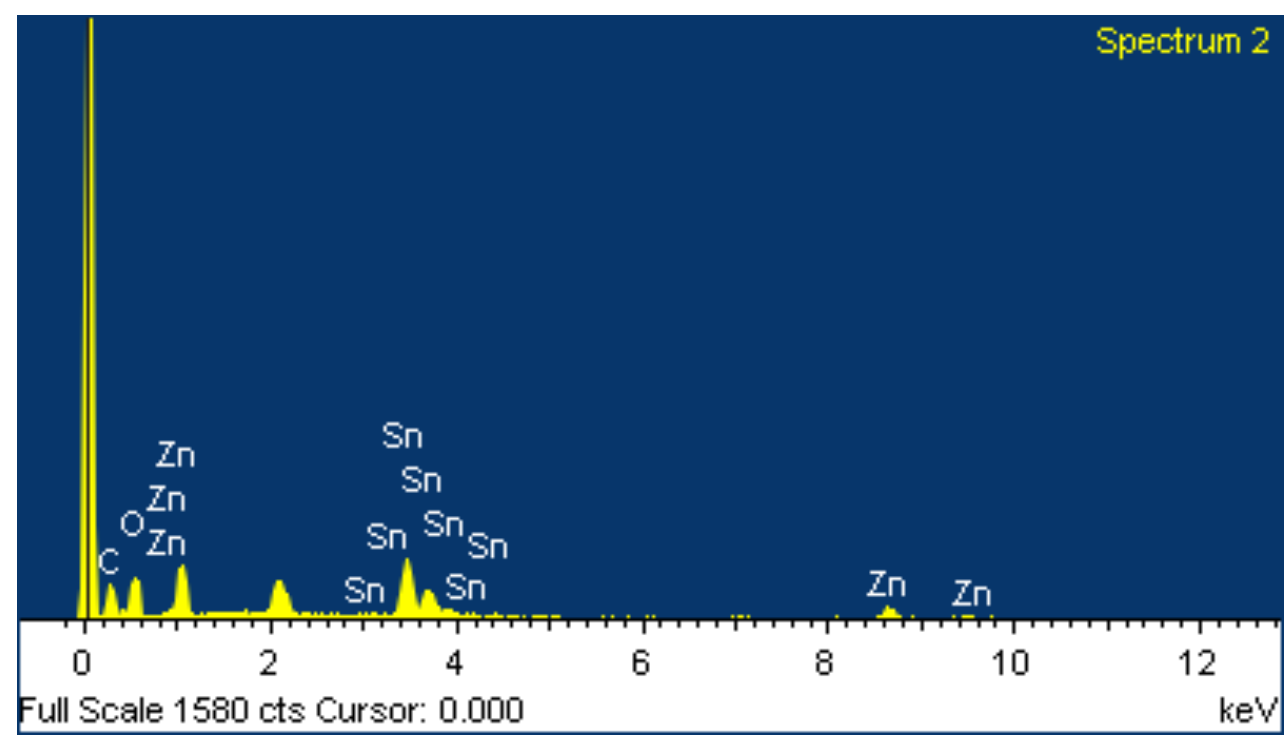

Figure 6.3 Energy dispersive $\mathrm{X}$-ray mapping of $\mathrm{ZnSnO}_{3}$ hollow cubes.

\subsection{Electrochemical measurements}

\subsubsection{Cyclic Voltammetry}

Electrochemical measurements of $\mathrm{ZnSnO}_{3}$ were carried out using a two-cell setup with $\mathrm{Li} / \mathrm{Na}$ foils as the counter and reference electrode as per described in section 3.4. Cyclic voltammogram (CV) was carried out at a scan rate of 0.1 $\mathrm{mV} \mathrm{s}^{-1}$ within a voltage window of $0.01-3.00 \mathrm{~V} \mathrm{vs.} \mathrm{Li}^{+} / \mathrm{Li}$ or $\mathrm{Na}^{+} / \mathrm{Na}$ (Figure 6.4). Common for MTMOs, the $1^{\text {st }}$ reduction reaction in both LIB and NIB comprises of an irreversible conversion processes in which $\mathrm{ZnSnO}_{3}$ first breaks down to form the individual elemental oxides, i.e. $\mathrm{ZnO} \& \mathrm{SnO}_{2}$. Subsequently, an ensuing reduction occurs to form its core element form, i.e. $\mathrm{Zn} \& \mathrm{Sn}$ (Equation 1). In both systems, the elemental $\mathrm{Zn}$ and $\mathrm{Sn}$ would be encapsulated within a $\mathrm{Li}_{2} \mathrm{O} / \mathrm{Na}_{2} \mathrm{O}$ matrix following the latter reaction. 
In the lithiation process, both $\mathrm{Zn}$ and $\mathrm{Sn}$ go on to alloy with $\mathrm{Li}$, forming $\mathrm{LiZn}$ and $\mathrm{Li}_{4.4} \mathrm{Sn}$ respectively. In the reverse oxidation process, dealloying of $\mathrm{LiZn}$ and $\mathrm{Li}_{4.4} \mathrm{Sn}$ occurs back into $\mathrm{Zn}$ and $\mathrm{Sn}$ respectively. Thereafter, deconversion process takes place to form back $\mathrm{ZnO}$ and $\mathrm{SnO}_{2}$. The theoretical capacity arising from both the conversion and alloying reactions amount to $1316 \mathrm{mAh}^{-}$ 1. The formation of $\mathrm{ZnSnO}_{3}$ has been reported to be not possible. ${ }^{12}$ The overall reaction is as follows:

$$
\begin{aligned}
& \mathrm{ZnSnO}_{3}->\mathrm{ZnO}+\mathrm{SnO}_{2} \\
& \mathrm{ZnO}+2 \mathrm{Li}^{+}+2 \mathrm{e}^{-} \leftrightarrows \mathrm{Zn}+\mathrm{Li}_{2} \mathrm{O} \\
& \mathrm{SnO}_{2}+4 \mathrm{Li}^{+}+4 \mathrm{e}^{-} \leftrightarrows \mathrm{Sn}+2 \mathrm{Li}_{2} \mathrm{O} \\
& \mathrm{Zn}+\mathrm{Li}^{+}+\mathrm{e}^{-} \leftrightarrows \mathrm{LiZn} \\
& \mathrm{Sn}+4.4 \mathrm{Li}^{+}+4.4 \mathrm{e}^{-} \leftrightarrows \mathrm{Li}_{4.4} \mathrm{Sn}
\end{aligned}
$$

Alloying reactions between $\mathrm{Sn}$ and $\mathrm{Na}$ have been widely reported in recent years in which multi-redox processes results in the formation of $\mathrm{Na}_{15} \mathrm{Sn}_{4}$, giving rise to a theoretical capacity of $847 \mathrm{mAh} \mathrm{g}^{-1} .1,13,14$ On the other hand, electrochemical performance for alloying of $\mathrm{Zn}$ and $\mathrm{Na}$ has yet to be reported. According to the Na-Zn phase diagram, the formation of $\mathrm{NaZn}_{13}$ is possible. However, the theoretical capacity (assuming reaction 3) obtainable from the alloying reaction contributes to only a mere $32 \mathrm{mAh} \mathrm{g}^{-1} .{ }^{15}$ Dominant $\mathrm{Sn}$ redox fingerprints in the $\mathrm{CV}$ curves further highlight this. While the electrochemical performance of $\mathrm{ZnSnO}_{3}$ has not been reported thus far, the theoretical overall reaction can be deduced as follows:

$$
\begin{aligned}
& \mathrm{ZnSnO}_{3}->\mathrm{ZnO}+\mathrm{SnO}_{2} \\
& \mathrm{ZnO}+2 \mathrm{Na}^{+}+2 \mathrm{e}^{-}->\mathrm{Zn}+\mathrm{Na}_{2} \mathrm{O} \\
& \mathrm{SnO}_{2}+4 \mathrm{Na}^{+}+4 \mathrm{e}^{-}->\mathrm{Sn}+2 \mathrm{Na}_{2} \mathrm{O} \\
& 13 \mathrm{Zn}+\mathrm{Na}^{+}+\mathrm{e}^{-} \leftrightarrows \mathrm{NaZn}_{13} \\
& \mathrm{Sn}+3.75 \mathrm{Na}^{+}+4.4 \mathrm{e}^{-} \leftrightarrows \mathrm{Na}_{3.75} \mathrm{Sn}
\end{aligned}
$$

A clear difference between the $1^{\text {st }}$ and $2^{\text {nd }}$ reduction sweeps in both systems 
could be observed from the CV curves, which is a result of capacity loss related to the irreversible initial transformation from $\mathrm{ZnSnO}_{3}$ as well as the formation of SEI layer on the electrode surface.
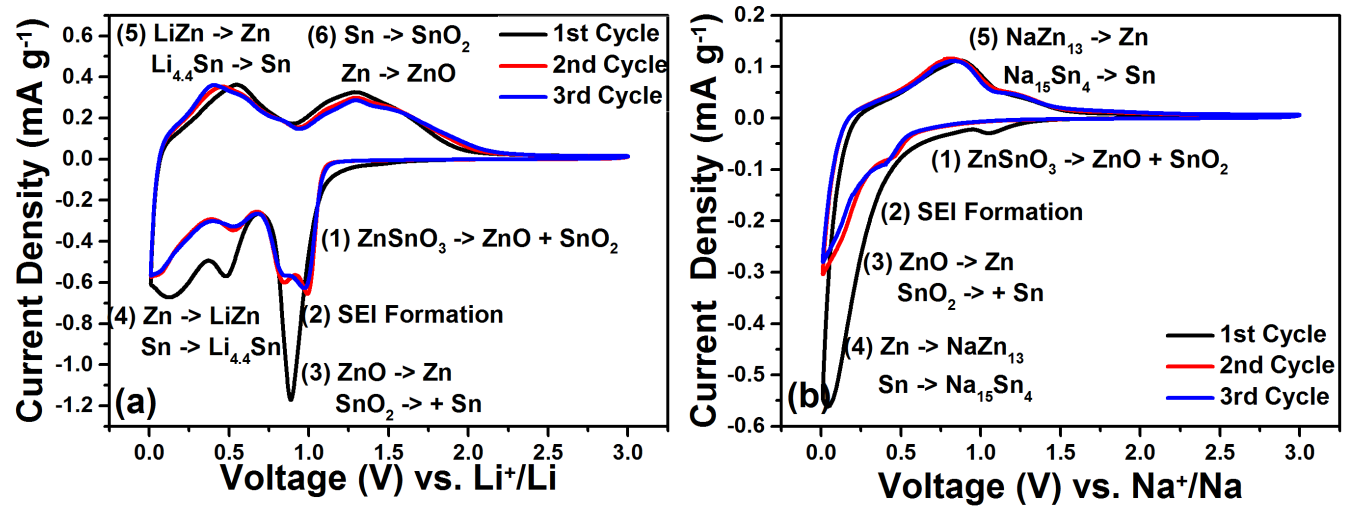

Figure 6.4 Cyclic voltammogram of $\mathrm{ZnSnO}_{3}$ under a scan rate of $0.1 \mathrm{mV} \mathrm{s}^{-1}$ in (a) LIB and (b) NIB.

\subsubsection{Galvanostatic cycling}

Galvanostatic charge-discharge was utilized to qualitatively evaluate the performance of $\mathrm{ZnSnO}_{3}$ in both LIB and NIB.

For the lithiation performance (Figure 6.5a) of $\mathrm{ZnSnO}_{3}$ hollow cubes, an initial capacity of $1564 \mathrm{mAh} \mathrm{g}^{-1}$ can be obtained at a current density of $100 \mathrm{~mA} \mathrm{~g}^{-1}$ within a voltage range between $0.01-3.00 \mathrm{~V}$ vs. $\mathrm{Li}^{+} / \mathrm{Li}$. The corresponding coulombic efficiency (C.E.) in the $1^{\text {st }}$ cycle is $\sim 64 \%$. In the subsequent cycle, a specific capacity of $1117 \mathrm{mAh} \mathrm{g}^{-1}$ is recorded along with a C.E. of $98 \%$. The higher than theoretical capacity and low C.E. in the $1^{\text {st }}$ cycle can be attributed to an additional irreversible consumption of $\mathrm{Li}^{+}$ions for the formation of a SEI layer. The sloping electrochemical signature of $\mathrm{ZnSnO}_{3}$ is largely different from that of pristine $\mathrm{ZnO}^{16}$ or $\mathrm{SnO}_{2}{ }^{17}$ materials, which can be ascribed to a continuous potential range that alloying can be allowed to occur.

The sodiation performance of $\mathrm{ZnSnO}_{3}$ can be found in Figure 6.5b. As could be seen, an initial discharge capacity of $635 \mathrm{mAh} \mathrm{g}^{-1}$ can be recorded at a current density of $30 \mathrm{~mA} \mathrm{~g}^{-1}$. The corresponding C.E. was calculated to be $\sim 48 \%$. In the second cycle, the discharge capacity recorded is $315 \mathrm{mAh} \mathrm{g}^{-1}$, while the C.E 
increases to $\sim 100 \%$, signifying efficient reversible charge storage processes in the second cycle. The low C.E. in the $1^{\text {st }}$ cycle is similar to its lithium counterpart and due to the formation of SEI layer. In addition, different from the lithiation process, the irreversible reduction of $\mathrm{ZnO}$ and $\mathrm{SnO}_{2}$ into $\mathrm{Zn}$ and Sn also contributes to the loss in capacity during the $1^{\text {st }}$ cycle. It should be noted that the flat discharge plateau at $\sim 0.45 \mathrm{~V}$ vs. $\mathrm{Na}^{+} / \mathrm{Na}$, corresponding to the irreversible conversion of $\mathrm{ZnSnO}_{3}$ into its elemental metals ( $\mathrm{Zn} \mathrm{\&} \mathrm{Sn),}$ disappears after the first cycle and a gentle sloping profile occurring between $0.30-0.01 \mathrm{~V}$ vs. $\mathrm{Na}^{+} / \mathrm{Na}$ is seen from the $2^{\text {nd }}$ cycle onwards.
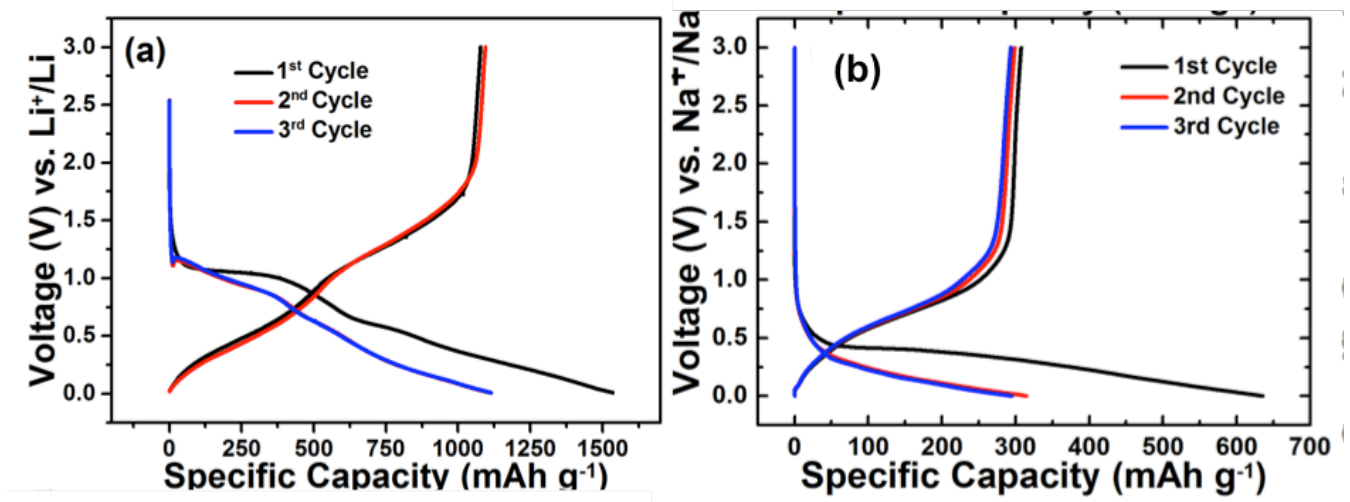

Figure 6.5 Initial galvanostatic charge-discharge curves of $\mathrm{ZnSnO}_{3}$ in (a) LIB at 100 $\mathrm{mA} \mathrm{g}^{-1}$ (b) NIB at $30 \mathrm{~mA} \mathrm{~g}^{-1}$

One additional advantage of using $\mathrm{ZnSnO}_{3}$ is that it provides an ideal low redox potential at $\sim 0.3 \mathrm{~V}$ vs. $\mathrm{Na}^{+} / \mathrm{Na}$, which could produce high output voltage when assembled with a cathode into a full cell configuration. This redox potential is much lower as compared to other bare $\mathrm{SnO}_{2}$ materials (See Appendix A4). It is evident that the presence of $\mathrm{Zn}$ alters the electrochemical characteristic of $\mathrm{SnO}_{2}$, which is similarly observed in other compounds. ${ }^{18}$ Moreover, the redox potential does not actually lie very close to $0 \mathrm{~V}$ (as compared to commercially used graphite anode in $\mathrm{LIB}\left(\sim 0.1 \mathrm{~V}\right.$ vs. $\left.\left.\mathrm{Li}^{+} / \mathrm{Li}\right)\right)$. Hence it is not adversely affected by alkali metal plating when cycled at high current rates.

The cycling performance of $\mathrm{ZnSnO}_{3}$ is shown in Figure 6.6. For the lithiation performance (Figure 6.6a), $\mathrm{ZnSnO}_{3}$ was cycled at $100 \mathrm{~mA} \mathrm{~g}^{-1}$ over 200 cycles. 
The compound experiences gradual decay in capacity from $1047 \mathrm{mAh} \mathrm{g}^{-1}$ in the $2^{\text {nd }}$ cycle down to $\sim 745 \mathrm{mAh} \mathrm{g}^{-1}$ at the $25^{\text {th }}$ cycle. The capacity stabilizes for about 50 more cycles before deteriorating to $\sim 180 \mathrm{mAh} \mathrm{g}^{-1}$ at the $200^{\text {th }}$ cycle. The overall capacity retention at the end of the $200^{\text {th }}$ cycle in the lithiated system is only $17.2 \%$. On the other hand, capacity retention of $92 \%$ could be obtained after 100 cycles of sodiation (Figure 6.6b). The impact of FEC additives was also evaluated (Figure 6.7). It was observed that cells without FEC additives showed significant capacity decay and unstable performance, especially from the $90^{\text {th }}$ cycle onwards. The enhancement in stability with FEC additive is a result of the formation of a more durable and insoluble SEI layer during cycling. In our example where both elements undergo alloying reactions during sodiation, a more efficient SEI layer would indeed be more beneficial in preventing the loss in electrical contact as well as the dissolution of material into the electrolyte during repeated cycling processes. ${ }^{19}$ In addition, it was noticed that the cycling behavior of $\mathrm{ZnSnO}_{3}$ cells with FEC additives showed a periodic increase and a decrease of capacity in the range of $4 \mathrm{mAh} \mathrm{g}^{-1}$. One possible explanation would be that a very small quantity of composite detaches itself from the main body followed by the continuous formation of a SEI layer, which results in an increment in capacity. The immediate formation of a much more durable SEI layer could help to bind the material together and prevent continuous pulverization as compared to FEC-less cells. The increase in capacity during cycling is common for conversion and alloying based materials and could also be explained by the continuous formation of a stable SEI layer into the structure of the composite. ${ }^{20,21}$
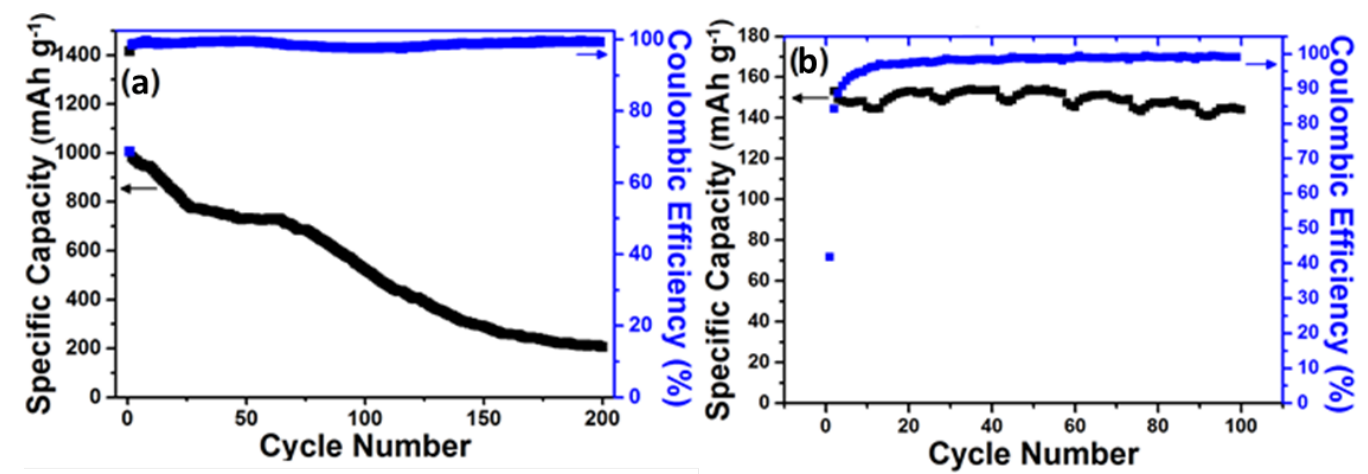
Figure 6.6 Cycling performance of $\mathrm{ZnSnO}_{3}$ within a voltage window of 0.01 to $3.00 \mathrm{~V}$ vs. $\mathrm{Li}^{+} / \mathrm{Li}$ or $\mathrm{Na}^{+} / \mathrm{Na}$ in (a) LIB at $100 \mathrm{~mA} \mathrm{~g}^{-1}$ and (b) NIB at $240 \mathrm{~mA} \mathrm{~g}^{-1}$

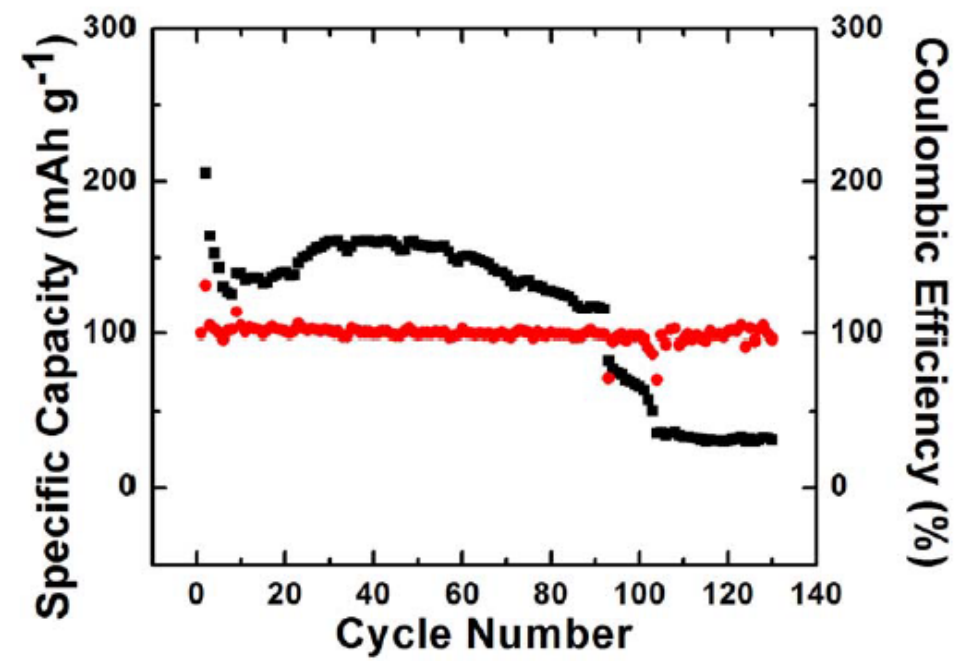

Figure 6.7 Cycling performance of $\mathrm{ZnSnO}_{3}$ in NIB system at $240 \mathrm{~mA} \mathrm{~g}^{-1}$ without FEC additives.

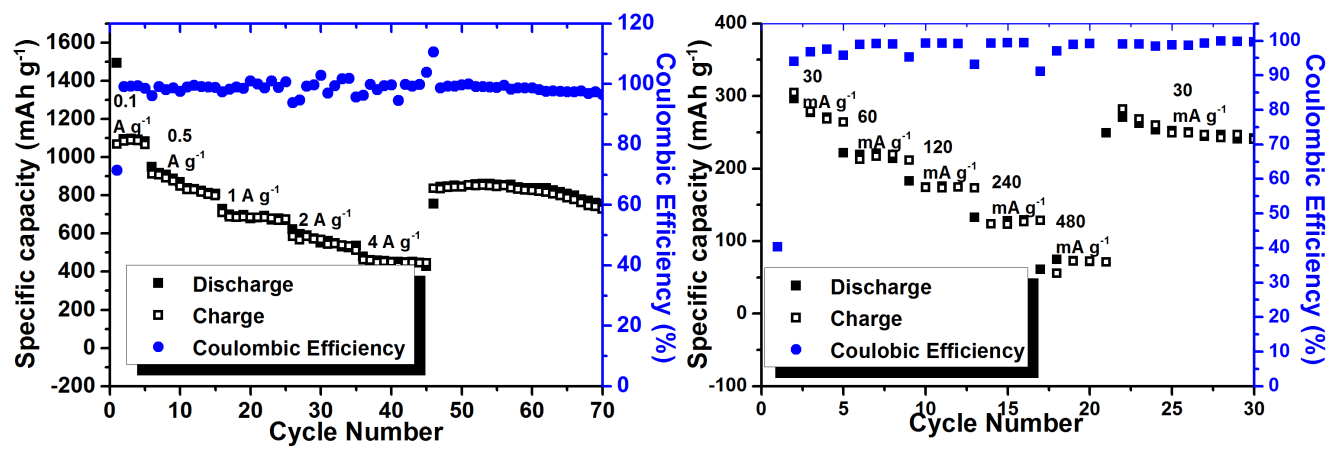

Figure 6.8 Rate performances of $\mathrm{ZnSnO}_{3}$ hollow cubes in (a) LIB and (b) NIB

The rate performances of $\mathrm{ZnSnO}_{3}$ hollow cubes were also evaluated in both LIB and NIB systems, which are illustrated in Figure 6.8. As could be seen, $\mathrm{ZnSnO}_{3}$ delivers a high specific capacity of $1150 \mathrm{mAh} \mathrm{g}^{-1}$ at $100 \mathrm{~mA} \mathrm{~g}^{-1}$. With increasing current density, the specific capacity drops due to stronger polarization and ionic resistance. At a current density of $4 \mathrm{~A} \mathrm{~g}^{-1}$, a specific capacity of $\sim 410 \mathrm{mAh} \mathrm{g}^{-1}$ could be obtained. The rate performance of $\mathrm{ZnSnO}_{3}$ hollow cube was also evaluated in NIB as seen in Figure 6.8b. An average 
specific capacity of $\sim 295 \mathrm{mAh} \mathrm{g}^{-1}$ could be obtained at $30 \mathrm{~mA} \mathrm{~g}^{-1}$, which gradually decreases to $\sim 50 \mathrm{mAh} \mathrm{g}^{-1}$ at a current of $480 \mathrm{~mA} \mathrm{~g}^{-1}$.

In the measurements presented above, we calculated the specific capacity according to the total mass of $\mathrm{ZnSnO}_{3}$. As $\mathrm{ZnSnO}_{3}$ is cycled in NIB for the first time, a more through understanding is needed. Half-cell testing using commercial $\mathrm{ZnO}$ showed that a reversible capacity of $37 \mathrm{mAh} \mathrm{g}^{-1}$ (Figure 6.9a) could be obtained by subtracting capacity contribution from Super $\mathrm{P},{ }^{22}$ which is in agreement with the theoretical value predicted above. To demonstrate the effectiveness of the intimate combination between $\mathrm{Zn}$ and $\mathrm{Sn}$, we also evaluated the electrochemical performance of manually blended $\mathrm{ZnO}-\mathrm{SnO}_{2}$ in NIB. Different galvanostatic discharge characteristics were also observed between $\mathrm{ZnSnO}_{3}$ (Figure 6.5b) and $\mathrm{ZnO}-\mathrm{SnO}_{2}$ (Figure 6.9b). The flat discharge potential at $\sim 0.45 \mathrm{~V}$ (contributing to about $300 \mathrm{mAh} \mathrm{g}^{-1}$ ) which corresponds to the irreversible conversion of $\mathrm{ZnSnO}_{3}$ into the respective elemental compound, was noted to be absent in the $\mathrm{ZnO}-\mathrm{SnO}_{2}$ compound. In subsequent cycles, $\mathrm{ZnSnO}_{3}$ recorded discharge capacity of $327 \mathrm{mAh} \mathrm{g}^{-1}$ as compared to $110 \mathrm{mAh} \mathrm{g}^{-1}$ in $\mathrm{ZnO}-\mathrm{SnO}_{2}$. It is logical to draw conclusion from this result that an intimate, homogeneous distribution of element with good structure design provides a superior electrochemical performance compared to manually blended mixture.
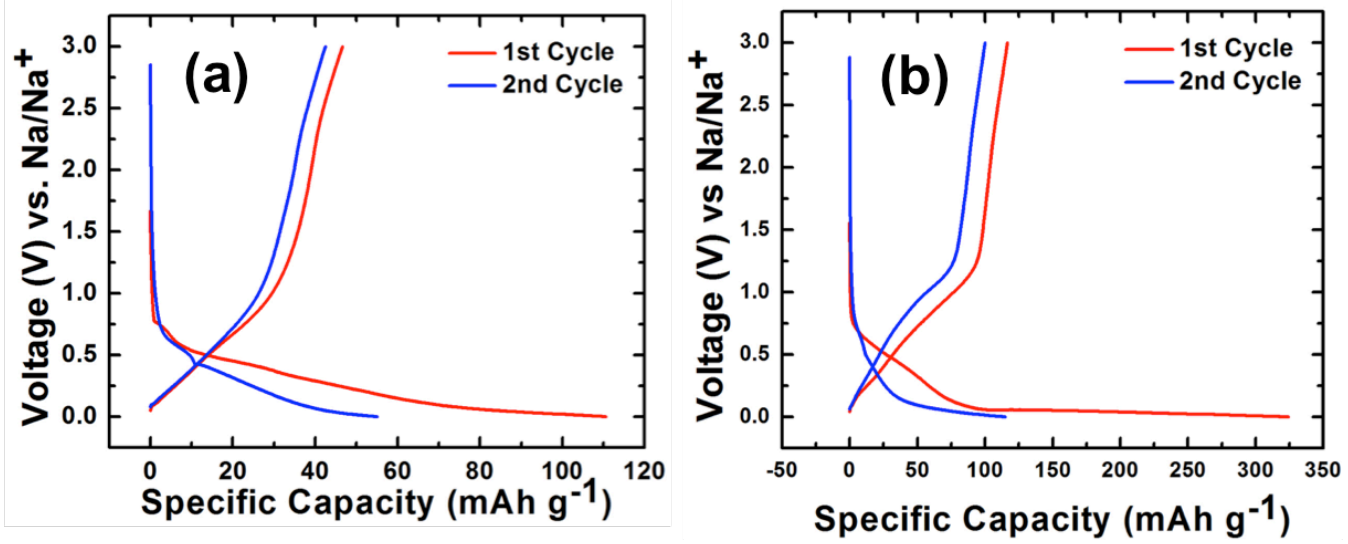

Figure 6.9 Initial galvanostatic charge-discharge curves of (a) $\mathrm{ZnO}$ and (b) $\mathrm{ZnO}-\mathrm{SnO}_{2}$ in NIB at $30 \mathrm{~mA} \mathrm{~g}^{-1}$.

The presence of nano-sized agglomerates, consistent element distribution, and 
hollow structure design allows for larger electrolyte-nanoparticles contact interface and also reducing $\mathrm{Li} / \mathrm{Na}$ diffusion paths. A recent report also pointed out that the distribution of metallic particles within the matrix in the initial conversion reaction has a significant impact on the reversibility of its subsequent reactions. ${ }^{23}$ As observed, our present hollow cubes have been derived from the agglomeration of nanoparticles, where the initial conversion process could easily form an interconnected network of elemental $\mathrm{Sn}$ and $\mathrm{Zn}$ while preventing agglomeration of individual metallic particles. Despite the similar reaction mechanisms, the improvement coming from the utilization of $\mathrm{ZnSnO}_{3}$ in LIB is not as drastic as compared to NIB.

Ex-situ SEM-EDX of $\mathrm{ZnSnO}_{3}$ after 3 cycles had been carried out to understand the distribution of elements within the sample. As could be seen in the figure 6.10 , it is conclusive that the elements, $\mathrm{Zn}, \mathrm{Sn}$ and $\mathrm{O}$ are well distributed in the sample even after cycling. We postulate that the relatively mediocre performance of $\mathrm{ZnSnO}_{3}$ in LIB could be due to the relatively similar theoretical size expansion in both $\mathrm{Zn} \quad(\sim 124 \%)$ and $\mathrm{Sn} \quad(\sim 306 \%)$ during charging/discharging. In essence, $\mathrm{Sn}$ has to endure additional strain induced from size expansion of $\mathrm{Zn}$ on top of the pulverization experience during $\mathrm{Sn}$ lithiation. Hence, this leads to additional mechanical stress and poorer performance in Li system compared to previously reported $\mathrm{SnO}_{2}$. On the other hand, we believe that the large difference in volume expansion of $\mathrm{Zn}(\sim 0 \%)$ and Sn $(645 \%)$ during sodiation is the key to the enhanced electrochemical performance. The relatively low size expansion in $\mathrm{Zn}$ renders it almost electrochemically inactive and acts as a buffer for $\mathrm{Sn}$ during sodiation processes (Figure 6.11). As we have seen previously in Appendix A4, it is worth noting that even with the presence of $\mathrm{Zn}$ (resulting in additional $\sim 30 \mathrm{wt} \%$ in $\mathrm{ZnSnO}_{3}$ and low overall capacity), $\mathrm{ZnSnO}_{3}$ was able to deliver a capacity comparable to bare $\mathrm{SnO}_{2}$ nanoparticles (without graphene loading or carbon coating). 


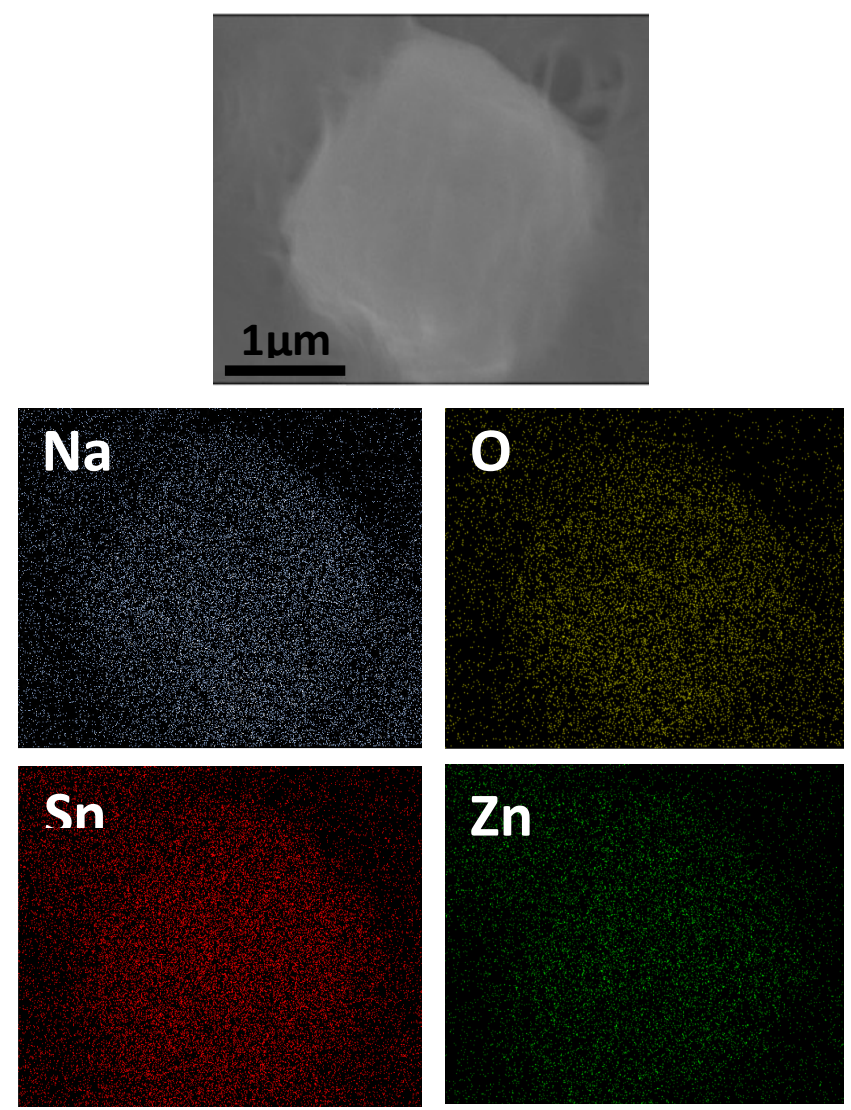

Figure 6.10. Ex-situ SEM-EDX of $\mathrm{ZnSnO}_{3}$ upon full discharge at $30 \mathrm{~mA} \mathrm{~g}^{-1}$.

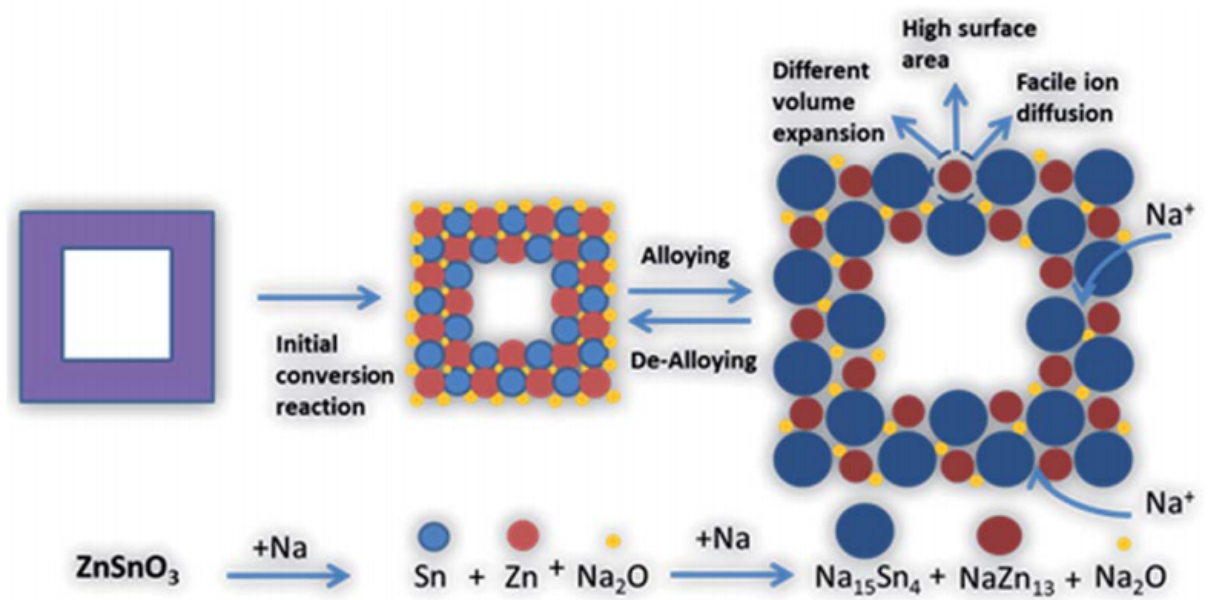

Figure 6.11 Schematic describing the energy storage process in polycrystalline $\mathrm{ZnSnO}_{3}$ hollow cubes. The $\mathrm{ZnSnO}_{3}$ first undergoes an irreversible conversion process into metallic $\mathrm{Zn}$ and $\mathrm{Sn}$ and subsequently, a reversible alloying process ensues, producing $\mathrm{Na}_{15} \mathrm{Sn}_{4}$ and $\mathrm{NaZn}_{13}$ alloys. 


\subsection{Summary}

In summary, we demonstrate the electrochemical performance of coprecipitated $\mathrm{ZnSnO}_{3}$ hollow cubes as anode material for both LIB and NIB. Characterizations revealed that the hollow cubes were constructed from the agglomeration of polycrystalline nanoparticles with an even distribution of $\mathrm{Zn}$ and Sn elements. When cycled in LIB, a reversible capacity of $1117 \mathrm{mAh} \mathrm{g}^{-1}$ can be obtained in the $2^{\text {nd }}$ cycle, which gradually deteriorated to $180 \mathrm{mAh} \mathrm{g}^{-1}$ at the end of the $200^{\text {th }}$ cycle. This corresponds to a capacity retention value of only $17.2 \%$. Conversely, the hollow cubes were able to deliver a reversible capacity of $315 \mathrm{mAh} \mathrm{g}^{-1}$ in the sodium system. The capacity retention during cycling at higher current $\left(240 \mathrm{~mA} \mathrm{~g}^{-1}\right)$ was recorded to be $\sim 92 \%$. We hypothesized that the enhanced electrochemical performance was derived from the synergistic effect of the intimate uniform distribution of intermetallic elements within the structure, which assisted in providing for an interconnected network of metallic elements, shortened $\mathrm{Na}^{+}$diffusion distances, efficient electron/ion transport and complimenting volume expansion. The poorer performance of $\mathrm{ZnSnO}_{3}$ can ascribe to the similar size expansion for both $\mathrm{Zn}$ and $\mathrm{Sn}$ with $\mathrm{Li}$, resulting in the absence of buffering effect like in NIB. That the results strongly support that competent design of materials by incorporating different transition metal oxides in an intimate manner could also benefit the electrochemical performance of NIBs.

\section{References:}

1. Y. Wang, D. Su, C. Wang and G. Wang, Electrochemistry Communications, 2013, 29, 8-11.

2. L. Zhang, H. B. Wu, B. Liu and X. W. Lou, Energy \& Environmental Science, 2014, 7, 1013-1017.

3. R. Alcántara, M. Jaraba, P. Lavela and J. L. Tirado, Chemistry of Materials, 2002, 14, 2847-2848.

4. A. V. Chadwick, S. L. P. Savin, S. Fiddy, R. Alcántara, D. Fernández Lisbona, P. Lavela, G. F. Ortiz and J. L. Tirado, The Journal of Physical Chemistry C, 2007, 111, 4636-4642.

5. H. Fan, Y. Zeng, X. Xu, N. Lv and T. Zhang, Sensors and Actuators B: Chemical, 2011, 153, 170-175. 
6. Y. Wang, P. Gao, D. Bao, L. Wang, Y. Chen, X. Zhou, P. Yang, S. Sun and M. Zhang, Inorganic Chemistry, 2014, 53, 12289-12296.

7. C. Yuejiao, Y. Ling, L. Qing, W. Yan, L. Qiuhong and W. Taihong, Nanotechnology, 2012, 23, 415501.

8. X. P. Gao, J. L. Bao, G. L. Pan, H. Y. Zhu, P. X. Huang, F. Wu and D. Y. Song, The Journal of Physical Chemistry B, 2004, 108, 5547-5551.

9. N. H. Zhao, L. C. Yang, P. Zhang, G. J. Wang, B. Wang, B. D. Yao and Y. P. Wu, Materials Letters, 2010, 64, 972-975.

10. H. T. Zhang and X. H. Chen, Nanotechnology, 2006, 17, 1384.

11. Z. Wang, Z. Wang, W. Liu, W. Xiao and X. W. Lou, Energy \& Environmental Science, 2013, 6, 87-91.

12. C. Yuan, H. B. Wu, Y. Xie and X. W. Lou, Angewandte Chemie International Edition, 2014, 53, 1488-1504.

13. J. Sangster and C. W. Bale, J Phs Eqil and Diff, 1998, 19, 76-81.

14. D. Su, H.-J. Ahn and G. Wang, Chemical Communications, 2013, 49, 3131-3133.

15. A. D. Pelton, Bulletin of Alloy Phase Diagrams, 1987, 8, 550-553.

16. H. Wang, Q. Pan, Y. Cheng, J. Zhao and G. Yin, Electrochimica Acta, 2009, 54, 2851-2855.

17. P. Gurunathan, P. M. Ette and K. Ramesha, ACS Applied Materials \& Interfaces, 2014, 6, 16556-16564.

18. P. F. Teh, S. S. Pramana, Y. Sharma, Y. W. Ko and S. Madhavi, ACS Applied Materials \& Interfaces, 2013, 5, 5461-5467.

19. S. Komaba, T. Ishikawa, N. Yabuuchi, W. Murata, A. Ito and Y. Ohsawa, ACS Applied Materials \& Interfaces, 2011, 3, 4165-4168.

20. C. Zhu, P. Yang, D. Chao, W. Mai and H. J. Fan, ChemNanoMat, 2015, DOI: 10.1002/cnma.201500091, n/a-n/a.

21. J. Zhu, T. Zhu, X. Zhou, Y. Zhang, X. W. Lou, X. Chen, H. Zhang, H. H. Hng and Q. Yan, Nanoscale, 2011, 3, 1084-1089.

22. L. Ji, M. Gu, Y. Shao, X. Li, M. H. Engelhard, B. W. Arey, W. Wang, Z. Nie, J. Xiao, C. Wang, J.-G. Zhang and J. Liu, Advanced Materials, 2014, 26, 2901-2908.

23. F. Wang, R. Robert, N. A. Chernova, N. Pereira, F. Omenya, F. Badway, X. Hua, M. Ruotolo, R. Zhang, L. Wu, V. Volkov, D. Su, B. Key, M. S. Whittingham, C. P. Grey, G. G. Amatucci, Y. Zhu and J. Graetz, Journal of the American Chemical Society, 2011, 133, 18828-18836. 


\section{Chapter 7}

\section{Discussion and Future work}

Different methods have been introduced for enhancing the electrochemical performance of $\mathrm{SnO}_{2}$ nanoparticles in both $\mathrm{LIB}$ and NIBs. This chapter serves to tie up the pros and cons of different effects and evaluate their performance as a whole. The suitability of individual methodologies will be considered with respect to commercialization. Subsequently, suggestions for reconnaissance work and its motivations will be outlined. 


\subsection{Impact of findings}

The main motivation for studying $\mathrm{SnO}_{2}$ as anode material in both LIB and NIB lies with its high theoretical capacity and low operating potential, which is translatable to high energy density. However, the performance is often plagued by its low cyclability and rate capability. Hence, this limits the number of cycles that it could be utilized and how fast it takes to be fully charged/discharged. Three different facile methods have been demonstrated in this thesis with the aim of engineering the performance of $\mathrm{SnO}_{2}$ and bring it closer to commercialization. All the engineered materials were tested in both LIB and NIB, with a standardized coating composition to facilitate comparison. The key outcomes, findings and extent of which the hypotheses have been proven, will be summarized and presented below.

\subsubsection{Outcome of hypothesis 1: The presence of a carbonaceous conductive} matrix could be beneficial in enhancing electronic conductivity while improving the overall structural integrity of the material.

Chapter 4 illustrates the one-pot synthesis of $\mathrm{rGO}-\mathrm{SnO}_{2}$ nanocomposite through laser pyrolysis and subsequently evaluates its electrochemical performance as an anode in both LIB and NIB. Comparative to other reported procedures for obtaining $\mathrm{SnO}_{2}$ from laser pyrolysis, the utilization of non-toxic and relatively low-cost precursors was demonstrated for the first time. Subsequently, with the addition of $\mathrm{GO}$ into the precursor solution, $\mathrm{rGO}-\mathrm{SnO}_{2}$ could be successfully obtained by laser pyrolysis. Characterization methods indicated the reduction of GO into rGO through thermal reduction as could be seen from an $\mathrm{I}_{\mathrm{D}} / \mathrm{I}_{\mathrm{G}}$ ratio that is $>1$. Furthermore, the $\mathrm{rGO}$ and $\mathrm{SnO}_{2}$ contents within the nanocomposite were found to be $\sim 19 \%$ and $\sim 81 \%$ respectively. The high mass loading of $\mathrm{SnO}_{2}$ increases its overall feasibility to be utilized as commercial battery electrodes. The excellent electrochemical performance of the $\mathrm{rGO}-\mathrm{SnO}_{2}$ nanocomposite could be observed for both their lithiation and sodiation performance. As shown 
in Figure 7.1, laser pyrolyzed $\mathrm{rGO}-\mathrm{SnO}_{2}$ nanocomposite demonstrated one of the best lithiation performance compared to other previously reported graphenebased $\mathrm{SnO}_{2}$ materials. Contrastingly, the other samples such as laser pyrolyzed $\mathrm{N}$-doped $\mathrm{SnO}_{2}$ or $\mathrm{ZnSnO}_{3}$ hollow cubes did not fare as well as in the rGO-SnO nanocomposite. Due to the limited publications on sodiation of $\mathrm{rGO}-\mathrm{SnO}_{2}$, we compared the electrochemical performance with other carbon-based $\mathrm{SnO}_{2}$ nanocomposites (Figure 7.2). Most of the reported performances calculate the specific capacity solely from the mass of $\mathrm{SnO}_{2}$, while the mass of the entire composite was considered in our laser pyrolyzed $\mathrm{SnO}_{2}$. This is important even if the rGO remains electrochemically inactive in the NIB system; it still contributes "dead-weight" into the overall cell. For instance, in the best performing " $\mathrm{SnO}_{2}$ confined in mesoporous carbon" composite, the proportion of $\mathrm{rGO}: \mathrm{SnO}_{2}$ is approximately $6: 4$, where the actual specific capacity of the composite should be less than half of the reported performance. Hence, while numerous articles claim to have demonstrated exceptional sodiation properties, the implication of a higher "dead-weight" is certainly not feasible for use in commercial batteries. The outstanding lithiation and sodiation performance recorded in our $\mathrm{rGO}-\mathrm{SnO}_{2}$ could be attributed to several key design properties. These properties includes: 1) the direct contact between the $\mathrm{SnO}_{2}$ nanoparticles with rGO enables excellent charge transfer reaction that could be manifested into exceptional rate capabilities; 2) the presence of $\mathrm{rGO}$ as a conductive strain buffering template that prevents agglomeration and detachment of active $\mathrm{SnO}_{2}$ from the current collector; 3) utilization of $\mathrm{SnO}_{2}$ nanoparticles which can reversibly undergo conversion and alloying reaction to deliver high specific capacity; 4) small size of laser pyrolyzed $\mathrm{SnO}_{2}$ that permits rapid diffusion of $\mathrm{Li}^{+} / \mathrm{Na}^{+}$throughout the entire nanoparticle.

The inclusion of a carbonaceous matrix into where $\mathrm{SnO}_{2}$ nanoparticles are anchored on it provides enhanced electrochemical performance in both LIB and NIB. Therefore hypothesis 2 has been proven true. 


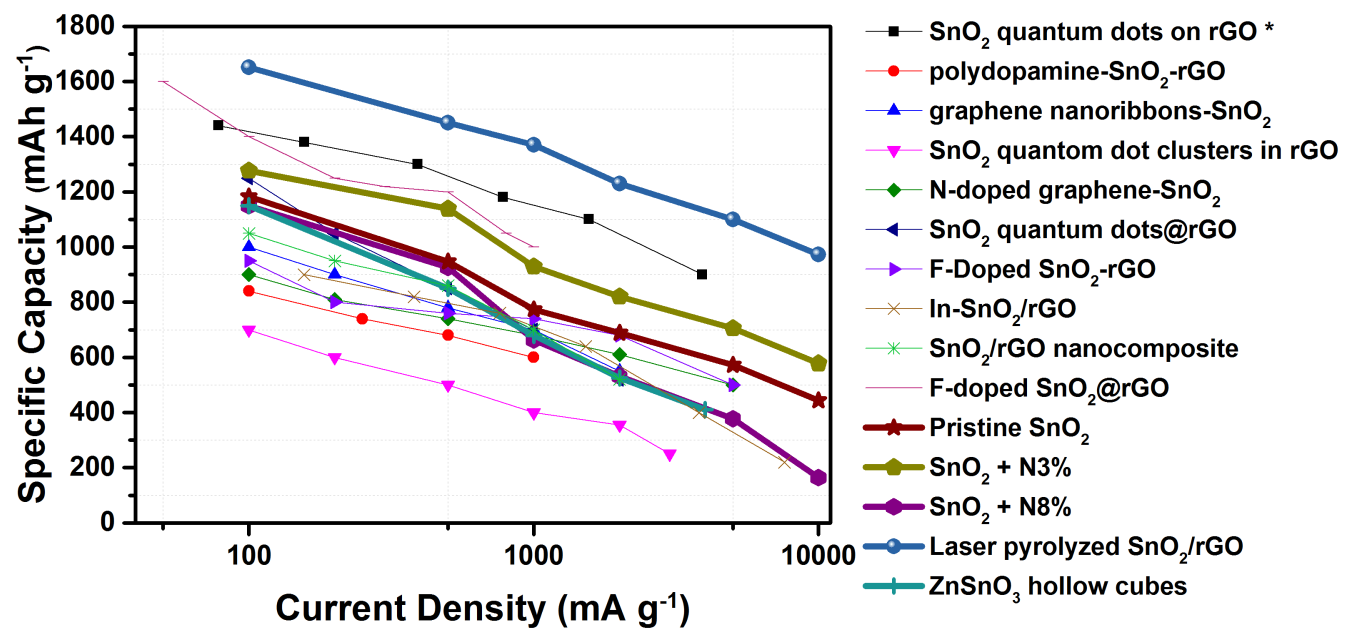

Figure 7.1 Specific capacity vs. current density plot of the lithiation performance of different graphene-SnO $\mathrm{Sn}_{2}$ based nanocomposites. * indicates capacity calculated from $\mathrm{SnO}_{2}$ only instead of the nanocomposites

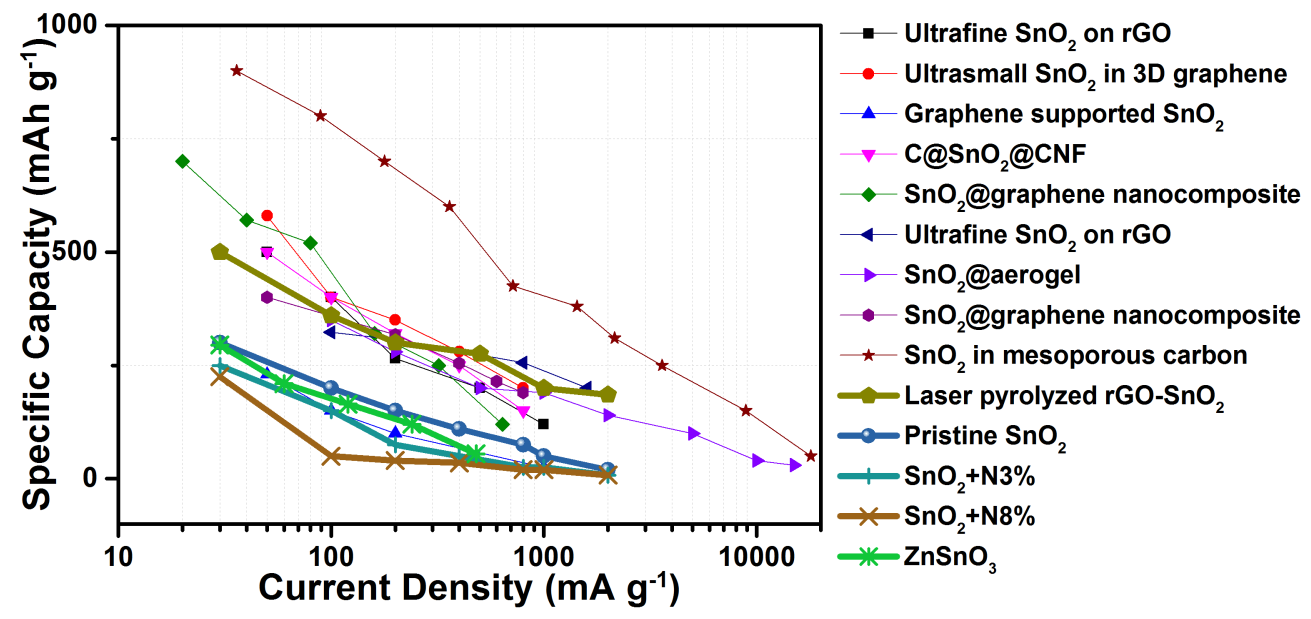

Figure 7.2 Specific capacity vs. current density plot of the sodiation performance of different carbon- $\mathrm{SnO}_{2}$ based nanocomposites. Reference specific capacities are calculated from $\mathrm{SnO}_{2}$ only. The specific capacity of laser pyrolyzed $\mathrm{SnO}_{2}$ is calculated from the mass of composite.

7.1.2 Outcome of hypothesis 2: Heterogeneous doping alters the electronic structure of the material, giving rise to improved conductivity. Prevention of long-range ordering that will be beneficial for cyclability will be made possible with the presence of heterogeneous atoms. 
The investigation into both the lithiation and sodiation performances of nitrogen doped $\mathrm{SnO}_{2}$ nanoparticles were carried out in Chapter 5. While doping of $\mathrm{SnO}_{2}$ and other compounds have been studied extensively, most of the reported works focus on cationic doping, i.e. substation of $\mathrm{Sn}^{4+}$ by other multivalent ions such as $\mathrm{Fe}^{3+}, \mathrm{Ni}^{2+}, \mathrm{Co}^{2+}$ and etc. Contrastingly, anionic doping has rarely been explored, with limited example such as F-doped $\mathrm{SnO}_{2}$. This chapter explores the substitution of $\mathrm{O}^{2=}$ by $\mathrm{N}^{3-}$ through laser pyrolysis process. Initial electron microscopy results illustrate the presence of multi-grains for $\mathrm{N}$ doped $\mathrm{SnO}_{2}$. The occurrence multi-grain particles as compared to single grain pristine $\mathrm{SnO}_{2}$ can be attributed to the presence of heterogeneous atoms (i.e. nitrogen dopants). With increasing concentration of nitrogen containing precursor, it was found that $\mathrm{Sn}^{4+}$ in the compound was systematically reduced to $\mathrm{Sn}^{0}$. This can be attributed to the reductive nature of $\mathrm{NH}_{3}$ gas. Unexpectedly, this also implies that there exists a maximum concentration of $\mathrm{N}$ that could be doped into $\mathrm{SnO}_{2}$.

Coincidentally, the lithiation performance also illustrates that over doping of $\mathrm{N}$ leads to detrimental consequences. As shown in the above Figures 6.9 and 6.11, over doping of $\mathrm{N}$ leads to decrease in conductivity and poorer rate performance. Unexpectedly, the optimum performance is observed in the $\mathrm{SnO}_{2}+\mathrm{N} 3 \%$ sample. Fundamental kinetic studies showed that the enhanced electrochemical performance of $\mathrm{SnO}_{2}+\mathrm{N} 3 \%$ over pristine $\mathrm{SnO}_{2}$ and $\mathrm{SnO}_{2}+\mathrm{N} 8 \%$ is due to superior $\mathrm{Li}^{+}$diffusion properties in the structure and reaction is determined by the influx rate of $\mathrm{Li}^{+}$onto the surface of the $\mathrm{SnO}_{2}+\mathrm{N} 3 \%$ nanoparticle. Considering that electrochemical studies on nitrogen doping in $\mathrm{SnO}_{2}$ has not been performed before and there exists a possibility that the nitrogen dopants might react with Li to form LiN, a series of ex-situ analyses were carried out to investigate the role of $\mathrm{N}$. While initial ex-situ SXRD shows the reversibility of $\mathrm{Sn}$ upon full charging, the presence of $\mathrm{SnO}_{2}$ was not detected. Comparatively, ex-situ XANES demonstrates that the Sn-redox state increases above 0 during 
the charging process, forming $\mathrm{SnO}_{\mathrm{x}}$ which was not detected in XRD. Furthermore, it is observable through ex-situ EXAFS that aside from the first coordination shell, the reversibility that $\mathrm{Sn}-\mathrm{O}$ bond in other coordination shells is generally inferior, which indicates poor long-order arrangement. Therefore, the $\mathrm{SnO}_{\mathrm{x}}$ compounds formed are most likely to be amorphous, while the cubic Sn formed upon charging are crystalline. This observation has also been recently demonstrated in other works.For the lithiation of $\mathrm{SnO}_{2}$, the conversion reaction that results in the breaking of $\mathrm{Sn}-\mathrm{O}$ bond $(1.6 \AA)$ has been well documented. ${ }^{1-5}$ Hence, we can safely assume that the Sn-O bond breaks and

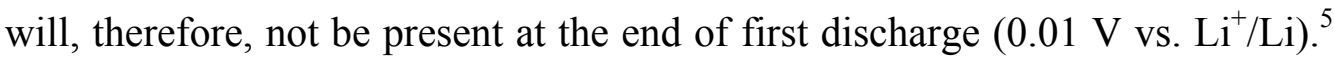
For example, the work by Kim et al. investigated the reaction mechanism of mesoporous $\mathrm{SnO}_{2}$ through ex-situ XAS analysis. In their article, it was found that the Sn-O bond at $1.6 \AA$ completely disappears upon complete discharge. However, one may argue that there could be incomplete decomposition of $\mathrm{SnO}_{2}$ into $\mathrm{Sn}$ and therefore $\mathrm{Sn}-\mathrm{O}$ bond could still be present in our sample. This can be refuted from our ex-situ SXRD and electrochemical measurements. Firstly, our ex-situ SXRD did not reveal the presence of $\mathrm{SnO}_{2}$ at the end of discharge. Only $\mathrm{Li}_{4.4} \mathrm{Sn}$ was detected at the end of discharge. Furthermore, the discharge capacities in the $1^{\text {st }}$ and $2^{\text {nd }}$ cycle approaches the theoretical value of $\mathrm{SnO}_{2}$, which suggests that conversion reaction should happen along with alloying reaction to give rise to such high capacity. It would be inaccurate to suggest that $\mathrm{Sn}_{3} \mathrm{~N}_{4}$ forms during the electrochemical reaction as for it to be $\mathrm{Sn}_{3} \mathrm{~N}_{4}$, we reckon that bonding in other coordination shells should be present as well. As could be observed in our EXAFS sample (Figure 6.13), the peak at 1.5-1.6 $\AA$ is still well present at the end of the first discharge cycle. Furthermore, the presence of crystalline $\mathrm{Sn}_{3} \mathrm{~N}_{4}$ was not detected in ex-situ SXRD, highly suggesting that $\mathrm{Sn}-\mathrm{N}$ not react to form $\mathrm{Sn}_{3} \mathrm{~N}_{4}$. Since we have ruled out the possibility of the peak being attributed to Sn-O bonding, we can then assign the peak at $\sim 1.5 \AA$ to be the Sn-N bond. The presence of an inactive 
Sn-N bond can then act as a backbone for reversible phase transformation, hence enhancing cyclability.

On the other hand, sodiation performance of $\mathrm{N}$-doped $\mathrm{SnO}_{2}$ nanoparticles demonstrated contrasting results. For instance, the discharge capacity of pristine $\mathrm{SnO}_{2}$ nanoparticle was $\sim 320 \mathrm{mAh} \mathrm{g}^{-1}$, much higher than 250 and 225 $\mathrm{mAh} \mathrm{g}^{-1}$ that was recorded for $\mathrm{SnO}_{2}+\mathrm{N} 3 \%$ and $\mathrm{SnO}_{2}+\mathrm{N} 8 \%$ respectively. When current densities were increased, it was found that both $\mathrm{SnO}_{2}+\mathrm{N} 3 \%$ and $\mathrm{SnO}_{2}+\mathrm{N} 8 \%$ suffer a sharp drop in capacities. This indicates that nitrogen doping has a counter-effect on the sodiation performance of $\mathrm{SnO}_{2}$. This implication is critical as doping of compounds is thought to low the energy band gap of semiconductor metals such as $\mathrm{SnO}_{2}$, facilitating charge transfer reaction, enhancing electrical conductivity and thus giving improving rate capabilities.

Seeing the contrasting electrochemical performance between lithiation and sodiation in $\mathrm{N}$-doped $\mathrm{SnO}_{2}$ nanoparticles, much more work has to be done especially in the NIB system to uncover the contrasting effect. Therefore, hypothesis 3 is proven to be partially true, where anionic doping enhances the electrochemical performance in LIB but is counter-effective in NIB.

7.1.3 Outcome of hypothesis 3: The incorporation of foreign element/matrix that is either electrochemically active or inactive could help buffer the size expansion incurred and prevent agglomeration during the cycling process.

In Chapter 6, we demonstrated the introduction of foreign phase, i.e. $\mathrm{ZnO}$ into the matrix of $\mathrm{SnO}_{2}$, for the formation of bimetallic oxide $\mathrm{ZnSnO}_{3}$. Through SEM-EDX elemental mapping, we were able to determine that the different elements (i.e. $\mathrm{Zn}, \mathrm{Sn}, \mathrm{O}$ ) were evenly distributed in each different hollow cubes. The rational for having the hollow cores is to facilitate ion diffusion during charging/discharging reactions. When tested as an anode in $\mathrm{LIB}, \mathrm{ZnSnO}_{3}$ first converts into $\mathrm{ZnO}$ and $\mathrm{SnO}_{2}$, before being reduced into $\mathrm{Zn}, \mathrm{Sn}$ and $\mathrm{Li}_{2} \mathrm{O}$. 
Subsequently in the same cycle, alloying reaction between $\mathrm{Li}$ and $\mathrm{Zn} / \mathrm{Sn}$ occurs, giving rise to $\mathrm{LiZn} / \mathrm{Li}_{4.4} \mathrm{Sn}$. As compared to previously reported $\mathrm{SnO}_{2}$ hollow spheres, hollow cubes or hollow structures, the performance with the addition of $\mathrm{ZnO}$ leads to poorer performance regarding cyclability. We postulate that the poor performance of $\mathrm{ZnSnO}_{3}$ in LIB could be due to the relatively similar theoretical size expansion in both $\mathrm{Zn}(\sim 124 \%)$ and $\mathrm{Sn}(\sim 306 \%)$ during charging/discharging. In essence, $\mathrm{Sn}$ has to endure additional strain induced from size expansion of $\mathrm{Zn}$ on top of the pulverization experience during $\mathrm{Sn}$ lithiation. Hence, this leads to additional mechanical stress and poorer performance in $\mathrm{Li}$ system compared to previously reported $\mathrm{SnO}_{2}$. The electrochemical profile (Figure 7.3) of $\mathrm{ZnSnO}_{3}$ hollow cubes, when compared to laser, pyrolyzed pristine $\mathrm{SnO}_{2}$ nanoparticle shows a more slope like behavior throughout the entire voltage window. Comparatively, discharge of $\mathrm{ZnSnO}_{3}$ commences at approximately $1.1 \mathrm{~V}$ vs. $\mathrm{Li}^{+} / \mathrm{Li}$, while pristine $\mathrm{SnO}_{2}$ starts at $\sim 1.25$ $\mathrm{V}$ instead. A lower electrochemical potential is beneficial as the overall potential of a battery is related by the equation: $E_{b a t t}=E_{c a t h o d e}-E_{\text {anode }}$. Hence, a smaller working voltage of an anode would translate to higher cell voltage and therefore higher energy density. Despite the intrinsic advantage, the cyclability of $\mathrm{ZnSnO}_{3}$ is still subpar as compared to other pristine $\mathrm{SnO}_{2}$. Hence, further work pertaining to extrinsic modification could be explored and will be discussed later.
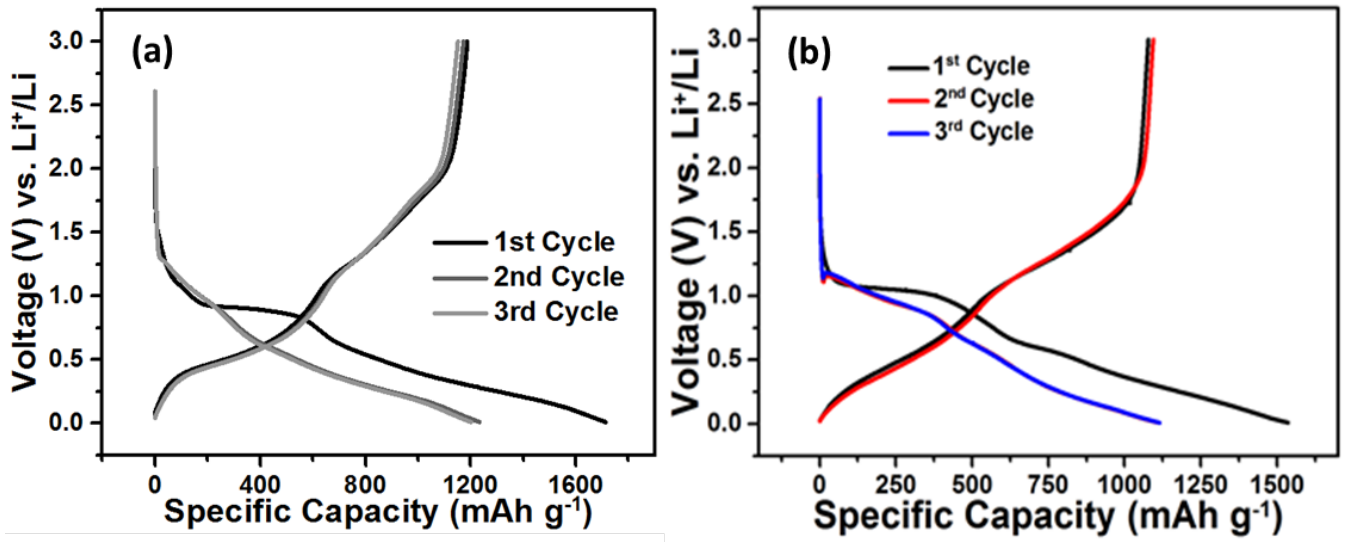

Figure 7.3 Lithiation galvanostatic charge-discharge at a current density of $100 \mathrm{~mA} \mathrm{~g}^{-1}$ of (a) laser pyrolyzed pristine $\mathrm{SnO}_{2}$ (b) $\mathrm{ZnSnO}_{3}$ hollow cubes 
The electrochemical performance of $\mathrm{ZnSnO}_{3}$ was also evaluated in NIB setup, where much better results were observed when compared to pristine $\mathrm{SnO}_{2}$. The large difference in volume expansion of $\mathrm{Zn}(\sim 0 \%)$ and $\mathrm{Sn}(645 \%)$ during sodiation is proposed to be the key to the enhanced electrochemical performance. The relatively low size expansion in $\mathrm{Zn}$ renders it almost electrochemically inactive and acts as a buffer for Sn during sodiation processes as could be seen in the schematic in Figure 6.10. It is also interesting to note from Table A2 that even with the presence of $\mathrm{Zn}$ (resulting in additional $\sim 30 \mathrm{wt} \%$ in $\mathrm{ZnSnO}_{3}$ and low overall capacity), $\mathrm{ZnSnO}_{3}$ was able to deliver a capacity comparable to bare $\mathrm{SnO}_{2}$ nanoparticles (without graphene loading or carbon coating). Similar to the electrochemical performance of $\mathrm{ZnSnO}_{3}$ in LIB, the electrochemical profile of $\mathrm{ZnSnO}_{3}$ shows a much lower electrochemical potential $(\sim 0.5 \mathrm{~V})$ as compared to pristine $\mathrm{SnO}_{2}(\sim 0.7-0.8 \mathrm{~V})$ (Figure 7.4). Considering the electrochemical near-inactivity of $\mathrm{Zn}$ within the compound, we can consider the lower electrochemical potential to be similar to the inductive effect seen in compounds such as $\mathrm{LiFePO}_{4}$ and $\mathrm{MnFe}_{2} \mathrm{O}_{4}$. This inductive effect shifts the conduction/valence band of its electronic structure, hence resulting in adjustment of the actual redox potential.
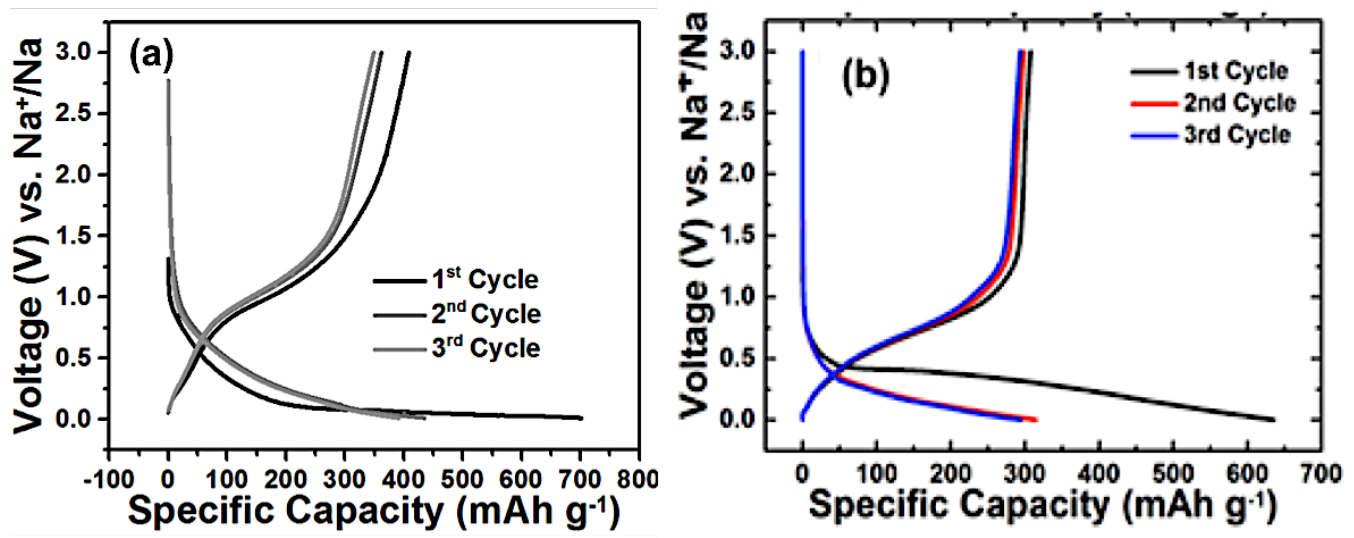

Figure 7.4 Sodiation galvanostatic charge-discharge at a current density of $30 \mathrm{~mA} \mathrm{~g}^{-1}$ of (a) laser pyrolyzed pristine $\mathrm{SnO}_{2}$ (b) $\mathrm{ZnSnO}_{3}$ hollow cubes

The incorporation of $\mathrm{ZnO}$ foreign phase for the formation of $\mathrm{ZnSnO}_{3}$ has shown to be effective in NIB. The substitution and utilization of $\mathrm{ZnO}$ instead of $\mathrm{SnO}_{2}$ 
reduces the overall cost and improves energy density in NIB. However, this strategy has shown to be rather counter effective in LIB, which was suggested to be due to two different size expanding elements. Therefore, hypothesis 1 has been proven to be partially true.

\subsection{Outstanding questions and future work}

The key rational for employing $\mathrm{SnO}_{2}$ as anode material for LIB and NIB is due to its high theoretical capacity and low operating voltage. In Chapters 4, 5 and 6, we have explored different avenues for the engineering of $\mathrm{SnO}_{2}$ materials and subsequently evaluated its electrochemical performance against other previously reported methods. Whilst the results for LIB are encouraging, the performances in NIB still have room for improvement. Herein, outstanding questions and potential work will be discussed.

\subsubsection{Investigation onto the gradual capacity decay during initial lithiation cycles}

It is well documented that the charge storage mechanism for $\mathrm{SnO}_{2}$ is based on a dual conversion-alloying mechanism. Whist it has often been argued that the conversion process is not reversible, recent works along with our XAS experiments in Chapter 6 has revealed that the conversion reaction is indeed reversible. However, as observed in several works and the presented results (Figures 4.7, 5.12 and 6.9), the specific capacity of $\mathrm{SnO}_{2}$ gradually decreases in the initial cycles before stabilizing. For example, the lithiation behavior of $\mathrm{SnO}_{2}+\mathrm{N} 3 \%$ was taken apart and plotted in Figure 7.5. Perfect overlapping could be observed at below $1.20 \mathrm{~V}$, signifying superior de-alloying reversibility during cycling. On the other hand, capacity fading was observed to occur only during de-conversion reaction, which could be attributed to grain boundary damage during phase transformation and thus resulting in Sn coarsening. ${ }^{6}$ 


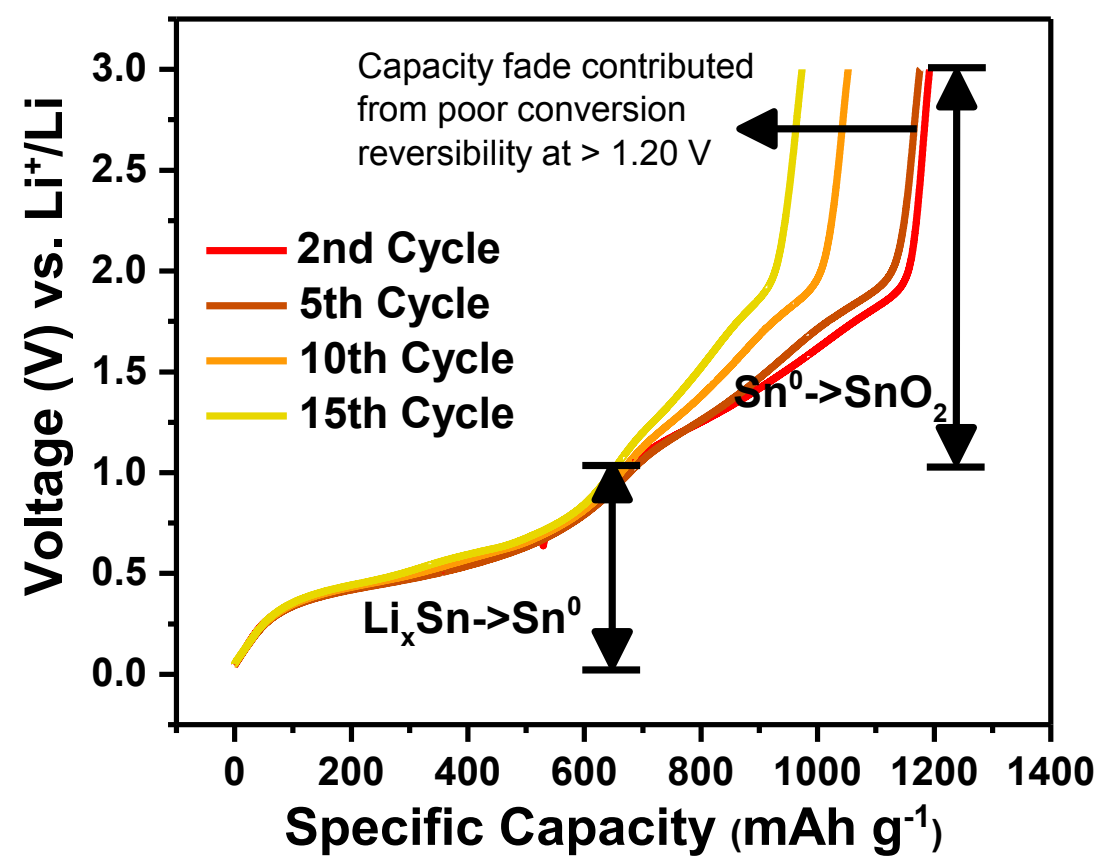

Figure 7.5 Charge profile of $\mathrm{SnO}_{2}+\mathrm{N} 3 \%$, in the $2^{\text {nd }}, 5^{\text {th }}, 10^{\text {th }}$ and $15^{\text {th }}$ cycle. Capacity loss can be seen from lower capacity contribution $>1.20 \mathrm{~V}$, indicating poor reversibility of conversion reaction. The alloying process, on the other hand, showed almost perfect capacity retention within the 15 cycles.

The outstanding question here that should be investigated is the factors pertaining to the capacity fade from the conversion reaction. While the issue has been attributed to the unavoidable grain boundary damage as well as grain coarsening, attempts to utilize multi-grained $\mathrm{SnO}_{2}$ nanoparticles to minimize conversion capacity loss has not been effective. Therefore, proper engineering methods at the grain boundary and nano-level should be studied extensively to address this problem.

\subsubsection{Further explore the different types of substitution metal for $\mathrm{ASnO}_{3}$} with other cations in the A site 
In Chapter 4, we have explored both the lithiation and sodiation properties of $\mathrm{ZnSnO}_{3}$. Despite the lackluster performance in the lithium system, pristine $\mathrm{ZnSnO}_{3}$ shows much better sodiation performance compared to pristine $\mathrm{SnO}_{2}$ as could be seen in Table A2. Furthermore, during sodiation of $\mathrm{ZnSnO}_{3}$, it is observable that the potential operating decreases and could be attributed to the inductive effect in the presence of $\mathrm{ZnO}$. Substitution of $\mathrm{Zn}^{2+}$ with transition metals such as $\mathrm{Co}^{2+}$ or group II alkali metals such as $\mathrm{Ca}^{2+}$ could serve as feasible alternatives. These metals are less expensive compared to $\mathrm{Sn}^{4+}$ and could serve to lower the overall cost. For example, Lou et al have studied amorphous $\mathrm{C} @ \mathrm{CoSnO}_{3}$ as a potential anode for LIB, which demonstrated exceptional performance regarding capacity and cycling stability. Therefore, it could be interesting to substitute the A site with alternatives such as $\mathrm{Co}^{2+}, \mathrm{Ca}^{2+}$ to produce alternative $\mathrm{ASnO}_{3}$ compounds.

\subsubsection{Laser pyrolysis of bimetallic tin oxides for LIB and NIB}

Laser pyrolysis has been shown in above chapters to be an effective synthesis method for producing nanoparticles and subsequently the use of these nanoparticles in alkali ion batteries. So far, an exploration into the synthesis of laser pyrolyzed metal oxides has been limited to mono-metals (i.e. $\mathrm{Fe}_{2} \mathrm{O}_{3}, \mathrm{ZnO}$ ). The synthesis of bimetallic tin oxides (i.e. $\mathrm{ZnFe}_{2} \mathrm{O}_{4}, \mathrm{ZnSnO}_{3}$ ) could be interesting. However, several challenges should be anticipated for the synthesis of such bimetallic oxides. When utilizing laser pyrolysis, the residence time that precursors stay in the reaction zone last for several milliseconds only. As seen in Chapter 5, when $\mathrm{SnCl}_{4}$ was utilized as precursor, a reduced form of $\mathrm{SnCl}_{2}$ was obtained instead of $\mathrm{SnO}_{2}$, despite being in the presence of oxidizing conditions. The short reaction time could have played a role in insufficient time for complete oxidation as well as due to thermodynamic reasons. Moreover, as the source of energy for decomposition comes from the emission of thermal blackbody radiation, it is difficult to measure the thermal energy radiated from the blackbody emission and therefore difficult to control the phase obtainable. 
In a trial experiment, we utilized stoichiometric ratios of $\mathrm{SnSO}_{4}$ and $\mathrm{ZnCl}_{2}$ in an attempt to prepare $\mathrm{ZnSnO}_{3}$ under similar conditions as to $\mathrm{SnO}_{2}$ (Chapter 4). The utilization of $\mathrm{SnCl}_{4}$ was omitted due to the above observations that $\mathrm{SnCl}_{2}$ would be the final product upon pyrolysis.

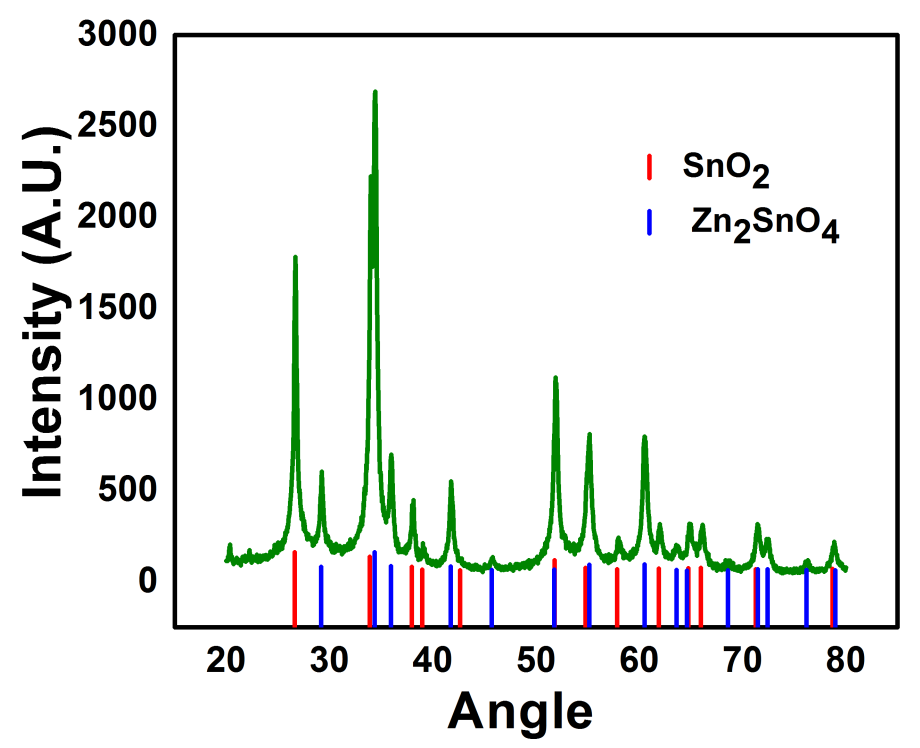

Figure 7.6 XRD spectrum of laser pyrolyzed product utilizing $\mathrm{SnSO}_{4}$ and $\mathrm{ZnCl}_{2}$ as initial precursors.

Figure 7.6 depicts the XRD spectrum of the product that was synthesized via laser pyrolysis in a one-pot $\mathrm{ZnCl}_{2}$ and $\mathrm{SnSO}_{4}$ precursor solution. The resultant product as could be seen is a mixture of $\mathrm{SnO}_{2}$ and $\mathrm{Zn}_{2} \mathrm{SnO}_{4}$ instead of $\mathrm{ZnSnO}_{3}$. The formation of the mixed $\mathrm{SnO}_{2}-\mathrm{Zn}_{2} \mathrm{SnO}_{4}$ compound from laser pyrolysis indicates that the synthesis temperature is too high as orthostannates are known to form from the decomposition of metastannate at temperatures above $750{ }^{\circ} \mathrm{C}$. ${ }^{7}$ Understandably, the blackbody radiation emitted is heavily dependent on several factors such as the flow rate and the concentration of the sensitizer gas. Fine-tuning the sensitizer gas conditions to attain optimum temperatures will be reserved for future work and could also be extended to other compounds too. 


\subsubsection{Assembly of full cell}

The results of our synthesized tin based oxides in both LIB and NIB are thus far, all under half-cell configurations. In order to move the technology closer to commercialization, it is pertinent to study the electrochemical performance in full cell with the replacement of $\mathrm{Li} / \mathrm{Na}$ anode by cathode materials such as $\mathrm{LiNi}_{0.8} \mathrm{Co}_{0.15} \mathrm{Al}_{0.05} \mathrm{O}_{2}$ or $\mathrm{Na}_{0.44} \mathrm{MnO}_{2}$. One of the possible issues to consider during the assembly of full cells would be the need for prelithiation/presodiation to overcome the irreversible capacity loss due formation of SEI layer. These prelithiation/presodiation methods are often done by electrochemically reducing the anode material $\left(\mathrm{SnO}_{2}\right)$ under half-cell configuration before disassembly to replace the metal counter electrode with the proper cathode material. One other way would be to put the anode material in direct contact with either $\mathrm{Li} / \mathrm{Na}$ foil in the presence of electrolyte. In this condition, an SEI layer would be chemically formed. However, this method is less viable due to uneven growth of SEI layer as well as the long time required for preparation. Recently, Cui's group has developed an ingenious method by fabrication of cathode additives using transition metal oxides $\left(\mathrm{Co}_{3} \mathrm{O}_{4}, \mathrm{NiO}\right)$ to help offset the irreversible capacity loss. Interestingly, the key criteria for utilizing this method lies with operating potential of the transition metal oxide addition metal. For instance, the additive should be able to delithiate/desodiate below the maximum cathode charge potential but not lithiate/sodiate at minimum potential of cathode charge.

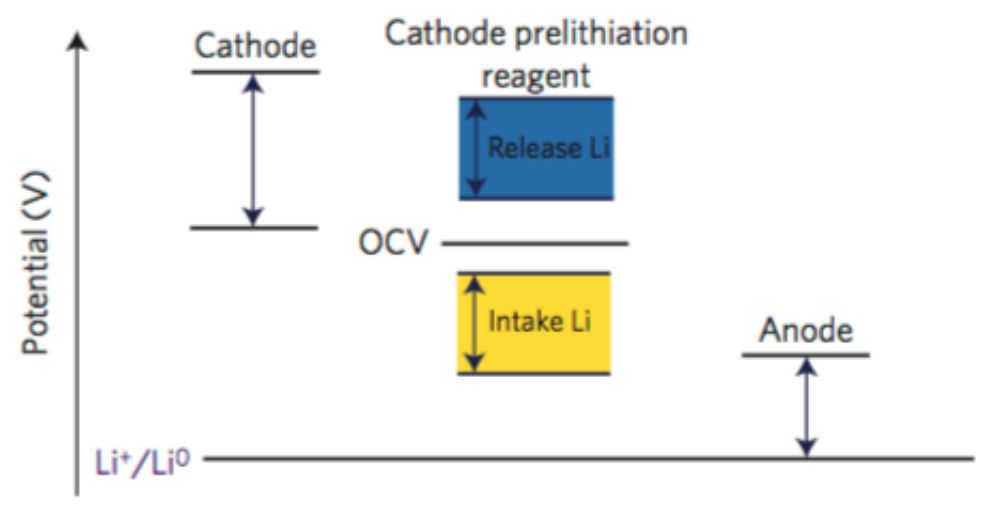

Figure 7.7 Potential requirements for the ideal cathode additives ${ }^{8}$ 
Asides from the problem of prelithiation, balance of mass between cathode and anode should be critically evaluated. During charging/discharge reactions, the presence of excess anode/cathode might result in overcharging of the opposite electrode, i.e. to assemble a full cell comprising of a $\mathrm{LiNi}_{0.8} \mathrm{Co}_{0.15} \mathrm{Al}_{0.05} \mathrm{O}_{2}$ cathode (theoretical capacity of $279 \mathrm{mAh} \mathrm{g}^{-1}$ ) and $\mathrm{SnO}_{2}$ anode (theoretical capacity of $1493 \mathrm{mAh} \mathrm{g}^{-1}$ ), the mass ratio between cathode to anode should be $5.35: 1$. In the case where the ratio of cathode is less than 5.35 , the cathode will have to charge beyond its safe working potential in order to compensate the additional capacity in the anode. This situation works vice versa.

Therefore, the assembly of full cells performances using our above studied tin based oxide anodes with cathodes is further recommended.

\section{References:}

1. Y. Deng, C. Fang and G. Chen, Journal of Power Sources, 2016, 304, 81-101.

2. Y. J. Hong, M. Y. Son and Y. C. Kang, Advanced Materials, 2013, 25, 2279-2283.

3. H. Kim, G. O. Park, Y. Kim, S. Muhammad, J. Yoo, M. Balasubramanian, Y.-H. Cho, M.-G. Kim, B. Lee, K. Kang, H. Kim, J. M. Kim and W.-S. Yoon, Chemistry of Materials, 2014, 26, 6361-6370.

4. K. Kisu, M. Iijima, E. Iwama, M. Saito, Y. Orikasa, W. Naoi and K. Naoi, Journal of Materials Chemistry A, 2014, 2, 13058-13068.

5. C. J. Pelliccione, E. V. Timofeeva and C. U. Segre, The Journal of Physical Chemistry C, 2016, 120, 5331-5339.

6. R. Hu, D. Chen, G. Waller, Y. Ouyang, Y. Chen, B. Zhao, B. Rainwater, C. Yang, M. Zhu and M. Liu, Energy \& Environmental Science, 2016, 9, 595-603.

7. T. Bora, M. H. Al-Hinai, A. T. Al-Hinai and J. Dutta, Journal of the American Ceramic Society, 2015, 98, 4044-4049.

8. Y. Sun, H.-W. Lee, Z. W. Seh, N. Liu, J. Sun, Y. Li and Y. Cui, Nature Energy, 2016, 1, 15008. 



\section{APPENDIX}

Appendix $\mathrm{A1} \mathrm{Li}$ and $\mathrm{Na}$ storage properties of widely used binary oxides. (Electrical conductivity is given for $\mathrm{TiO}_{2},{ }^{1,2} \mathrm{Fe}_{3} \mathrm{O}_{4},{ }^{3} \mathrm{Fe}_{2} \mathrm{O}_{3},{ }^{4} \mathrm{Co}_{3} \mathrm{O}_{4},{ }^{5} \mathrm{CuO},{ }^{6} \mathrm{MoO}_{2},{ }^{7} \mathrm{MoO}_{3},{ }^{8} \mathrm{MnO},{ }^{9} \mathrm{Mn}_{3} \mathrm{O}_{4},{ }^{10}$ $\mathrm{ZnO},{ }^{11} \mathrm{SnO}_{2},{ }^{12,}{ }^{13} \mathrm{Sb}_{2} \mathrm{O}_{3}{ }^{14}$ ). Theoretical E.M.F is calculated with thermodynamic data ${ }^{15}$ using Nernst equation ${ }^{16}$.

\begin{tabular}{|c|c|c|c|c|c|}
\hline Compound & Electrochemical reaction & 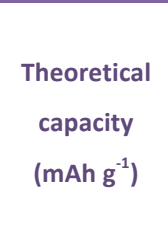 & $\begin{array}{c}\text { Average } \\
\text { discharge } \\
\text { potential vs. } \\
\mathrm{Li}^{+} / \mathrm{Li} \text { or } \\
\mathrm{Na}^{+} / \mathrm{Na}(\mathrm{V})\end{array}$ & $\begin{array}{c}\text { Size } \\
\text { Expansion } \\
\text { (\%) }\end{array}$ & $\begin{array}{l}\text { Electrical } \\
\text { conductivity (S } \\
\mathrm{cm}^{-1} \text { ) at } 300 \mathrm{~K}\end{array}$ \\
\hline $\mathrm{TiO}_{2}$ & $\begin{array}{c}\mathrm{TiO}_{2}+\mathrm{Li}^{+}+\mathrm{e}^{-} \leftrightarrow \mathrm{LiTiO}_{2} \\
\mathrm{TiO}_{2}+\mathrm{Na}^{+}+\mathrm{e}^{-} \leftrightarrow \mathrm{NaTiO}_{2}\end{array}$ & $335(\mathrm{Li}, \mathrm{Na})$ & - & 4 (Li) & $\begin{array}{l}\text { Anatase: } 8.11 \\
\qquad \times 10^{-11} \\
\text { Rutile: }{ }_{6}^{2 \times 10}\end{array}$ \\
\hline$\alpha-\mathrm{Fe}_{2} \mathrm{O}_{3}$ & $\begin{array}{c}\mathrm{Fe}_{2} \mathrm{O}_{3}+6 \mathrm{Li}^{+}+6 \mathrm{e}^{-} \leftrightarrow 2 \mathrm{Fe}+3 \mathrm{Li}_{2} \mathrm{O} \\
\mathrm{Fe}_{2} \mathrm{O}_{3}+6 \mathrm{Na}^{+}+6 \mathrm{e}^{-} \leftrightarrow 2 \mathrm{Fe}+3 \mathrm{Na}_{2} \mathrm{O}\end{array}$ & $\begin{array}{l}1007 \text { (Li , } \\
\mathrm{Na})\end{array}$ & $\begin{array}{l}\text { Li: } 1.629 \\
\text { Na: } 0.682\end{array}$ & $\begin{array}{l}92.9(\mathrm{Li}) \\
215(\mathrm{Na})\end{array}$ & $2.2 \times 10^{-6}$ \\
\hline $\mathrm{Fe}_{3} \mathrm{O}_{4}$ & $\begin{array}{c}\mathrm{Fe}_{3} \mathrm{O}_{4}+8 \mathrm{Li}^{+}+8 \mathrm{e}^{-} \leftrightarrow 3 \mathrm{Fe}+4 \mathrm{Li}_{2} \mathrm{O} \\
\mathrm{Fe}_{3} \mathrm{O}_{4}+8 \mathrm{Na}^{+}+8 \mathrm{e}^{-} \leftrightarrow 3 \mathrm{Fe}+4 \mathrm{Na}_{2} \mathrm{O}\end{array}$ & 924 (Li, Na) & $\mathrm{Na}: 0.649$ & $\begin{array}{c}74.4(\mathrm{Li}) \\
181.8(\mathrm{Na})\end{array}$ & 2.5 \\
\hline $\mathrm{CoO}$ & $\mathrm{CoO}+2 \mathrm{Li}^{+}+2 \mathrm{e}^{-} \leftrightarrow \mathrm{Co}+\mathrm{Li}_{2} \mathrm{O}$ & 715 (Li) & Li: 1.801 & 84.9 (Li) & - \\
\hline $\mathrm{Co}_{3} \mathrm{O}_{4}$ & $\begin{array}{c}\mathrm{Co}_{3} \mathrm{O}_{4}+8 \mathrm{Li}^{+}+8 \mathrm{e}^{-} \leftrightarrow 3 \mathrm{Co}+4 \mathrm{Li}_{2} \mathrm{O} \\
\mathrm{Co}_{3} \mathrm{O}_{4}+8 \mathrm{Na}^{+}+8 \mathrm{e}^{-} \leftrightarrow 3 \mathrm{Co}+ \\
4 \mathrm{Na}_{2} \mathrm{O}\end{array}$ & $890(\mathrm{Li}, \mathrm{Na})$ & $\begin{array}{l}\text { Li: } 1.882 \\
\text { Na: } 0.935\end{array}$ & $\begin{array}{c}101.5(\mathrm{Li}) \\
227.7(\mathrm{Na})\end{array}$ & $1.96 \times 10^{-5}$ \\
\hline $\mathrm{NiO}$ & $\begin{array}{c}\mathrm{NiO}+2 \mathrm{Li}^{+}+2 \mathrm{e}^{-} \leftrightarrow \mathrm{Ni}+\mathrm{Li}_{2} \mathrm{O} \\
\mathrm{NiO}+2 \mathrm{Na}^{+}+2 \mathrm{e}^{-} \leftrightarrow \mathrm{Ni}+\mathrm{Na}_{2} \mathrm{O}\end{array}$ & 717 (Li, Na) & $\begin{array}{l}\text { Li: } 1.815 \\
\text { Na: } 0.868\end{array}$ & $\begin{array}{c}91.6(\mathrm{Li}) \\
202.7(\mathrm{Na})\end{array}$ & $5 \times 10^{-7}$ \\
\hline $\mathrm{CuO}$ & $\begin{array}{c}\mathrm{CuO}+2 \mathrm{Li}^{+}+2 \mathrm{e}^{-} \leftrightarrow \mathrm{Cu}+\mathrm{Li}_{2} \mathrm{O} \\
\mathrm{CuO}+2 \mathrm{Na}^{+}+2 \mathrm{e}^{-} \leftrightarrow \mathrm{Cu}+\mathrm{Na}_{2} \mathrm{O}\end{array}$ & $674(\mathrm{Li}, \mathrm{Na})$ & $\begin{array}{l}\text { Li: } 2.247 \\
\text { Na: } 1.299\end{array}$ & $\begin{array}{c}74.2(\mathrm{Li}) \\
172.9(\mathrm{Na})\end{array}$ & $1 \times 10^{-6}$ \\
\hline $\mathrm{MoO}_{2}$ & $\mathrm{MoO}_{2}+4 \mathrm{Li}^{+}+4 \mathrm{e}^{-} \leftrightarrow \mathrm{Mo}+2 \mathrm{Li}_{2} \mathrm{O}$ & 838 (Li) & Li: 1.530 & $98.0(\mathrm{Li})$ & $8.8 \times 10^{-5}$ \\
\hline$\alpha-\mathrm{MoO}_{3}$ & $\begin{aligned} \mathrm{MoO}_{3}+6 \mathrm{Li}^{+}+6 \mathrm{e}^{-} \leftrightarrow \mathrm{Mo}+3 \mathrm{Li}_{2} \mathrm{O} \\
\mathrm{MoO}_{3}+6 \mathrm{Na}^{+}+6 \mathrm{e}^{-} \leftrightarrow \mathrm{Mo}+3 \mathrm{Na}_{2} \mathrm{O}\end{aligned}$ & 1117 (Li, Na) & $\begin{array}{l}\text { Li: } 1.758 \\
\text { Na: } 0.810\end{array}$ & $\begin{array}{c}76.0(\mathrm{Li}) \\
197.5(\mathrm{Na})\end{array}$ & $\sim 1 \times 10^{-6}$ \\
\hline Mno & $\mathrm{MnO}+2 \mathrm{Li}^{+}+2 \mathrm{e}^{-} \leftrightarrow \mathrm{Mn}+\mathrm{Li}_{2} \mathrm{O}$ & 756 (Li) & Li: 1.031 & 69.7 (Li) & $\sim 1 \times 10^{-9}$ \\
\hline $\mathrm{Mn}_{2} \mathrm{O}_{3}$ & $\mathrm{Mn}_{2} \mathrm{O}_{3}+6 \mathrm{Li}^{+}+6 \mathrm{e}^{-} \leftrightarrow 2 \mathrm{Mn}+3 \mathrm{Li}_{2} \mathrm{O}$ & 1018 (Li) & Li: 1.389 & 68.7 (Li) & - \\
\hline
\end{tabular}


Appendix

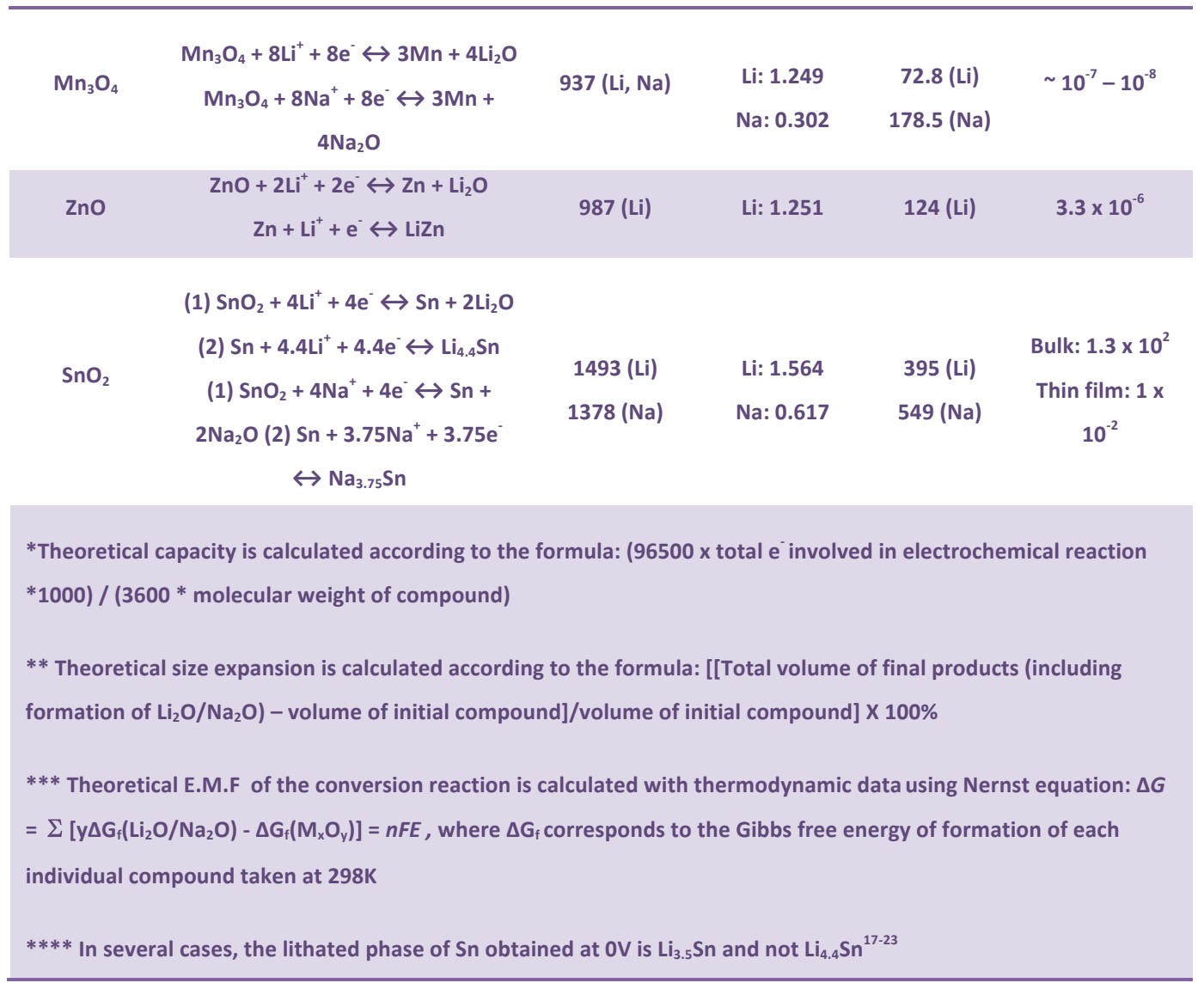

\section{References for Appendix A1}

1. K. Pomoni, M. V. Sofianou, T. Georgakopoulos, N. Boukos and C. Trapalis, Journal of Alloys and Compounds, 2013, 548, 194-200.

2. D. C. Cronemeyer, Physical Review, 1952, 87, 876-886.

3. B. Evans, 1975.

4. Z. Fan, X. Wen, S. Yang and J. G. Lu, Applied Physics Letters, 2005, 87, 013113.

5. S. Sakamoto, M. Yoshinaka, K. Hirota and O. Yamaguchi, Journal of the American Ceramic Society, 1997, 80, 267-268.

6. B. Wang, X.-L. Wu, C.-Y. Shu, Y.-G. Guo and C.-R. Wang, Journal of Materials Chemistry, 2010, 20, 10661-10664.

7. Y. Shi, B. Guo, S. A. Corr, Q. Shi, Y.-S. Hu, K. R. Heier, L. Chen, R. Seshadri and G.

D. Stucky, Nano Letters, 2009, 9, 4215-4220.

8. Z. Hu, C. Zhou, M. Zheng, J. Lu, B. Varghese, H. Cheng and C.-H. Sow, The Journal of Physical Chemistry C, 2012, 116, 3962-3967.

9. M. Pai and J. M. Honig, Journal of Solid State Chemistry, 1981, 40, 59-63.

10. C. Wang, L. Yin, D. Xiang and Y. Qi, ACS Applied Materials \& Interfaces, 2012, 4, 1636-1642.

11. A. Y. Polyakov, N. B. Smirnov, A. V. Govorkov, E. A. Kozhukhova, S. J. Pearton, D. P. Norton, A. Osinsky and A. Dabiran, Journal of Elec Materi, 2006, 35, 663669. 
12. Y.-C. Ji, H.-X. Zhang, X.-H. Zhang and Z.-Q. Li, physica status solidi (b), 2013, 250, 2145-2152.

13. Y. Ma, Q. Xie, X. Liu, Y. Zhao, D. Zeng, L. Wang, Y. Zheng and D.-L. Peng, Electrochimica Acta, 2015, 182, 327-333.

14. H. Bryngelsson, J. Eskhult, L. Nyholm, M. Herranen, O. Alm and K. Edström, Chemistry of Materials, 2007, 19, 1170-1180.

15. I. Barin, in Thermochemical Data of Pure Substances, Wiley-VCH Verlag GmbH, 2008, DOI: 10.1002/9783527619825.ch2, pp. 21-31.

16. H. Li, P. Balaya and J. Maier, Journal of The Electrochemical Society, 2004, 151, A1878-A1885.

17. A. Mahmoud, M. Chamas, J.-C. Jumas, B. Philippe, R. Dedryvère, D. Gonbeau, I. Saadoune and P.-E. Lippens, Journal of Power Sources, 2013, 244, 246-251.

18. C. Marino, M. T. Sougrati, A. Darwiche, J. Fullenwarth, B. Fraisse, J. C. Jumas and L. Monconduit, Journal of Power Sources, 2013, 244, 736-741.

19. D. E. Conte, M. Mouyane, L. Stievano, B. Fraisse, M. T. Sougrati, J. OlivierFourcade, P. Willmann, C. Jordy, M. Artus, S. Cassaignon, K. Driezen and J.-C. Jumas, J Solid State Electrochem, 2012, 16, 3837-3848.

20. M. Mouyane, M. Womes, J. C. Jumas, J. Olivier-Fourcade and P. E. Lippens, Journal of Power Sources, 2012, 204, 139-148.

21. M. Chamas, P.-E. Lippens, J.-C. Jumas, K. Boukerma, R. Dedryvère, D. Gonbeau, J. Hassoun, S. Panero and B. Scrosati, Journal of Power Sources, 2011, 196, 7011-7015.

22. S. Naille, C. M. Ionica-Bousquet, F. Robert, F. Morato, P. E. Lippens and J. Olivier-Fourcade, Journal of Power Sources, 2007, 174, 1091-1094.

23. W. Choi, J. Y. Lee, B. H. Jung and H. S. Lim, Journal of Power Sources, 2004, 136, 154-159.

24. Y. Zhang, J. Xie, S. Zhang, P. Zhu, G. Cao and X. Zhao, Electrochimica Acta, 2015, 151, 8-15.

25. J. Ding, Z. Li, H. Wang, K. Cui, A. Kohandehghan, X. Tan, D. Karpuzov and D. Mitlin, Journal of Materials Chemistry A, 2015, 3, 7100-7111.

26. Y. Wang, D. Su, C. Wang and G. Wang, Electrochemistry Communications, 2013, 29, 8-11.

27. D. Su, H.-J. Ahn and G. Wang, Chemical Communications, 2013, 49, 3131-3133.

28. S. Li, Y. Wang, J. Qiu, M. Ling, H. Wang, W. Martens and S. Zhang, RSC Advances, 2014, 4, 50148-50152.

29. X. Xie, D. Su, J. Zhang, S. Chen, A. K. Mondal and G. Wang, Nanoscale, 2015, 7, 3164-3172.

30. Y. C. Lu, C. Ma, J. Alvarado, T. Kidera, N. Dimov, Y. S. Meng and S. Okada, Journal of Power Sources, 2015, 284, 287-295.

31. J. Park, J.-W. Park, J.-H. Han, S.-W. Lee, K.-Y. Lee, H.-S. Ryu, K.-W. Kim, G. Wang, J.-H. Ahn and H.-J. Ahn, Materials Research Bulletin, 2014, 58, 186-189.

32. D. Su, C. Wang, H. Ahn and G. Wang, Physical Chemistry Chemical Physics, 2013, 15, 12543-12550. 
Appendix A2. Diffraction data of casserite $\mathrm{SnO}_{2}$ from the American Mineralogist Crystal Structure Database

Schiferl D, Cromer D T, Schwalbe L A, Mills R L

Acta Crystallographica B39 (1983) 153-157

Structure of 'Orange' $18 \mathrm{O} 2$ at $9.6 \mathrm{GPa}$ and $297 \mathrm{~K}$

Locality: Synthetic

_database_code_amcsd 0020615

CELL PARAMETERS: $4.2151 \quad 2.9567 \quad 6.6897 \quad 90.000 \quad 90.000 \quad 90.000$

SPACE GROUP: Fmmm

X-RAY WAVELENGTH: 1.541838

MAX. ABS. INTENSITY / VOLUME**2: 20.18016518

2-THETA INTENSITY D-SPACING H K L Multiplicity

$\begin{array}{lcccccc}26.65 & 26.81 & 3.3449 & 0 & 0 & 2 & 2 \\ 39.59 & 100.00 & 2.2761 & 1 & 1 & 1 & 8 \\ 42.91 & 25.23 & 2.1075 & 2 & 0 & 0 & 2 \\ 51.23 & 5.14 & 1.7831 & 2 & 0 & 2 & 4 \\ 54.90 & 3.05 & 1.6724 & 0 & 0 & 4 & 2 \\ 62.86 & 4.95 & 1.4784 & 0 & 2 & 0 & 2 \\ 69.52 & 1.32 & 1.3522 & 0 & 2 & 2 & 4 \\ 72.10 & 1.80 & 1.3101 & 2 & 0 & 4 & 4 \\ 76.39 & 6.09 & 1.2468 & 3 & 1 & 1 & 8 \\ 79.13 & 3.61 & 1.2103 & 2 & 2 & 0 & 4 \\ 82.35 & 5.20 & 1.1710 & 1 & 1 & 5 & 8 \\ 85.28 & 1.13 & 1.1381 & 2 & 2 & 2 & 8 \\ 87.49 & 1.21 & 1.1150 & 0 & 0 & 6 & 2\end{array}$

Appendix A3. ICSD data of casserite $\mathrm{SnO}_{2}$ from the American Mineralogist Crystal Structure Database

data_global

chemical_name_mineral 'Cassiterite'

loop

publ_author_name

'Bolzan A A'

'Fong $\mathrm{C}^{\prime}$

'Kennedy B J'

'Howard C J' 


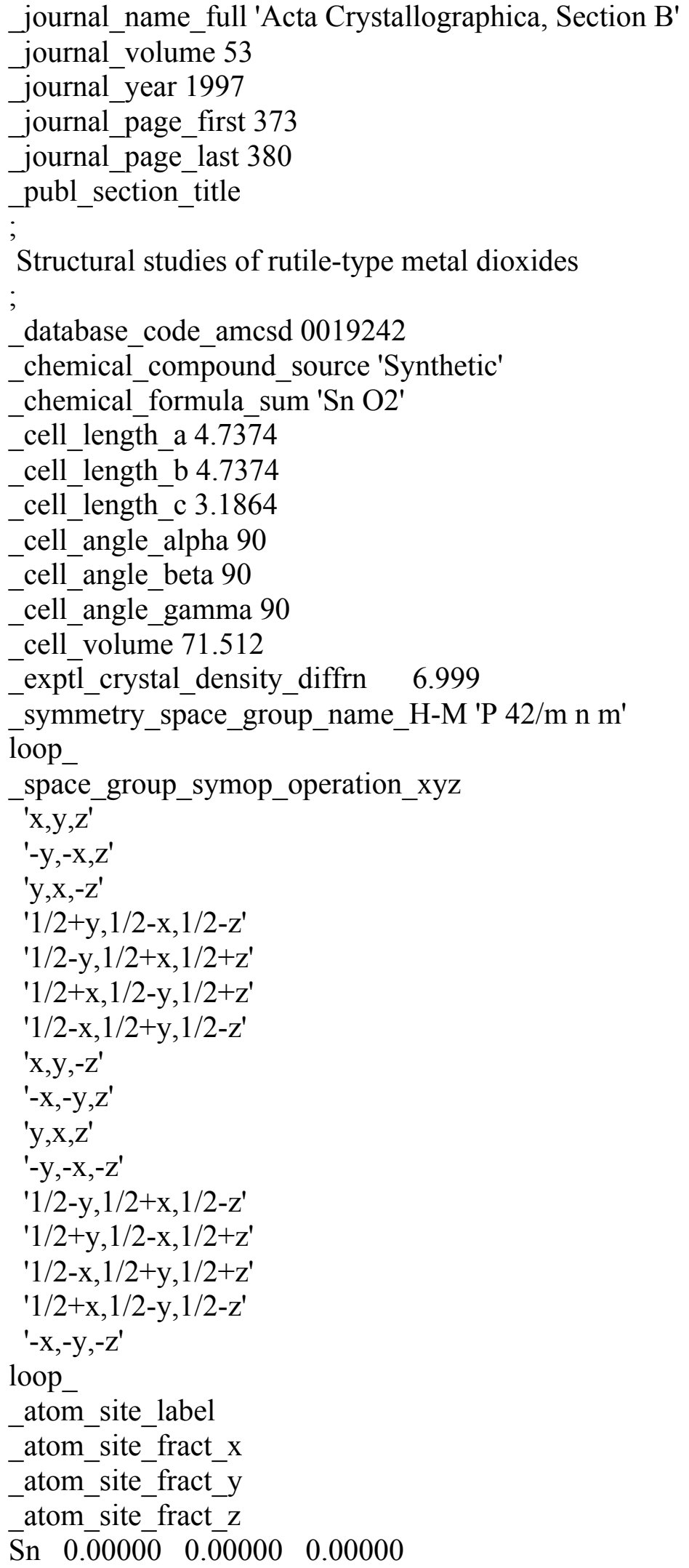


$\begin{array}{llll}\mathrm{O} & 0.30562 & 0.30562 & 0.00000\end{array}$

loop_

_atom_site_aniso_label

_atom_site_aniso_U_11

_atom_site_aniso_U_-22

_atom_site_aniso_U_33

_atom_site_aniso_U_12

_atom_site_aniso_U_-13

- atom_site_aniso_U_23

$\overline{\text { Sn }} 0.004400 .004 \overline{4} 0 \overline{0} .003100 .000400 .000000 .00000$

O 0.006600 .000000 .005500 .001600 .000000 .00000

Appendix A4. Comparison of electrochemical performance of hollow $\mathrm{ZnSnO}_{3}$ with bare $\mathrm{SnO}_{2}$ in literature

\begin{tabular}{|c|c|c|c|}
\hline Method of preparation & $\begin{array}{c}\text { Discharge } \\
\text { voltage range } \\
(\mathrm{V}) \mathrm{vs} . \\
\mathrm{Na}^{+} / \mathrm{Na}\end{array}$ & $\begin{array}{c}\% \text { Capacity retention } \\
\text { at end of cycling }\end{array}$ & ref \\
\hline hydrothermal & $0-0,80$ & $\begin{array}{c}0 \% \text { at } 100 \mathrm{~mA} \mathrm{~g}^{-1} \text { after } \\
100 \text { cycles }\end{array}$ & 24 \\
\hline hydrothermal & $0-0,80$ & $\begin{array}{c}0 \% \text { at } 80 \mathrm{~mA} \mathrm{~g}^{-1} \text { after } 50 \\
\text { cycles }\end{array}$ & 25 \\
\hline solvothermal & $0-0,75$ & $\begin{array}{c}16,8 \% \text { at } 0,1 \mathrm{C} \text { after } 50 \\
\text { cycles }\end{array}$ & 26 \\
\hline hydrothermal & - & $\begin{array}{c}\sim 82 \% \text { at } 20 \mathrm{~mA} \mathrm{~g}^{-1} \text { after } \\
100 \text { cycles }\end{array}$ & 27 \\
\hline ball milling & - & $\begin{array}{c}0 \% \text { at } 100 \mathrm{~mA} \mathrm{~g}^{-1} \text { after } \\
100 \text { cycles }\end{array}$ & 28 \\
\hline hydrothermal & $0-0,50$ & $\begin{array}{c}\sim 20 \% \text { at } 20 \mathrm{~mA} \mathrm{~g}^{-1} \text { after } \\
100 \text { cycles }\end{array}$ & 29 \\
\hline hydrothermal & $0-0,8$ & $\begin{array}{c}0 \% \text { at } 50 \mathrm{~mA} \mathrm{~g}^{-1} \text { after } \\
50 \text { cycles }\end{array}$ & 30 \\
\hline
\end{tabular}


Appendix

\begin{tabular}{|c|c|c|c|}
\hline commercial SnO2 & $0-\sim 0,1$ & $\begin{array}{c}\sim 100 \% \text { at } 100 \mathrm{~mA} \mathrm{~g}^{-1} \\
\text { after } 10 \text { cycles }\end{array}$ & \\
\hline hydrothermal & $0-0,5$ & $\begin{array}{c}60,8 \% \text { at } 160 \mathrm{~mA} \mathrm{~g}^{-1} \\
\text { after } 100 \text { cycles }\end{array}$ & 32 \\
\hline Co-precipitation $\mathrm{ZnSnO}_{3}$ & $0-0.3$ & $\begin{array}{c}92 \% \text { after } 100 \text { cycles at } \\
250 \mathrm{~mA} \mathrm{~g}^{-1}\end{array}$ & $\begin{array}{c}\text { Current } \\
\text { work }\end{array}$ \\
\hline
\end{tabular}

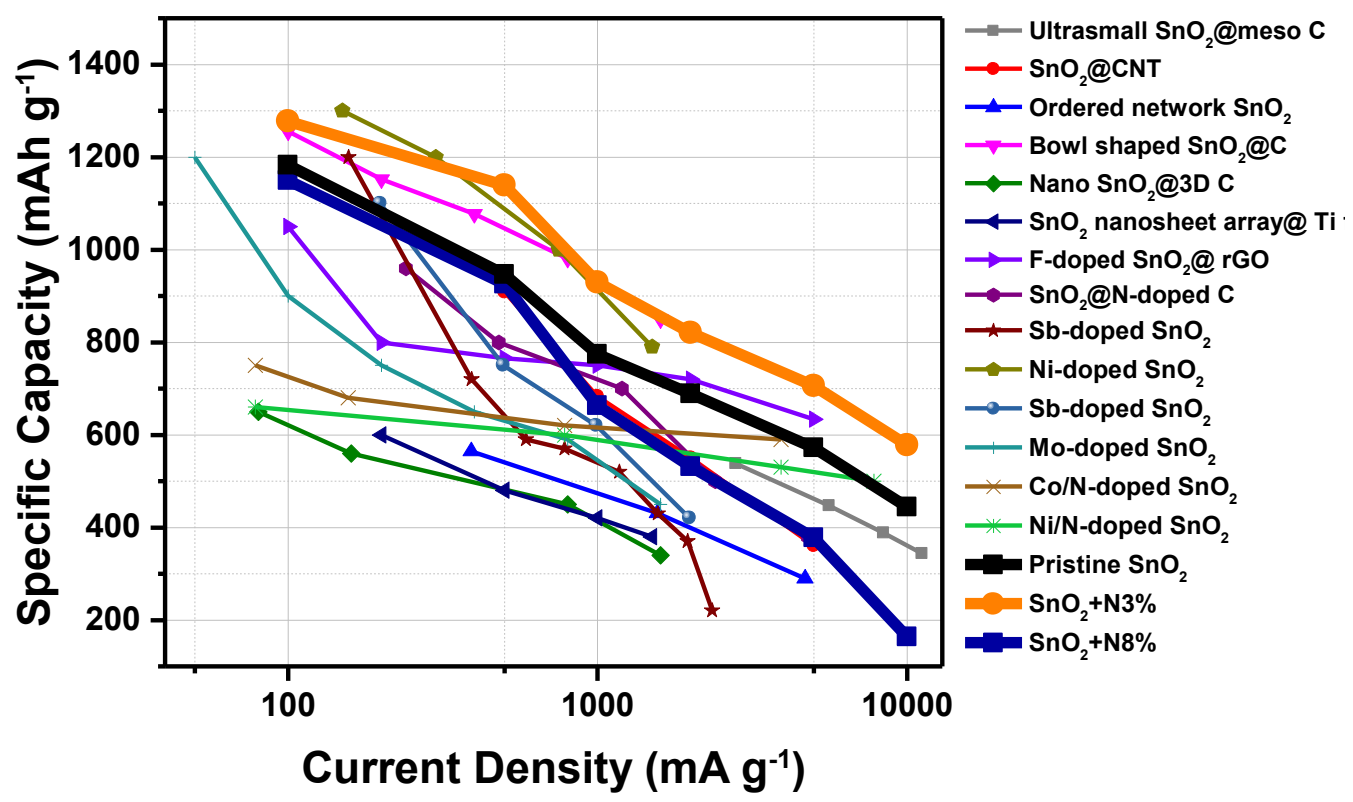

Appendix A5. Capacity vs. current density comparison between laser pyrolyzed samples (highlighted) and recently reported $\mathrm{SnO}_{2}$ materials. The references selected are based on 2 categories: $\mathrm{SnO}_{2}$-carbon containing composites and element doped $\mathrm{SnO}_{2}$ compounds. Laser pyrolyzed $\mathrm{SnO}_{2}+3 \% \mathrm{~N}$ shows the best performance at both low and high current densities, even without the presence of conductive carbon. Capacities plotted are average obtained from the rate performance- results. 